\title{
Structural change in developing countries
}

Citation for published version (APA):

Mensah, E. B. (2020). Structural change in developing countries: patterns, causes and consequences. [Doctoral Thesis, Maastricht University]. ProefschriftMaken. https://doi.org/10.26481/dis.20201123em

Document status and date:

Published: 01/01/2020

DOI:

10.26481/dis.20201123em

Document Version:

Publisher's PDF, also known as Version of record

\section{Please check the document version of this publication:}

- A submitted manuscript is the version of the article upon submission and before peer-review. There can be important differences between the submitted version and the official published version of record.

People interested in the research are advised to contact the author for the final version of the publication, or visit the DOI to the publisher's website.

- The final author version and the galley proof are versions of the publication after peer review.

- The final published version features the final layout of the paper including the volume, issue and page numbers.

Link to publication

\footnotetext{
General rights rights.

- You may freely distribute the URL identifying the publication in the public portal. please follow below link for the End User Agreement:

www.umlib.nl/taverne-license

Take down policy

If you believe that this document breaches copyright please contact us at:

repository@maastrichtuniversity.nl

providing details and we will investigate your claim.
}

Copyright and moral rights for the publications made accessible in the public portal are retained by the authors and/or other copyright owners and it is a condition of accessing publications that users recognise and abide by the legal requirements associated with these

- Users may download and print one copy of any publication from the public portal for the purpose of private study or research.

- You may not further distribute the material or use it for any profit-making activity or commercial gain

If the publication is distributed under the terms of Article $25 \mathrm{fa}$ of the Dutch Copyright Act, indicated by the "Taverne" license above, 


\title{
Structural change in developing countries: Patterns, causes, and consequences
}

\author{
Emmanuel B. Mensah
}


Copyright (C) Emmanuel B. Mensah, November 2020

Cover design: Fenna Schaap and ProefschriftMaken

Cover inspiration: Victor Osei Kwadwo

Printing: ProefschriftMaken || www.proefschriftmaken.nl

ISBN 97894 6423-072-7

All rights reserved. No part of this publication may be reproduced, stored in a retrieval system or transmitted, in any form or by any means, electronic, mechanical, photocopying, recording or otherwise, without prior permission of the author or the copyright-owning journals for previous published chapters. 


\title{
Structural change in developing countries: Patterns, causes and consequences
}

\author{
DISSERTATION
}

to obtain the degree of Doctor at Maastricht University, on the authority of the Rector Magnificus, Prof. Dr. Rianne M. Letschert, in accordance with the decision of the Board of Deans, to be defended in public on Monday 23 November 2020, at 16 hours

by

Emmanuel B. Mensah 


\section{Supervisors}

Prof. Dr. Neil Foster-McGregor

Prof. Dr. Bart Verspagen

\section{Assessment Committee}

Prof. Dr. Pierre Mohnen (chair)

Prof. Dr. Margaret McMillan (Tufts University, USA)

Dr. Tania Treibich

Dr. Gaaitzen de Vries (University of Groningen) 


\section{Summary}

The main objective of the thesis is to investigate the patterns, causes, and (labor market) consequences of structural change in developing countries especially those in Africa. The thesis begins from the premise that our understanding of structural change in Africa is limited by a great statistical problem. Building on the existing work, the thesis produces a new sectoral database for Africa. Using this database, which reflects current sectoral development in Africa, the thesis establishes many empirical regularities about the patterns, causes and consequences of structural change in Africa.

Chapter 1 provides a general introduction and the thesis outline. The construction of new sectoral indicators in Africa is discussed in Chapter 2.

Chapter 3 provides empirical evidence on the patterns of structural change and labor market consequences of structural change in Africa. The analysis in this chapter suggests that while structural change has played an important role in the productivity growth of Africa, the general direction of change of the structure of African economies may not bode well for sustainable growth and poverty reduction. Particularly, there has been a reallocation of workers to lower-paid jobs or into the informal sector, leading to increased uncertainty for workers.

Chapter 4 examines technological change and the role of structural change in technological catch-up within Africa. The motivation for examining technological catch-up to a local frontier is based on the well-established evidence that suggests that the diffusion of technological knowledge from the global frontier decreases in intensity with geographical and institutional distance. The analysis highlights that successful convergence is driven more by technological catch-up and less by technological change. The chapter explores further the special role of technological catch-up by decomposing it into withinsector convergence, between-sector convergence and initial specialization. The results emphasize the special role of structural change in catch-up within Africa.

There is a general view that Africa is deindustrializing. Chapter 5 examines the extent to which the existing results are sensitive to sample size and new sectoral indicators. The chapter shows that deindustrialization is not the typical experience of most countries in the region. Instead, we observe a pattern where the manufacturing output share for a typical African country has not significantly changed since 1970. The chapter further examines the potential drivers of manufacturing performance in Africa.

There is a growing literature that attributes cross-country differences in the speed of structural change and labor productivity growth to distortions. Structural reforms are often described as the magic wand that can be used to reduce rigidities that exist in markets. In developing countries where a series of structural reforms have been implemented over the last decades, there is little evidence on the impacts of these reforms on labor productivity growth. Most importantly, the few studies that exist focus on the effects of reforms on productivity growth but do not assess how these effects are distributed between the within and structural components. This masks the allocative efficiency channels through which reforms affect labor productivity growth. Chapter 6 of this thesis sheds light on the mechanisms through which structural reforms affect productivity growth in developing countries. The results 
overwhelmingly show that reforms affect growth in developing countries mostly by inducing an efficient reallocation of resources within sectors but not across sectors.

Chapter 7 present the concluding remarks of thesis, policy recommendations, limitations and opportunities for future research. 


\section{Acknowledgment}

In every Ph.D. undertaken - from course work to final draft of thesis - there are those who are directly involved and those behind the scenes who play key roles in the process of turning the research idea into a full-blown thesis.

I would like to begin by thanking my supervisory team, Prof. Dr. Neil Foster-McGregor, the late Prof. Dr. Adam (Eddy) Szirmai, and Prof. Dr. Bart Verspagen for accepting to work on this project with me. Neil, we have been on this roller coaster together, but as always, you have been gracious in your critique and contribution. You have directly and indirectly thought me many things that have inspired and shaped me along this path. Your attention to detail, thorough questioning, and extra sacrifices pushed me to the finish line. Thanks for your help with the World Bank project. I am grateful for this enriching and wonderful experience. I cannot gainsay your monumental role. I want to posthumously express my heartfelt gratitude to Eddy for being a great advisor and a perpetual motivator. Eddy constantly showed keen interest in my work, inspiring me to take data work seriously. Eddy was still working on my thesis a few days before he passed away. Though he is not here to witness this wonderful end, his ideas and inspiration would continue to live in my heart. Bart, I am thankful for the insightful comments at the proposal stage and the final stage of the thesis.

I wish to express my sincere gratitude to the thesis assessment committee - Prof. Dr. Pierre Mohnen, Prof. Dr. Margaret McMillan, Dr. Gaaitzen de Vries, and Dr. Tania Treibich - for your constructive comments and stimulating suggestions which has improved some chapters of the thesis.

Apart from my supervisors, there are those behind the scenes who work very hard with me. First, I want to thank Solomon Owusu, with whom I share two chapters of the thesis, for the thoughtprovoking and stimulating discussions on structural change in Africa and for being a wonderful colleague. I would also like to thank my other co-authors Dr. Maty Konte and Dr. Wilfred Kouame for the intellectually stimulating conversations on structural reforms and structural change. Maty you deserve a special mention for being positive, supportive, and exemplary in your courtesy and encouragement. One of the key highlights of my PhD journey is the Extended Africa Sector Database (EASD). The construction of the EASD would not have been possible with the kind support and feedback from Klaas de Vries and Gaaitzen de Vries. Thank you for always being kind and approachable.

I have also benefited from the courses, interaction, and leadership of many faculty members at UNUMERIT and Maastricht University. Thank you to Prof. Dr. Robin Cowan, Prof. Dr. Theophile Azomahou, Dr. Gerald Silverberg, Prof. Dr. Eleonora Nillesen, Prof. Dr. Shyama Ramani, Dr. Nyasha Tirivayi, and Dr. Mindel van de Laar for the interesting courses. Special thanks to the leadership of the Ph.D. program, Prof. Dr. Robin Cowan and Dr. Tatiana Skripka, for your interest in our progress and the quick response to my budget request. Thank you to Dr. Kaj Thomsson for interesting discussions on the political economy aspect of my topic. A special thank you to Dr. Bruno Martarano, 
Dr. Serdar Turkeli, and the past and present MPP program leadership for the opportunity to teach in the quantitative track of the course.

As part of the journey, I had the opportunity to work on other projects which have enriched my knowledge and CV. I would like to express my sincere gratitude to the African Chief Economist Office of the World Bank especially my TTLs - Emmanuel Lartey and Taye Mengistae - for the opportunity to work on a background paper for the 'Industrializing for jobs in Africa' report. Through this project, I met Prof. Jo van Biesebroeck, who has been wonderful to me. Thanks, Jo, for the opportunities. I would like to thank Daniel Kwabena Boakye and Marina Bakanova of the East Africa Region of the World Bank for the opportunity to work on the Liberia Growth and Diversification Report.

I would be remiss if I did not express my heartfelt gratitude to my family - Rhoda and Joshua - for being compassionate, patient, and enduring over the years. I am very grateful for always cheering me on even when things are not so good. Special thanks to my senior brothers, Vincent and Gordon, for being a great inspiration to us and my parents for the sacrifices they made to bring us this far.

Starting and finishing a Ph.D. program requires the genuine support of administrative staff. I must acknowledge Eveline in de Braek for always willing to listen to me and assist whenever needed. Your motherly support has remained strong and constantly affirming. Thanks Eveline! I must also thank Ad, Herman, Howard, and Marc for their swift support. A special thanks to Ingeborg, Ingrid, Mieke, Monique, Sueli, and Wilma for always willing to talk and help.

I started this journey with eleven level-headed colleagues - Joseph, Danilo, Rose, Patima, Giulia, Bart, Tamara, Kaleab, Halefom, Victor, and Bea - with whom I share so many memories especially during the first year. Thank you all for your help and diverse support during these years. The first year's assignments, courses, and presentations took away our weekends and, for those of us who love football, the 2015/2016 football season, but through team spirit and the willingness to help each other, we sailed through. I am very proud of your achievements and I look forward to hearing more from you and about you in the future.

I have benefited from my interactions with colleagues from the Institute. I would like to express my sincere gratitude to Gideon (Nze of UNU-MERIT) for your help with trade-related questions and data. I am also grateful to Davina. Your Jollof rice remains the best in Maastricht. Many thanks to my brother from another mother, Elvis. The Friday night parties you organized whilst in Maastricht was a place of solace to most of us in the African community. I would also use this opportunity to acknowledge some of my past and present colleagues at UNU-MERIT whom I have received moral supports including Late Ibrahima (Kouli), Mary (dancing buddy), Chuks (local-anchor), Alison, Hassen, Hubert (a great brother from another mother), Racky, Robert (My Mathematician), Alison, Tantende, Godsway, Cho, Ayo (Aristotle), Elisa, Iulia, Mueid, Michelle Momo, Maria Tomai, Tigits, and Hiwot Mefin. Thanks for being awesome colleagues. 
To my other comrades including Testi, Halle, Edit, Salome, Amanda (aka Mrs. Tata), Benjamin, Edit, Ada, Onallia (aka Onalium Utalium), Martin Ayanore, Martin (Belgium), Tata (who is always living his best life), you have all being intrinsic to the joy I share today. I say a big thank you for being part of my success story. As a man is a combination of being and spirit, I would also like to thank Bethel Maastricht for providing the requisite spiritual support I needed in the course of this journey. In particular, my special thanks go to the entire family of Pastor and Mrs. Benjamin Odetola-Benjamin. I will forever cherish you. To my beautiful office mates (Iman, Joseph, Aline, Fernando, and Hanh), of course, I have not forgotten you. Collectively, we created a conducive working environment in the office. We also shared remarkable moments that remain indelible in my heart. Thanks for being the best office mates I could ever wish for.

I would like to express my sincere thanks to the professors of my alma mater who always look out for me and check my progress especially Dr. Daniel Sakyi and Dr. Grace Abebrese. Thanks to Mr. Franklin Cudjoe for past and present opportunities. My special gratitude to other family members and friends especially Monica, Bria, Stephanie (Asebobotua), Patience, Roland, Adwoa and any other person who has helped me along this journey, but I may have forgotten you in this writing.

Finally, my most sincere gratitude goes to UNU-MERT for financial support to pursue this Ph.D. It provided me the ample opportunity to travel and meet people from all works of life, explore topics and ideas I had never thought of before, and to enjoy the serenity and beauty of Maastricht. Thank you UNU-MERIT for all that you are, availed me, and made me become. 
To the memory of Prof. Adam (Eddy) Szirmai, a wonderful supervisor and human being. It has been an immense honor and pleasure to be one of Eddy's students. 


\section{Contents}

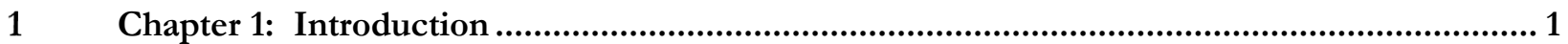

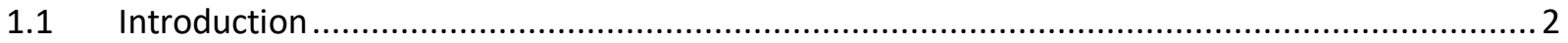

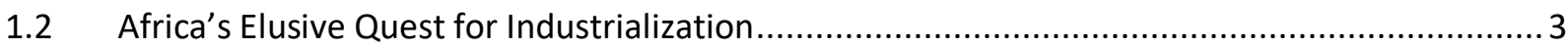

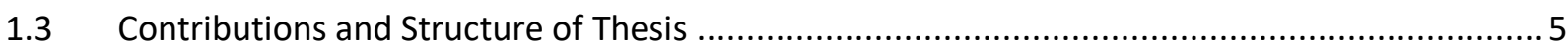

$2 \quad$ Chapter 2: The Extended Africa Sector Database .............................................................. 9

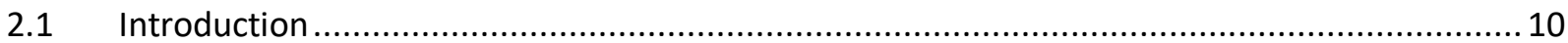

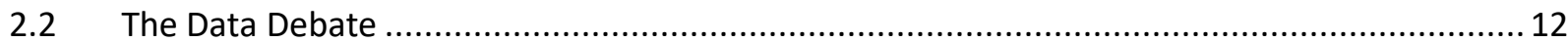

2.3 Expanding the Africa Sector Database (ASD) .............................................................. 13

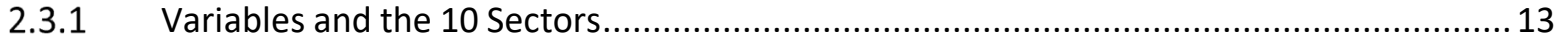

2.3.2 Sectoral Classification and Treatment of Dwellings ................................................. 14

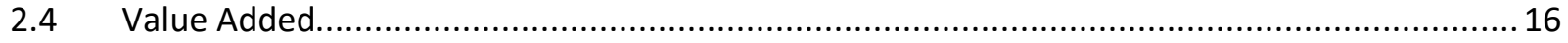

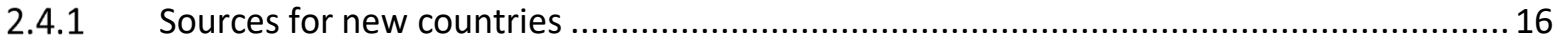

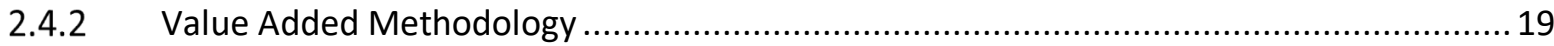

2.4.3 Update of Value Added for existing ASD countries...................................................... 19

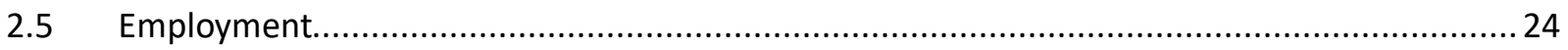

2.5.1 Sources of employment data for new countries......................................................... 24

2.5.2 Using Population and Housing Censuses as Benchmarks...........................................26

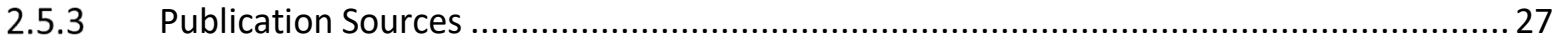

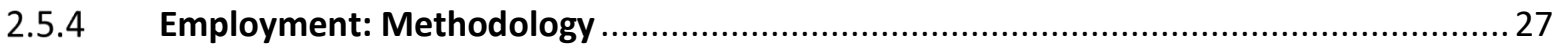

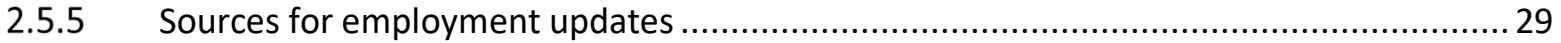

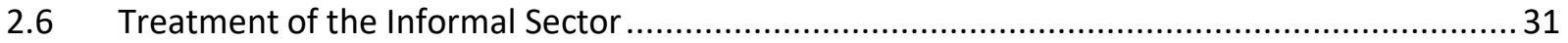

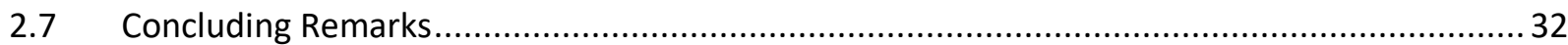

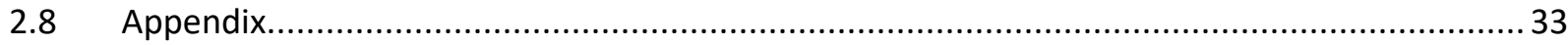

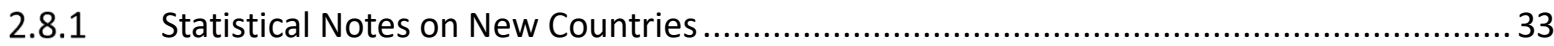

2.8.2 Statistical References of New Countries................................................................ 48

3 Chapter 3. Structural Change, Productivity Growth and Labor Market Turbulence in Africa54

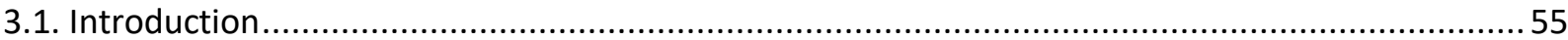

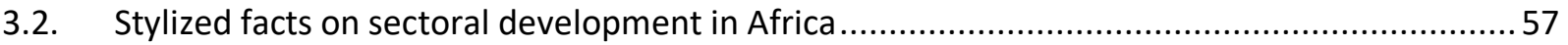

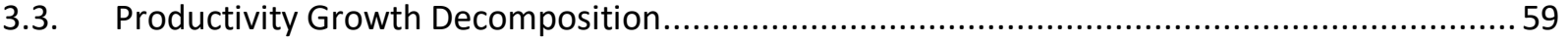

3.4. Sectoral Reallocation and Labor Market Turbulence (LMT) in Africa ................................... 63 
3.5. Job Reallocation and Productivity Growth in Sub-Saharan Africa: The Role of Employment

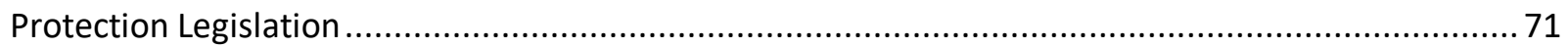

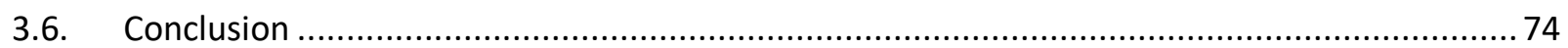

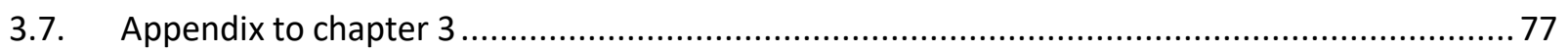

4 Chapter 4: Productive Efficiency, Technological Change and Catch-up within Africa...........81

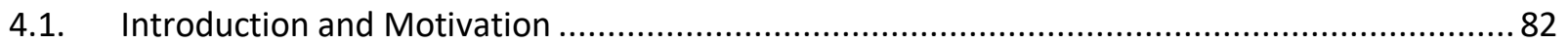

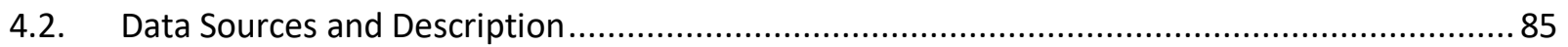

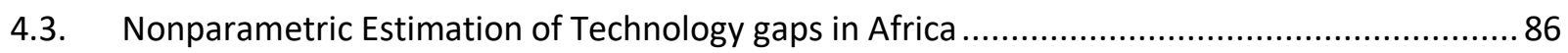

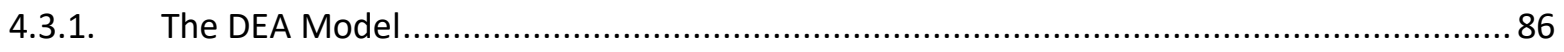

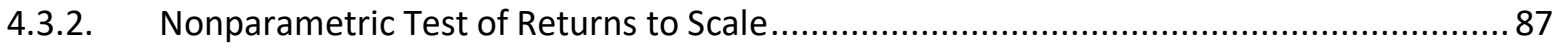

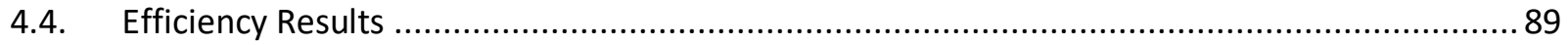

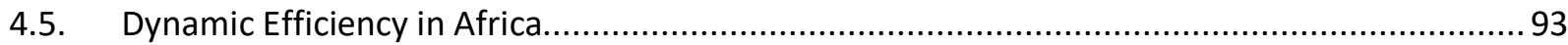

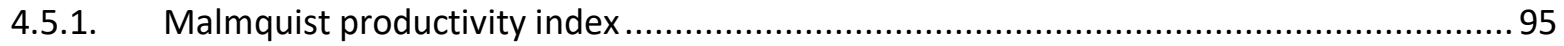

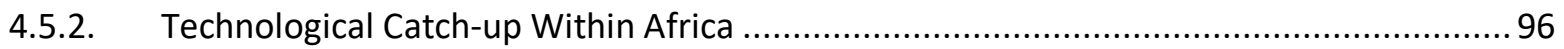

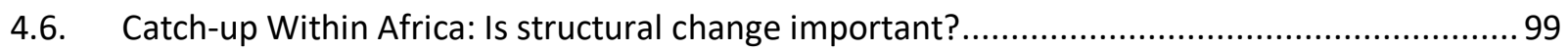

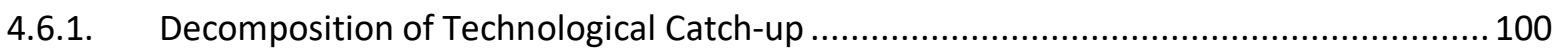

4.6.2. Long-run Relative Productivity Patterns and Technological Catch-up in Africa............... 101

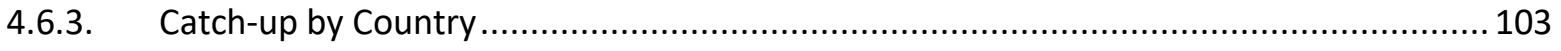

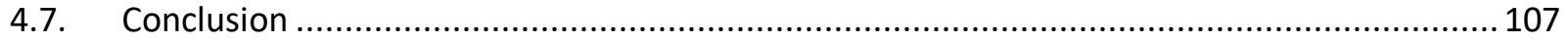

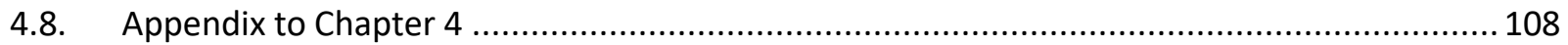

4.8.1. South Africa: A Leader in Education and Innovation.............................................. 108

4.8.2. Robustness Checks of Efficiency Measures .............................................................. 110

4.8.3. Decomposition of catch-up by country and period............................................... 112

$5 \quad$ Chapter 5: Is Africa Deindustrializing?..............................................................................118

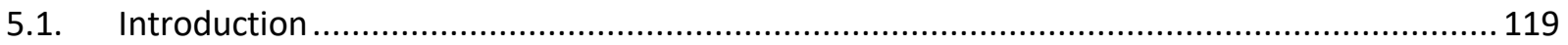

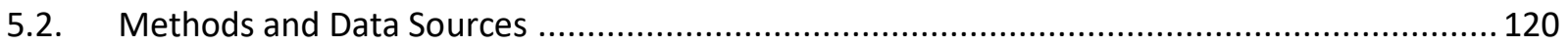

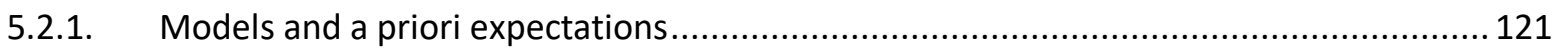

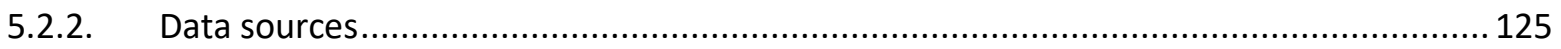

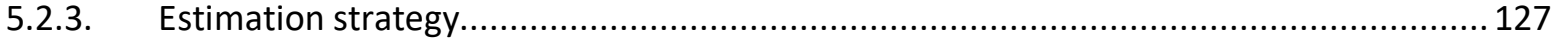

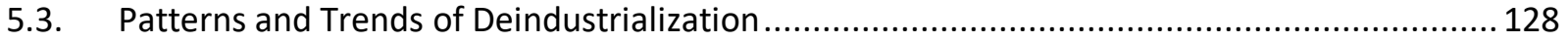

5.3.1. Evidence on the Changing Structure of the World Economy …................................. 128

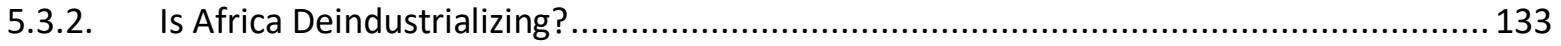

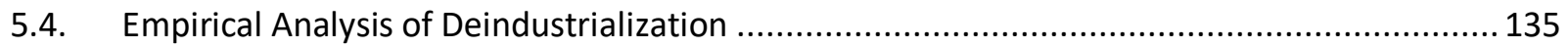


5.5. The deep drivers of manufacturing performance in Africa ............................................ 143

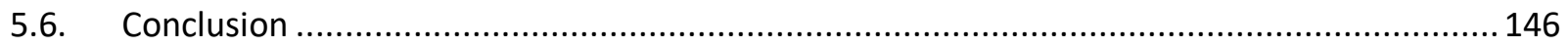

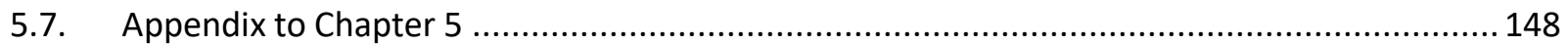

6 Chapter 6. Reforms and productivity growth in developing countries: Inter or intra -

allocative efficiency channel? ...............................................................................................................149

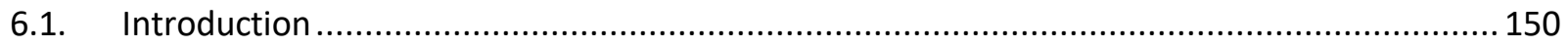

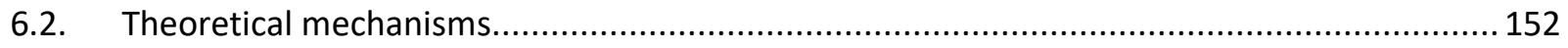

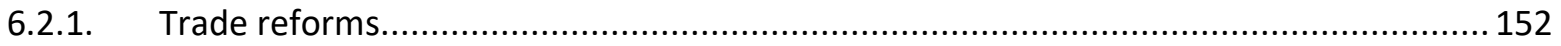

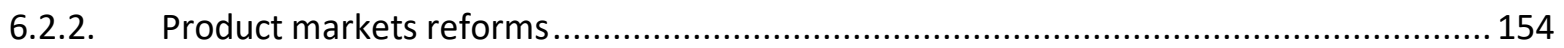

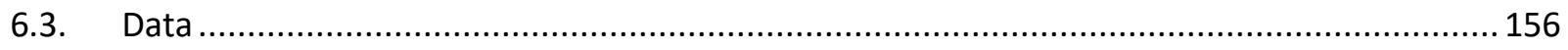

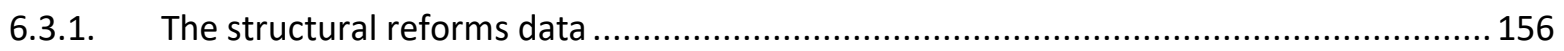

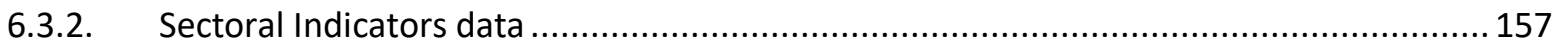

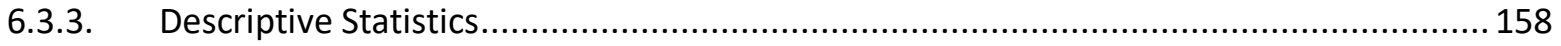

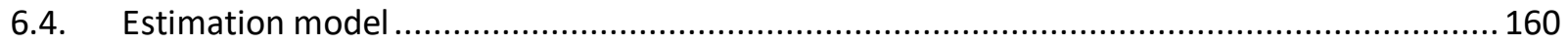

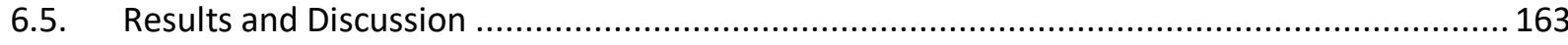

6.5.1. Reforms and Aggregate Labor productivity growth ............................................. 163

6.5.2. Intra-sectoral or Intersectoral Reallocation? .......................................................... 164

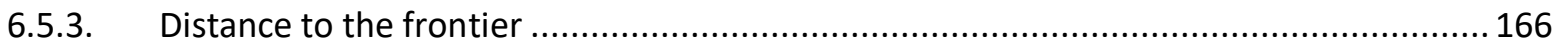

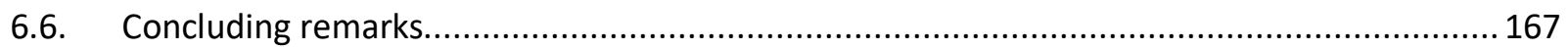

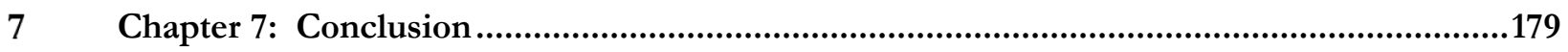

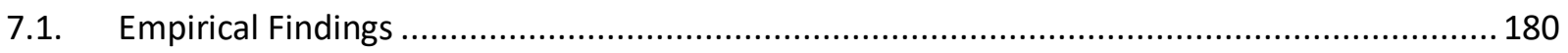

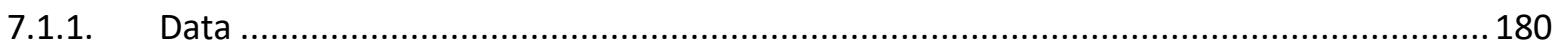

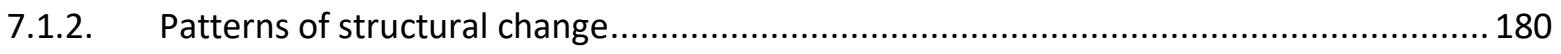

7.1.3. Potential causes of structural change ….............................................................. 181

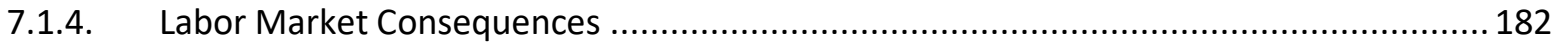

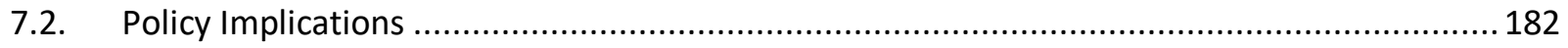

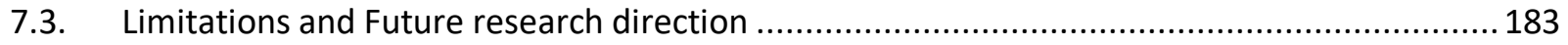

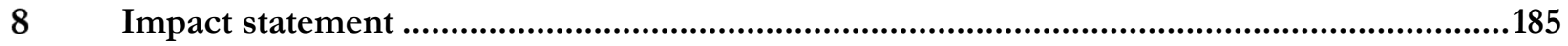

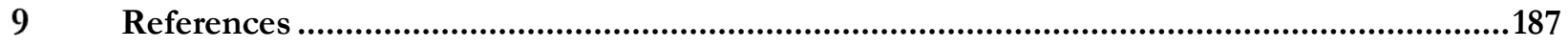

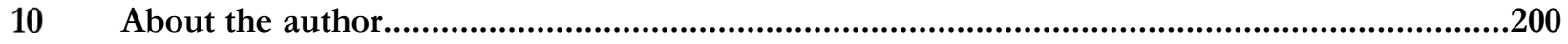




\section{List of Figures}

Figure 2.1: The structure of Nigerian economy before and after rebasing........................................... 20

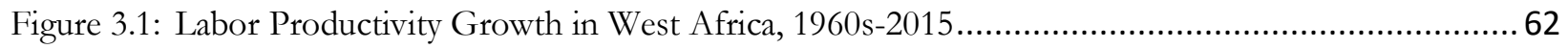

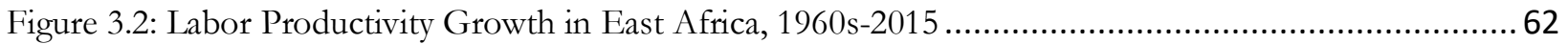

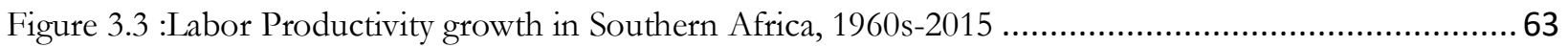

Figure 3.4: Scatterplot of EPL and Job Reallocation in Africa (2000-2015)........................................... 72

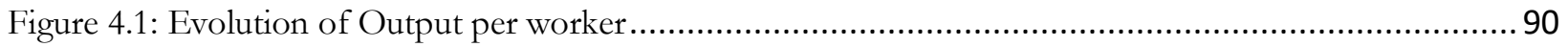

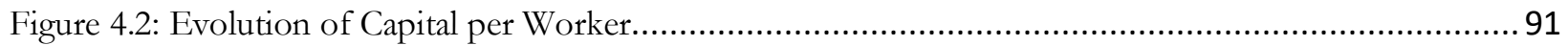

Figure 4.3: Output Per Worker 2014 Plotted Against Capital Per Worker 2014 ........................................ 98

Figure 4.4: Technology Change Between 1970-2014 Plotted Against Output Per Worker 1970 ................... 98

Figure 4.5: Technology Change Between 1970-2014 Plotted Against Output Per Worker 2014 .................. 99

Figure 4.6: Relative Labor Productivity as a measure of Technology gap (SA=1) ................................. 102

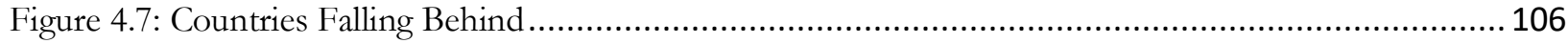

Figure 5.1: Evolution of sectoral employment shares in the world ................................................. 131

Figure 5.2: Evolution of sectoral employment shares in the Sub-Saharan Africa ................................... 132

Figure 5.3: Manufacturing share of employment by sub-region over time........................................... 134

Figure 5.4: Manufacturing share of real value added by sub-region over time ….................................... 135

Figure 5.5: Trends of manufacturing share in value added by sub-region............................................ 136 


\section{List of Tables}

Table 2.1: List of Countries in the Africa Sector Database................................................................. 13

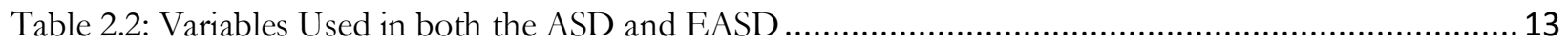

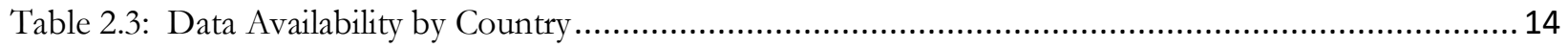

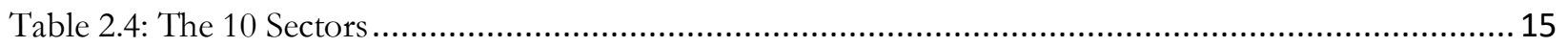

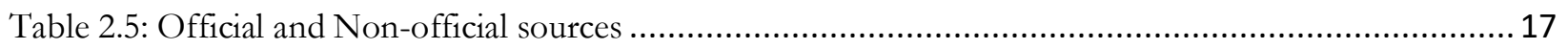

Table 2.6: Availability of data sources for new countries ............................................................ 18

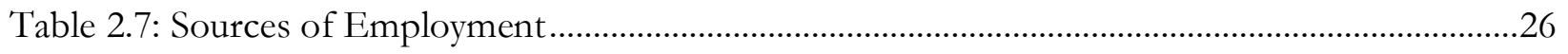

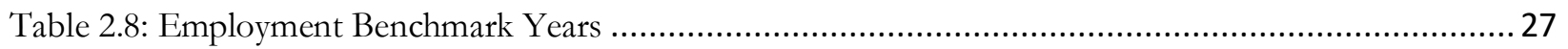

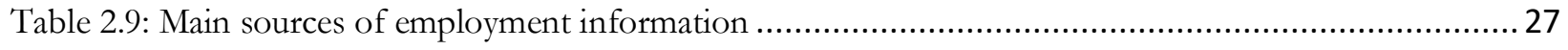

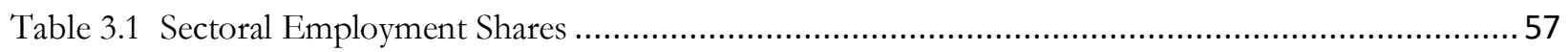

Table 3.2 : Relative Productivity in Africa …............................................................................ 58

Table 3.3: Decomposition of Labor Productivity Growth in Sub-Saharan Africa .....................................6 60

Table 3.4: Job Creation, Job Destruction and Job Reallocation in Sub-Saharan Africa, 1960s-2015 .............66

Table 3.5: LMT (Lilien Index) Decomposition Results Africa (percentages), 1960-2015...........................67

Table 3.6: Job Creation, Job Destruction and Job Reallocation in Sub-Saharan Africa, by Periods ............... 70

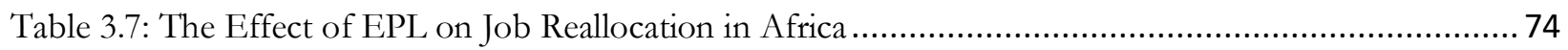

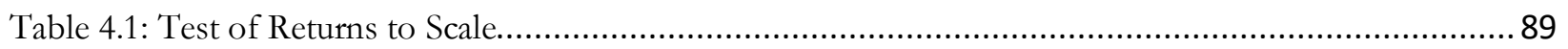

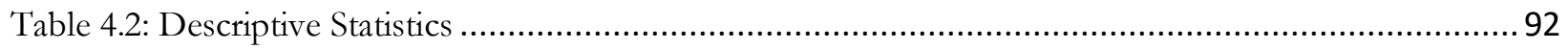

Table 4.3: Radial Measures of Technical Efficiency for African Countries............................................ 92

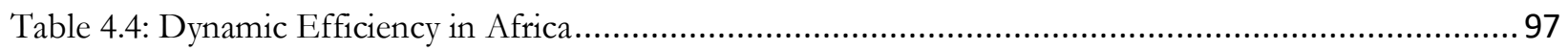

Table 4.5: Decomposition of Technological Catch-up to SA ............................................................ 103

Table 4.6: Catch-up by Country (average annual percentage change) .................................................................... 104

Table 5.1: Evidence on Deindustrialization in Sub-Saharan Africa (EASD) .......................................... 139

Table 5.2: Evidence on Deindustrialization in Sub-Saharan Africa (GGDC Africa Sector Database).......... 140

Table 5.3: Evidence on Deindustrialization in Sub-Saharan Africa (UN Database)................................. 141

Table 5.4: Evidence on Deindustrialization by Sub-region (UN Database) ........................................... 142

Table 5.5: Deep Drivers of Manufacturing Employment Shares in Africa, 1970-2015 ............................ 144

Table 6.1: Annual Labor Productivity Growth by Region (\%), 1975-2005 .......................................... 160

Table 6.2: Average Annual Labor Productivity Growth by Country (\%), 1975-2005 ............................... 161

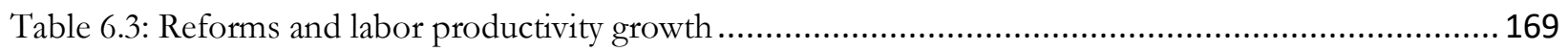

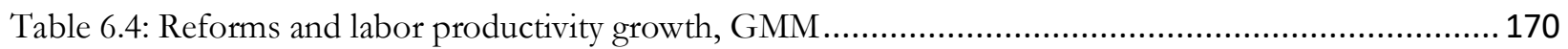

Table 6.5: Reforms and labor productivity growth with additional control variables............................... 171

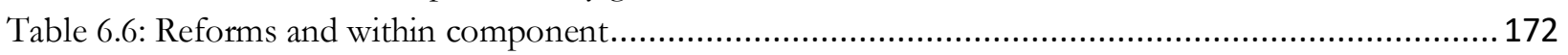

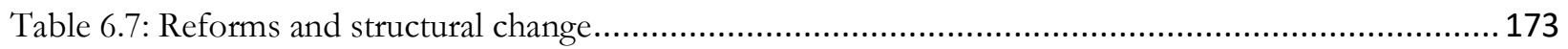

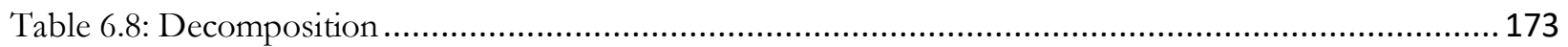

Table 6.9: Reforms and labor productivity growth with distance to the technological frontier .................. 174

Table 6.10: Reforms and within effect with distance to the technological frontier................................. 175

Table 6.11: Reforms and structural change with distance to the technological frontier ............................ 176 


\section{Chapter 1: Introduction}




\subsection{Introduction}

It is now evident that economic development involves the successful transformation of the structure of the economy. This process involves multi-dimensional changes in the socio-economic system, including its demographic composition, production structure, institutional setting, and social structure (Nissanke, 2019). Structural change ${ }^{1}$ - i.e., changes in the productive structure or the shift of resources from low productivity sectors to high productivity sectors - is the central feature of this transformation and often precedes changes in the other dimensions of the socio-economic system. The postwar experience of developing countries has shown that structural change is at the heart of the divergent growth paths with different patterns of structural change explaining much of the variation in total labor productivity and income growth among developing countries. While the past decades have been marked as boom times for industrial transformation in many countries in Asia, the rate of productive transformation in Sub-Saharan Africa (henceforth Africa) and Latin America was unsatisfactory, and at best, lackluster.

After independence, many African countries with the advantage of backwardness ${ }^{2}$, sectoral productivity gaps, and the substantial endowment of manufacturing-relevant natural resources were expected to achieve rapid industrialization, sustained economic growth, and poverty reduction. In the 1960s, Africa's growth potential was ranked ahead of East Asia's by a leading development economics textbook and the then chief economist of the World Bank expected the growth rate of some African countries to reach or exceed 7 percent per annum (Enke, 1963 and Kamark, 1967 cf Easterly \& Levine, 1997). However, six decades after independence, industrialization is elusive, economic development has mostly eluded the continent in sharp contrast to this initial optimism and the immediate postindependence nationalist aspirations for rapid growth. Similarly, Latin America, with the favorable initial condition - a higher per capita income than the rest of the developing world after the Second World War - was expected to catch-up to the then industrialized world. And yet, today, many countries in Latin America are still middle-income countries facing considerable challenges to moving out of the middle-income trap and reducing pervasive inequality. Conversely, some countries in Asia enjoyed a process of profound structural transformation, which altered the productive structure of their economy.

At the core of this transformation are significant productivity increases within countries, productivity convergence within East Asia, and the closure of the productivity gap with the technology frontier, i.e., the US. What is often understated in the East Asian miracle story is the phenomenon of productivity catch-up within East Asia. For much of the $20^{\text {th }}$ century, Japan was the economic leader of East Asia. By the turn of the $21^{\text {st }}$ century, the productivity of Hong Kong, Japan, Singapore, South Korea, and Taiwan converged. The productivity gap of China, Malaysia, and the Philippines with Japan has also reduced significantly. By catching-up with the productivity of the regional economic leader, the productivity gap of East Asia with the US has also reduced considerably. But this is not the case for Africa and Latin America. For example, the aggregate labor productivity level of East Asia

\footnotetext{
${ }^{1}$ Here I am referring to structural change that has a positive impact on productivity.

${ }^{2}$ In the catch-up literature, the greater the backlog of technological knowledge with a developing country, the greater possibility of rapid industrialization because learning from existing technological knowledge or imitation is often faster and less expensive than new innovations. However, the ability of the country to benefit from the advantage of backwardness often depends on the social capabilities of the country (Abramovitz, 1986)
} 
was $15 \%$ of the US level in 1963 but had reached $70 \%$ of the US level by 2010 . The productivity of Latin American was 35\% of the US level in 1963 but shrank to 25\% by 2010 (Üngör, 2017). The labor productivity of Africa was less than $15 \%$ of the US productivity level in the 1960 s and has widened over time (see chapter 4 figure A4.2). At the sectoral level, labor productivity in the manufacturing and services sectors of Africa has reduced from about $20 \%$ in the 1960 s to $10 \%$ in 2010 (see figures 3A \& 3B in de Vries, Timmer, \& de Vries, 2015)

There is a voluminous literature trying to explain the sources of this divergence, notably; the causes of the East Asia miracle; Africa's growth tragedy; Latin America's failure; and the awry economic performance of Africa and Latin America relative to East Asia. These comparative studies focus on the differences in institutional and policy reforms in explaining the divergence, mostly based on empirical analysis of aggregate macroeconomic indicators. These explanations have often generated controversy and unproductive bickering among development economists. In recent periods, a less controversial approach - the structural approach - has evolved in the literature, which emphasizes the different patterns of structural change as an explanation for much of the variation in total labor productivity and income growth between Asia and the rest of the developing world (e.g. see McMillan et al., 2014; Timmer et al., 2015; Üngör, 2017; Lavopa \& Szirmai, 2018). ${ }^{3}$ These explanations being offered take their theoretical inspiration from the two-sector model of Lewis (1954).

The evolving literature has emphasized structural change as a missing ingredient in Africa's recent growth turnaround. As a result, industrialization and structural change are now very much a part of the prevailing policy rhetoric. While the specific aspect of structural change, such as deindustrialization, has not been disputed in Asia and Latin America, the pattern of deindustrialization in Africa is inconclusive. Furthermore, much of the rapidly evolving literature on structural change in Africa is based on a database built before the recent statistical reforms which have significantly improved sectoral indicators in Africa. A further concern is that much of the literature on Africa focuses on the extent of labor reallocation and labor productivity, neglecting other consequences of structural change such as labor market volatility, which are among the root causes of (transitory or structural) unemployment. The purpose of this thesis is to bring up-to-date the empirical patterns of structural change in Africa, in the light of new sectoral indicators; and extend the empirical analysis from the mere examination of patterns of structural change to potential causes as well as consequences of structural change in Africa. In addition, we also consider structural reforms as a fundamental correlate of productivity growth either via intra or inter-reallocation mechanisms in all developing countries for which data is available. In doing so, this thesis provides empirical evidence to guide policymakers in Africa to move from rhetoric to the realization of absorbing the majority of the labor force in the modern sector.

\subsection{Africa's Elusive Quest for Industrialization}

In the pursuit of economic development, the post-independence era in Africa saw nationalist aspirations being closely connected with the quest for rapid industrialization. For example, Kwame Nkrumah, the leader of Africa's political renaissance, said, 'industry... is the means by which rapid

\footnotetext{
${ }^{3}$ These studies renewed interest in the role that structural change plays in the economic development of countries. Earlier studies emphasizing the role of economic structure in development include Chenery $(1955,1960,1982)$, Chenery \& Taylor (1968) and Syrquin \& Chenery (1989).
} 
improvement in Africa's living standards is possible..." (Nkrumah, 1965 cf Page, 2011). The passion for rapid industrialization is understandable since, both in theory and history, industrialization has been the well-known path to modernization. For example, manufacturing offers unique opportunities for capital accumulation, effective backward and forward linkages, economies of scale, and both embodied and disembodied technological progress (Szirmai, 2012:410). These special growth effects were first observed as a stylized fact of growth by Kuznets and later formalized into three laws by Kaldor (1966). This special role of manufacturing is known as the engine of growth hypothesis in the literature. Historically, the industrial revolution made possible the sustained productivity growth of Europe and the US in the $18^{\text {th }}$ century, then Japan in the late $19^{\text {th }}$ century (Rodrik, 2016). The East Asian miracle is a story of industrialization. Therefore, for post-independence African leaders, dreaming about industrialization was a step in the right direction. However, dreaming is one thing, realizing that dream is another thing.

Many African countries were inspired by a vision of development set in motion by a 'big push', which primarily involves a significant investment effort by the state. In line with the proposition that industry is the means to increase per capita income, the state invested heavily in industry, emphasizing importsubstitution, structural change, and a less open economy (Killick, 2010). Industrialization, in a broad sense, was seen synonymously as development. This notion of development did not take place within an intellectual vacuum. The industrial policies of post-independence Africa were, in many ways, similar to or influenced by a set of leading ideas on economic development after the Second World War. The first prominent idea was that economic development involves the process of discontinuous structural transformation (e.g., Hirschman, 1958; Lewis, 1954; Rostow, 1960). Second, beyond a certain threshold of per capita income, economic growth is self-sustaining, and below this threshold, countries will remain in poverty traps (e.g., Leibenstein, 1957; Nurkse, 1953). Third, to escape poverty traps and achieve self-sustaining growth, 'a critical minimum effort' or 'a big push' is required (e.g., Leibenstein, 1957; Rosenstein-Rodan, 1943). Fourth, the big push should be targeted at increasing the ratio of investment to national income (Domar, 1957; Harrod, 1948). Finally, to alter the inherited colonial structure of exporting primary products and importing manufactures, rapid (import-substitution) industrialization is needed to satisfy domestic demand for manufactures (see Killick, 2010, for further discussion). Making theory work in practice often involves a heuristic process of contextualization.

As is well-known, import-substitution industrialization failed in Africa. The import-substituting industries created by the state were often uncompetitive and unsustainable (Page, 2011). The drive for manufacturing in Africa lost steam with the political and economic crisis of the 1970s. Following the economic collapse of the 1970s, there was a strong argument against excessive government intervention in Africa, with market-oriented development policy displacing state-led industrial development. The World Bank's Structural Adjustment Programs (SAPs) of the 1980s are an embodiment of this new orientation in development policy. The SAPs emphasized the removal of price distortions, trade liberalization, and a strong focus on agriculture. This new development paradigm marginalized industrial development, leaving it to the mercy of the market. "Indeed, beyond a preoccupation with trade policy, there was no comprehensive industrial strategy within SAPs" (Fahnbulleh, 2005: 10).

Industrial policy has re-emerged in Africa in the past two decades, with regional organizations leading the charge. For example, the African Union's (AU) Agenda 2063 emphasizes industrialization as a 
means and end to productivity growth in Africa. The Africa Development Bank has also stressed industrialization as one of its pillars (high fives) for transforming Africa. With the incoming youth bulge, African countries need to create quality jobs to absorb the estimated 11 million youth who enter the labor market each year, according to the ILO (2018). However, Africa's higher productivity sectors failed to generate sufficient employment for the rapidly growing labor force (Newman et al., 2016). In the absence of high productivity jobs in Africa, and to survive, the youth have been engaging in relatively unproductive economic activities - i.e., retail trade and distribution - in the informal sector. As a result, the share of informal services in employment and output is rising, a trend we describe as the informal tertiarization of African economies in this thesis. If the current slow pace of structural transformation continues with the high number of youth entering the labor force each year, the informal services sector will be the major employer of youth for many years to come (Fox, Senbet, \& Simbanegavi, 2016).

\subsection{Contributions and Structure of Thesis}

Many attempts have been made to explain why Africa has failed to industrialize and structurally modernize (e.g., McMillan \& Headey, 2014; McMillan \& Harttgen, 2014; McMillan \& Rodrik, 2011; Mcmillan \& Verduzco-Gallo, 2014; Rodrik, 2014, 2015, 2016; de Vries, Timmer, \& Vries, 2015). However, there is a huge statistical problem: data coverage is limited, and data reliability is often debatable. This has often led to contrasting conclusions about industrial development in Africa. For example, while Rodrik (2016) concludes that Africa is deindustrializing prematurely, Diao et al. (2017), using the same dataset, concludes that it is difficult to say that Africa is deindustrializing. The most comprehensive database used by researchers to analyze the long-run sectoral performance of Africa economies is the Africa Sector Database (ASD) developed by the Groningen Growth and Development Center (GGDC). The ASD, however, only covers 11 relatively rich countries in Africa with higher educational, health and nutritional outcomes than the majority of the countries in the region, raising important questions about the representativeness of the sample for research and policy conclusions (Diao, Mcmillan, \& Wangwe, 2018). A second concern relates to the fact that after the construction of the ASD most countries have revised their GDP estimates which has changed the structure of reported production resulting from structural undercounting in previous estimates. As a first step towards establishing empirical regularities about long-run industrial development in Africa, Chapter 2 of the thesis presents a new sectoral database on Africa economic performance: The Extended Africa Sector Database (EASD). The database covers about $80 \%$ of GDP in Africa, and it is used throughout the rest of thesis to answer essential questions about structural change in Africa.

There is a growing literature focusing on the relationship between the extent of structural change and productivity growth in Africa (e.g. Barrett, Christiaensen, Sheahan, \& Shimeles, 2017; Diao et al., 2017; Diao, Kweka, \& McMillan, 2018; Diao \& McMillan, 2018; M. McMillan \& Verduzco-Gallo, 2014; de Vries et al., 2015). While these studies have revealed important insights into the patterns of structural change in Africa and have indicated that structural change has been an important phenomenon in the productivity growth of Africa, its impact on other outcomes - most notably labor market outcomes are less well known. Indeed, these studies tend to ignore the impact of structural changes on other features of the economy, with its impact on labor markets, and labor market volatility in particular, being an important omission. While structural change may enhance aggregate productivity, there is also the possibility that it helps generate transitory unemployment and may lead to a reallocation of 
workers to lower-paid jobs or into the informal sector, leading to increased uncertainty for workers. Using the data constructed in Chapter 2, Chapter 3 of the thesis provides a fuller picture of the role of structural change on economic performance by combining an analysis of structural change on productivity growth with an analysis of structural change on labor market outcomes. The chapter contributes to the literature in several ways by shedding light on atypical patterns of structural change, on labor market turbulence, and on the institutional arrangements in Africa responsible for these outcomes.

The peculiar nature of African development presents unique technological challenges. This often requires African-induced innovation or a combination of frontier and local technologies to solve problems unique to Africa. Several innovations, such as mPedigree, MPesa, etc., illustrate this point. An important finding in the economics literature is that the slow diffusion of technology is responsible for the slow speed of productivity convergence (Barro \& Sala-i-Martin, 1997; Mankiw, Romer, \& Weil, 1992). However, most researchers study technological change in Africa in relation to some globally defined technology frontier (e.g., Harchaoui \& Üngör, 2018). The diffusion of knowledge from this global frontier to other regions, however, decreases in intensity with geographic and relational distance. $^{4}$

Given that African countries are geographically and relationally close to each other, Chapter 4 of the thesis departs from this existing literature and studies technological change and technological catchup within Africa by considering catch-up with respect to an African technology leader. We do this by using structural (shift-share catch-up decompositions) and nonparametric (Data Envelopment Analysis) methods to estimate an African production frontier. A combination of both approaches offers more comprehensive insights than would otherwise be possible. For example, while the nonparametric approach provides an explanation of productivity convergence at the aggregate level, the structural approach traces the sources of this productivity convergence to its sectoral origins. We further measure productivity change in A frica and disentangle the change due to general technological progress and technological catch-up using the Malmquist Productivity Index (MPI). Our results show that Botswana and Mauritius are the only two countries in Africa which have converged to the technology level of the frontier. This successful convergence was driven more by technological catchup and less by technological change. We explore further the special role of technological catch-up by decomposing it into within-sector convergence, between-sector convergence, and initial specialization. The results highlight the special role of structural change in catch-up. This chapter contributes to recent evidence suggesting that countries can climb up the income ladder at a faster rate through a two-pronged transformation - i.e., structural change and technological catch-up.

In addition to the data gap, the labor market gap, and the technology-related gap in the literature, there is inconclusive evidence on the presence or otherwise of deindustrialization in Africa. While some researchers believe that Africa is deindustrializing (Page, 2012; Rodrik, 2016; Tregenna, 2015), others conclude that Africa is not deindustrializing (Diao et al., 2017; Naudé, 2019; Nguimkeu \& Zuefact, 2019). This debate relates to data coverage and the reliability of sectoral indicators in Africa. In addition to the data contribution in Chapter 2, Chapter 5 of the thesis collects sectoral data that covers 46 countries in Africa to provide extensive evidence on deindustrialization in Africa. The results show

\footnotetext{
${ }^{4}$ Relational proximity is defined as "the similarities of two areas in terms of shared behavioral codes, common culture, mutual trust, sense of belonging and cooperation capabilities.” (Basile et al., 2011:21).
} 
that the manufacturing output share for a typical African country has not changed since 1970 . We document, however, important regional differences with East Africa industrializing and Southern Africa deindustrializing. Based on this extensive evidence, we argue that the appropriate characterization of the evidence is industrial stagnation, not premature deindustrialization. While Africa has not deindustrialized, manufacturing performance is disappointing. Several factors account for these outcomes with import penetration and limited intra-African trade playing an important role in the industrial development of the continent. The new intra-African trade agreement could, therefore, open new opportunities for the future industrialization of Africa if implemented successfully.

As mentioned above, while many Asian countries have successfully undergone a deep structural change that boosted labor productivity, other developing regions have struggled to implement an efficient reallocation of labor across sectors that could generate higher productivity growth. This is specifically the case for the majority of African and Latin American countries that recorded relatively low labor productivity growth, mostly driven by within-sector productivity growth (McMillan et al., 2014). This raises the question of why some countries have higher productivity growth and a more dynamic shift of labor across sectors than others.

There is a growing literature that attributes cross-country differences in the speed of structural change and labor productivity growth to distortions. Several studies have shown that market and institutional frictions lead to a suboptimal allocation of scarce resources across and within sectors penalizing overall productivity growth (e.g., Bartelsman et al., 2013; Hsieh \& Klenow, 2009; Restuccia \& Rogerson, 2008). The logical corollary of this finding is that if countries can remove barriers and obstacles to an efficient reallocation of resources, such as labor and capital, aggregate productivity will grow at its optimum rate. Structural reforms are often described as the magic wand that can be used to reduce rigidities that exist in markets. In developing countries where a series of structural reforms have been implemented over the last decades, there is little evidence on the impacts of these reforms on labor productivity growth (Dabla-Norris, Ho, \& Kyobe, 2016; Kouamé \& Tapsoba, 2019).

Most importantly, the few studies that exist focus on the effects of reforms on productivity growth as a whole but do not assess how these effects are distributed between the within and structural components. This masks the allocative efficiency channels through which reforms affect labor productivity growth. While some reforms induce a stronger inter-allocative efficiency, other sets of reforms generate stronger intra-allocative efficiency. Chapter 6 of this thesis sheds light on the mechanisms through which structural reforms affect productivity growth in developing countries. The results overwhelmingly show that reforms affect growth in developing countries mostly by inducing an efficient reallocation of resources within sectors but not across sectors, further providing empirical support for the argument that many developing countries had structural adjustments programs without structural change (Page, 2012).

The rest of the thesis is structured as follows. Chapter 2 discusses the construction of the Extended Africa Sector Database. Evidence of structural change and labor market consequences in Africa is presented in Chapter 3. Chapter 4 discusses technological catch-up within Africa. Chapter 5 presents extensive evidence of deindustrialization in Africa and assesses the determinants of manufacturing 
performance in Africa. Chapter 6 presents how reforms affect labor productivity growth either via the intra or inter allocative efficiency channel. Chapter 7 concludes. 


\section{Chapter 2: The Extended Africa Sector Database ${ }^{5}$}

${ }^{5}$ Co-authored with Adam Szirmai. I also acknowledge the supportive role of Klaas de Vries and Gaaitzen de Vries when writing this chapter. 


\subsection{Introduction}

There is a growing literature that portrays African National statistics as notoriously unreliable and potentially misleading. The negative characterization of African data has been referred to in the literature as: the African Statistical Tragedy (Devarajan, 2013), the Jerven Debate, and the Political Economy of Bad data (Sandefur and Glassman, 2015). One of the key concerns is that changes such as rebasing of time series or improvements in the estimates of the informal sector and subsistence and untaxed activities lead to substantial changes in GDP. Mentioning this in almost all of his papers, Jerven argues that the 60\% overnight increase in Ghana's GDP as a result of rebasing is a potential source of worry (Jerven, n.d., 2009, 2010, 2011, 2013a, 2013b, 2014; Jerven \& Duncan, 2012; Jerven \& Johnston, 2015).

In response to these concerns, a UN high-level conference on post-MDGs development goals has called for a data revolution in Africa and called for African national governments to disseminate information under an open data protocol (Sandefur and Glassman, 2015). This culminated in a resolution (L4) at the African Union known as the African Data Consensus (ADC). The ADC seeks to "create an inclusive data ecosystem involving government, private sector, academia, civil society, local communities and development partners that tackles the informational aspects of development decision-making in a coordinated way" (UNECA, 2015). This generates the needed information to drive social, economic, and structural transformation and to track progress on nationally, regionally, and globally agreed goals such as the Ouagadougou Declaration on Employment Poverty Alleviation in Africa, the AU Agenda 2063, and the SDGs.

While the concerns raised in the literature may have motivated the ADC, which is very important for creating the data ecosystem that Africa needs, we argue that some academics have exaggerated the data problems and made wrong calls on some points. There are more data available for Africa than many observers realize if one is willing to dig deep enough to unearth them. For instance, Jerven (2013) argues that all discrepancies and problems in international income databases concerning Africa necessarily derive all their problems from the weaknesses of African national statistics (Jerven, 2013). We disagree with Jerven on this point. The differences between Penn World Tables (PWT), Maddison Database, and World Development Indicators (WDI) are primarily due to differences in statistical methods and not necessarily to the underlying African statistics.

Unlike some of these overly pessimistic scholars, we think it is worthwhile to make a genuine effort to study, on a country by country basis, the different data sources and link them in a way that produces a reliable sectoral dataset for African economies. We argue that a meticulous study of the statistical sources, methods, statistical reforms, and macroeconomic reforms, such as currency redenomination, can result in a statistical database that can be used to analyze economic developments in Africa.

Our starting point is the Africa Sector Database (ASD), developed by the Groningen Growth and Development Center (GGDC), which provides long-run series on sectoral development in Africa for 11 countries from 1960 to 2010. The ASD database is constructed based on an in-depth study of

available statistical sources on a country by country basis (de Vries et al. 2013). It builds on earlier efforts by McMillan and Rodrik (2011). 
In this chapter, we expand the Africa Sector Database by adding sectoral data for seven additional countries from 1960 to 2015 (Burkina Faso, Cameroon, Lesotho, Mozambique, Namibia, Rwanda, and Uganda). We also extend the existing data for the countries already in the ASD up to 2015, taking into account recent statistical and currency reforms in some of the countries. ${ }^{6}$ We strictly follow the ASD methodology to ensure data continuity, consistency, and comparability (see de Vries et al. 2013). As this chapter is meant to be read as a stand-alone chapter, some overlap and repetition of de Vries et al. (2013) in the description of methods and procedures is inevitable. We would at the outset, therefore, like to fully and explicitly acknowledge our intellectual debt to the earlier paper by de Vries et al. (2013).

The result of the empirical exercise in this chapter is an Extended Africa Sector Database (EASD) with sectoral data on employment and value added for 18 economies in Africa from the 1960s to $2015^{7}$. The resulting dataset covers about $80 \%$ of the GDP of Africa.

An examination of the trends in the data reveals that the service sector is increasingly the most important sector in Africa, both in terms of employment and value added. Agriculture is losing its position as the mainstay of African economies. This is consistent with the literature on structural change, which argues that over the course of development, inputs shift from primary sectors to more dynamic sectors such as manufacturing and services, and in response, these sectors contribute more to GDP. What is very striking is that industrial sectors and especially manufacturing sectors are rapidly losing steam as the engines of growth in most African countries at relatively low levels of GDP per capita, the. This immediately raises three essential questions: Why has manufacturing remained constant or declined in several countries in Africa (premature deindustrialization)? Is the growth in services strong and dynamic enough to avoid becoming a potential structural change burden in Africa? Is the recent growth in Africa due to within-sector growth, structural change, or changes in labor participation? These are the kinds of questions that can be analyzed with the EASD and are discussed in later chapters of the thesis.

The rest of the chapter is organized as follows: Section 2 reviews the literature on African data and prepares the ground for a meticulous study of the statistical sources, methods, and reforms in the seven new countries: Burkina Faso, Cameroun, Lesotho, Mozambique, Namibia, Rwanda, and Uganda. Section 3 describes the general content and layout of the database. It covers measures of output and labor input for the seven new African countries at the 10-sector level, usually from the 1960s to 2015, and further describes the data on output and labor input used to update the existing countries in the database from 2010 to 2015. The sources and methodology used in constructing the value-added variables are described in Section 4. Section 5 describes the sources and methodology used in constructing the employment variables. Section 6 describes the process of updating the original ASD from 2010-2015, taking into account recent statistical and exchange rate reforms in some countries. Section 7 summarizes and concludes.

\footnotetext{
${ }^{6}$ Rebasing in Nigeria, Kenya, Tanzania and Zambia, and Currency Redenomination in Zambia.

${ }^{7}$ In the case of Uganda the data go back to the 1950s. In some other countries the data start from 1970.
} 


\subsection{The Data Debate}

The study of structural transformation in Africa is limited by a lack of reliable long-run sectoral data. Data, in general, have been highlighted to be problematic in Africa (Devarajan, 2013: 9). Before Devarajan (2013) identified this problem, Young (2012) argued that measures of real consumption based on demographic health survey (DHS) data indicate that living standards in Africa are growing at a rate 3.5 to 4 times greater than the rate stated in national accounts datasets. Using the growth in household assets as a proxy for growth in incomes and consumption, he concludes that economic performance is better than suggested by national income data, putting the quality of national data in Africa into question. Harttgen et al. (2013) challenged this claim by showing that the trend in assets is a biased proxy for the trend in income or consumption since there is a weak relationship between the growth of assets and the growth of income or consumption, with asset growth exhibiting drift behavior.

Jerven, in various papers, ${ }^{8}$ has further argued that African national statistics are highly unreliable and potentially misleading. Comparing the ranking of income per capita based on World Development Indicators (WDI), Penn World Tables (PWT), and the Maddison historical database, he shows striking discrepancies. Countries are ranked into different income categories according to these databases. He concludes that there is a black box of uncertainty surrounding African data, resulting in knowledge and governance problems.

While this may have created the policy momentum for better measurement and the timely dissemination of data in Africa, we argue that some of Jerven's arguments and generalizations are unfounded. Jerven (2013) argues that all discrepancies and problems in international income databases concerning Africa necessarily derive all their problems from the weaknesses of African national statistics (Jerven, 2013). We argue that Jerven is wrong on this point. The differences between PWT, the Maddison Database, and WDI are due to differences in statistical methods, not necessarily to the underlying African statistics. Garcia-verdu (2014) highlights the fundamental problems of definition and many other inaccuracies in Jerven's book.

What this debate shows is that there are still severe problems of statistical measurement in Africa. Unfortunately, much of our current understanding of the nature of structural change and productivity growth in Africa is based on imperfect data. The informal sector, subsistence, and untaxed activities are poorly measured (Young, 2012); measurement of manufacturing output is characterized by margins of errors (Ridell, 1990 cited in Jerven, 2009); and data quality, in general, is graded C or D in the PWT 6.2, reflecting an error margin of $30 \%$ or $40 \%$. These problems of measurement produce a considerable amount of uncertainty in our continuous attempts to estimate the effect of structural change on productivity growth in Africa.

${ }^{8}$ See (Jerven, 2009, 2010, 2011, 2013b, 2013a, 2014; Jerven \& Johnston, 2015) 
In many cases, little can be done about these measurement problems by users of African statistics. But as a second-best solution, de Vries et al. $(2013,2015)$ developed a methodology to make the data "intertemporally, internationally and internally consistent". The Africa Sector Database provides longrun series on sectoral development in Africa based on national and international sources. Their approach covers only 11 countries in Africa. However, the same sources used to construct the series are available for seven other African countries from 1960-2015: Burkina Faso, Cameroon, Lesotho, Mozambique, Namibia, Rwanda, and Uganda.

\subsection{Expanding the Africa Sector Database (ASD)}

The original ASD covers 11 countries from 1960 to 2010 (de Vries et al., 2013). We have added seven new countries and updated the original ASD that ended in 2010 to the year 2015. The resulting expanded and updated ASD covers data for 18 African countries, with four variables reported across 10 sectors from 1960 to 2015. The industry classification is based upon the International Standard Industrial Classification of All Economic Activities (ISIC) Rev.3.1. To ensure that the labor productivity of the Business Services $(J+K)$ sector is not overestimated, value added for Dwellings is presented separately ${ }^{9}$. The update includes revisions of the data for Nigeria, Kenya, Tanzania, and Zambia in recent periods (see details in the update section 4.3) because of the recent rebasing of GDP in the countries mentioned above and currency redenomination in Zambia. The table below presents the countries in the original database and the new additions.

Table 2.1: List of Countries in the Africa Sector Database

\begin{tabular}{|l|l|}
\hline ASD Database & $\begin{array}{l}\text { Botswana, Ethiopia, Ghana, Kenya, Malawi, Mauritius, Nigeria, Senegal, South Africa } \\
\text { Tanzania, and Zambia }\end{array}$ \\
\hline Expansion & Burkina Faso, Cameroon, Lesotho, Mozambique, Namibia, Rwanda, and Uganda \\
\hline
\end{tabular}

\subsubsection{Variables and the 10 Sectors}

Table 2.2 lists the variables covered in the ASD. We include the same variables in the update to ensure continuity and consistency.

Table 2.2: Variables Used in both the ASD and EASD

\begin{tabular}{|l|l|}
\hline Variable Code & Description \\
\hline VA & Value added in current prices in local currency \\
\hline VA_Q05 & Value added in constant 2005 prices in local currency \\
\hline VA_P & Value added price deflator $(2005=100)$ \\
\hline EMP & Persons engaged (usually $\geq 15$ years) \\
\hline
\end{tabular}

\footnotetext{
9 There is no labor input for dwellings
} 
For these four variables, data were usually available from the 1960s until 2015, in particular for value added at current prices. The length of the time series for value added at constant prices and employment differ for some countries depending on data availability. For Uganda, employment data go back to 1952, and value added is available from 1955 onwards. Value added at current and constant prices is measured in millions of local currency while employment is measured in thousands of persons. Because of currency redenomination in some countries at different points in time, all valueadded data are converted to new national currencies. ${ }^{10}$ Table 3 gives an overview of data availability in the EASD.

Table 2.3: Data Availability by Country

\begin{tabular}{|l|l|l|l|l|l|l|}
\hline Code & Country & Currency & VA & VA_Q05 & VA_P & EMP \\
\hline BWA & Botswana & Pula (P) & $1964-2015$ & $1968-2015$ & $1964-2015$ & $1964-2015$ \\
\hline BFA & Burkina Faso & Franc (CFA) & $1965-2015$ & $1966-2015$ & $1966-2015$ & $1970-2015$ \\
\hline CMR & Cameroon & Franc (CFA) & $1965-2015$ & $1965-2015$ & $1965-2015$ & $1965-2015$ \\
\hline ETH & Ethiopia & Birr (Br) & $1961-2015$ & $1961-2015$ & $1961-2015$ & $1961-2015$ \\
\hline GHA & Ghana & Cedi (c) & $1960-2015$ & $1960-2015$ & $1960-2015$ & $1960-2015$ \\
\hline KEN & Kenya & Shilling (KSh) & $1960-2015$ & $1964-2015$ & $1964-2015$ & $1969-2015$ \\
\hline LSO & Lesotho & Molati (LSL) & $1964-2015$ & $1965-2015$ & $1965-2015$ & $1970-2015$ \\
\hline MWI & Malawi & Kwacha (MK) & $1960-2015$ & $1966-2015$ & $1966-2015$ & $1966-2015$ \\
\hline MUS & Mauritius & Rupee (R) & $1960-2015$ & $1970-2015$ & $1970-2015$ & $1970-2015$ \\
\hline MOZ & Mozambique & Metical (MT) & $1966-2015$ & $1966-2015$ & $1966-2015$ & $1970-2015$ \\
\hline NAM & Namibia & Dollar (N\$) & $1965-2015$ & $1965-2015$ & $1965-2015$ & $1960-2015$ \\
\hline NGA & Nigeria & Naira ( $)$ & $1960-2015$ & $1960-2015$ & $1960-2015$ & $1960-2015$ \\
\hline RWA & Rwanda & Franc (RWF) & $1966-2015$ & $1966-2015$ & $1966-2015$ & $1970-2015$ \\
\hline SEN & Senegal & Franc (CFA) & $1960-2015$ & $1970-2015$ & $1970-2015$ & $1970-2015$ \\
\hline ZAF & South Africa & Rand (R) & $1960-2015$ & $1960-2015$ & $1960-2015$ & $1960-2015$ \\
\hline TZA & Tanzania & Shilling (SHS) & $1960-2015$ & $1960-2015$ & $1960-2015$ & $1960-2015$ \\
\hline UGA & Uganda & Shilling (Ush) & $1955-2015$ & $1955-2015$ & $1955-2015$ & $1952-2015$ \\
\hline ZMB & Zambia & Kwacha (ZK) & $1960-2015$ & $1965-2015$ & $1965-2015$ & $1965-2015$ \\
\hline
\end{tabular}

\subsubsection{Sectoral Classification and Treatment of Dwellings}

The ASD followed the International Standard Industrial Classification of All Economic Activities (ISIC) Rev.3.1 to define the ten sectors. Table 4 reports the ISIC Rev 3.1 codes, the ASD sector name, and the corresponding sub-sectors. Owner-Occupied Dwellings (70) are given special treatment in the ASD. Ownership of dwellings is the imputed rent, which would typically be paid by the owneroccupier if $s /$ he were renting the property rather than owning it. In other words, it is an estimate for

\footnotetext{
${ }^{10}$ For example, one new Zambian Kwacha adopted in 2013 is equivalent to thousand old kwacha. We converted data estimated in old currency to the new currency by simply dividing it by a multiplicand of one thousand.
} 
the economy as a whole of what owner-occupiers would charge for the use of their housing. The estimate is usually based on the number of dwellings given in the population and housing census and an imputed rent per month. In the ASD, it is implicit in real estate activities, which is part of Business Services $(J+K)$. It has no employment equivalent, therefore, in productivity analysis, and as such, tends to overestimate the productivity of the real estate sector if it is not deducted. As a result, it is treated separately in the ASD and EASD. This is particularly important for Africa, where many workers live in their own houses.

In the case of the seven additional countries, the National Statistical Institutes of Lesotho and Uganda construct a separate series for owner-occupied Dwellings. For Burkina Faso and Cameroon, we used the share of Dwellings in Business Services $(J+K)$ of Senegal to build a separate series for Dwellings (70). Since Burkina Faso, Cameroon and Senegal are AFRISTAT members, are in the same monetary zone and have a similar economic structure, we apply the share of Dwellings in Business Services $(\mathrm{J}+\mathrm{K})$ of Senegal to give a reasonable estimate of dwellings in the other two Francophone countries. As Namibia does not report separate series on dwellings, we applied the share of dwellings in Business Services $(J+K)$ of Lesotho to arrive at an estimate for Namibia. Namibia and Lesotho are in the Common Monetary Area (CMA) and have a similar real estate structure. Rwanda and Mozambique also do not report separate series on Dwellings. For these two countries, we applied the share of Dwellings in Business Services $(\mathrm{J}+\mathrm{K})$ of Uganda and Tanzania, respectively, since the economic structure of these countries is similar to the two countries that do not report these data.

Table 2.4: The 10 Sectors

\begin{tabular}{|c|c|c|}
\hline ISIC Rev3.1 code & ASD sector name & ISIC Rev3.1 description \\
\hline $\mathrm{AtB}$ & Agriculture & Agriculture, Hunting, Forestry, and Fishing \\
\hline $\mathrm{C}$ & Mining & Mining and Quarrying \\
\hline $\mathrm{D}$ & Manufacturing & Manufacturing \\
\hline $\mathrm{E}$ & Utilities & Electricity, Gas and Water Supply \\
\hline F & Construction & Construction \\
\hline $\mathrm{G}+\mathrm{H}$ & Trade Services & $\begin{array}{l}\text { Wholesale and Retail trade; repair of motor vehicles, motorcycles and } \\
\text { personal and household goods, Hotels and Restaurants. }\end{array}$ \\
\hline $\mathrm{I}$ & Transport & Transport, Storage and Communications. \\
\hline $\mathrm{J}+\mathrm{K}$ & Business Services & Financial Intermediation, Real Estate, Renting and Business Activities. \\
\hline 70 & Dwellings & Owner occupied Dwellings (is part of Business services) \\
\hline L,M,N & $\begin{array}{l}\text { Government } \\
\text { Services }\end{array}$ & Public Administration and Defence, Education, Health and Social work \\
\hline $\mathrm{O}, \mathrm{P}$ & Personal Services & $\begin{array}{l}\text { Other Community, Social and Personal service activities, Activities of } \\
\text { Private Households }\end{array}$ \\
\hline TOT & Total Economy & Total Economy \\
\hline
\end{tabular}




\subsection{Value Added}

\subsubsection{Sources for new countries}

In expanding and updating the ASD, we followed carefully the approach used by de Vries et al. (2013, 2015) in constructing the value added series to ensure comparability, consistency, and continuity. In the ASD, de Vries et al. (2013:12) apply the follow rules and methods:

- They make a distinction between 'official' (NSI produced), and 'non-official' (estimates) sources.

- Official NSI data are used as the primary source.

- Non-official data are used to bridge gaps in official data using growth trends.

- When detailed sectoral data are missing, growth trends of aggregate sectors are applied.

- The most recent revision of the National Accounts data is used as the benchmark. Time series are constructed by extrapolating the benchmark value added levels forward and backward in time.

- Historical series are linked using growth rates, which ensure consistency over time.

- Current price series and price deflator series derive from the source data. Volume series (constant price series) are calculated implicitly by dividing current price series by a price deflator.

Official data are usually obtained from national statistical institutes. The main sources are yearly publications such as the Statistical Bulletins, Statistical Yearbooks, and National Accounts reports. All countries in this study use the UN System of National Accounts in preparing value added data, ensuring that the data is highly comparable across countries. For some years, official sources are not available from National Statistical Institutes. In those years, in our expansion and updating exercise, we complement the available official sources with value added data from the UN Yearbook of National Accounts and the online database of UN Official Country Data. These two UN sources are based on information elicited from the UN National Accounts questionnaire sent to the National Statistical Institutes. UN national accounts data are usually available from 1970. However, for Mozambique and Namibia, the UN data starts from 1991 and 1980, respectively, which is the same period for which we had national accounts data from the National Statistical Institutes. For Lesotho, the Bureau of Statistics started computing volume and price series from 1980 onwards.

If value added or price information is missing, we fill gaps in the data using information from the Africa Statistical Yearbook produced by UNECA (1970-1990)). Other (non-digital) official and Nonofficial sources were mostly obtained from the SAOS, University of London Library, and the British Library. Table 5 summaries the sources used in ASD and EASD. 
Table 2.5: Official and Non-official sources

\begin{tabular}{|l|l|}
\hline Official Sources & Non-official Sources \\
\hline $\begin{array}{l}\text { National Statistics Institute National Accounts } \\
\text { publications (NSI) }\end{array}$ & $\begin{array}{l}\text { UN Economic Commission for Africa, African Statistical } \\
\text { Yearbook UNECA (ASYB) } \\
\text { UN Yearbook of National Accounts Statistics (UN YB) } \\
\begin{array}{l}\text { Online database of UN Estimates of National Accounts } \\
\text { (UN E) }\end{array} \\
\begin{array}{l}\text { Online database of UN Official Country Data UN OCD } \\
\end{array}\end{array}$ \\
\hline
\end{tabular}

These sources are reported with different historical base years, methods, and different versions of the System of National Accounts. Also, some countries over the years changed or redenominated their currencies. For example, Lesotho changed its national accounts currency from the Rand to the Maloti, while Uganda also changed its national accounts currency from Pounds sterling to Ugandan Shillings and redenominated its old shillings to new shillings in 1989. As a result, we observed significant breaks in the levels of the series over time. The ASD back-casting technique is used to remove these breaks in series to ensure consistency over time.

For the new countries added to the database, the National Statistical Institutes of Burkina Faso, Lesotho, and Namibia extrapolated value-added series backward in time to the 1980s. The other four countries have the latest revision of National Accounts starting in the 1990s. For the 1960s and 1970s we have value added series produced with different methods, standards, and SNA, resulting in breaks and inconsistent series.

We remove major breaks in series by using the first year of the most recent revisions of national accounts (value added) as our benchmark level data. We link the benchmark level series to historical series using growth rates. This repairs the breaks by adjusting the level of historical series to reflect current information and methodologies while maintaining historical growth rates. Table 6 indicates years for which recently revised national accounts are available for benchmark levels and years for which growth trends have been used.

For some years, Education; Health and Social Work; and Other Community, Social and Personal Services $(\mathrm{M}+\mathrm{N}+\mathrm{O})$ are lumped together as a single sector in the UN database (UN OCD). We added Public Administration and Defence, and Compulsory Social Security (L) and Activities of Private Households with employed persons $(\mathrm{P})$ to get an aggregate sector $(\mathrm{L}+\mathrm{M}+\mathrm{N}+\mathrm{O}+\mathrm{P}) .{ }^{11} \mathrm{We}$ then applied the growth rate of this aggregate sector $(\mathrm{L}+\mathrm{M}+\mathrm{N}+\mathrm{O}+\mathrm{P})$ to those years for which data were available for both Government Services $(\mathrm{L}+\mathrm{M}+\mathrm{N})$ and Personal Services $(\mathrm{O}+\mathrm{P})$ as defined in the ASD. Whenever detailed sector information is missing in the NSI sources and the Africa Statistical Yearbooks, we followed a similar procedure.

\footnotetext{
${ }^{11}$ Often sector $\mathrm{P}$ is not distinguished separately in the UN data. It is included in sector O.
} 
Table 2.6: Availability of data sources for new countries

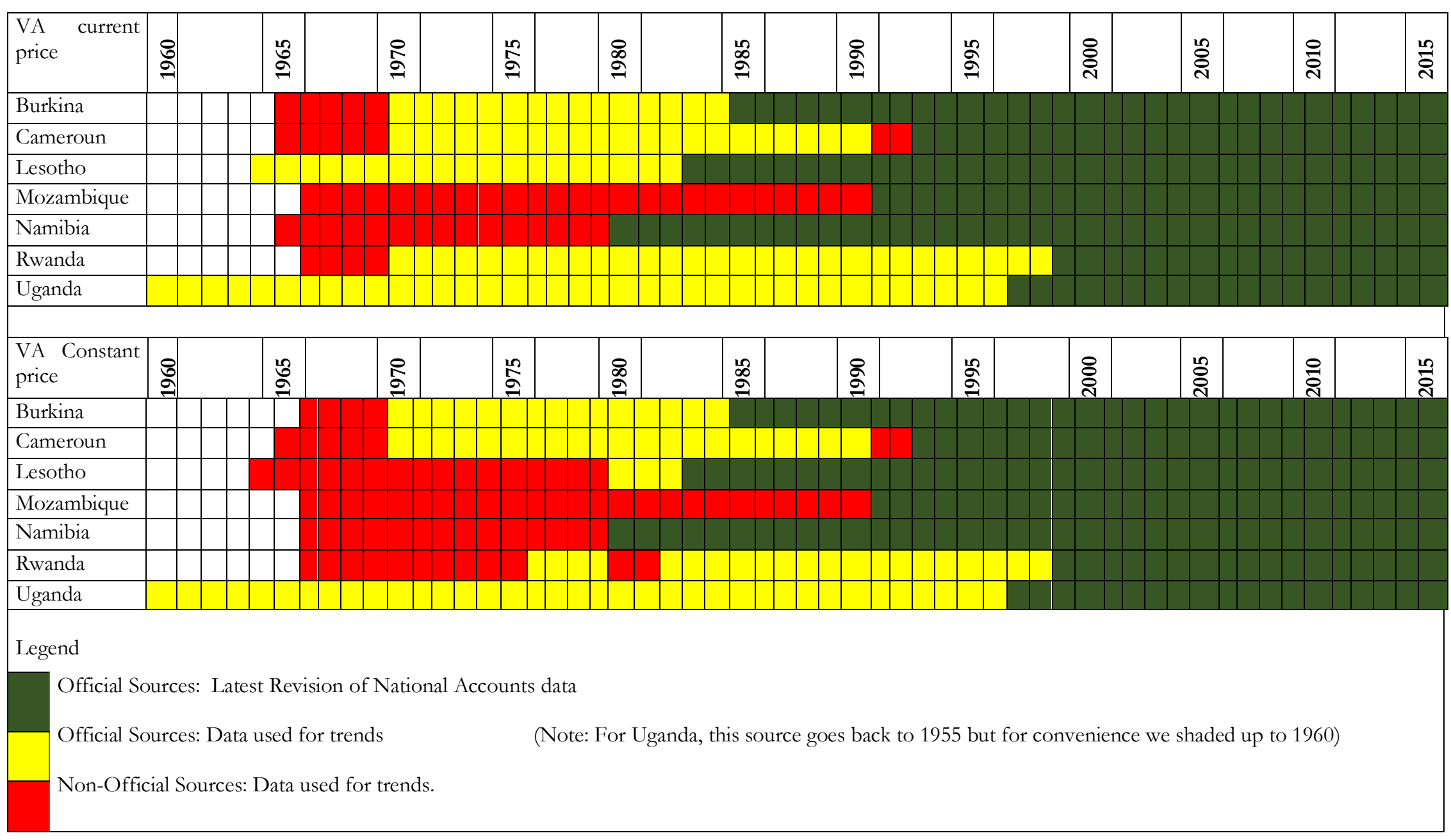




\subsubsection{Value Added Methodology}

Value added series in current and constant prices for each of the ten sectors are constructed by linking historical data to the value-added data from the latest revision of the national accounts. Using the same sources, we compute price deflator growth rates for each of the ten sectors. Using these price deflators, we deflate the value-added data in current prices to obtain value added in constant prices using 2005 as the reference year. Total economy figures are obtained by the summation of the values of the ten sectors for each year (see de Vries et al, 2013).

The current value-added series is computed by linking historical data to benchmark level estimates as:

$$
V A_{t+1}=V A_{t} \times\left[\frac{V A_{t+1}^{e}}{V A_{t}^{e}}\right]
$$

Where $V A_{t}$ represents the current value added in the benchmark year $t$ and $V A_{t}^{e}$ is the value added from the external non-official source. This preserves the historical growth rates by adjusting the levels in the maintained period to reflect the latest revision in the national accounts.

To obtain continuous data on current value added and price deflators, we calculate deflator growth rates using the current and constant valued added from the same source as:

$$
\Delta V A_{-} P_{t+1}=\ln \left\{\left[\frac{V A_{t+1}^{e}}{V A_{-} Q_{t+1}^{e}}\right] /\left[\frac{V A_{t}^{e}}{V A_{-} Q_{t}^{e}}\right]\right\}
$$

Where $\Delta V A_{-} P_{t}$ is the logarithmic growth rate of the price deflator in year $t$, and $V A_{t}^{e}$ and $V A_{-} Q_{t}^{e}$ are the nominal and volume valued added data respectively for year $t$. Based on (2.1) and (2.2), we compute the sectoral volume data as:

$$
V A_{-} Q_{t}=V A_{-} Q_{t+1} / E X P\left[\ln \left(\frac{V A_{t+1}}{V A_{t}}\right)-\Delta V A_{-} P_{t+1}\right]
$$

Where $V A_{-} Q_{t}$ is the sectoral volume index for the year $t$. The advantage of this approach is that when detailed sector data is missing, we can use aggregate growth trends to represent the detailed underlying sectors. "It is more reasonable to make this assumption for price developments than for volume growth rates" (de Vries et al, 2013:15). When primary sources are not available, this method allows us to use price developments from external sources (de Vries et al., 2013).

\subsubsection{Update of Value Added for existing ASD countries}

The ASD has been used widely to analyze the long-run structural transformation of Africa. It contains data on six variables across ten sectors for 11 African countries. Since the construction of the ASD, many African countries in the database have undergone statistical reforms or macroeconomic reforms. "For instance, in 2014 alone, Kenya, Nigeria, Tanzania, and Zambia all completed rebasing exercises, which led to significant revaluations of their GDPs: Nigeria's latest (2013) GDP nearly doubled, Tanzania's grew by a third, and Kenya's and Zambia's increased by a quarter" (Sy, 2015). Nigeria revised its GDP estimates and recalculated historical data back to 1981 while Zambia also redenominated its currency.

GDDC acknowledged the significant break in the sectoral series of Nigeria following the rebasing but they did not update the original data in the ASD because the Nigeria Bureau of Statistics (NBS) 
had not re-estimated the historical GDP. ${ }^{12}$ NBS has now re-estimated old series backward to 1981, taking into account new sources and methods. The figure below compares the structure of production under the old national accounts and the new national accounts. The old estimates portray the Nigerian economy as industry-driven, but the latest estimates show that the Nigerian economy is service-driven. Therefore, we updated the original ASD to reflect these recent reforms and statistical revisions in Nigeria as well as other African countries. For each country, we take the first year of the revised estimates as a benchmark. We then change the reference year to 2005. The notes below provide information about the update process that was adopted for each country in the ASD.

Figure 2.1: The structure of Nigerian economy before and after rebasing.

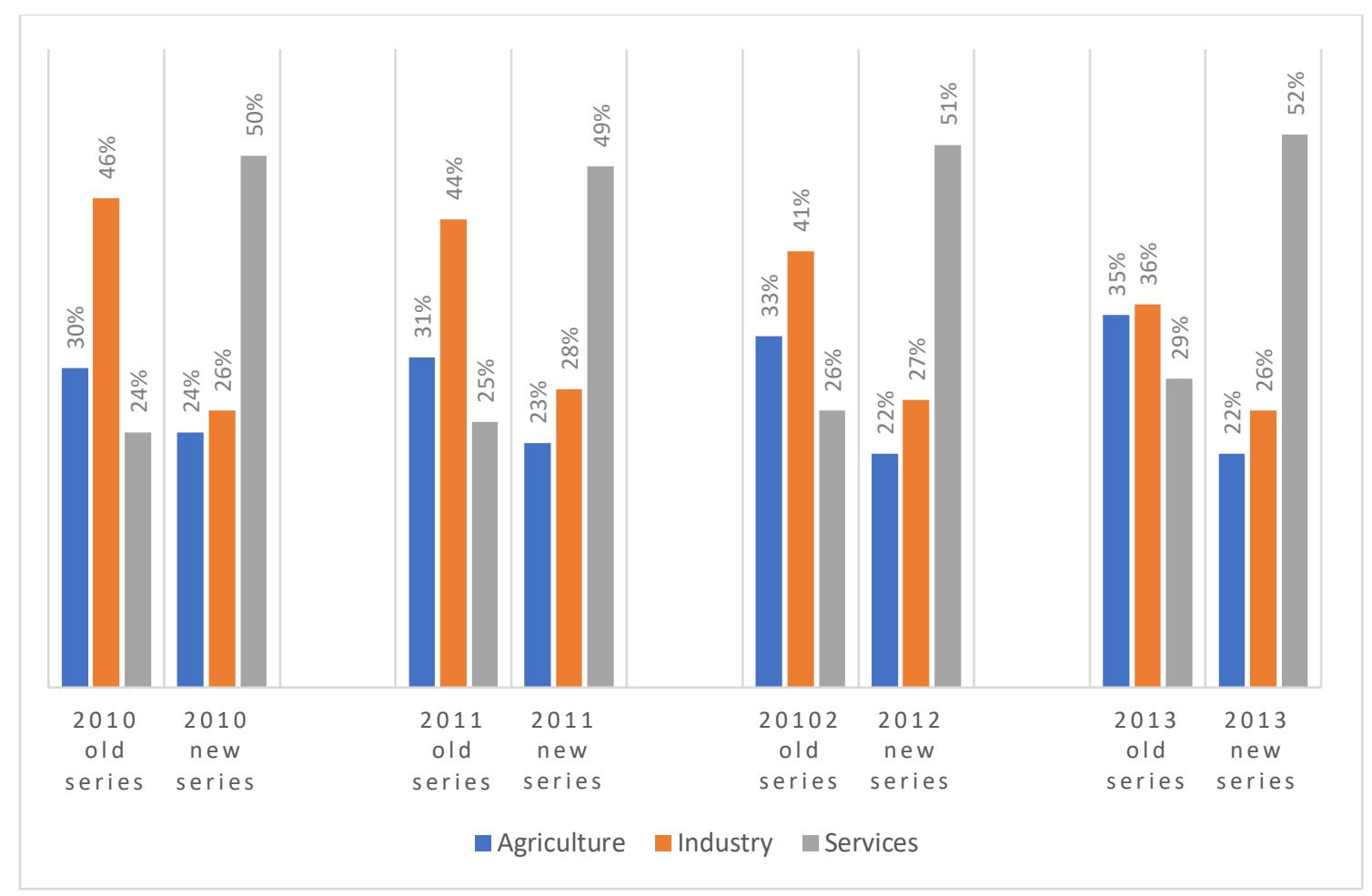

Source: NBS (2016). The figure shows the percentage share of Agriculture, Industry and Services in GDP. It compares each sector before and after rebasing. It shows a significant re-evaluation of the structure of production after rebasing.

\subsubsection{Botswana}

Value added by type of economic activity in both current and 2006 constant prices were obtained from Statistics Botswana. ${ }^{13}$ The yearly data covers the period 2004-2015, thus containing seven years of overlapping data with the ASD. We compared the level data of the overlapping years (2004-2010) with the Botswana value added data in the ASD. For 2004-2005 data from both sources were the same since the ASD used the latest revision, at the time of construction, as the benchmark level data. However, from 2006-2010 the data obtained differ from the ASD benchmark level data following revisions undertaken by Statistics Botswana. Statistics Botswana usually revises the first estimate of yearly or quarterly data after receiving updated source data such

\footnotetext{
12 https://set.odi.org/comments-page-3/

13 http://www.statsbots.org.bw/sites/default/files/publications/GDP\%20Q3\%20December\%202016.pdf. The website leads you to a PDF published by Statistics Botswana. On Page 13, you will find the yearly and quarterly data
} 
as "finalized or audited data from companies in which differences and inconsistencies in the previously published data may be observed" (Statistics Botswana, 2016). As a result, we update ASD starting from 2006 to 2015 and joined it with the ASD data from 1960-2005. We chose 2005 as our reference year to recalculate the value-added series in constant prices to obtain a volume series from 2006 to 2015 that is consistent with the ASD volume series from 1960 to 2005.

\subsubsection{Ethiopia}

For Ethiopia, current information on value added is not available on the website of the National Statistical Institute. We, therefore, used value added data from the 2016 Africa Statistical Yearbook (ASY).${ }^{14}$ We used the growth trend from the value added in current prices to update the Ethiopian value added data in the original ASD from 2010 to 2015. In the ASY, value added in constant prices is not reported, but the annual growth rate of GDP by kind of economic activity in constant prices is reported. We used the annual growth rate to update the value added series from 2010 to $2015 .{ }^{15}$ For Dwellings in current prices, we assume that the share of Dwellings (70) in Business Services $(J+K)$ has been constant since 2010. Using this constant ratio, we derive the Dwellings series in current prices from 2011 to 2015. For Dwellings in constant prices, we used the growth rate of Business Services from 2010 to 2015 to update. This smoothly updates the original ASD without any inconsistency or significant breaks.

\subsubsection{Ghana}

The update period for Ghana is 2011-2015. GDP by type of economic activity in both current and 2006 constant prices were obtained from the Ghana Statistical Service (Revised Annual GDP 2015, Ghana Statistical Service(GSS)). ${ }^{16}$ GSS reports the value added data in current and 2006 constant prices from 2006 to 2015. This overlaps with the Ghana data in the ASD. The data for overlapping years are the same as the data in the ASD since the recent revision was used as the benchmark level data in the ASD. As a result, we used the level data for the period 2011-2015 to update the ASD from 2010 to 2015. We then changed the reference year from 2006 to 2005 to obtain volume data consistent with the ASD.

\subsubsection{Kenya}

Kenya finished a rebasing exercise in September 2014 using some of the recommendations of the 2008 System of National Accounts. This increased GDP by about $15 \%$, with minor changes in the structure of production. The Kenya National Bureau of Statistics provides an estimate of Gross Domestic Product by kind of economic activity from 2006 to $2015 .{ }^{17}$ The last year of the rebased series was used as the benchmark year with the data then retropolated back to 1960 using the growth trend from the original ASD. We deflated the nominal series using the price index

\footnotetext{
${ }^{14}$ https://www.afdb.org/fileadmin/uploads/afdb/Documents/Publications/African Statistical Yearbook 2016.pd $\underline{\mathrm{f}}$

${ }^{15}$ The update is done using the simple growth formula: $V A_{t+1}=V A_{t}(1+g)$; where $g$ is the annual growth rate reported in the ASY. VA is sectoral value added in constant prices.

${ }^{16}$ http://www.statsghana.gov.gh/gdp_revised.html. The website leads you to the Revised Annual 2015 GDP, September 2016 Edition in Excel format, which covers the period 2006-2015.

${ }^{17}$ www.knbs.or.ke/gross-domestic-product-gdp/ https://www.knbs.or.ke/download/rebased-gdp-facts/
} 
constructed from the rebased national accounts and the ASD. This updates the Kenya data to reflect the rebasing, the 2008 SNA, and minor changes in the structure of production.

\subsubsection{Malawi}

The update period for Malawi is 2009-2015, and thus includes two overlapping years with the ASD. Gross Domestic Product by economic activity in both current and constant prices was obtained from the National Statistical Institute of Malawi. ${ }^{18}$ The data for the overlapping years (2009-2010) differ from the data in the original ASD since the national accounts have been updated with recent information. As a result, we used the level data for the period 2009-2015 to update the ASD. We then changed the reference year from 2010 to 2005 to obtain volume data consistent with the ASD.

\subsubsection{Mauritius}

Gross Domestic Product by kind of economic activity in both current and constant prices from 2006-2015 was obtained from Statistics Mauritius. ${ }^{19}$ The Mauritius data is based on the 2013 CEA, the 2008 SNA and the National Standard Industrial Classification (NSIC) Rev. 2. The update period for Mauritius is 2006-2015. We compare value added data for the overlapping years (20062010) with value added data from the original ASD. We found a slight difference for the overlapping years. Since the new official source embodies recent updates and revisions, we used it in place of the ASD data.

\subsubsection{Nigeria}

The GGDC constructed value added series for Nigeria in the ASD utilizing information based on a severely outdated system of national accounts and base year. The entire data, including recent years, was based on the 1968 UN System of National Accounts and 1990 as a base year. In 2014, Nigeria rebased this old base year to 2010 following international standards and guidelines. The National Bureau of Statistics updated its survey frame, and "as a result, the size of the sample frame expanded from 83,733 to 851,628 establishments. In addition, the number of economic activities reported in the GDP computation framework increased to 46 compared to 33 in the previous series" (NBS, 2014). The new GDP data was compiled following the 2008 UN System of National Accounts (SNA 2008 version), the International Standard Industrial Classification (ISIC Revision 4), the Central Product Classification (CPC version 2), and the ongoing development of a SUT for Nigeria (NBS, 2014). The rebasing also covered more economic activities including new sectors such as entertainment, research, and patents and copyrights, in addition to broader coverage of the services sector, particularly the informal sector. Following the update, nominal GDP in 2010 increased by 59.5 percent, and the structure of the Nigerian economy changed significantly, with the service sector being the fastest growing sector and contributing more to GDP than previously estimated under the old base year. Historical data were recalculated backward to 1981 using the new base year. This presents output information that is

\footnotetext{
${ }^{18} \mathrm{http}: / /$ www.nsomalawi.mw/images/stories/data on line/general/Quarterly $\% 20$ Bulletins/Quarterly $\% 20$ Statistica 1\%20Bulletin, \%20December\%202016.pdf

${ }^{19} \mathrm{http}: / /$ statsmauritius.govmu.org/English/StatsbySubj/Pages/National-Accounts.aspx
} 
significantly different from the output used to construct the original ASD. As a result, we reconstruct the entire value-added data for Nigeria in ASD by:

- Using the newly revised estimate for the period 1981-2015 as level data.

- Using 1981 as a splicing point to backcast to 1960 using the growth trend from the ASD data.

- Recalculating the volume data using 2005 as a reference year, and then deriving the price index.

Value added series in current and constant prices (1981-2015) used as the level data was obtained from the Nigeria Bureau of Statistics. ${ }^{20}$ For the period 1960-1981, we used the growth trend from the original ASD.

While the update has provided key updates of sectoral data, the reliability of some of the sectoral estimates deserve further scrutiny. For example, the nominal value added share of information and communication services in GDP is $11.45 \%$ in 2015 in Nigeria. This seems to be overstated when compared to highly digital African economies like Kenya and advanced countries like UK, which estimate the share information and communication services at $1.60 \%$ and $6.3 \%$, respectively.

\subsubsection{Senegal}

GDP by kind of economic activity in both current and constant prices was obtained from UN Official Country Data. It covers the period 2009-2014, with two overlapping years. The data for the overlapping years are the same as the data in the original ASD since the original ASD was constructed using the same source. As a result, we used the level data for the period 2011-2014 to update the ASD from 2010 to 2014. We then changed the reference year to 2005 to obtain volume data consistent with the ASD. Since Government and Personal Services are put together in the UN OCD, we applied the growth trend of this aggregate sector to obtain separate series for both Government Services and Personal Services.

\subsubsection{South Africa}

Value added by kind of economic activity in both current and constant prices were obtained from Statistics South Africa. ${ }^{21}$ We used yearly data from 2005 to 2015, thus giving six years of overlapping data with the ASD. We compared the level data of the overlapping years (2004-2010) with value added data in the ASD, and observe slight differences following revisions undertaken by Statistics South Africa. Statistics South Africa continuously updates and revises the first estimates of yearly or quarterly data after receiving finalized primary source data. Hence, we used level data from 2005 to 2015 in this revision and joined it with the ASD data from 1960-2004. We chose 2005 as our reference year to recalculate the value-added series to obtain a volume series from 1960-2004 that is consistent with the new volume series from 2005 to 2015.

\subsubsection{Tanzania}

In 2014, Tanzania completed a rebasing exercise that changed its base year from 2001 to 2007. This rebasing takes into account the natural gas discovery and the mobile money revolution in

${ }^{20} \mathrm{http}: / /$ nigerianstat.gov.ng/elibrary?queries[search]=GDP

${ }^{21} \mathrm{http}: / /$ www.statssa.gov.za/?page_id=1854\&PPN=P0441\&SCH=6675 
Tanzania. This increased Tanzanian GDP by about 33\%. As a result of this rebasing exercise, we update the Tanzanian value-added series in the ASD using this revised data. Data on value added by kind of economic activity in both current and constant prices were obtained from the National Bureau of Statistics of Tanzania. ${ }^{22}$ Thus giving six years of overlapping data. For the overlapping years, we used this revised source in place of the ASD.

\subsubsection{Zambia}

Another important update in this database is the value-added series of Zambia. The primary source used to construct value added series for Zambia in the original ASD is based on the $1968 \mathrm{UN}$ System of National Accounts. This version of the system of national accounts is quite outdated and hence a re-benchmarking of the national accounts of Zambia was long overdue. In 2014, Zambia completed a rebasing exercise that benchmarked the base year in 2010 using the 2008 UN System of National Accounts as a guideline. The input data used in the benchmarking exercise is based on the 2011/2012 Economic Census, the 2013 Non-agriculture Informal Sector Survey, the 2009/2010 Post Harvest Survey, and the 2010 Living Conditions Monitoring Survey. "The main source of data for this benchmarking exercise was the Economic Census, which was specifically undertaken to address the challenges of compiling economic statistics, such as the old benchmark year (1994), the limited scope of coverage, and use of inappropriate price and volume indices. Overtime, the structure of the Zambian economy had significantly changed since 1994 largely on account of the development of new industries and technological innovation" (CSO, 2014:1). In addition to this statistical revision, Zambia redenominated the Kwacha in January $2013 .{ }^{23}$ The revised national accounts are reported in the new currency, but value-added data in the original ASD was published in the old currency.

To account for these revisions, we update the original ASD by first converting the ASD data to the new Zambian Kwacha. We used value added series from the revised national accounts (20102015) as our benchmark level data and then backcast to 1960 using the growth trend from the original ASD converted to the new currency. We used 2005 as our reference year, resulting in a consistent value-added series in both current and constant prices from 1960 to 2015. The benchmark level data was obtained from the Central Statistical Office (CSO), Zambia. ${ }^{24}$

\subsection{Employment}

\subsubsection{Sources of employment data for new countries}

The primary sources for employment data are: Population and Housing Censuses, Labor Force Surveys, (Other) Household Surveys, Establishment Surveys, and Economically Active Population in Agriculture. The UN system of national accounts and the Africa Charter on Statistics govern the production of national accounts statistics in Africa, meaning that value added data are consistent over time and space. The national accounts do not cover employment, however. Historically, household surveys with a different focus, scope, and definitions have been used to measure sectoral employment, meaning that country-by-country comparisons of sectoral

\footnotetext{
${ }^{22}$ http://www.nbs.go.tz/nbs/takwimu/na/HIGHLIGHTS FOR THE THIRD QUARTER GDP 2016.pdf

231000 old Kwacha=1 new Kwacha.

${ }^{24}$ http://zambia.opendataforafrica.org/dwieeid/national-accounts-of-zambia?indicator $=1004870$
} 
employment estimates based solely on household surveys are, in principle, difficult. More recently, African countries have used labor force surveys based on international harmonization of concepts and definitions to measure sectoral employment, but sampling size and methods still vary across countries (McMillan et al., 2014; de Vries et al., 2013). For example, whereas Rwanda, which has an estimated population of about 12 million, uses "a rotation sample scheme with a sample size of 9,344 households per round, selected by means of a stratified two-stage probability design..." (Rwanda Labor Force Survey Report, 2016), Ghana, with an estimated population of 29 million, uses a sample size of 6,030 households constructed using two-stage random sampling (Ghana Labor Force Report, 2015). Though the methods, in this case, are similar, the sample size to population ratio varies significantly.

Establishment surveys are another source of sectoral employment. These surveys tend to focus on formal establishments above a specific size. As a result, sectoral employment is underestimated in agriculture and retail trade, where self-employed, family workers, and informal workers are more widespread. Moreover, this source does not cover establishments that employ workers below the threshold number of employees considered in the survey.

To overcome these shortcomings, de Vries et al. (2013) and Timmer \& de Vries(2009) defined employment as all persons employed (15 years and above). This definition allows them to use population and housing census (PHC) data as the main source of employment because PHC covers not only employees but also self-employed, family workers, and all informal sector workers. To derive employment figures consistent with the coverage of the value-added series in the seven countries, we followed the ASD approach strictly by using PHC data as benchmarks. When the PHC sectoral employment estimates are not reliable or not available, we adjust it or replace it with data from labor force surveys. The problem with this approach is that population censuses are typically conducted every ten years. We, therefore, interpolate between benchmark years using data from Household Surveys and Establishment Surveys (ES). De Vries et al. (2013) distinguish between two interpolations based on data availability, in particular: "when ES data is available, interpolation is based on annual growth trends. When this data is unavailable, interpolation is based on average trends in labor productivity between the benchmark years". We followed the same general approach. In the case of Agriculture, growth trends from the ILO economically active population in Agriculture are used to interpolate between benchmark years. The table below shows the primary sources of employment data. 
Table 2.7: Sources of Employment

\begin{tabular}{|l|}
\hline Population and Housing Census \\
\hline Labor Force Surveys \\
\hline Household Surveys \\
- \\
- Houving Standard Measurement Surveys \\
- Pomographic Health Surveys \\
- Priority Surveys \\
\\
\\
\hline Informal Sector Surveys \\
\hline Establishment Surveys \\
\hline FAO data on the economically active in agriculture \\
\hline ILO Estimates of employment-to-population ratios \\
\hline
\end{tabular}

\subsubsection{Using Population and Housing Censuses as Benchmarks}

The aim of a census is the complete counting of the population in a given country. This involves collating demographic and socioeconomic information on the population. For many African countries, the PHC is the main source of representative employment data. Although questions about employment in the PHC are not as detailed as the Labor Force Survey (LFS), the PHC covers the entire working population, including the self-employed, family workers, and informal sector workers. Also, PHC results are typically used to create the sampling frames for labor force surveys during the intercensal period. This enables cross-referencing and adjustment of sectoral employment figures from both sources within a defined period. We used the PHC as benchmarks for the construction of the employment data. The table below shows the years for which data are used as benchmarks. If PHC data are not reliable, we adjust or replace using data from labor force surveys. 
Table 2.8: Employment Benchmark Years

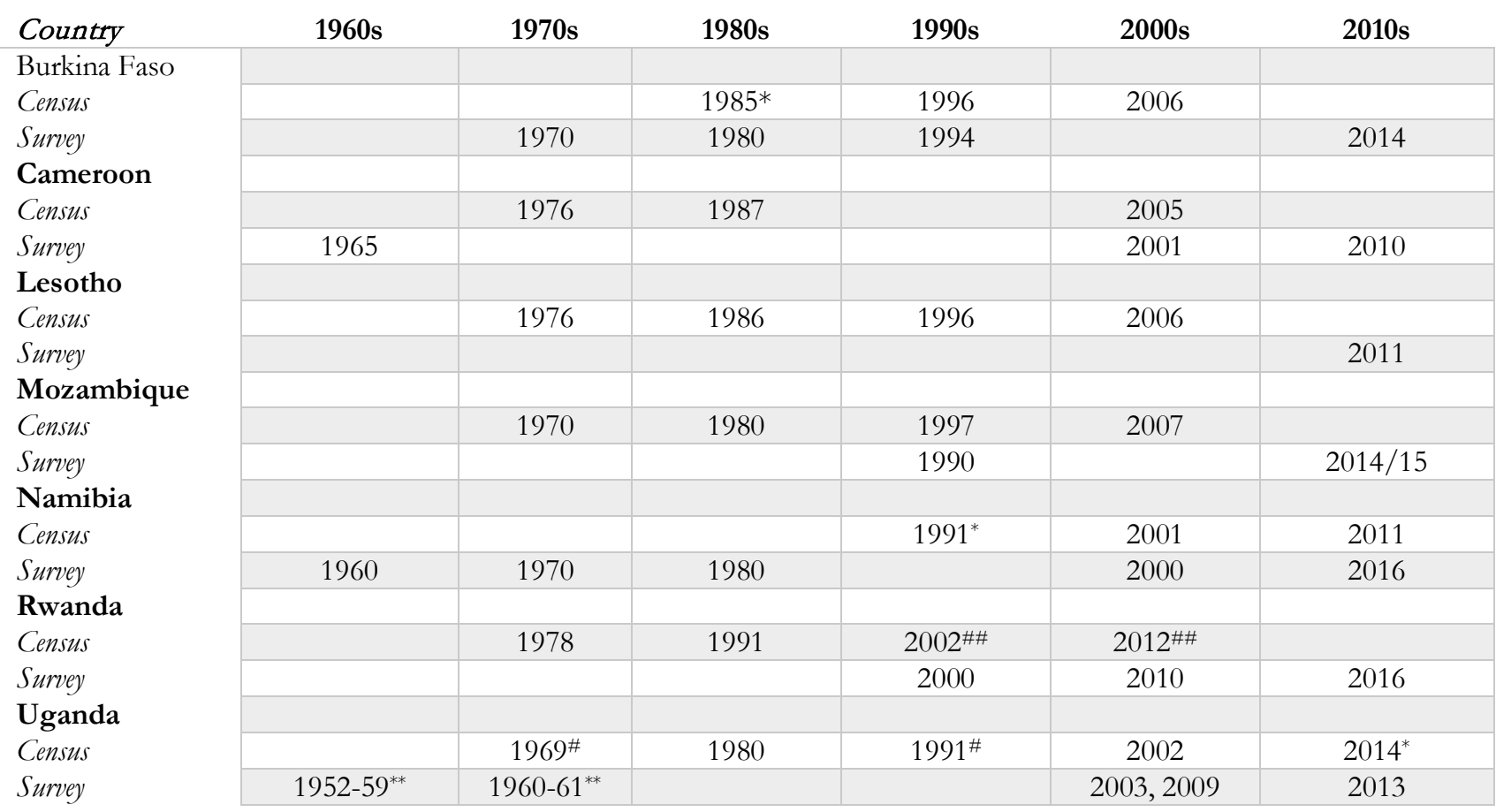

*For these censuses, the sectoral distribution is taken from the surveys of the nearest year. \# For these censuses, employment by occupation is available, the surveys in the nearest year are used to map occupations to sectors. **Agriculture and Trade Services is adjusted using information from the 1969 population census. \#\# Figures are adjusted using surveys in the years below.

\subsubsection{Publication Sources}

The main publication sources of employment statistics are recent and historical publications from National Statistical Institutes. We obtained recent publications online and obtained historical publications from the reference sections of the SOAS University of London Library and the British Library. We also obtained data from international sources such as the ILO's Key Indicators of Labor Markets, Africa Integrated Census Micro Data, and IPUMS International.

Table 2.9: Main sources of employment information

\begin{tabular}{|cl|}
\hline Sources & Acronym \\
\hline National Statistical Institutes Publications & NSI \\
\hline $1 . \quad$ Census and Survey Reports & \\
\hline $2 . \quad$ Statistical Bulletins and Yearbooks & \\
\hline $3 . \quad$ Research Publications & AICM \\
\hline Online database: Africa Integrated Census Microdata & KILM \\
\hline Online database: ILO Key Indicators of Labor Markets & IPUMS \\
\hline Online database: IPUMS International, Minnesota Population Center & ILO YB \\
\hline ILO Yearbooks of Labor Statistics & FAO \\
\hline Online FAO Database on Economically Active population & \\
\hline
\end{tabular}

\subsubsection{Employment: Methodology ${ }^{25}$}

\footnotetext{
25 This paragraph closely follows the methodology outlined in De Vries et al. (2013), pp. 20-23.
} 
Employment figures from population censuses are used as benchmarks. For the intervening years we interpolate using employment figures from establishment surveys or external sources (e.g. FAO data). Where establishment surveys are not available, we interpolate between years using average productivity growth rates. Interpolation based on survey or FAO data is given as:

$$
E_{t}=E_{t-1} \times E X P\left[\ln \left(\frac{E_{t}^{e}}{E_{t-1}^{e}}\right)-\frac{\ln \left(\frac{E_{b 2}^{e}}{E_{b 1}^{e}}\right)}{(b 2-b 1)}+\frac{\ln \left(\frac{E_{b 2}}{E_{b 1}}\right)}{(b 2-b 1)}\right]
$$

Where $b 2>t>b 1, b 1$ and $b 2$ are the first and second benchmarks. The $e$ superscript represents data from external sources. Employment in each sector in year $t$ is denoted by $E_{t}$. The interpolation based on average trends in labor productivity is computed as:

$$
E_{t}=\frac{V A_{-} Q_{t}}{L P_{t-1}} / E X P\left[\frac{\ln \left(\frac{L P_{b 2}}{L P_{b 1}}\right)}{b 2-b 1}\right]
$$

Where $b 2>t>b 1$ and $L P_{t}=V A_{-} Q_{t} / E_{t}$ is labor productivity. The advantage of this method is that it harmonizes movements in employment and value added since "linearly interpolated employment figure may be inconsistent with the growth trends of VA, resulting in irregular productivity patterns.” (de Vries et al., 2013).

\subsubsection{Extrapolation and Backcasting}

Depending on data availability, extrapolation and backcasting are necessary to complete the dataset. If data are available from external sources, we use sectoral trends to extrapolate and backcast from the nearest benchmark using (2.6) and (2.7):

2.6 Extrapolation: $E_{t}=E_{t-1} *\left(\frac{E_{t}^{e}}{E_{t-1}^{e}}\right)$

2.7 Backcasting: $E_{t}=E_{t+1} *\left(\frac{E_{t+1}^{e}}{E_{t}^{e}}\right)$

Where $E_{t}$ is sectoral employment in year $\mathrm{t}$, and superscript $e$ indicates that data are from external sources. When establishment and external data are limited, we use average labor productivity to backcast and extrapolate between benchmark years using (2.8) and (2.9):

$$
E_{t}^{*}=\frac{V A_{Q_{t}}}{L P_{t-1}} / E X P\left[\frac{\ln \left(\frac{L P_{b 2}}{L P_{b 1}}\right)}{b 2-b 1}\right] \quad \text { Where } t>b 2 ; L P_{t}=V A_{-} Q_{t} / E_{t}
$$

$$
E_{t}^{*}=\frac{V A_{Q_{t}}}{L P_{t+1}} / E X P\left[\frac{\ln \left(\frac{L P_{b 2}}{L P_{b 1}}\right)}{b 2-b 1}\right] \quad \text { Where } t<b 1 \text { and } b 1 \text { and } b 2 \text { are benchmark years. }
$$

Using (2.8) and (2.9) it is assumed that the average labor productivity between $b 1$ and $b 2$ can sufficiently represent the productivity of the extrapolated or backcasted years due to sectoral employment statistics not being available. To overcome this constraint, de Vries et al. (2013) use total economy employment estimates from the ILO-E database and normalize sectoral results from equation (2.8) using: 


$$
2.11 \quad \text { Normalization: } \quad E_{i, t}=E_{i, t}^{*}\left[\frac{E_{t}^{T O T}}{\sum_{j=1}^{s} E_{j, t}^{*}}\right]
$$

Where $E_{t}^{T O T}$ is total employment in year $\mathrm{t}, E_{t}^{I L O}$ is the total employment level from the ILO-E database in year t, $E_{i, t}^{*}$ is estimated employment based on labor productivity levels between the closest benchmark years for sector $i$, and $E_{i, t}$ is the sectoral employment level normalized to the total employment level. This method aligns sectoral productivity with total economy productivity growth trends.

\subsubsection{Sources for employment updates}

ASD is arguably the only database that provides reliable long-run sectoral employment data for Africa. It has been used to analyze long-run productivity trends. However, since the construction of the ASD, most countries in the database have conducted comprehensive new labor force surveys and PHC. Therefore, the ASD is updated from 2010 to 2015 using these recent surveys and censuses.

\subsubsection{Botswana}

We used employment information for the year 2011 from the 2011 Population and Housing Census published in the 2011 Labor Statistics Report and employment information for 2013 from the 2013 HIV/AIDS Impact Survey published in the 2013 Labor Statistics Report. The total employment figure for Agriculture in the original ASD estimate is 251,000, but the 2011 Population Census report Agricultural employment as 98,000, a difference of 153,000. To ensure continuity and avoid an irregular productivity pattern, we used the ASD estimate as a benchmark in 2011. We then extrapolated using the growth trend estimated from 2011 to 2015, using the trends from data obtained from the 2011 Population and Housing Census and the HIV/AIDS Impact Survey. The same procedure was followed to estimate employment values for Transportation Services, Government Services, and Personal Services. For the other sectors, we use the 2011 employment figure from the 2011 Population and Housing Census and 2013 data from the HIV/AIDS Impact Survey as benchmarks, and then interpolate for 2012 and extrapolate for 2014 and 2015.

\subsubsection{Ethiopia}

We used 2013 employment information from the 2013 National Labor Force Survey and the 2010 ASD figure as benchmarks and then used labor productivity trends to interpolate for 2011-2012 and extrapolate for 2014-2015. We observed a sharp increase in Personal Services, Trade, and Utilities. We adjusted the figures for these sectors to ensure smooth growth by using the 2010 ASD estimate as a benchmark and then extrapolating using labor productivity trends. 


\subsubsection{Ghana}

We used the employment component of the Ghana Living Standard Survey Round 6 (2013) and the Ghana Labor Force Survey 2015 as the benchmark data. We then interpolate for 2011, 2012, and 2014 using information from the Economically Active Population in Agriculture from FAO, the 2014 Integrated Business Establishment Survey, and Labor productivity trends.

\subsubsection{Kenya}

We used employment data from the Kenya Economic Survey from 2010-2015. We used the 2010 value from ASD data as a benchmark and then extrapolated all sectors, except Trade Services. Comparing the values in the Kenya Economic Survey and the ASD estimates, we concluded that the ASD underestimates employment for Trade Services. We, therefore, used the 2010 figure from the Kenya Economic Survey as a benchmark and used the trends from ASD to backcast to 1969.

\subsubsection{Malawi}

We used the 2013 Labor Force Survey and the ASD estimate for 2010 as benchmarks, and then linearly interpolated between these years and linearly extrapolated for 2014 and 2015 using labor productivity.

\subsubsection{Mauritius}

We used the employment data from the 2011 population census as a benchmark and then extrapolated to 2015 using total employment information by industry from the Mauritius Labor Series.

\subsubsection{Nigeria}

Detailed sectoral employment data is not reported in the Nigeria Quarterly Labor Force Statistics report. However, the total number of people employed is reported. We used trends in total employment and ASD estimates for 2010 as benchmarks to extrapolate total economy employment figures, and then used sectoral ratios based on labor productivity extrapolation to disaggregate the total economy figures.

\subsubsection{Senegal}

We used the 2010 ASD estimate as a benchmark and then used the 2013 PHC and 2015 National Labor Force Survey to extrapolate for 2011-2015. Note that the detailed sectoral level data are not reported in the 2013 PHC, but the total employment level is reported. We used the sectoral shares stated in the 2015 Labor Force Survey to disaggregate the 2015 data. We then interpolate between these years using trends from 2011-2015. We used the trends in sectoral employment and 2010 ASD level data as a benchmark to extrapolate.

\subsubsection{South Africa}

We used data from the Quarterly Labor Force Survey (QLFS) for the years 2011-2016, except in the case of Agriculture, Government Services, and Personal Services, for which we used trends to 
extrapolate the 2010 ASD employment figures for 2011-2016. The agriculture figures reported in the QLFS are three times lower than the ASD estimate for 2010. Community and Other Social Services are lumped together in the QLFS. To get consistent figures for Agriculture, Government Services, and Personal Services, we used growth trends from the QLFS to extrapolate the 2010 data to 2015.

\subsubsection{Tanzania}

We used employment information for the year 2012 from the Population and Housing Census and the 2014 Labor Force Survey as benchmarks. For some sectors, the data were checked for reliability and if necessary, were replaced by using ASD 2010 data as a benchmark instead. We then interpolate for 2011 and extrapolate data for 2013-2015 using the employment series from the Employment and Earnings Survey, 2010-2015.

\subsubsection{Zambia}

We used employment data from the 2012 and 2014 Labor Force Survey as benchmarks, then interpolated for 2011 and 2013 and extrapolated for 2015. Note that the labor force figures are twice as high as those in the 2010 benchmark used in the ASD, except in the case of Agriculture and the Mining, Manufacturing and Trade Sectors. To ensure continuity and to avoid sudden jumps in productivity we used the 2010 ASD estimate as a benchmark and then extrapolated for the other sectors using trends from the Labor Force Surveys.

\subsection{Treatment of the Informal Sector}

The AfDB (2013) estimates that the informal sector accounts for about $80 \%$ of total employment and about 50\% of GDP in Africa. The importance of the informal sector in Africa implies that the reliability of the sectoral value-added and employment data depends on the reliability of the informal employment and GDP estimates, which in turn depends on three things. First, the sampling frame for the measurement of economic activities must include broader coverage of informal activities. Second, it requires that all countries in the sample similarly measure informal economic activities. Finally, the reliability of the data requires that informal sector employment and GDP be treated in similar ways to ensure reliable productivity estimates.

In the 1980s and 1990s, when statistical capacity declined in Africa, estimates of GDP relied mostly on economic censuses, which did not cover many activities in the informal sector, resulting in structural undercounting of informal activities. However, in the recent wave of statistical reforms across Africa, many African countries have updated their sampling frame to cover more economic activities, which were previously not covered, including broader coverage of informal activities. To arrive implicitly at a reliable coverage of informal activities, we use recent estimates of GDP by sector as benchmarks and extrapolate backward. This adjusts the levels in years (the 1980s and 1990s) that informal activities are undercounted to reflect current trends while maintaining historical growth rates. This ensures that the data is consistent over time. However, the reliability of this adjustment decreases as we go back in time.

All countries in the sample use the SNA to compile the value added. The 1993 SNA, which was used by most countries in the sample, treats the informal sector under the household sector and its sub-sectors (S.14). It introduces the concept of the informal sector and refers to the guidelines developed by the International Labor Organization (ILO) on employment in the informal sector. 
For employment, we use population census (PC) complemented with labor force surveys (LFS), which covers both formal and informal sectors, as benchmarks. The key is that most countries in Africa measure employment in the informal sector in the PC and LFS using the ILO guidelines on the measurement of the informal sector. In principle, the use of employment estimates from PCs and SNA ensures that implicit estimates of informal employment and GDP are comparable across countries and variables.

\subsection{Concluding Remarks}

The basis of this chapter is the Africa Sector database. The ASD provides long-run sectoral data for the analysis of the structure of 11 African economies. Since the construction of the ASD, there has been a wave of statistical reforms in some of the countries in the ASD, leading to a significant revaluation of GDP. These reforms have provided a clearer picture of the size and structure of production of the countries involved. We update the ASD to reflect these statistical changes. Most importantly, we expand the ASD by constructing sectoral data for seven new African countries: Burkina Faso, Cameroon, Lesotho, Mozambique, Namibia, Rwanda, and Namibia. This has resulted in an expanded database (from the 1960s to 2015) covering about $80 \%$ of GDP in Africa. We strictly follow the ASD methodology to ensure data continuity, consistency, and comparability. The ASD methodology ensures the internal, international, and intertemporal consistency of the data.

African National Statistics are evolving. In recent years, many African countries are revising national accounting frameworks and base years previously used to estimate GDP. This has led to the re-evaluation of GDP estimates, providing timely and more reliable data on production, income, and expenditure with implications for both producers (national statistical authorities, central banks, etc.) and users of African statistics such as researchers, government and investors. For producers of statistics, the production of more reliable and timely data could increase their visibility, international collaboration, and funding. For researchers, timely and reliable data significantly equips researchers to diagnose the problems of African economies better and offer the right policy prescriptions. For governments, it enhances their ability to predict and better manage expenditure and revenues (consolidates fiscal positions), understand the key growth drivers, and take the policy initiatives necessary to spur growth. For investors, more accurate information enhances their investment decisions and returns. Therefore, the relevance of the recent statistical reforms across Africa cannot be overemphasized. One lesson that is clear from the construction of the EASD is that while African statistical institutes are improving the production of information on output, there is a long way to go on the production of data on inputs such as employment, hours worked and sectoral information on capital and Research and Development (R\&D). The frequency of employment information is often ten years (mostly from PHC and LFS), which impairs government's ability to plan and deliver on creating employment for the 11 million youth entering the labor force in Africa each year, according to ILO(2018). While this is the case for most African countries, there are also good practices on the continent. For example, South Africa conducts quarterly labor force surveys with detailed information on sectoral employment, occupation, and hours worked. In most parts of Africa however, data on hours worked is mostly missing, largely due to the high level of informality on the continent. Although the informal sector is significant in Africa, reliable and consistent time series data on informal sector output and employment is missing from African statistics. 


\subsection{Appendix}

\subsubsection{Statistical Notes on New Countries}

\subsubsection{Burkina Faso}

\subsection{Background of National Accounts Statistics}

In 2001, Burkina Faso adopted the 1993 UN System of National Accounts (SNA 1993) and changed the base year from 1985 to 1999. Prior to the adoption of the 1993 SNA, the Population Census of 1996, the Informal Sector Survey in 1997 and the Commercial and Industrial Census of 1998 revealed that the 1968 SNA underestimated output and productivity. Therefore, the adoption of the 1993 SNA was long overdue. With technical support from the Observatoire economique et statistique d'afrique Subsaharienne (AFRISTAT), the Institut National de la Statistique et de la Demographie (INSD) upgraded to the 1993 SNA using the CRETES module. The CRETES software consolidates the use of SNA93 through the full integration of concepts, definitions, and methods. AFRISTAT member states have common nomenclatures for activities (NAEMA) and for products (NOPEMA). This constitutes an important tool for harmonization available to member states for their statistical work, in particular for the collection of statistical data and the preparation of national accounts. These nomenclatures are based on United Nations International Nomenclatures, including the International Standard Industrial Classification of All Economic Activities (ISC Rev 3) and the Central Product Classification (CPC). This ensures international comparison with non-French speaking African Countries.

The first publication that implemented the SNA93 is the National Economics Account, 2001 (Les comptes économiques de la nation 2001). The three years of accounts (1999, 2000 and 2001) were developed using the new system with 1999 as the base year. The old series of GDP (from 1985 to 1998) was also retroactively extrapolated to match the concepts and definitions of the SNA93 and the new base year. This publication links the old GDP backcast series (1985-1998) and three new accounts (1999-2001). More recent publications such as the National Economic Account 19992012, and the Burkina Faso Statistical Yearbook (Annuaire Statistique 2015) use the SNA93, though data for the period 1965-1984 uses the 1968 UN system of national accounts. To link this historical series with the new series we used data from recent series as the benchmark level data and backcast to 1965 using equation 1 . See notes on data construction.

\begin{tabular}{|l|l|l|}
\hline Period & Source & Notes \\
\hline $\mathbf{2 0 1 3 - 2 0 1 4}$ & $\begin{array}{l}\text { Annuaire Statistique 2015, pg 171- } \\
172, \text { INSD }^{26}\end{array}$ & Level used for nominal value added. SNA1993 \\
\hline $\mathbf{1 9 9 9 - 2 0 1 2}$ & $\begin{array}{l}\text { Les Comptes Economiques de la } \\
\text { Nation 1999 à 2012: Comptes } \\
\text { Définitifs }\end{array}$ & Levels data used for nominal value added SNA1993 \\
\hline $\mathbf{1 9 9 4 - 1 9 9 8}$ & $\begin{array}{l}\text { Les Comptes Economiques de la } \\
\text { Nation 1994-1999, pp. 18-19 and } \\
96-98, \text { INSD }^{28}\end{array}$ & $\begin{array}{l}\text { Level used. Originally published in SNA1968 but } \\
\text { retroactively extrapolated when SNA1993 was adopted by } \\
\text { INSD. }\end{array}$ \\
\hline
\end{tabular}

\footnotetext{
${ }^{26}$ http://www.insd.bf/n/contenu/pub periodiques/annuaires stat/Annuaires stat nationaux BF/Annuaire stat 2015.pdf

${ }^{27} \mathrm{http}: / / \mathrm{www}$. insd.bf/n/contenu/pub periodiques/comptes eco/Comptes eco nat 99-2012.pdf

$28 \mathrm{http://www.insd.bf/n/contenu/pub} \mathrm{periodiques/comptes} \mathrm{eco/Comptes} \mathrm{eco} \mathrm{nat} 94$ 99.pdf
} 


\begin{tabular}{|l|l|l|}
\hline 1985-1993 & $\begin{array}{l}\text { Les Comptes Economiques de la } \\
\text { Nation 2001, pp. 19-24 and 58-63, } \\
\text { INSD }^{29}\end{array}$ & $\begin{array}{l}\text { Level used for sectors A-I. Services (J-P) do not follow ISIC } \\
\text { astinction. Growth rate of the aggregate sector was } \\
\text { applied to each subsector. }\end{array}$ \\
\hline 1970-1984 & $\begin{array}{l}\text { UN National Accounts Official } \\
\text { Country Data }\end{array}$ & $\begin{array}{l}\text { Trend used, difficult to disentangle personal and } \\
\text { government services so aggregate growth rate was applied. } \\
\text { Published in SNA1968 }\end{array}$ \\
\hline 1965-1969 & $\begin{array}{l}\text { Africa Statistical Yearbook } \\
\text { of } 1972 \text { and } 1975\end{array}$ & $\begin{array}{l}\text { Trend used. Data on services (J-P) has not been } \\
\text { defined separately so aggregate growth rate is applied to } \\
\text { each subsector. }\end{array}$ \\
\hline
\end{tabular}

\subsection{Construction Notes on Value Added Series}

- The recent series is published according to the 1993 UN System of National Accounts. We used the first year of the recent series as the benchmark level data and link it to the historical data using equation 1 . This repairs major breaks by adjusting levels of historical series to reflect current information, methodologies and system of national accounts while maintaining historical growth rates.

- For 1985-1998, the branches of economic activities are: Agriculture (AtB), Mining and Quarrying (C), Manufacturing (D), Utilities (E), Construction (F), Trade Services $(G+H)$, Transport and Communication (I), Bank and Insurance, Other Services of Merchants, and Services of Non-Merchants (J-P).

- Sectors A-I match perfectly with the ASD sector classification, but sectors J-P do not. The levels data were used for Sector A-I, while we matched Bank and Insurance, Other Services of Merchants, and Services of Non-Merchants to the ASD classification J-P by applying the growth rate of the sum of the aforementioned sectors to each detailed sector that corresponds to the ASD sectors.

- There is no information on Dwellings (70). The Share of Dwellings in Business Services $(\mathrm{J}+\mathrm{K})$ for Senegal was applied. Both Senegal and Burkina Faso are AFRISTAT members, are in the same monetary zone and have similar economic structure.

- For the period 1970-1984, UN OCD was used. Sectors A-K correspond to the ASD classification, while sectors L-P slightly differ with Community and Government services being combined. We applied the aggregate growth rate of sectors L-P to both Government and Personal Services.

- For the period 1965-1969, data were obtained from the Africa Statistical Yearbook, 1972 and 1975. UNECA provides estimates of value added for Burkina Faso, then known as Upper Volta. Sectors J-P do not match the ASD classification. The aggregate growth rate of the main sectors was applied to each sub-sector.

- Price information is not available for 1965.

\subsection{Construction Notes on Employment}

\begin{tabular}{|l|l|l|}
\hline Year & Primary Sources & Source of Publication \\
\hline 1975 & Total Employment from the General Population Census & INSD $^{32}$ \\
\hline 1980 & Economically active population by Sector from AYB & UNECA \\
\hline 1985 & Occupational employment levels from 1985 PHC & IPUMs International \\
\hline
\end{tabular}

\footnotetext{
${ }^{29} \mathrm{http}: / / \mathrm{www}$. insd.bf/n/contenu/pub periodiques/comptes eco/Comptes des nations 2001.pdf

30 http:/ / data.un.org/Data.aspx?d=SNA\&f=group code $\% 3 a 201$

31 Obtained from the SOAS, University of London Library. https://library.soas.ac.uk/Record/386159

32 http://www.insd.bf/n/nada/index.php/catalog/21\#page=accesspolicy\&tab=study-desc
} 


\begin{tabular}{|c|c|c|}
\hline 1994 & Sectoral ratios from $\mathrm{HIEC}^{33}$ & ILO KILM \\
\hline 1996 & Sectoral employment Levels from 1996 PHC & IPUMS International \\
\hline 2006 & Sectoral employment levels from 2006 PHC & ILO KILM \\
\hline 2014 & Sectoral employment levels from 2014 HIEC & ILO KILM \\
\hline $\begin{array}{ll}2003, & 2005, \\
2007 & \end{array}$ & Distribution of workers by Industry from Household Surveys & $\mathrm{INSD}^{34}$ \\
\hline $1980-2015$ & Trend from the Economically Active Population in Agriculture & FAOSTAT \\
\hline
\end{tabular}

- We used level data from 1975, 1985, 1996, 2006 and 2014 as benchmarks.

- For the 1975 benchmark, total employment data was obtained from the report of the General Population Census. We applied the sectoral distributions of the economically active population from 1980, reported in the Africa Statistical Yearbook, to disaggregate the total employment figure into sectoral levels.

- In 1985, employment by occupation is available but employment by sector is not available. We map employment by occupation to sectors using the 1980 sectoral distributions of the economically active population.

- For Agriculture, we interpolate between benchmark years using growth trends from the economically active population in Agriculture from 1981 to 2015. From 1970 to 1980, retropolate and extrapolate using the average trend of labor productivity (see equation 7 , 10,11). Average labor productivity trends are obtained by calculating labor productivity for benchmark years and linearly interpolating between these benchmark years.

\subsubsection{Cameroon}

\subsection{Background of National Accounts Statistics}

The first national account of Cameroon was prepared in 1964 and covers 1959, 1962/63 and 1963/64 for East Cameroon. These accounts were prepared to provide the empirical basis for the implementation of the Second Five-Year Economic Development Plan (1966-1971). After the unification that led to the creation of the Federal Republic of Cameroon in October 1961, a virtual national account was prepared for the new federation that covered East Cameroon as well as other new regions with the help of French technical assistance. Oleg Arkhipoff was the French technical assistant who helped to build the first national account system that covers the entire federation. The Arkhipoff methodology was derived directly from the French Courcier System. Industrial censuses and administrative information from tax units were used as the primary source of information for the construction of national accounts. The methodology was used to prepare national accounts of Cameroon until the 1970/71 fiscal year when the National Statistic Institutes adopted the 1968 UN System of National Accounts (National Institute of Statistics, 2013).

The 1968 System of National Accounts was used to produce the 1971 national accounts and to convert previous accounts in the Cameroonian Courcier System to the SNA. The adoption of the 1968 SNA came with the introduction of the residence notion into the national accounting system. This emphasized the importance of national territory in the production of goods and services, unlike the Cameroonian Courcier System which included foreign administration and international organizations. National accounts were constructed by grouping institutional units according to functions: Non-Financial Companies and Quasi-Companies; Financial Institutions; Public administration; and Households and non-profit organizations at the service of households. The

\footnotetext{
${ }^{33}$ Household Income and Expenditure Survey

${ }^{34}$ http://www.insd.bf/n/index.php/indicateurs?id=72
} 
Courcier System operated under five accounts: production accounts; exploitation accounts; appropriation accounts; capital account; and external accounts. With the adoption of the 1968 SNA, the production and exploitation accounts were merged, and the appropriation accounts were divided into income, expenditure, and final consumption accounts (National Institute of Statistics, 2013).

In 1993, the Institut National de la Statistique benefited from EU, French government and Africa's Economic and Statistical Observatory (AFRISTAT) joint support to reshape and upgrade the national accounts to the 1993 UN SNA. This project was integrated into the ERETES package of AFRISTAT, with Cameroon being the pilot country. The Institut National de la Statistique adopted the 1993 SNA, ISIC Rev 3, the Central Product Classification (CPC) and the ERETES package and changed the base year to $1989 / 90$. This led to the production of a series of national accounts published in November 2004. The national account was published in both fiscal and calendar years. In the recent revision used as a benchmark, the base year was changed to 2000 and the national account was reconstructed backwards to 1993. The Institut National de la Statistique is planning to upgrade to the 2008 SNA using 2005 as the base year, further updating the data backwards to 1959 using 2005 as a reference year, as well as producing quarterly accounts with the assistance of AFRISTAT and Regional Accounts to help the decentralization process (National Institute of Statistics, 2013).

\begin{tabular}{|c|c|c|}
\hline Period & Source & Notes \\
\hline $2012-2015$ & $\begin{array}{l}\text { Les Comptes Nationaux de 2015, pg 5-11, } \\
\text { Institut National de la Statistique }\end{array}$ & Levels data used and the 1993 SNA \\
\hline 1993-2011 & $\begin{array}{l}\text { Les Comptex Nationaux, Optique } \\
\text { production, Tables } 6-22 \text {, Institut National de } \\
\text { la Statistique }\end{array}$ & $\begin{array}{l}\text { Level data used for both value-added in } \\
\text { current and constant prices. }\end{array}$ \\
\hline $1965-1992$ & $\begin{array}{lr}\text { Comptex Nationaux du Cameroun, } \\
\text { 1969/70-2008 publications, } \\
\text { National de la Statistique }^{37}\end{array}$ & $\begin{array}{l}\text { Trend used for value added in current prices } \\
\text { for the whole period. It was also used to } \\
\text { construct price series from 1971-1992. Price } \\
\text { information is not available for the 1965-1970 } \\
\text { period. }\end{array}$ \\
\hline 1965-1969 & $\begin{array}{l}\text { Africa Statistical Yearbook }{ }^{38} \text {, Part } 2 \text { of } 1970 \text {, } \\
1972 \text { and } 1975\end{array}$ & $\begin{array}{l}\text { Trend used to construct price series from } \\
1965-1970 \text {. } \\
\text { Data on Services (J-P) has not been } \\
\text { defined separately so the aggregate growth rate } \\
\text { is applied to each subsector. }\end{array}$ \\
\hline
\end{tabular}

\subsection{Data Construction Notes}

- The recent series is published in the 1993 UN System of National Accounts. We used the first year of the recent series as the benchmark level data and linked it to the historical data using equation 2.1.

- The NSI started estimating volume data after the adoption of the 1963 SNA in 1971, therefore price information is not available from 1965-1970 from our primary source. We complement our primary source by using information from the Africa statistical yearbook to construct price series from 1965 to1970. In the ASY, data on services (J-P) has not been defined separately so the aggregate growth is applied to each subsector.

\footnotetext{
$35 \quad$ Available online at $\underline{\text { http: } / / \mathrm{slmp}-550-}$ 104.slc.westdc.net/ stat54/downloads/2016/Comptes Nationaux 2015 final.pdf

${ }^{36}$ Available online at http:// nso.cameroon.opendataforafrica.org/xkrcbs/national-summary-data-page

37 Available at the SOAS, University of London Library https://library.soas.ac.uk/Record/383822

38 Obtained from the SOAS, University of London Library. https://library.soas.ac.uk/Record/386159
} 
- There is no information on Dwellings (70). The share of Dwellings in Business Services $(\mathrm{J}+\mathrm{K})$ for Senegal was applied. Both Senegal and Cameroon are AFRISTAT members and have a similar economic structure. The price index of Business Services $(J+K)$ was used to derive volume data on Dwellings (70).

\subsection{Construction Notes on Employment}

\begin{tabular}{|l|l|l|}
\hline Year & Primary Source & Source of Publication \\
\hline $1965-1968$ & Number of Employees by Industry from 1975 ASY & UNECA \\
\hline $1972-1974$ & Number of Employees by Industry from 1980 ASY & UNECA \\
\hline $1973-1981$ & Number of Employees by Industry from 1985 ASY & UNECA \\
\hline 1976 & Employment by Occupation from the 1976 PHC & IPUMS International \\
\hline 1976 & $\begin{array}{l}\text { Economically Active Population by Industry from the Yearbook of } \\
\text { Labor Statistics, 1945-1989 }\end{array}$ & ILO \\
\hline 1986 & Sectoral Employment Levels from 1986 NSI Estimate & KILM \\
\hline 2001 & Sectoral Employment Levels from 2001 Household Survey & KILM \\
\hline 2005 & Sectoral Employment levels from the 2005 PHC & IPUMS International \\
\hline 2005 & Sectoral Employment Levels from the 2005 ESSI 1 & NSI of Cameroon \\
\hline 2010 & Sectoral Employment Levels from the 2010 ESSI 2 & NSI of Cameroon \\
\hline $1980-2015$ & Economically Active Population in Agriculture & FAOSTAT \\
\hline
\end{tabular}

- We use level data from 1976, 1986, 2001, 2005, and 2010 as benchmarks. There was no available information for benchmark in the 1990s, making the interpolation period between 1986 and 2001 quite long.

- In 1976, employment by occupation is available but employment by sector is not available. We map employment by occupation to sectors using the 1976 sectoral distributions of the economically active population by industry reported by ILO. The figures reported by ILO and the figures we obtained after mapping turn out to be very similar.

- Using the 1976 data from PHC as benchmark, we extrapolate to 1980 and retropolate to 1965 using growth trends from the annual number of employees by sector reported in the 1975, 1980 and 1985 Africa Statistical Yearbooks.

- From 1980 onwards, for the agricultural sector, we interpolate between benchmark years using the growth trend of the economically active population in Agriculture.

- For the other sectors, we retropolate and extrapolate using the average growth trend of labor productivity (see equations $7,10,11$ ). Average labor productivity trends are obtained by calculating labor productivity for benchmark years and linearly interpolating between these benchmark years.

\subsubsection{Lesotho}

\subsection{Background of National Accounts Statistics}

The first National Accounts report was issued by the Bureau of Statistics in July 1967. This covers the 1964/65-1965/66 fiscal years. The National Accounts estimate was initiated by Mr. Michael Ward of the School of Applied Economics, Cambridge University. Interim work was circulated to governments' officials and agencies and based on their inputs and the additional information provided many corrections and some changes in concepts and treatment were made. The concepts and definitions used in this report are generally in accordance with the principles laid down by the UN 1953 System of National Accounts although the presentation of tables follows more closely the practices of the Central Statistical Office of the United Kingdom (Lesotho Bureau of Statistics (LBS henceforth), 1967). 
The Bureau reports the potential margin of error associated with each statistical table, with ' $\mathrm{A}$ ' representing errors in major aggregates probably less than $10 \%$, 'B' representing errors in major aggregates probably between $10-25 \%$, and $\mathrm{Z}$ representing errors not known, possibly in excess of $25 \%$. Value added data by industry at current and factor costs were classified under B reflecting possible error between 10\%-25\%. One other important issue is that the 1964/65-1974/75 value added data is estimated in thousands of Rand. We converted it to Maloti. The Maloti was pegged at parity with the Rand. From 1964 to 1974, the data were estimated in the fiscal year, with the Bureau of Statistics starting to estimate value added in in the calendar year in 1975. As a result, the growth trend from the fiscal years 1964/ 65 to 1974/75 was used to estimate levels data for the calendar years 1964 to 1974 in this update.

Over the years as more information was gathered and the SNA was revised, the LBS also revised its series from 1975-1986 to reflect current information and methodologies. The period account was converted from the fiscal year to the calendar year in 1975 and value added in constant prices was computed beginning in 1980. Recently the 2008 UN SNA was adopted, with the base year changing to 2012 and the historical series recalculated back to 1982 to reflect the revision in method and system of National Accounts.

\begin{tabular}{|c|c|c|}
\hline Period & Source & Notes \\
\hline 2007-2015 & $\begin{array}{l}\text { National Accounts } 2015 \text { Publication Tables, Lesotho Bureau of } \\
\text { Statistics (LBS), 2015. }\end{array}$ & Level used \\
\hline $1982-2006$ & National Accounts Revised estimates from 1982-2014, LBS. ${ }^{40}$ & Level data used \\
\hline 1964-1981 & 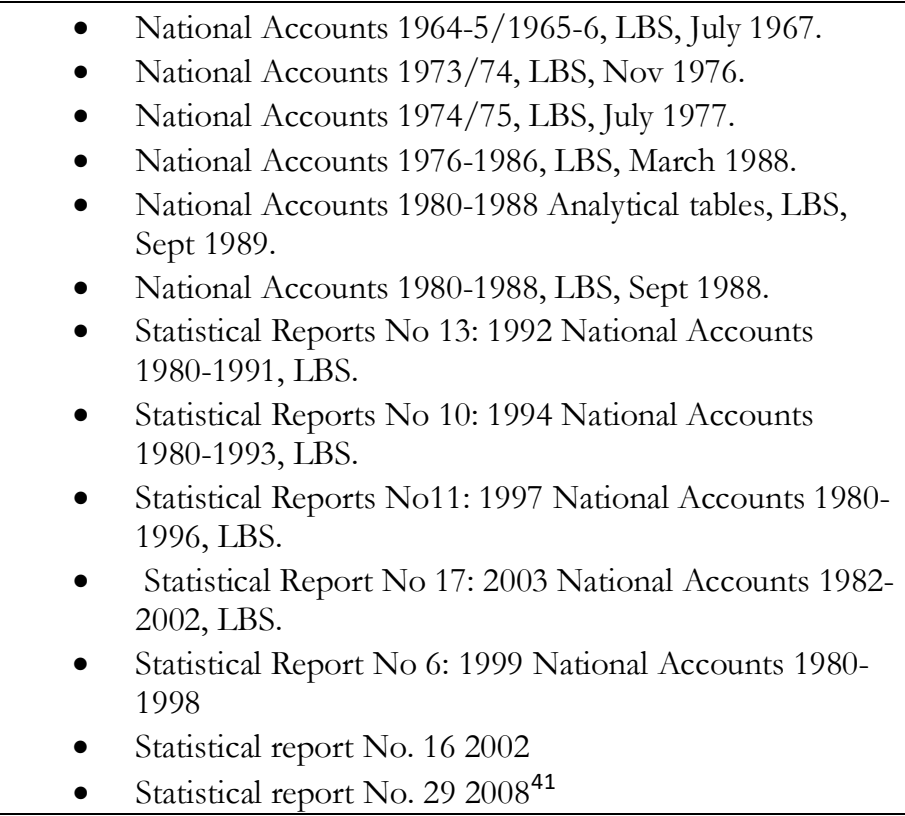 & $\begin{array}{l}\text { Trend used for nominal value } \\
\text { added. } \\
\text { We mostly used these reports } \\
\text { to construct nominal value } \\
\text { added and price series on } \\
\text { dwellings. }\end{array}$ \\
\hline 1970-1979 & UN National Accounts Official Country Data ${ }^{42}$ & $\begin{array}{l}\text { Trend used to construct price } \\
\text { series. }\end{array}$ \\
\hline 1964-1969 & Africa Statistical Yearbook, 1970, 1972 and 1974 Publications ${ }^{43}$ & $\begin{array}{l}\text { Trend used to construct price } \\
\text { series. }\end{array}$ \\
\hline
\end{tabular}

\footnotetext{
39 Available online at http://www.bos.gov.ls/

${ }^{40}$ Available online at http://www.bos.gov.ls/

${ }^{41}$ These reports were obtained from SOAS, University of London Library. https://library.soas.ac.uk/Record/524079.

${ }^{42}$ Available online at http://data.un.org/Data.aspx?d=SNA\&f=group code $\% 3 a 201$

43 Available at SOAS, University of London Library. https://library.soas.ac.uk/Record/386089
} 


\subsection{Notes on Data Construction}

- The current revision used as the benchmark level data is constructed according to the 2008 UN System of National Accounts.

- The data from 1982-2015 were obtained from the website of the LBS. We used the earliest year of this latest series as the benchmark for retropolation.

- The base year for the benchmark level information is 2012. Following the GGDC ASD methodology, we used 2005 as our reference year.

- The value-added historical series in current prices from 1964-1981 was obtained from the National Accounts and Statistical reports of LBS. The estimation of the value-added series was based on sectoral income so there is no information on prices from 1964-1979. The bureau started computing value added in constant prices in 1980. We filled this gap by constructing price series from 1964-1981 using information from the UN OCD and the ASY

- We linked the historical series (1964-1981) to the benchmark level data (1982-2015) using the growth trend.

- We then derived the volume data using the value-added series in current prices and the price series.

- In 1972/73 only the wages and salaries of employees of the mining companies were taken into account when estimating value added for the Mining $(C)$ sector. The LBS did not include the operating surplus.

- In 1973/74, no company carried out mining activity in Lesotho, with the LBS estimate for this fiscal year based on diggers only.

- In 1974/75, the estimate of the Mining sector (C) is based on the value of diamonds exported because diamonds were the only mineral extracted in Lesotho during this fiscal year.

- From the fiscal year 1964/65 to 1974/75 value added data is estimated in thousands of Rand. We converted it to Maloti and then used the growth trend. The Maloti is pegged at parity with the Rand.

- From 1964 to 1974, data were estimated according to the fiscal year. The LBS started estimating the value added in the calendar year in 1975. Therefore, the growth trend from the fiscal years 1964/65 to 1974/75 was used to estimate the levels data for the calendar years 1964 to 1974 in this update.

- The recent revision of the national accounts which is online (1982-2015) does not report ownership of dwellings separately. However, the Statistical Reports published by the LBS contains figures on Ownership of dwellings.

- Data on dwellings are taken from various Statistical Reports published by the LBS (see table above).

\subsection{Construction Notes on Employment}

\begin{tabular}{|l|l|l|}
\hline Year & Primary Sources & Source of Publication \\
\hline 1976 & Sectoral Employment Levels from the 1976 PHC & ILO \\
\hline 1986 & Sectoral Employment Levels from the 1986 PHC & Lesotho Bureau of Statistics \\
\hline 1996 & Sectoral Employment Levels from the 1996 PHC & KILM \\
\hline
\end{tabular}




\begin{tabular}{|l|l|l|}
\hline 2006 & Sectoral Employment levels from the 2006 PHC & Lesotho Bureau of Statistics \\
\hline 2008 & Sectoral Employment Levels from the 2008 LFS & Lesotho Bureau of Statistics \\
\hline 2011 & $\begin{array}{l}\text { Sectoral Employment levels from the 2011 Lesotho } \\
\text { Demographic Survey }\end{array}$ & Lesotho Bureau of Statistics \\
\hline $1980-2015$ & Economically Active Population in Agriculture & FAOSTAT \\
\hline
\end{tabular}

- LBS defines the minimum age of employment as 10 years. The data used covers persons engaged who are 10 years old and above.

- We used sectoral employment levels from PHC of 1976, 1986, 1996, 2006 and 2011 and the 2011 Lesotho Demographic Survey as benchmarks.

- From 1980 to 2015, for the agricultural sector, we interpolate between benchmark years using the growth trend of the economically active population in Agriculture. From 1970 to 1980, we retropolate and extrapolate using the average trend of labor productivity.

- For the other sectors, we retropolate and extrapolate using the average growth trend for labor productivity (see equation $7,10,11$ ).

\subsubsection{Mozambique}

Background to National Accounts Statistics

\begin{tabular}{|l|l|l|}
\hline Period & Sources & Notes \\
\hline $1991-2015$ & $\begin{array}{l}\text { National Accounts, Instituto } \\
\text { Nacional De Estatistica }\end{array}$ & $\begin{array}{l}\text { Level data used for both value-added in constant and } \\
\text { current prices. }\end{array}$ \\
\hline $1966-1990$ & $\begin{array}{l}\text { Africa Statistical Yearbooks, 1972- } \\
1995 \text { yearbooks 45 }\end{array}$ & Trend used \\
\hline
\end{tabular}

\subsection{Notes on Data Construction}

- Revised value-added series starting from 1991 was obtained online from the National Statistical institute.

- The revised series have been compiled in accordance with the 1993 UN System of National Accounts. We used the first year of this series as our benchmark data.

- We obtained non-official information from the Africa Statistical Yearbooks from 19661990. We linked this historical series to the benchmark level data using equation 1.

- The National Statistical Institute does not publish a separate series for dwellings. However, reports of a mission from Statistics Denmark to Maputo indicate that INE construct series for Owner-occupied dwellings. Because we are not privy to this information, we applied the share of Dwellings in Business Services $(J+K)$ of Tanzania to construct a separate series for Dwellings (70) because both countries have a similar economic structure.

\subsection{Construction Notes on Employment}

\begin{tabular}{|l|l|l|}
\hline Year & Primary Sources & Source of Publication \\
\hline 1970 & Economically active population by industry from the 1970 Census & ILO \\
\hline 1980 & $\begin{array}{l}\text { Economically Active population by industry from the 1980 } \\
\text { Census }\end{array}$ & ILO \\
\hline $\begin{array}{l}1996 / 97- \\
2008 / 09\end{array}$ & Sectoral employment distributions from Jones and Tarp (2013) & $\begin{array}{l}\text { UNU WIDER WP } \\
45 / 2013\end{array}$ \\
\hline
\end{tabular}

44 Available online at http://www.ine.gov.mz/estatisticas/estatisticas-economicas/contas-nacionais/anuais$1 /$ pib optica producao.xlsx/view

45 Available at SOAS, University of London Library. https://library.soas.ac.uk/Record/386089 


\begin{tabular}{|l|l|l|}
\hline 1997 & Sectoral Employment levels from the 1997 PHC & IPUMS International \\
\hline 2003 & Sectoral Employment levels from the 2003 HS & KILM \\
\hline 2005 & $\begin{array}{l}\text { Sectoral Employment distribution from the 2004/2005 Integrated } \\
\text { Survey on Labor Force }\end{array}$ & INE \\
\hline 2005 & Sectoral Employment distribution from the 2005 HBS & INE \\
\hline 2009 & $\begin{array}{l}\text { Sectoral Employment levels from the 2008/09 Employment } \\
\text { Survey }\end{array}$ & INE \\
\hline 2010 & Sectoral Employment distribution from the 2010 HBS & INE \\
\hline 2007 & Sectoral Employment Levels from the 2007 PHC & IPUMS International \\
\hline 2015 & Sectoral Employment levels from the 2014/2015 HS & INE \\
\hline $1970-2015$ & General Employment Information from the Anuario Estatistico & INE \\
\hline $1980-2015$ & Total Economically Active Population in Agriculture & FAOSTAT \\
\hline
\end{tabular}

- Data from 1970, 1980, 1997, 2007, and 2015 are used as benchmarks.

- We adjust the benchmark data for mining, manufacturing, and utilities sectors for 1970 and 1980 using data from the Industrial Surveys.

- We generate series for the period 1996-2015 using 1996, 2005, 2010 and 2015 data points from the Household Surveys as benchmarks, then linearly interpolating between these benchmark years. This results in a household Survey series that is used for interpolating between population census benchmarks.

- Labor productivity series is generated for the period 1970-1996. Average labor productivity trends are obtained by calculating labor productivity for benchmark years and linearly interpolating between these benchmark years

- For agriculture we interpolate between benchmark years using trends from the economically active population in Agriculture.

- For the other sectors, we interpolate between benchmark years for the periods 1970-1996 and 1997-2015 using labor productivity trends and trends from the generated Household Survey series, respectively.

2.8.1.5 Namibia

\begin{tabular}{|l|l|l|}
\hline Period & Sources & Notes \\
\hline 1980-2015 & National Account Time Series & $\begin{array}{l}\text { Level data used for value added in constant } \\
\text { and current prices }\end{array}$ \\
\hline 1965-1979 & $\begin{array}{l}\text { Africa Statistical Yearbooks, 1972-1995 } \\
\text { yearbooks } 47\end{array}$ & Trend used \\
\hline
\end{tabular}

Notes on Data Construction

- The recent revision has been compiled in accordance with the 2008 UN System of National Accounts and retrospectively extrapolated to 1980 by the Namibia Statistical Agency. We used the earliest year of this series as our benchmark level data.

- We obtained non-official information from the Africa Statistical Yearbooks from 19661979. We linked this historical series to the benchmark level data using the growth trend.

- Namibia does not report separate series on dwellings. As a result, we applied the share of dwellings in Business Services $(\mathrm{J}+\mathrm{K})$ of Lesotho to arrive at an estimate for Namibia. Namibia and Lesotho are in the Common Monetary Area (CMA) and have a similar real estate structure.

\subsection{Construction notes on Employment}

\begin{tabular}{|l|l|l|}
\hline Year & Primary Sources & Source of Publication \\
\hline
\end{tabular}

\footnotetext{
${ }^{46}$ Available online at http://nsa.org.na/page/publications

47 Available at SOAS, University of London Library. https://library.soas.ac.uk/Record/386089
} 


\begin{tabular}{|l|l|l|}
\hline 1960 & Economically active population by Industry & UNECA \\
\hline 1970 & Economically active population by Industry & UNECA \\
\hline 1980 & Economically active population by Industry & UNECA \\
\hline $1987-1996$ & Economically active population by Sector & UNECA \\
\hline 1991 & Sectoral employment levels from the 1991 PHC & NSA $^{48}$ \\
\hline 2000 & Sectoral employment levels from the 2000 LFS & KILM \\
\hline 2001 & Sectoral employment levels from the 2001 PHC & NSA \\
\hline 2004 & Sectoral employment levels from the 2004 LFS & KILM \\
\hline 2011 & Sectoral employment levels from the 2011 PHC & NSA \\
\hline 2012 & Sectoral employment levels from the 2012 LFS & NSA \\
\hline 2013 & Sectoral employment levels from the 2013 LFS & NSA \\
\hline 2014 & Sectoral employment levels from the 2014 L FS & NSA \\
\hline 2016 & Sectoral employment levels from the 2016 LFS & NSA \\
\hline $1980-2016$ & Total economically active population in Agriculture & FAOSTAT \\
\hline
\end{tabular}

- Data from 1960, 1970, 1980, 1991, 2001, 2011, 2016 as benchmarks.

- Note that the 1960,1970, 1980 benchmarks were computed by applying the economy wide unemployment rate to each sector's economically active population reported by UNECA in the Africa Statistical yearbooks.

- The Namibia Statistical Agency (NSA) report the 2001 employment by 4 aggregate sectors: Agriculture, Manufacturing and other Industries, Trade Services, and Private and Public Services. To obtain data points for the 10 sectors, we used the sectoral distribution from the 2000 labor force survey to disaggregate the 4 sectors reported in the census report into 10 sectors.

- Sectoral employment levels for the 2016 benchmark was obtained from the 2016 labor force survey.

- For the agricultural sector, we interpolate between benchmark years using the growth trend from the economically active population in Agriculture. From 1960 to 1980, we interpolate between benchmark years using the average trend of labor productivity.

- For the other sectors, we interpolate between benchmark years using the average trend of labor productivity (see equation $7,10,11$ ). Average labor productivity trends are obtained by calculating labor productivity for benchmark years and linearly interpolating between these benchmark years.

\subsubsection{Rwanda}

\begin{tabular}{|l|l|l|}
\hline Period & Source & Notes \\
\hline $1999-2015$ & $\begin{array}{l}\text { "GDP, National Accounts, 2015" National } \\
\text { Institute of Statistics of Rwanda }\end{array}$ & $\begin{array}{l}\text { Level used for value added in current and } \\
\text { constant prices. }\end{array}$ \\
\hline $1970-1998$ & $\begin{array}{l}\text { UN National Accounts Official Country } \\
\text { Data } 50\end{array}$ & $\begin{array}{l}\text { Trend Used. Continuous series for value } \\
\text { added in current prices were available. For } \\
\text { value added in constant prices, data for the } \\
\text { periods 1970-1975 and 1980-1981 were } \\
\text { missing. We fill in these gaps using } \\
\text { information from the 1976 and 1985 } \\
\text { Africa Statistical Yearbooks. }\end{array}$ \\
\hline $1966-1969$ & Africa Statistical Yearbooks & Trend used \\
\hline
\end{tabular}

\footnotetext{
${ }^{48}$ Namibia Statistical Agency

49 Available online at http://www.statistics.gov.rw/publication/gdp-national-accounts-2015

${ }^{50}$ Available online at http:/ / data.un.org/Data.aspx?d=SNA\&f=group code $\% 3 a 201$
} 


\subsection{Notes on Data Construction}

- The earliest year of the recent value-added series is used as the benchmark level data. The recent data were obtained online from the website of National Statistical Institute of Rwanda. The series was compiled using the 1993 UN System of National Accounts.

- From 1970 to 1998, the value-added series from the UN Official Country Data was used. We linked this series to the benchmark level information using the growth trend. Continuous series for value added in current price was available but continuous series for value added in constant prices was not available. For value added in constant prices, data for the periods 1970-1975 and 1980-1981 were missing. We fill in these gaps using price information from the Africa Statistical Yearbooks.

- Sectors A-K correspond to the ASD classification, while sectors L-P differ slightly as Community and Government services are combined. We applied the aggregate growth rate for sectors L-P to both Government and Personal Services.

- For 1987-1989, the value-added series in constant prices of sector $\mathrm{G}+\mathrm{H}^{51}$ includes Transport, storage and communications and financial intermediation, Real estate, Renting and business activities. We applied the overall growth rate to all the sub-sectors defined in the ASD.

- The Rwanda National Statistical Institute does not report a separate series for Dwellings (70). As a result, we applied the share of Dwellings in Business Services $(\mathrm{J}+\mathrm{K})$ of Uganda to estimate a separate series on Dwellings (70) for Rwanda. Uganda and Rwanda are neighbors and have a similar economic structure.

\subsection{Employment Construction Notes}

\begin{tabular}{|l|l|l|}
\hline Year & Primary Sources & Sources of Publication \\
\hline 1978 & Sectoral employment levels from 1978 PHC & ILO \\
\hline 1989 & Sectoral employment levels from 1991 PHC & NISR \\
\hline 2000 & Sectoral employment levels from 2000 EICV 1 & NISR $^{52}$ \\
\hline 2002 & Sectoral employment levels from the 2002 PHC & KILM \\
\hline 2005 & Sectoral employment levels from the 2005 EICV II & NISR \\
\hline 2010 & Sectoral employment levels from the 2010 EICV III & NISR \\
\hline 2012 & Sectoral employment levels from the 2012 PHC & NISR \\
\hline 2013 & Sectoral employment levels from the EICV IV & NISR \\
\hline 2014 & Sectoral employment levels from the 2014 ES & NISR \\
\hline 2016 & Sectoral employment levels from the 2016 LFS & NISR \\
\hline $1980-2016$ & Economically active population in Agriculture & FAOSTAT \\
\hline
\end{tabular}

- Employment data from the PHC of 1978, 1989, 2002, 2012, and the 2016 LFS were used as benchmarks.

- In most sectors, the 2002 and 2012 PHC tends to underestimate employment. Therefore, the 2002 PHC benchmark is adjusted using the data from the 2000 Integrated Household Living Condition Survey (EICV I).

- The 2012 PHC is also adjusted using information from the 2012 Integrated Living condition Survey (EICV III).

- We interpolate between benchmark years using the trend in average labor productivity, except for the period 2000-2016 when the trend from the EICV is used.

\footnotetext{
51 Wholesale, retail trade, repair of motor vehicles, motorcycles and personal and household goods; hotels and restaurants

52 National Institute of Statistics Rwanda
} 
- For agriculture, we interpolate between benchmark years using the trend in the economically active population in Agriculture.

\subsubsection{Uganda}

\begin{tabular}{|c|c|c|}
\hline Period & Sources & Notes \\
\hline $1997-2015$ & Statistical Abstracts, Uganda Bureau of Statistics ${ }^{53}$ & $\begin{array}{l}\text { Data used as benchmark level data for value } \\
\text { added in constant and current prices }\end{array}$ \\
\hline 1955-1996 & $\begin{array}{l}\text { UN Yearbook of National Accounts Statistics, } 1964- \\
2000 \text { Publications. }\end{array}$ & $\begin{array}{l}\text { Trend used. We checked for reliability, and } \\
\text { when unusual growth rates are observed we } \\
\text { replaced them with growth rates from UN } \\
\text { OCD online or historical publication by the } \\
\text { Uganda Bureau of Statistics (See rows } \\
\text { below). }\end{array}$ \\
\hline 1970-1996 & UN National Accounts Official Country Data ${ }^{55}$ & $\begin{array}{l}\text { Trend used. For some years, information on } \\
\text { producers of government services is not } \\
\text { reported in the UN Yearbook, however, } \\
\text { information on narrowly defined } \\
\text { government and other community services } \\
\text { from UN OCD is used to fill the gap. }\end{array}$ \\
\hline $1955-1962$ & $\begin{array}{l}\text { The Real growth of the economy of Uganda, 1954- } \\
\text { 1962, Uganda. Ministry of Economic Affairs, } \\
\text { Statistics Branch. } \\
\text { [Entebbe], 1964. }\end{array}$ & $\begin{array}{l}\text { Trend used to complement the growth } \\
\text { trend from UN Yearbooks. It was the first } \\
\text { National Accounts estimation that reports } \\
\text { on prices. As a result, several assumptions } \\
\text { were made about some sectoral prices (See } \\
\text { notes below). }\end{array}$ \\
\hline 1956-1961 & $\begin{array}{l}\text { Statistical Abstract, Ministry of Economic Affairs, } \\
\text { Statistics Branch, [Entebbe], } 1962 .{ }^{57}\end{array}$ & $\begin{array}{l}\text { Trend used to complement the growth } \\
\text { trend from UN Yearbooks. Some } \\
\text { household production was excluded, and } \\
\text { some accounts were reconciled after } \\
\text { marketing boards were taken over by } \\
\text { private firms (See notes below). }\end{array}$ \\
\hline
\end{tabular}

\subsection{Notes on Data Construction}

- Uganda revised its GDP in 2014, changing the base year from 2003 to 2009/2010. This revised GDP was compiled in accordance with the 2008 UN System of National Accounts and the International Standard for Industrial Classification (ISIC Rev.4). We used the first year of this revised series as our benchmark level data.

- We linked the benchmark series to the historical series obtained from the UN Yearbook of National Accounts/UN OCD using equation 1. We complement this with information

\footnotetext{
53 Available online at http://www.ubos.org/publications/statistical-abstract

54 Available at SOAS, University of London Library. https://library.soas.ac.uk/Record/299769 and https://library.soas.ac.uk/Record/299769.

55 Available online at http://data.un.org/Data.aspx?d=SNA\&f=group code $\% 3 a 201$

56 Obtained from the British Library.

http:/ / explore.bl.uk/primo library/libweb/action/display.do?tabs=more'Tab\&ct $=$ display\&fn $=$ search\&doc $=$ BLL01 003702038\&ind $\mathrm{x}=1 \& \mathrm{recIds}=$ BLL01003702038\&recIdxs=0\&elementId=0\&renderMode=poppedOut\&displayMod $\mathrm{e}=$ full\&frbrVersion $=\& v i d=$ BLVU1\&mode $=$ Basic\&tab $=$ local tab\&dscnt $=0 \& v 1($ freeText 0$)=$ The $\% 20$ real $\% 20$ growt $\underline{\mathrm{h} \% 20 \text { of } \% 20 \text { the } \% 20 \text { economy } \% 20 \text { of } \% 20 \text { uganda\&dstmp }=1502795627989}$

57 Available at the British Library.

http://explore.bl.uk/primo library/libweb/action/display.do?tabs=more'Tab\&ct=display\&fn=search\&doc $=$ BLL01 003702039\&ind $\mathrm{x}=1 \& \mathrm{xrecId}=$ BLL01003702039\&recIdxs=0\&elementId=0\&renderMode = poppedOut\&displayMod $\underline{\mathrm{e}=\text { full } \& \text { frbrVersion }=\& \mathrm{frbg}=\& \& v \mathrm{l}(488279563 \mathrm{UI} 0)=\text { any } \& \mathrm{dscnt}=0 \& \text { scp.scps }=\text { scope } \% 3 \mathrm{~A} \% 28 \mathrm{BLCONTENT} \% 29 \& \mathrm{t}}$ $\underline{\mathrm{b}=\mathrm{t} \& \mathrm{vid}=\mathrm{BLVU} 1 \& \text { mode }=\text { Basic\&srt }=\text { rank\&tab }=\text { local tab\&dum }=\text { true } \& v 1(\text { freeText } 0)=1962 \% 20 \text { Statistical } \% 20 \mathrm{Abst}}$ ract $\% 2 \mathrm{C} \% 20$ Statistics $\% 20$ Branch $\% 20$ Uganda\&dstmp $=1502797195660$
} 
from historical publications by the statistics branch of the Ministry of Economic Affairs. The historical National Accounts is published in three different SNAs: the 1953, 1968 and 1993 Systems of Accounts.

- For 1955-1971, data were obtained from the 1964, 1970 and 1975 UN Yearbooks of National Accounts. For the 1964 Yearbook, the industrial origin of production was published in current factor cost as well as 1960 factor cost. This was compiled according to the 1953 UN System of National Accounts but tailored to fit the "special character of the economy of Uganda" (UN Yearbook of National Accounts, 1964). The value-added series was published in millions of pounds. Wholesale and retail trade; and Banking, insurance and real estate were aggregated into one sector. We applied the growth rate of this aggregate sector to both Trade Services $(\mathrm{G}+\mathrm{H})$ and Business Services $(J+K)$. Government is narrowly defined as Public Administration and Defence, while the contribution of education and health to GDP is transferred to Other Services (item 11 on the UN table). This does not uniquely map into Government services (L, M, N) and Personal Services (O, P) defined in this database. We added Public administration and Defence to Services to obtain an aggregate sector, then applied the growth rate to both Government Services (L, M, N) and Personal Services (O, P). For the 1975 yearbook, the value-added series was produced in accordance with the 1968 SNA. We used value added series from 1965-1971 from this yearbook. The figures were reported in Uganda Shillings. We map producers of Government Services to Government Services (L, M, N) defined in this database. The Sectoral data for 1964 was obtained from the 1970 Yearbook.

- For 1972-1978, data were obtained from the 1980 UN Yearbook of National Accounts Statistics, Volume 1, Part 2. Value added in current and 1966 constant prices were published in accordance with the classifications and definitions recommended in the 1968 UN System of National Accounts. Value added in constant prices was available from 1972 to 1978 and value added in current prices was available from 1972 to 1976 . There is no available data from 1976 to 1980 for value added in current prices and from 1978 to 1980 for value added in constant prices. In these cases, we linearly interpolate for missing years.

- For 1981-1988, data were obtained from the 1990 UN National Accounts Statistics: Main Aggregates and Detailed Tables, part II. Value added in current and 1987 constant prices were published in accordance with the classifications and definitions recommended in the 1968 UN System of National Accounts. Community, Social and Personal Services were put together and no value was reported for Producers of Government Service. We used information from the UN OCD on Public administration and Defence; Compulsory social security (L); and Education; health and social work; other community, social and personal services $(\mathrm{M}+\mathrm{N}+\mathrm{O})$. We map this to Government Services $(\mathrm{L}, \mathrm{M}, \mathrm{N})$ and Personal Services $(\mathrm{O}, \mathrm{P})$ by using the aggregate growth trend.

- For 1989-1996, data were obtained from the 2000 UN National Accounts Statistics: Main Aggregates and Detailed Tables. Value added in current and 1991 constant prices were published in accordance with the classifications and definitions recommended in the 1968 UN System of National Accounts. In 1987, Uganda redenominated it currency, with 1 new shilling being equivalent to 100 old shillings. All data were converted to new shillings. Public administration and Defence; Compulsory Social Security; Education, Health and Social work; and Other community, Social and Personal Services were put together as one sector. We applied the aggregate growth rate to both Government Services (L, M, N) and Personal Services $(\mathrm{O}, \mathrm{P})$. 
- We obtained information on Dwellings (70) mostly from the Statistical Abstracts published by the Uganda Bureau of Statistics or the Statistics Branch of Ministry of Economic Affairs, Entebbe. Owner occupied dwelling is reported under non-monetary GDP. From 2008 to 2015, it was reported under real estate of non-monetary GDP.

- We compared the growth rate from the UN historical data to the historical data published by the Government of Uganda. In cases where the UN estimate is not consistent, we replaced it with the growth rate from the National Accounts published by the Statistics Branch of the Ministry of Economic Affairs, [Entebbe]. Particularly for 1955-1963, two such publications were used: "The Real growth of the economy of Uganda, 1954-1962, Uganda" and the "Statistical Abstract, Ministry of Economic Affairs, Statistics Branch, [Entebbe], 1962".

- Several assumptions were made about prices and values of some items in these publications. For instance, a sale of cotton during the ending of the season is used as an indicator of the fixed value added of cotton. This presumes that cotton harvested towards the end of the season is the same as the cotton harvested for the entire calendar year. For milk, a constant price is assumed in the current price calculation, meaning that the constant value equals the current value. For beer, the quantity per capita is assumed to be constant for the whole period but to differ among districts. The 1960 price is applied to calculate the total consumption of beer. For transportation, net output per vehicle is assumed to be constant from 1954 to 1962, which means as a result that the constant value is the same as current value. Gross output of the sector differed because of the rising input price. Household activities such as food preparation and beer brewing for home consumption as well as peasant house construction were excluded. ${ }^{58}$

\subsection{Construction Notes on Employment Data}

\begin{tabular}{|l|l|l|}
\hline Year & Primary Sources & Source of Publication \\
\hline $1952-1961$ & $\begin{array}{l}\text { Sectoral employment levels from the Annual Enumeration of } \\
\text { Employees }\end{array}$ & $\begin{array}{l}\text { Statistics Branch, Ministry of } \\
\text { Economic Affairs, 1962 }\end{array}$ \\
\hline 1969 & Total Employment from the 1969 PHC. & UBOS \\
\hline $1965-1973$ & Number of employees by Industry from 1975 YBLS & $\begin{array}{l}\text { ILO (1975) Yearbook of Labor } \\
\text { Statistics }\end{array}$ \\
\hline 1970 & Economically active population by Industry from 1975 ASY & UNECA \\
\hline 1980 & Economically active population by Industry from the 1986 ASY & UNECA \\
\hline 1980 & Employment by Occupation from the 1980 PHC & UBOS \\
\hline 1991 & Employment by Occupation from the 1991 PHC & UBOS \\
\hline 2002 & Sectoral employment levels from the 2002 PHC & UBOS \\
\hline 2003 & Sectoral employment levels from the 2003 LFS & KILM \\
\hline 2005 & Sectoral employment levels from the 2005 LFS & KILM \\
\hline 2005 & Sectoral employment levels from the 2005 HIES & KILM \\
\hline 2009 & Sectoral employment levels from the 2009 HIES & KILM \\
\hline 2012 & Sectoral employment levels from the 2012 HIES & KILM, unreliable \\
\hline 2013 & Sectoral employment levels from the 2013 HIES & KILM \\
\hline 2014 & Sectoral employment levels from the 2014 PHC & UBOS \\
\hline $1980-2015$ & Economically active population in agriculture & FOASTAT \\
\hline
\end{tabular}

- We used data from the 1969, 1980, 1991, 2002 and 2014 Censuses as Benchmarks.

58 See paragraph 1 of "Statistical Abstract, Ministry of Economic Affairs, Statistics Branch, [Entebbe], 1962" and paragraph 67-128 of "The Real growth of the economy of Uganda, 1954-1962, Ministry of Economic Affairs, Statistics Branch, [Entebbe], 1964" for more details. 
- For the 1969 Benchmark, total employment is taken from the population census and disaggregated into sectors using the 1970 sectoral distributions of the economically active population reported in the 1975 Africa Statistical Yearbook. We repeated the same procedure to derive the 1980 Benchmark. Total employment was taken from the 1980 census and sectoral distribution was taken from the economically active population by sector reported in the 1985 Africa Statistical Yearbook.

- From 1952-1961, employment by sector was reported in the 1962 Statistical Abstract. These figures are based on the annual enumeration of employment. Because this is an employee survey; the agricultural sector, trade services and personal services are underestimated. We adjust the figures for these sectors using information from the 1969 population census.

- In 1991 employment by occupation is available. We map occupations into sectors using information from household surveys.

- From 1952 to 1973, we interpolate between benchmark years using the trend in the number of employees by sector.

- From 2000 to 2015, we interpolate between benchmark years using the trend in sectoral employment reported in household and income surveys.

- For the remaining period, 1974 to 1999, we interpolate between benchmark years using the trend in average labor productivity. In the case of agriculture, we used the trend from the economically active population in Agriculture.

\subsubsection{Update of the ASD}

\begin{tabular}{|l|l|l|l|}
\hline Country & Update Period & Source of Data & Notes \\
\hline Botswana & $2006-2015$ & $\begin{array}{l}\text { Gross Domestic Product, Third Quarter, Statistics } \\
\text { Botswana }\end{array}$ & Level data used \\
\hline Ethiopia & $2011-2015$ & Africa Statistical Yearbook, 2016, AfDB & Growth trend used \\
\hline Ghana & $2011-2015$ & Revised Annual GDP 2015, Ghana Statistical Service & Level data used. \\
\hline Kenya & $1960-2015$ & $\begin{array}{l}\text { Quarterly GDP Reports, Kenya Bureau of Statistics, 2006- } \\
2015\end{array}$ & Level data used \\
ASD, 1960-2005 & Trend used \\
\hline Malawi & $2009-2015$ & $\begin{array}{l}\text { Quarterly Statistical Bulletin, National Statistical office of } \\
\text { Malawi }\end{array}$ & Level data used. \\
\hline Mauritius & $2006-2015$ & Digest, National Accounts of Mauritius & \\
\hline Nigeria & $1960-2015$ & $\begin{array}{l}\text { GDP 1981-2010 Revision Post Rebasing and the Quarterly } \\
\text { Statistical Bulletin } \\
\text { ASD, 1960-1980 }\end{array}$ & Level data Used \\
\hline Senegal & $2011-2015$ & UN OCD & Trend used \\
\hline $\begin{array}{l}\text { South } \\
\text { Africa }\end{array}$ & $2005-2015$ & GDP_Detailed Annual Tables, Statistics South Africa & Level data used \\
\hline Tanzania & $2005-2015$ & $\begin{array}{l}\text { Gross Domestic Product, 2016. Highlights for the Third } \\
\text { Quarters }\end{array}$ & Level data used \\
\hline
\end{tabular}

\footnotetext{
59 data.http://www.statsbots.org.bw/sites/default/files/publications/GDP\%20Q3\%20December\%202016.pdf

${ }^{60}$ http://www.nsomalawi.mw/images/stories/data on line/general/Quarterly $\% 20$ Bulletins/Quarterly $\% 20$ Statistica 1\%20Bulletin, $\% 20$ December $\% 202016 . p d f$

${ }^{61}$ http://statsmauritius.govmu.org/English/StatsbySubj/Pages/National-Accounts.aspx

62 http://www.nigerianstat.gov.ng/report/371, $\quad \underline{\text { http://www.nigerianstat.gov.ng/report/220 }}$

http://nigerianstat.gov.ng/elibrary?queries[search]=GDP

63 http:/ / www.statssa.gov.za/?page id=1854\&PPN=P0441\&SCH=6675

${ }^{64} \mathrm{http://www.nbs.go.tz/nbs/takwimu/na/HIGHLIGHTS} \mathrm{FOR} \mathrm{THE} \mathrm{THIRD} \mathrm{QUARTER} \mathrm{GDP} \mathrm{2016.pdf}$
} 


\begin{tabular}{|l|l|l|l|}
\hline Zambia & $1960-2015$ & $\begin{array}{l}\text { GDP by type of economic activity, Central Statistical } \\
\text { Office, 2010-2015 } \\
\text { ASD, 1960-2010 }\end{array}$ & $\begin{array}{l}\text { Level data used for 2010- } \\
2015 . \\
\text { Trend Used }\end{array}$ \\
\hline
\end{tabular}

\subsubsection{Statistical References of New Countries}

\subsubsection{Burkina Faso}

ILO(2016). Key Indicators of the Labor Market (KILM), Ninth Edition

INSD (2015). Annuare Statistique. The Institut National de la Statistique et de la Demographie bttp:// wmw.insd.bf/n/index.php/publications? id $=36$

INSD (2015) Les Comptes Economiques de la Nation 1999 à 2012: Comptes définitifs. bttp:// wmw.insd.bf/n/contenu/pub periodiques/comptes eco/Comptes eco nat 99-2012.pdf

INSD(2006) Les Comptes Economiques de la Nation 2001 bttp://wmw.insd.bf/n/contenu/pub periodiques/comptes eco/Comptes des nations 2001.pdf

INSD(2003) Les Comptes Economiques de la Nation 1994-1999 http:// wmw.insd.bf/n/contenu/pub periodiques/comptes eco/Comptes eco nat 94 99.pdf

INSD (2003) Analyse des Resultats Del'equete Burkinabe Sur Les Conditions Vie Des Manages http: / / wmw. ilo.org/dyn/lfsurvey/lfsurvey. list? p lang=enerp country $=B F$

INSD (2005) Analyse des Resultats Del'equete Burkinabe Sur Les Conditions Vie Des Manages et $\begin{array}{lllll}\mathrm{du} & \text { suivi la } & \text { pauvrete } & \end{array}$ bttp:/ / www.ilo.org/public/ libdoc//igo/P/484726/484726(2005)199.pdf

INSD (2007) Analyse des Resultats De l'enquete Annuelle sur les Conditions de vie des Menages en 2007. http:// wmw.ilo.org/public/libdoc//igo/P/484726/484726(2007)182.pdf

McCaa et al. Using Integrated Census Microdata for Evidence-Based Policy Making: The IPUMS International Global Initiative

Minnesota Population Center. Integrated Public Use Microdata Series, International: Version 6.5 [dataset]. Minneapolis, MN: University of Minnesota, 2017.

UNECA (1972). Africa Statistical Yearbook. Part 2 West Africa https:// library.soas.ac.uk/Record/386159

UNECA (1975). Africa Statistical Yearbook. Part 2 West Africa bttps:// library.soas.ac.uk/Record/386159

UNECA (1980). Africa Statistical Yearbook. Part 2 West Africa https:// library.soas.ac.uk/Record/386159

UNECA (1985). Africa Statistical Yearbook. Part 2 West Africa bttps:// library.soas.ac.uk/Record/386159

UNECA (1987). Africa Statistical Yearbook. Part 2 West Africa bttps:/ / library.soas.ac.uke/Record/386159

${ }^{65}$ http://zambia.opendataforafrica.org/dwieeid/national-accounts-of-zambia?indicator=1004870 
UNSD (2017). UN National Accounts Official Country Data. bttp:/ / data.un.org/Data.aspx? $d=S N A$ erfogroup code $\% 3$ a201

UNSD (2013). National Accounts Statistics: Main Aggregates and Detailed Tables, pp 544-573

\subsubsection{Cameroon}

FAO (2017). Economically Active Population in Agriculture, FAOSTAT

ILO(2016). Key Indicators of the Labor Market (KILM), Ninth Edition

ILO (1990). Yearbook of Labor Statistics, Retrospective Edition, 1945-1989

Minnesota Population Center. Integrated Public Use Microdata Series, International: Version 6.5 [dataset]. Minneapolis, MN: University of Minnesota, 2017.

NSI (2016). Les Comptes Nationaux de 2015, pg 5-11, Institut National de la Statistique http://slmp-550-104.slc.westdc.net/ stat54/downloads/2016/Comptes Nationaux 2015 final.pdf

NSI (2015). Les Comptex Nationaux, Optique production, Tables 6-22, Institut National de la Statistique. http://nso.cameroon.opendataforafrica.org/xkrcbs/national-summary-data-page

NSI (2010). Survey of Employment and the Informal Sector (ESSI 2)

http:// wmw.statistics-cameroon.org/news.php?id $=137$

NSI (2005). Survey of Employment and the Informal Sector (ESSI 1)

http:// wmw.statistics-cameroon.org/news.php? id =137

NSI (1970-2011) Comptex Nationaux du Cameroun, 1969/70-2011 publications, Institut National de la Statistique. https:// library.soas.ac.uk/Record/383822

UNECA (1970). Africa Statistical Yearbook. Part 2 West Africa bttps:// library.soas.ac.uk/Record/386159

UNECA (1972). Africa Statistical Yearbook. Part 2 West Africa bttps:// library.soas.ac.uk./Record/386159

UNECA (1975). Africa Statistical Yearbook. Part 2 West Africa - https:// library.soas.ac.uk/Record/386159

UNECA (1980). Africa Statistical Yearbook. Part 2 West Africa bttps:// library.soas.ac.uk/Record/386159

UNECA (1985). Africa Statistical Yearbook. Part 2 West Africa

Obtained from the SOAS, University of London Library. https:// library.soas.ac.uk/Record/386159

\subsubsection{Lesotho}

FAO (2017). Economically Active Population in Agriculture, FAOSTAT

ILO(2016). Key Indicators of the Labor Market (KILM), Ninth Edition

ILO (1990). Yearbook of Labor Statistics, Retrospective Edition, 1945-1989

LBS (2016). National Accounts Publication Tables, Lesotho Burean of Statistics (LBS)

bttp:/ / wmw.bos.gov.ls/ 
LBS (2015). National Accounts Revised Estimates, 1982-2014. Lesotho Burean of Statistics bttp:// wmw.bos.gov.ls/

LBS (2013). 2011 Lesotho Demographic Survey Report. Lesotho Burean of Statistics

bttp://wmw.bos.gov.ls

LBS (2009). 2006 Population and Housing Census Analytical Report, Volume IIIB Socio Economic Characteristics. http:// www.bos.gov.ls

LBS (2008). 2008 Labor Force Survey Report. Lesotho Burean of Statistics

bttp:// wmw.bos.gov.ls

LBS (1964-2008), National Accounts and Statistical Reports. Lesotho Bureau of Statistics. Various Issues. bttps:/ / library.soas.ac.uk/Record/ 524079

LBS (1992). 1986 Population Census Analysis Report. Volume III (Socio-economic and Environmental Aspect. bttps:// library.soas.ac.uk/Record/327820

Minnesota Population Center. Integrated Public Use Microdata Series, International: Version 6.5 [dataset]. Minneapolis, MN: University of Minnesota, 2017.

UNSD (2017), UN National Accounts Official Country Data. United Nations Statistical Division bttp:/ / data.un.org/Data.aspx? $d=S N A$ \& of $=$ group code\% $\%$ a201

UNECA (1970-74). Africa Statistical Yearbooks. 1970, 1972 and 1974 Issues

https:// library.soas.ac.uk/Record/386089

\subsubsection{Mozambique}

FAO (2017). Economically Active Population in Agriculture, FAOSTAT

ILO(2016). Key Indicators of the Labor Market (KILM), Ninth Edition

ILO (1990). Yearbook of Labor Statistics, Retrospective Edition, 1945-1989

INE (2016). National Accounts, 1991-2015. Instituto Nacional De Estatistica de Mozambique bttp:// www.ine.gov.ms/estatisticas/estatisticas-economicas/contas-nacionais/ anuais-

1/pib optica producao.xlsx/view

INE (2006): Inquérito Integrado à Força de Trabalho (IFTRAB 2004/05). Relatório Final. Instituto Nacional de Estatística de Moçambique, Maputo.

INE (2006): Informal Sector in Mozambique - First National Survey (INFOR 2004). National Statistical Institute of Mozambique, Maputo.

INE (2005, 2010, 2015). Household Budget Survey Instituto Nacional De Estatistica de Mozambique

INE (1969/76) Bulletin mensuel de statistique Mozambique. Instituto Nacional de Estatistica Vol. 9(7)-15(2), 1968-74; v.16(7), 1975. https:// library.soas.ac.uk/Record/387875

INE (1974) Anuario Estatistico. Instituto Nacional De Estatistica de Mozambique Vol 15-Vol 45 bttps:/ / library.soas.ac.uk/Record/ 386376

Jones, S and Tarp, F (2013). Jobs and Welfare in Mozambique. UNU WIDER Working Paper $45 / 2013$

Minnesota Population Center (2017). Integrated Public Use Microdata Series, International: Version 6.5 [dataset]. Minneapolis, MN: University of Minnesota. 
UNECA (1972-95). Africa Statistical Yearbooks. Various Issues https:// library.soas.ac.uk/Record/386089

\subsubsection{Nambia}

FAO (2017). Economically Active Population in Agriculture, FAOSTAT

ILO(2016). Key Indicators of the Labor Market (KILM), Ninth Edition

ILO (1990). Yearbook of Labor Statistics, Retrospective Edition, 1945-1989

NSA (2017) Nambia Labor Force Survey 2016 Report. Namibia Statistical Agency (NSA) bttps:// cms.my.nalassets/documents/Labor Force Survey - 20161.pdf

NSA (2016). National Account Time series, 1980-2015. Namibia Statistical Agency bttp:/ / nsa.org.na/page/publications

NSA(2015) Nambia Labor Force Survey 2014 Report. Namibia Statistical Agency bttps:/ / cms.my.nal assets/ documents/9b8e77842e3dec459407c2a76b9d79ab.pdf

NSA(2014) Nambia Labor Force Survey 2013 Report. Namibia Statistical Agency bttps:// cms.my.nal assets/documents/Namibia Labor Force Survey report 2013.pdf

NSA(2013) Nambia Labor Force Survey 2012 Report. Namibia Statistical Agency bttps:/ / cms.my.na/ assets/documents/p19dmnb3g84n115k.kcch9busk1.pdf

NSA (2003). 2001 Population and Housing Census, National Report: Basic Analysis with Highlights https:// library.soas.ac.uk./Record/640424

NSA (1993). 1991 Population and Housing Census: Report A Statistical Tables Volume III https://library.soas.ac.uk/Record/310258

UNECA (1974-95). Africa Statistical Yearbooks. Various Issues. bttps://library.soas.ac.uk/Record/386089

\subsubsection{Rwanda}

FAO (2017). Economically Active Population in Agriculture, FAOSTAT

ILO(2016). Key Indicators of the Labor Market (KILM), Ninth Edition

ILO (1990). Yearbook of Labor Statistics, Retrospective Edition, 1945-1989

Minnesota Population Center (2017). Integrated Public Use Microdata Series, International: Version 6.5 [dataset]. Minneapolis, MN: University of Minnesota.

NISR (2017). 2016 Labor Force Report National Institute of Statistics Rwanda bttp:/ / wmw.statistics.gov.rw/publication/ labor-force-survey-report-angust-2016

NISR (2016). Integrated Household Living Conditions Survey (EICV 4) Thematic ReportEconomic Activity. National Institute of Statistics Rwanda http:// www.statistics.gov. mw/datasource/ integrated-household-living-conditions-survey-eicv

NISR (2015). GDP, National Accounts, 2015. National Institute of Statistics Rwanda (NISR) bttp:// mww.statistics.gov.rw/publication/gdp-national-accounts-2015

NISR (2015). Integrated Household Living Conditions Survey (EICV 3) Thematic ReportEconomic Activity. National Institute of Statistics Rwanda bttp:/ / wmw.statistics.gov.rw/ datasource/ integrated-household-living-conditions-survey-eicv 
NISR (2015). 2014 Establishment Census Report National Institute of Statistics Rwanda bttp:/ / www.statistics.gov.rw/ datasource/establishment-census

NISR (2014) Fourth Population and Housing Census, Rwanda, 2012. Thematic Report: Labor force Participation. http:/ / mw w.statistics.gov.rw/datasource/population-and-housing-census

NISR (2011). 2011 Establishment Census Report National Institute of Statistics Rwanda bttp:/ / wmw.statistics.gov.rw/ datasource/ establishment-census

NISR (2007) Integrated Household Living Conditions Survey (EICV 2): Labor Markets and Economic Trends in Rwanda. National Institute of Statistics Rwanda. bttp:// wmw.statistics.gov.rw/ datasource/33

NISR (2003) 3rd General Census of Population and Housing of Rwanda - August 2002 Final Results: Statistical Tables. http:// mmw.statistics.gov.rm/datasource/population-and-housing-census

NISR (2002) Integrated Household Living Conditions Survey (EICV 1) National Institute of Statistics Rwanda http:// wmw.statistics.gov.rw/publication/integrated-household-living-conditions-survey-report-rwanda

NISR (1993). Second Population and Housing Census of Rwanda-1991 National Institute of Statistics Rwanda. bttp:// mww.statistics.gov. mw/datasource/population-and-bousing-census

UNSD (2017), UN National Accounts Official Country Data. United Nations Statistical Division bttp:/ / data.un.org/Data.asp $x$ ? $d=S N A$ o of $=$ group code $\% 3$ a 201

UNECA (1970- 88/89). Africa Statistical Yearbooks Volume II: Central Africa and Others. 1970, 1972, 1974, 1975, 1980, 1985, 1987, and 1988/89 Issues

bttps:// library.soas.ac.uk./Record/386089

\subsubsection{Uganda}

Department of Information (1961). Uganda Population Census 1959, Kampala. bttps:// library.soas.ac.uk/Record/589908

FAO (2017). Economically Active Population in Agriculture, FAOSTAT

ILO(2016). Key Indicators of the Labor Market (KILM), Ninth Edition

ILO (1975). Yearbook of Labor Statistics, 1975

Langsland, B. W. (1974). Atlas of Population Census 1969 for Uganda. bttps:// library.soas.ac.uk/Record/341578

Minnesota Population Center (2017). Integrated Public Use Microdata Series, International: Version 6.5 [dataset]. Minneapolis, MN: University of Minnesota.

UBOS (1997-2016). Statistical Abstracts, 1997-2016 Issues. Uganda Bureau of Statistics bttp:// wmw.ubos.org/publications/statistical-abstract

UBOS (2016) The National Population and Housing Census 2014 - Main Report, Kampala, Uganda wmw.ubos.org/onlinefiles/uploads/ubos/NPHC/2014\%20National\%20Census\%20Main\%20Report.pdf

UBOS (1994). The 1991 Population and Housing Census. National Summary. Statistics Department, Ministry of Finance and Economic Planning, Entebbe, Uganda 
UBOS (1980). Population Census, 1980. Statistics Department, Ministry of Finance, Planning and Economic Development. $\quad$ http:// mww.ubos.org/unda/ index.php/catalog/29\#page=accesspolicy \&otab=studydesc

UBOS (1964). 1962 Statistical Abstract. Statistics Branch, Ministry of Economic Affairs, Entebbe.

UBOS (1964). The Real Growth of the Economy of Uganda, 1954-1962. Statistics Division, Ministry of Planning and Community Development.

UNECA (1974- 88/89). Africa Statistical Yearbooks Part III: Eastern and Southern Africa. 1974, 1975, 1980, 1985, 1986, 1987, and 1988/89 Issues https:// library.soas.ac.uk/Record/386089

UNSD (1970-2005). UN Yearbook of National Accounts Statistics, 1964-2000 Publications https://library.soas.ac.uk/Record/299769

UNSD (2017), UN National Accounts Official Country Data. United Nations Statistical Division http://data.un.org/Data.aspx?d=SNA\&f=group code\%3a201 


\section{Chapter 3. Structural Change, Productivity Growth and Labor Market Turbulence in Africa ${ }^{66}$}

\footnotetext{
66 This chapter is based on Mensah, E. B., Owusu, S., Foster-Mcgregor, N., \& Szirmai, A. (2018). "Structural Change,
} Productivity Growth and Labor Market Turbulence in Sub-Saharan Africa”. 


\subsection{Introduction}

Interest has recently been renewed in the role that structural change plays in the development experiences of countries (e.g., McMillan \& Rodrik, 2011). Numerous reasons for this interest exist, with the evidence of premature deindustrialization suggesting that the role of manufacturing as a driver of long-run development is diminishing. Structural shifts to other sectors, such as modern services, are seen by some to be an alternative to a manufacturing-based development strategy (Connell, 2014; Hallward-Driemeier \& Nayyar, 2018; Newfarmer, Page, \& Tarp, 2018; Lavopa and Szirmai, 2018).

Despite Africa being among the fastest-growing regions in the world in recent decades, these concerns about the role of economic structure for development are particularly acute in the case of Africa. One reason for this is that the continent depends heavily on the production and export of primary commodities. As a result, many African countries are vulnerable to fluctuations in commodity prices (UNECA, 2016). This has raised questions about the sustainability of the recent growth performance and of the ability of this growth to eliminate poverty on the continent. It has been argued that for this recent growth to be sustainable, African countries must actively create unique pathways of structural transformation that involve diversification, export competitiveness, technological upgrading, and improvements in human wellbeing (ACET, 2014). The key concern is whether this rapid growth is underpinned by growth-enhancing changes in the production structure, technological dynamism, and job creation. A further concern is that the process of deindustrialization has set in very early in the case of Africa, with certain services sectors particularly non-tradable services that are often associated with high levels of informal employment - having grown relatively rapidly at the expense of manufacturing.

Starting from the work of McMillan \& Rodrik (2011), a number of studies have examined the role of structural change in fostering economic growth in Africa. Later studies by de Vries et al. (2013, 2015) show that after independence, African countries moved resources towards manufacturing industries, but that this process stalled from 1975 onwards before rebounding in the 1990s. Despite the renewed shift towards manufacturing in this latter time period, labor was mostly relocated to informal trading activities. These services are neither tradable nor technologically dynamic (Rodrik, 2016), and as a result, their productivity levels lag behind other sectors' productivity. McMillan et al. (2014) find that the reallocation of workers across sectors was growth-reducing in the 1990s but growth-promoting in the 2000s, and that this improved performance in the 2000s may be more sustainable due to an expansion of the manufacturing sector.

These studies - and others - focus on the relationship between the extent of structural change and productivity growth, which further implies that the direction of structural change is also relevant (i.e., a shift towards or away from high productivity sectors). In these studies, a finding that structural change has led to higher productivity growth is considered to be a case of successful structural change. While the above studies indicate that structural change has been an important phenomenon in the productivity growth of Africa, its impact on other outcomes - most notably labor market outcomes - are less well known. Indeed, these studies tend to ignore the impact of structural changes on other features of the economy, with its impact on labor markets, and labor market volatility in particular, being an important omission. While structural change may enhance aggregate productivity, there is also the possibility that it helps generate transitory unemployment and may lead to a reallocation of workers to lower-paid jobs or into the informal sector, leading to increased uncertainty for workers.

In this chapter, we provide a fuller picture of the role of structural change in economic performance by combining an analysis of the impact of structural change on productivity growth with an analysis of the impact of structural change on labor market outcomes. The chapter 
contributes to the literature in three important ways, which are discussed in the following paragraphs.

The first contribution relates to the use of new sectoral indicators. A shortcoming of much of the literature on structural change is the lack of long time-series on economic structure for a relatively large number of countries. McMillan \& Rodrik (2011), for example, address this problem by constructing sectoral data from 1990 to 2005, but this period misses important development episodes, especially the import-substitution era and the lost decades. ${ }^{67} \mathrm{~A}$ more comprehensive attempt was presented by the Africa Sector Database (ASD), developed by the Groningen Growth and Development Centre (GGDC), which provides long-run sectoral data for 11 African countries from the 1960s to 2010. The database is constructed on the basis of an in-depth study of available statistical sources on a country by country basis (De Vries et al., 2013). These contributions are limited in terms of the number of African countries for which data are available however, with the included countries also tending to be the relatively rich countries within Africa. Moreover, since the construction of the ASD, there has been a wave of statistical reforms in some of the countries in the ASD, leading to significant revaluations of GDP. These reforms have provided a clearer picture of the size and structure of production of the countries involved (Sy, 2015). For example, in 2014, Nigeria revised its GDP estimates and recalculated historical data back to 1981, which resulted in Nigeria being classified as a service-based economy (and not an industry-based economy as the original ASD suggests). In this chapter we use the extended database constructed in Chapter 2, which includes data for seven relatively poor African countries: Burkina Faso, Cameroon, Lesotho, Mozambique, Namibia, Rwanda and Uganda, thus addressing a criticism of existing studies that they are biased towards richer African countries (Diao et al., 2017:427).

Using the extended database, we repeat and update the structural decompositions of McMillan et al. (2014) and de Vries et al. (2015), further considering the changing importance of structural change as a driver of productivity growth over time. The results indicate that, despite differences across country groups and across time, structural change has played an important role in driving the observed growth of labor productivity within Africa, particularly in East Africa, where structural change accounted for more than half of all productivity growth.

The second contribution of the chapter is to consider whether structural change within Africa is associated with labor market turbulence. While structural change is found to have been productivity-enhancing, there has been a strong shift towards services, which may have important implications for labor market outcomes. As such, we construct various indicators of labor market turbulence and show that the effect of structural change on labor markets has been felt most strongly in the services sector, where employment has been subject to large fluctuations. Because of the labor-intensive and weather-dependent nature of agriculture, jobs are relatively stable but less productive, penalizing overall labor productivity in Africa.

The third contribution of the chapter is to consider the determinants of labor market turbulence, and whether the presence of labor market rigidities can limit the extent of labor market turbulence in Africa. Given the observed increase in labor market turbulence, we consider whether there are policy responses that may alleviate the impact of recent structural changes on labor market turbulence. Lilien (1982) argues that sectoral shifts are the main culprits behind the 1970s unemployment fluctuations in the US because labor market frictions prevented displaced workers from immediately relocating from shrinking sectors to expanding sectors. It has been found that strict national employment protection legislation on regular contracts in the European Union adversely affects the net reallocation of workers to the services sector (D'Agostino, Serafini, \&

${ }^{67}$ In this work 'lost decades' is defined as the period between 1975-1990. 
Ward-Warmedinger, 2006). McMillan et al. (2014:12) also find that the rate of labor productivity growth due to structural change is directly related to the degree of labor market flexibility. More flexible labor markets facilitate rapid structural change. Based upon these findings, we empirically examine the effect of labor market flexibility on labor market turbulence in Africa. Our findings indicate that a high level of Employment Protection Legislation (EPL) is associated with lower levels of job reallocation, which, on the one hand, makes it more difficult for countries to reallocate surplus labor to sectors where they could be more productive, but, on the other hand, may provide more job security and certainty for workers.

The remainder of the chapter is organized as follows: Section 3.2. reports descriptive statistics and long run stylized facts on sectoral development in Africa; Section 3.3 discusses the methodology and results of the productivity growth decomposition; Section 3.4 and 3.5 describes the result of the analysis of labor market turbulence and the effect of labor market flexibility on such turbulence; Section 3.6 concludes.

\subsection{Stylized facts on sectoral development in Africa}

The summary statistics presented in this section are based on the Expanded Africa Sector Database (EASD). The EASD updates and extends the Africa Sector Database constructed at the GGDC. It covers measures of output and employment for 18 African countries at the 10-sector level, usually from the 1960s to 2015 (see Chapter 2 for more details). Table 3.1 reports information using the EASD on the shares of employment by sector for the set of African countries as a whole. The table reveals that Africa remains predominantly agrarian. While the agricultural employment share decreased from $71.9 \%$ in 1960 to $49.4 \%$ in 2015, this share is still 13 percentage points higher than the next largest sector, services. The primary beneficiary of the reallocation of these workers has been the services sector rather than the industrial sector (see De Vries et al., 2015; Rodrik et al., 2017). Of the $22.5 \%$ of the labor force that moved from agriculture during the period 1960 2015, the services sector received $19.1 \%$ and the industrial sector just 3.3\%. Although the manufacturing share in total employment increased from 5.0\% in 1960 to $7.6 \%$ in 2015, this change was not as rapid as the change in domestic trade services, which more than doubled within the same period.

Table 3.1 Sectoral Employment Shares

\begin{tabular}{lcccccc}
\hline & \multicolumn{5}{c}{ Sectoral Employment Shares (in percent) } \\
Sector & 1960 & 1975 & 1990 & 2000 & 2010 & 2015 \\
\hline Agriculture & $\mathbf{7 1 . 9}$ & $\mathbf{6 9 . 6}$ & $\mathbf{6 4 . 8}$ & $\mathbf{6 0 . 2}$ & $\mathbf{5 3 . 4}$ & $\mathbf{4 9 . 4}$ \\
Industry & $\mathbf{1 0 . 8}$ & $\mathbf{1 0 . 2}$ & $\mathbf{1 1 . 2}$ & $\mathbf{1 1 . 1}$ & $\mathbf{1 2 . 5}$ & $\mathbf{1 4 . 2}$ \\
Manufacturing & 5.0 & 5.5 & 6.4 & 6.8 & 7.4 & 7.6 \\
Mining & 2.9 & 1.4 & 1.3 & 0.9 & 1.1 & 1.5 \\
Utilities & 0.3 & 0.4 & 0.4 & 0.4 & 0.4 & 0.5 \\
Construction & 2.7 & 2.9 & 3.1 & 3.1 & 3.6 & 4.6 \\
Services & $\mathbf{1 7 . 3}$ & $\mathbf{2 0 . 2}$ & $\mathbf{2 4 . 0}$ & $\mathbf{2 8 . 7}$ & $\mathbf{3 4 . 1}$ & $\mathbf{3 6 . 4}$ \\
Market Services & 9.7 & 8.7 & 11.7 & 15.5 & 21.4 & 23.4 \\
Trade, Restaurant and Hotels & 7.3 & 6.0 & 8.5 & 11.0 & 15.2 & 16.7 \\
Transport, Storage and Communications & 1.8 & 2.0 & 2.0 & 2.4 & 3.0 & 3.0 \\
FIRBS & 0.6 & 0.7 & 1.2 & 2.1 & 3.2 & 3.8 \\
Non-Market Services & 7.5 & 11.5 & 12.3 & 13.1 & 12.8 & 13.0 \\
Government Services & 4.4 & 5.3 & 6.3 & 7.0 & 7.1 & 7.0 \\
Community, Social and Personal Services & 3.1 & 6.2 & 6.0 & 6.2 & 5.6 & 6.0 \\
\hline
\end{tabular}


Note: this table reports the share of total employment by sector for Africa. These percentages are unweighted averages of the 18 countries included in EASD. FIRBS stands for financial, real estate and business services.

Table 3.2 reports sectoral relative productivity levels for the aggregate of African countries, constructed from the EASD as the ratio of each sector's labor productivity to total economy labor productivity. Several patterns are immediately obvious. Despite advances in agricultural technology, relative productivity in agriculture has remained largely unchanged since independence, with average productivity in agriculture being $40 \%$ of the average productivity of the whole economy. Relative productivity in all other sectors is above one, with productivity in industry tending to be larger than that in services.

Table 3.2 : Relative Productivity in Africa

\begin{tabular}{lcccccc}
\hline & \multicolumn{5}{c}{ Relative Productivity Levels } \\
Sectors & $\mathbf{1 9 6 0}$ & $\mathbf{1 9 7 5}$ & $\mathbf{1 9 9 0}$ & $\mathbf{2 0 0 0}$ & $\mathbf{2 0 1 0}$ & $\mathbf{2 0 1 5}$ \\
\hline Agriculture & $\mathbf{0 . 4}$ & $\mathbf{0 . 4}$ & $\mathbf{0 . 4}$ & $\mathbf{0 . 4}$ & $\mathbf{0 . 4}$ & $\mathbf{0 . 4}$ \\
Industry & $\mathbf{8 . 7}$ & $\mathbf{7 . 5}$ & $\mathbf{1 0 . 1}$ & $\mathbf{8 . 2}$ & $\mathbf{6 . 9}$ & $\mathbf{5 . 7}$ \\
Mining & 14.2 & 14.2 & 22.9 & 13.4 & 8.9 & 7.4 \\
Manufacturing & 2.5 & 2.7 & 3.0 & 3.2 & 2.4 & 2.3 \\
Utilities & 9.6 & 7.0 & 10.5 & 13.0 & 14.0 & 10.8 \\
Construction & 8.5 & 6.1 & 4.1 & 3.1 & 2.3 & 2.5 \\
Services & $\mathbf{5 . 7}$ & $\mathbf{5 . 2}$ & $\mathbf{5 . 0}$ & $\mathbf{4 . 1}$ & $\mathbf{3 . 9}$ & $\mathbf{3 . 2}$ \\
Market Services & 8.2 & 7.5 & 6.9 & 5.6 & 5.4 & 4.4 \\
Trade, Restaurants and Hotels & 8.4 & 4.6 & 2.7 & 1.9 & 1.2 & 1.2 \\
Transport, Storage and Communication & 6.7 & 5.2 & 5.6 & 5.3 & 5.3 & 5.1 \\
FIRBS & 9.6 & 12.7 & 12.6 & 9.8 & 9.7 & 6.9 \\
Non-Market Services & 2.0 & 1.8 & 2.1 & 1.8 & 1.6 & 1.4 \\
Government Services & 2.5 & 2.6 & 2.9 & 2.5 & 2.1 & 2.0 \\
Community, Social and Personal Services & 1.4 & 1.0 & 1.2 & 1.1 & 1.0 & 0.8 \\
\hline
\end{tabular}

Notes: Authors' calculation based on the Expanded Africa Sector Database (EASD). Relative productivity equals the ratio of each sectors output per worker to the output per worker of the whole economy. The figures are unweighted averages of the 18 countries included in EASD. FIRBS stands for financial, real estate and business services.

Within services, a number of sub-sectors perform relatively well however, the major example being FIRBS (Finance, Insurance, Real Estate, and Business Services). Within industry, productivity is relatively high in the capital-intensive mining sector and to a lesser extent in utilities, with manufacturing productivity being significantly lower than in these two sectors. Relative productivity in manufacturing increased from 2.5 to 2.7 during the golden era of industrialization despite the expansion in employment shares over this period, and further increased during the 1980s and 1990s, but its relative productivity level in 2015 was below that achieved in 1960. Overall, the table reveals large productivity differences across sectors. In 2015, the industrial sector was about 14 times more productive than the agricultural sector and 5.7 times more productive than the whole economy. The services sector is on average 8 times more productive than the agricultural sector and about 3 times more productive than the economy as a whole. These productivity gaps have persisted since the 1960s and, while falling over time, remain large. This is indicative of the allocative inefficiency that penalizes overall labor productivity in Africa (McMillan et al., 2014). 


\subsection{Productivity Growth Decomposition}

Though the sectoral productivity gaps observed in Table 2 reflect duality and allocative inefficiencies, as emphasized by Lewis (1954), their presence could also be a potential source of productivity growth as workers move from less productive sectors such as agriculture to more productive sectors such as manufacturing and market services. We therefore employ the wellknown productivity growth (shift-share) decomposition to study the productivity growth implications of structural change in the African economy. To begin, let $Y_{t}$ and $E_{t}$ be the total level of output (or value added) and total employment at time $t$ respectively. Economy-wide labor productivity $y_{t}$ is given as:

$$
y_{t}=Y_{t} E_{t}=\sum_{i=1}^{N} y_{i t} s_{i t}
$$

where $y_{i t}$ is labor productivity of sector $i$ in time $t, s_{i t}$ is the sectoral share of employment for sector $i$ at time $t$, and $N$ is the number of sectors. Given the above, the growth rate of economywide labor productivity between time $(T)$ and $(0)$ can be expressed as:

$$
\dot{y}=\frac{\Delta y}{y_{0}}=\sum_{i=1}^{N}\left[\frac{y_{i T}-y_{i 0}}{y_{0}}\right] s_{i 0}+\sum_{i=1}^{N}\left[\frac{\left.s_{i T}-s_{i 0}\right)}{y_{0}}\right] y_{i 0}+\sum_{i=1}^{N}\left[\frac{\left(s_{i T}-s_{i 0}\right) \times\left(y_{i T}-y_{i 0}\right)}{y_{0}}\right]
$$

The first component on the right-hand side is the sum of each sector's within-sector labor productivity growth rate, weighted by the sector's initial labor share in the economy. In other words, it is that part of overall productivity growth caused by productivity growth within sectors. The final two terms capture the structural change or between effect. The second term is the static reallocation effect, which measures the part of productivity growth arising from changes in the sectoral composition of employment. It captures whether workers move to above-average productivity sectors. The third term - the interaction/dynamic reallocation effect-measures the joint effect of changes in employment shares and sectoral productivity. It captures whether productivity growth is higher in sectors that are expanding in terms of employment shares. It is positive when labor move from sectors with lower productivity growth to sectors with higher productivity growth.

Our approach mimics the standard shift-share method (see Fabricant, 1942; Sánchez \& Roura, 2009; Timmer and Szirmai, 2000; De Vries et al., 2015; Rodrik \& McMillan, 2011), albeit with the introduction of a referenced or economy-wide productivity level, $y^{0}$ (Griliches \& Regev 1995). The introduction of the referenced economy-wide productivity level helps to identify which of the sectors are contributing positively or negatively to the static shift effect. At the aggregate level, however, the sum of these positive and negative effects is the same as the unreferenced version.

Table 3.3 reports the results from the shift-share analysis described above. The table reports the weighted average productivity growth of the sample of 18 African countries. The weights used to compute the indicative regional productivity are the total employment of each country since our measure of productivity reflects GDP per worker and not GDP per capita. From 1960 to 2015, weighted average labor productivity grew by $1.8 \%$ per annum, which is low when compared with the Asian annual average of $3.73 \%$ reported in Timmer et al (2014). Of this $1.8 \%$, productivity growth within sectors accounted for 0.9 percentage point with structural change accounting for 0.9 percentage point. For the entire period therefore, structural change has been growthenhancing, though in the context of weak productivity performance. This is obvious from the fact that the agricultural share of employment has fallen from $71.9 \%$ to $49.4 \%$, the primary beneficiary 
being the service sector which is about 11 times more productive than the agricultural sector for the entire period. Our findings of growth enhancing structural change contradict those of McMillan and Rodrik (2014) to some extent, with these authors concluding that structural change was growth retarding in the 1990 s at least.

We further divide the whole period into historical development episodes, namely: the import substitution era (1960-1975), the lost decades (1975-1990), the post structural adjustment era (1990-2000), and the recent or MDGs era (2000-2015). The whole period is divided according to the centrality of industrialization within the prevailing national development strategy. Whilst the import substitution era saw the projection and promotion of industrialization, the lost decades and the structural adjustment era have seen the marginalization of industrial development in favor of liberalization and privatization. However, since the failure of the structural adjustment programs, industrial policy has been part of national development strategies developed around the MDGs since the early 2000s.

There were static gains and dynamic losses from structural change throughout the different development epochs, confirming the empirical findings of de Vries et al (2015). While the service sector as a whole is more productive than the agricultural sector, the beneficiary of the reallocation is mostly trade services which have productivity levels far below modern market services and manufacturing, though still higher than agriculture. Whether structural change is growthenhancing or growth-reducing depends on the structural balance i.e. the sum of static gains and dynamic losses. Throughout the different periods, structural change has been growth-enhancing. Even during the lost decades when productivity growth was very low at $0.1 \%$, structural change contributed $0.4 \%$ to productivity growth. The political turmoil and adverse economic conditions during the lost decades heavily impeded industrial innovation and technology adoption, and as a result within sectoral productivity declined by $0.3 \%$ per annum. In the other periods, within sector productivity growth contributed significantly and positively to total productivity growth.

Table 3.3: Decomposition of Labor Productivity Growth in Sub-Sabaran Africa

\begin{tabular}{lcccccc}
\hline & Period & $\begin{array}{c}\text { Total } \\
\text { Productivity } \\
\text { Growth }\end{array}$ & Within & $\begin{array}{c}\text { Between } \\
\text { Static }\end{array}$ & $\begin{array}{c}\text { Between } \\
\text { Dynamic }\end{array}$ & $\begin{array}{c}\text { Structural } \\
\text { Change }\end{array}$ \\
\hline Entire Period & $1960-2015$ & $1.8 \%$ & $0.9 \%$ & $1.1 \%$ & $-0.2 \%$ & $0.9 \%$ \\
Import Substitution & $1960-1975$ & $2.1 \%$ & $1.2 \%$ & $1.2 \%$ & $-0.2 \%$ & $0.9 \%$ \\
Lost Decades & $1975-1990$ & $0.1 \%$ & $-0.3 \%$ & $0.5 \%$ & $-0.1 \%$ & $0.4 \%$ \\
Post SAP & $1990-2000$ & $1.4 \%$ & $0.5 \%$ & $1.0 \%$ & $-0.1 \%$ & $0.7 \%$ \\
MDGs & $2000-2015$ & $3.6 \%$ & $2.4 \%$ & $1.5 \%$ & $-0.3 \%$ & $1.2 \%$ \\
\hline
\end{tabular}

Source: Authors computations based on the Expanded Africa Sector Database. The sum of the within and structural change equals total productivity. Structural change is the sum of the static reallocation and dynamic reallocation.

The period between 1960 and 1975 - the import substitution era - has been described as the golden age of Africa's growth performance, with productivity growth of $2.1 \%$ and an annual average GDP growth rate of $6 \%$. This was followed by disappointing growth across the region, chiefly attributed to the 1970 oil crisis, currency instability, political upheavals witnessed across the region from the mid-1970s and the cumulative effect of inefficiencies and distortions introduced during the import-substitution period (Ellis, 2002). Productivity growth steadily picked up after the implementation of Structural Adjustment Programs. The recent data show that the import substitution era is no more the golden era of Africa's development. We observe the highest rates of productivity growth - around 3.6\% - during the MDGs era. The 3.6\% growth rate is chiefly 
driven by the weights of Nigeria and Ethiopia, the two most populous countries in Africa - with a combined average employment share of $42.5 \%$ during the MDGs era - whose productivity grew by $5.3 \%$ and $5.4 \%$ per annum respectively during the same period. Despite the expanded sample, the results reported using the EASD compare well with the estimates of de Vries et al (2015).

These general observations differ by country. The weighted annual average growth rates of labor productivity show that East Africa grew by $1.3 \%$ per annum, southern Africa by $1.6 \%$ and West Africa $^{68}$ by $2.6 \%$ from 1960 to 2015 .

Figures 3.1, 3.2 and 3.3 show labor productivity growth for the three regions and for the countries within each of these regions. In West Africa, significant productivity growth comes from within sector productivity growth. This is the case for the five countries studied in the region. In Ghana and Nigeria, $100 \%$ and $80 \%$ respectively, of average productivity growth comes from within-sector productivity growth. In Francophone West Africa, structural change tends to play a more significant role in the growth process, but within-sector growth still dominates. In Burkina Faso and Cameroon, a little over half of average productivity growth comes from within-sector productivity. Structural change tends to be growth-enhancing but within sector productivity changes tend to be growth-reducing in Senegal, resulting in low aggregate productivity growth. The strongest productivity growth in this region is found in Nigeria. This is driven by the $4.6 \%$ productivity growth rate during the import substitution era (1960-1975) and the 5.3\% growth rate in the MDGs era (2000-2015). ${ }^{69}$

In East Africa, structural change contributed more to labor productivity growth than within sector productivity in five out of the six countries studied. In Ethiopia, Tanzania, and Uganda almost all the productivity gains were due to the movement of workers from low productivity to high productivity sectors. This arises due to regional specialization patterns. In addition to the traditional primary products exported by most African countries, East African countries are specialized in services where jobs are currently being reallocated, most notably travel, tourism, and transport services. ${ }^{70}$ Conversely, West and southern African countries are specialized in mining which is capital intensive, hence the high within effect. ${ }^{71}$

In the case of Rwanda more than half of the productivity gain is due to structural change. In Mauritius, structural change is growth-enhancing but within sector productivity growth is dominant. This latter result is not surprising given the relatively low share of agricultural employment in the country (see Diao et al., 2017). In Rwanda, productivity growth was negative during the lost decades, but robustly increased to 5.9\% during the MDGs era. The performance of Uganda was relatively poor, with productivity growth falling from $3.2 \%$ in the 1990 s to $-0.3 \%$ in the 2000s.

In southern Africa, within sector productivity contributes more to overall average productivity growth than structural change. However, individual country results are mixed. While structural change dominates in Lesotho and Malawi, within productivity growth dominates in Namibia and South Africa. Botswana is not only an outlier in this region but also in Africa. As is well-known productivity performance in the relatively advanced economy of South Africa is mediocre (Kaplan, 2015).

\footnotetext{
${ }^{68}$ Politically, Cameroon is not part of West Africa. It is part of Central Africa and shares a border with Nigeria but for convenience we added Cameroon to the group of countries that are politically part of West Africa.

${ }^{69}$ See Table A4 in the online Appendix for full results.

${ }^{70}$ Except Ethiopia which has coffee as its major exports in 2015.

${ }^{71}$ Except Malawi where $56 \%$ of their exports in 2015 is accounted for by Tobacco and structural change accounts for all productivity growth.
} 
Figure 3.1: Labor Productivity Growth in West Africa, 1960s-2015

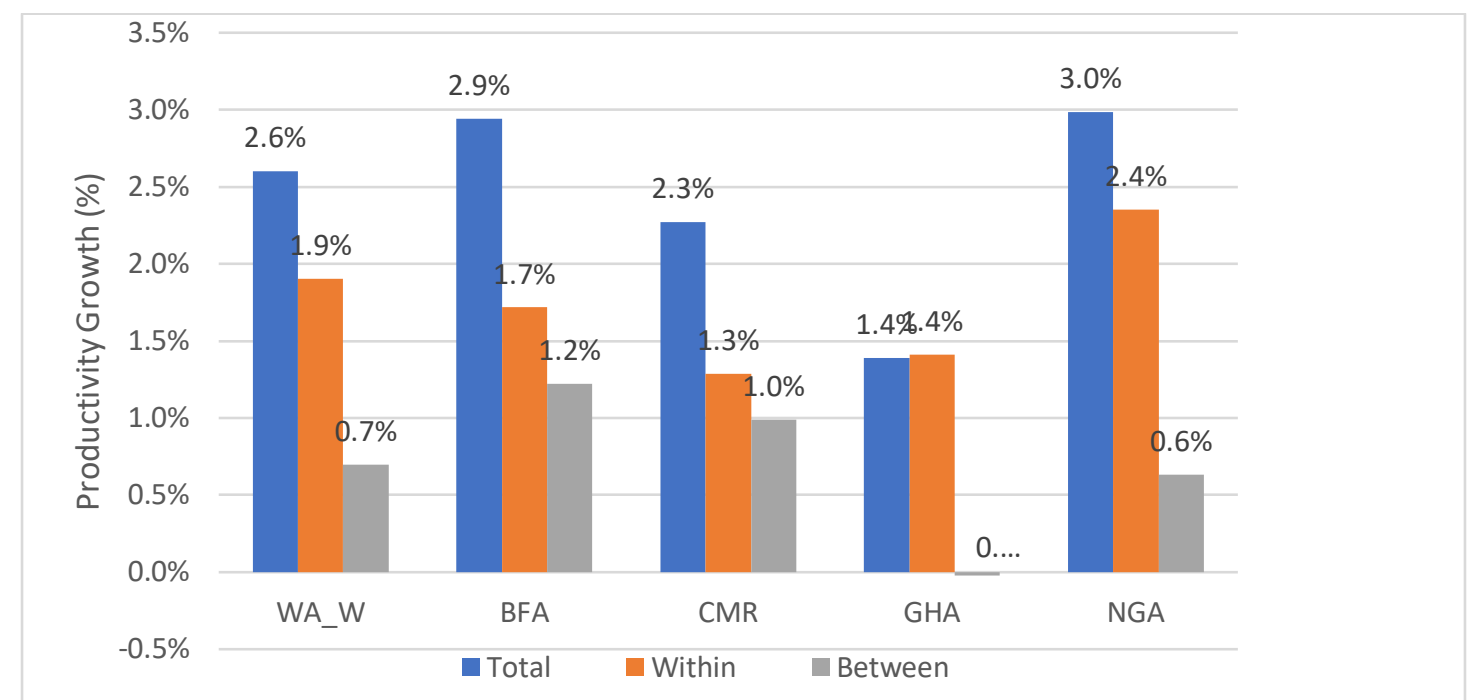

Note: WA_W is Weighted Average r, BFA is Burkina Faso, CMR is Cameroon, GHA is Ghana, NGA is Nigeria and SEN is Senegal.

Figure 3.2: Labor Productivity Growth in East Africa, 1960 s-2015

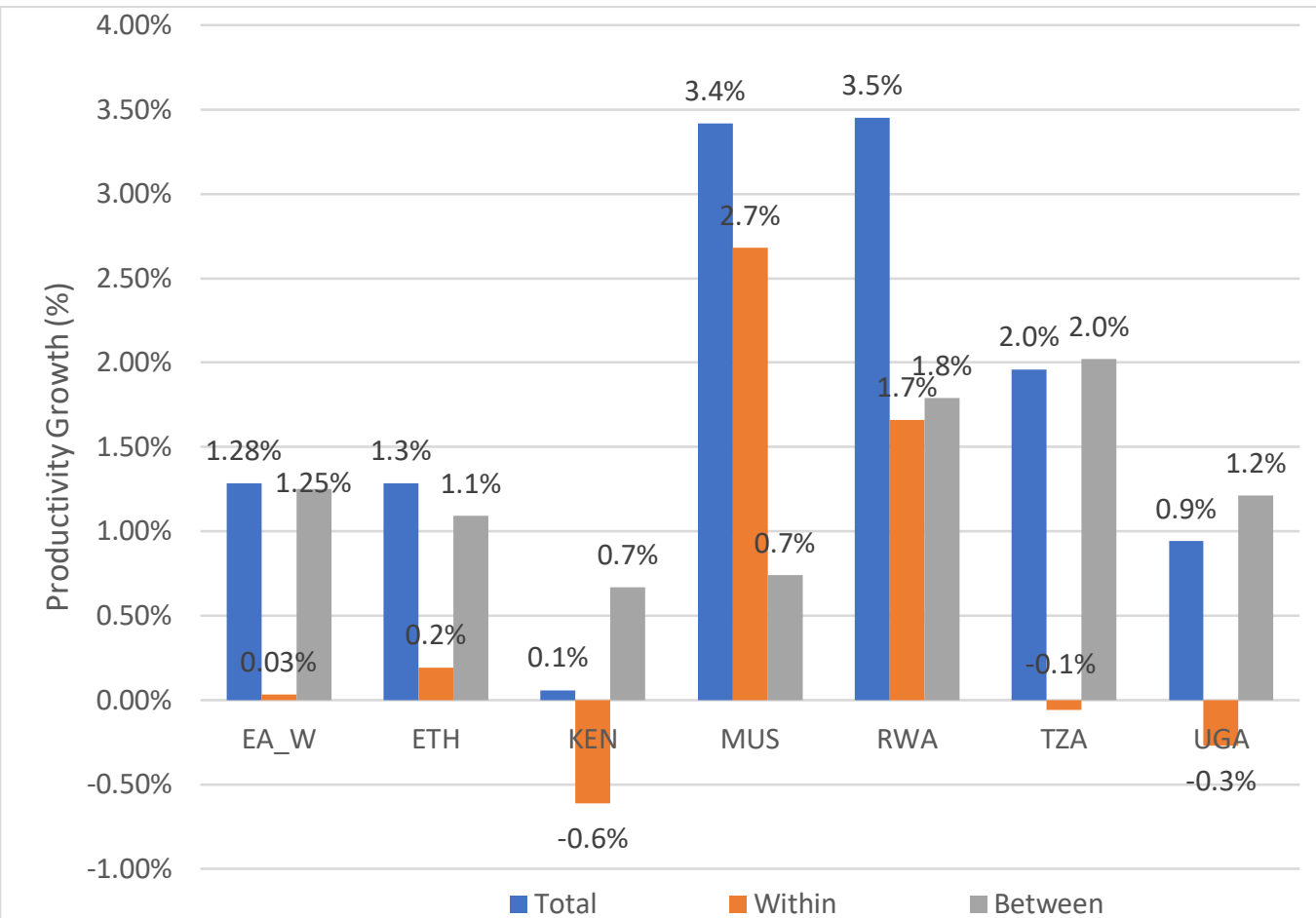

Note: EA_W is East Africa Weighted Average, ETH is Ethiopia, KEN is Kenya, MUS is Mauritius, RWA is Rwanda, TZA is Tanzania and UGA is Uganda. 
Figure 3.3 :Labor Productivity growth in Southern Africa, 1960s-2015

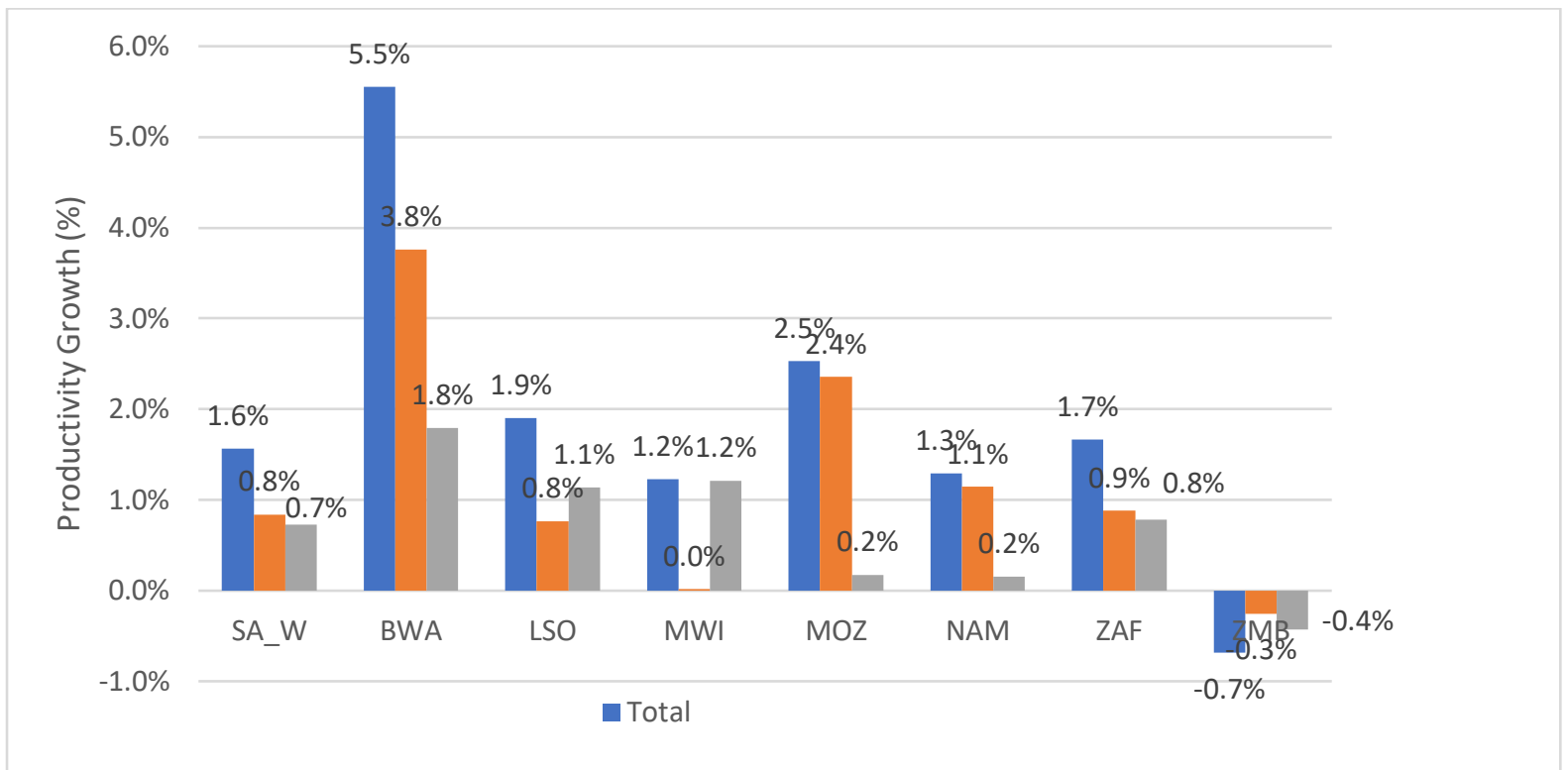

Note: SA_W is Southern Africa Weighted Average, BWA is Botswana, LSO is Lesotho, MWI is Malawi, MOZ is Mozambique, NAM is Namibia, ZAF is South Africa, and ZMB is Zambia.

\subsection{Sectoral Reallocation and Labor Market Turbulence (LMT) in Africa}

In the preceding section we established that structural change is an ongoing process in Africa, being more rapid in East Africa than in other parts of Africa. The contribution of structural change to productivity growth is however lower than the experience of East Asia, in which there was a similar employment shift (of about 16\%) from agriculture. Unlike the case of East Asia, where there was a shift towards manufacturing and high-tech services, in Africa there has been a strong shift towards lower paid jobs in services. Non-tradable services often associated with high levels of informality have grown relatively rapidly at the expense of tradable services and manufacturing. This may have important implications for labor market outcomes in Africa for several reasons. During structural transition, simultaneous job creation and job destruction could take place within narrowly defined industries or sectors (De Loecker \& Konings, 2006). This could impact employment stability and the protection of workers within these sectors. To this end, we argue that the study of structural change needs to move beyond the usual labor productivity decomposition towards examining empirical relationships between sectoral shifts and key labor market outcomes. However, most studies of structural change in Africa neglect this very important feature of structural change.

The effect of structural change on labor market outcomes such as the natural rate of unemployment and job mobility within and across sectors is well established in studies in advanced countries. Lilien (1982:777) argues that "most of the unemployment fluctuations of the seventies (unlike those in the sixties) were induced by unusual structural shifts within the U.S. economy". Diprete et al. (1997) argue that job mobility is induced by either structural change (collectivist regime) or individual decisions (individualistic regime). Testing the sensitivity of the job mobility rate to structural change and individual choices in the US, Germany, Netherlands and Sweden they 
conclude that "U.S. rates of job mobility showed the greatest sensitivity to structural change and to the labor market resources of individual workers" (Diprete et al., 1997:318). We fill this gap for Africa by examining the extent to which observed structural change within Africa is characterized by labor market turbulence. By analyzing turbulence in the labor market, we are able to identify sectors where the labor force is most affected as well as highlighting the differences that exist in the expanding and contracting sectors (Bachmann \& Burda, 2009).

To do this we estimate the labor turbulence effect of structural change in Africa appealing to the definition of Lilien (1982). The measures of job creation, job destruction and job reallocation follow Bartelsman (2013), Bartelsman et al. (2013), Davis et al (1996), and Haltiwanger et al (2014) and are given as follows:

$$
\text { Job Creation by sector: } J C_{i t}=\sum_{i \epsilon J} E W_{i t}\left(\Delta P E_{i t} / \overline{l_{l t}}\right)
$$

where $J C_{i t}$ is the job creation effect of sector $i$ (belonging to economy $j$ ) in year $t, \Delta P E_{i t}$ is the sum of positive employment changes (employment gains) in an expanding sector over time, $\overline{l_{l t}}$ is the sector's average employment over time and is given by $\overline{l_{l t}}=0.5\left(l_{i T}+l_{i 0}\right)$, and $E W_{i t}$ is the sector employment weight and is given by the average or mean employment of sector $i$ divided by the average employment of the aggregated economy $j$ it belongs: $\left(E W_{i t}=\overline{L_{l t}} / \overline{L_{\jmath t}}\right)$.

$$
\text { Job Destruction by sector: } J D_{i t}=\sum_{i \epsilon J} E W_{i t}\left(\Delta N E_{i t} / \overline{l_{l t}}\right)
$$

where $J D_{i t}$ is the job destruction effect of sector $i$ (belonging to the economy $j$ ) in year $t$, and $\Delta N E_{i t}$ is the sum of the negative employment changes (employment losses in absolute value) in a contracting sector over time.

The difference between $J C_{i t}$ and $J D_{i t}$ is Net Employment Growth, which shows the total employment change and is given by: $N E G_{i t}=J C_{i t}-J D_{i t}$.

The sum of $J C_{i t}$ and $J D_{i t}$ is the Gross Job Reallocation rate, and measures the rate at which employment positions are reallocated across sectors and is given by: $G J R_{i t}=J C_{i t}+J D_{i t}$.

Excess Job Reallocation is the difference between the gross job reallocation rate and the absolute value of net employment growth. It is a measure of job reallocation which is in excess of the amount of job reallocation necessary to accommodate a given net employment growth rate (Masso et al., 2005; De Loecker \& Konings, 2006). Such a measure indicates the magnitude of deep restructuring that needs to take place in order to accommodate a given aggregate employment growth rate (De Loecker \& Konings, 2006) and is given by:

$$
E J R_{i t}=J C_{i t}+J D_{i t}-\left|N E G_{i t}\right|
$$

The average yearly Job Creation and Job Destruction rate is the sum of the positive and negative employment changes (employment losses in absolute value-levels) respectively in an expanding and a contracting sector divided by the number of years considered.

Further to this, we assess the dispersion in employment growth using the Lilien Index given by:

$$
3.6 L M T_{j t}=\left[\sum_{i=1}^{k} s_{i t}\left(\varpi_{i t}-\varpi_{j t}\right)^{2}\right]^{0.5}
$$

where $k$ is the number of (sub-)sectors, $s_{i t}$ is the share of the $i$ th sub-sector employment in total employment of the aggregated sector $j, \varpi_{i t}$ is the rate of growth of employment in the $i$ th subsector and $\varpi_{j t}$ is the rate of growth of employment in the $j$ th aggregated sector. The Lilien Index captures the structural shift of employment demand between sectors of the economy. This allows us to see which sectors of the economy experience high or low dispersion in employment growth overtime. 
The results of the $\mathrm{LMT}^{72}$ analysis are reported in Tables 3.4, 3.5, 3.6 and (A6 in the appendix), with Table 3.4 reporting results for job creation, job destruction and job reallocation for Africa as a whole and for the different regions of Africa (for comparison with the results from the shift-share decomposition above). Table 3.5 reports results from the Lilien index for each of the countries in our dataset and for both the total economy and for the aggregated sectors, agriculture, industry, and services. Finally, Table 3.6 reports the job creation, job destruction and job reallocation rates for Africa as a whole for the four different time periods used in the above analysis (i.e. the import substitution era, the lost decades, the post structural adjustment period, and the MDGs era).

\footnotetext{
72 This is a proxy measure of LMT at the aggregate level. The true measure of LMT are based on establishment or
} firm level data that tracks firm entry and exit in addition to job creation and job destruction in a given period. 
Table 3.4: Job Creation, Job Destruction and Job Reallocation in Sub-Sabaran Africa, 1960s-2015

\begin{tabular}{|lccccc|}
\hline \multicolumn{1}{|c}{ Africa (1960s-2015) } & & & & & \\
Sector & JC & JD & NEG & GJR & EJR \\
Agriculture & $1.2 \%$ & $0.3 \%$ & $1.1 \%$ & $1.5 \%$ & $0.4 \%$ \\
Mining & $0.0 \%$ & $0.0 \%$ & $0.0 \%$ & $0.1 \%$ & $0.0 \%$ \\
Manufacturing & $0.3 \%$ & $0.1 \%$ & $0.2 \%$ & $0.4 \%$ & $0.2 \%$ \\
Utilities & $0.0 \%$ & $0.0 \%$ & $0.0 \%$ & $0.0 \%$ & $0.0 \%$ \\
Construction & $0.1 \%$ & $0.1 \%$ & $0.0 \%$ & $0.2 \%$ & $0.2 \%$ \\
Trade services & $0.4 \%$ & $0.0 \%$ & $0.4 \%$ & $0.4 \%$ & $0.0 \%$ \\
Transport services & $0.1 \%$ & $0.0 \%$ & $0.1 \%$ & $0.1 \%$ & $0.0 \%$ \\
Business services & $0.1 \%$ & $0.0 \%$ & $0.1 \%$ & $0.1 \%$ & $0.0 \%$ \\
Government services & $0.2 \%$ & $0.0 \%$ & $0.2 \%$ & $0.3 \%$ & $0.1 \%$ \\
Personal services & $0.2 \%$ & $0.1 \%$ & $0.1 \%$ & $0.2 \%$ & $0.1 \%$ \\
Total Economy & $2.5 \%$ & $0.2 \%$ & $2.3 \%$ & $2.7 \%$ & $0.4 \%$ \\
\hline
\end{tabular}

\section{East Africa Average (1960s-2015)}

\begin{tabular}{llllll} 
Sector & JC & JD & NEG & GJR & EJR \\
Agriculture & $1.2 \%$ & $0.1 \%$ & $1.1 \%$ & $1.3 \%$ & $0.2 \%$ \\
Mining & $0.0 \%$ & $0.0 \%$ & $0.0 \%$ & $0.0 \%$ & $0.0 \%$ \\
Manufacturing & $0.3 \%$ & $0.1 \%$ & $0.2 \%$ & $0.4 \%$ & $0.2 \%$ \\
Utilities & $0.0 \%$ & $0.0 \%$ & $0.0 \%$ & $0.0 \%$ & $0.0 \%$ \\
Construction & $0.1 \%$ & $0.0 \%$ & $0.1 \%$ & $0.2 \%$ & $0.1 \%$ \\
Trade services & $0.4 \%$ & $0.0 \%$ & $0.4 \%$ & $0.4 \%$ & $0.0 \%$ \\
Transport services & $0.1 \%$ & $0.0 \%$ & $0.1 \%$ & $0.1 \%$ & $0.0 \%$ \\
Business services & $0.1 \%$ & $0.0 \%$ & $0.1 \%$ & $0.1 \%$ & $0.0 \%$ \\
Government services & $0.2 \%$ & $0.0 \%$ & $0.2 \%$ & $0.2 \%$ & $0.0 \%$ \\
Personal services & $0.1 \%$ & $0.0 \%$ & $0.1 \%$ & $0.2 \%$ & $0.0 \%$ \\
Total Economy & $2.6 \%$ & $0.1 \%$ & $2.5 \%$ & $2.6 \%$ & $0.1 \%$ \\
\hline
\end{tabular}

Agriculture

Mining

Manufacturing

Utilities

Construction

Trade services

Transport services

Business services

Government services

Personal services

Total Economy

\begin{tabular}{llrrr} 
JC & JD & NEG & GJR & EJR \\
$1.2 \%$ & $0.1 \%$ & $1.1 \%$ & $1.3 \%$ & $0.2 \%$ \\
$0.0 \%$ & $0.0 \%$ & $0.0 \%$ & $0.0 \%$ & $0.0 \%$ \\
$0.3 \%$ & $0.1 \%$ & $0.2 \%$ & $0.4 \%$ & $0.2 \%$ \\
$0.0 \%$ & $0.0 \%$ & $0.0 \%$ & $0.0 \%$ & $0.0 \%$ \\
$0.1 \%$ & $0.0 \%$ & $0.1 \%$ & $0.2 \%$ & $0.1 \%$ \\
$0.4 \%$ & $0.0 \%$ & $0.4 \%$ & $0.4 \%$ & $0.0 \%$ \\
$0.1 \%$ & $0.0 \%$ & $0.1 \%$ & $0.1 \%$ & $0.0 \%$ \\
$0.1 \%$ & $0.0 \%$ & $0.1 \%$ & $0.1 \%$ & $0.0 \%$ \\
$0.2 \%$ & $0.0 \%$ & $0.2 \%$ & $0.2 \%$ & $0.0 \%$ \\
$0.1 \%$ & $0.0 \%$ & $0.1 \%$ & $0.2 \%$ & $0.0 \%$ \\
$2.6 \%$ & $0.1 \%$ & $2.5 \%$ & $2.6 \%$ & $0.1 \%$ \\
\hline
\end{tabular}

ote: Note: JC = job creation; JD = job destruction; NEG = net employment growth; GJR = gross job reallocation; EJR = Excess job reallocation. Relative contributions to the economy are calculated by dividing the variables by corresponding total economy values. West Africa Average for Burkina Faso, Cameroun, Ghana, Nigeria, and Senegal. East Africa Average for Ethiopia, Kenya, Mauritius, Rwanda, Tanzania, and Uganda. Southern Africa for Botswana, Lesotho, Malawi, Mozambique, Namibia, South Africa, and Zambia.

\begin{tabular}{|lccccc|}
\hline West Africa Average (1960s-2015) & & & & \\
Sector & JC & JD & NEG & GJR & EJR \\
Agriculture & $1.3 \%$ & $0.5 \%$ & $0.8 \%$ & $1.8 \%$ & $1.0 \%$ \\
Mining & $0.0 \%$ & $0.0 \%$ & $0.0 \%$ & $0.0 \%$ & $0.0 \%$ \\
Manufacturing & $0.3 \%$ & $0.1 \%$ & $0.2 \%$ & $0.4 \%$ & $0.2 \%$ \\
Utilities & $0.0 \%$ & $0.0 \%$ & $0.0 \%$ & $0.0 \%$ & $0.0 \%$ \\
Construction & $0.1 \%$ & $0.0 \%$ & $0.1 \%$ & $0.1 \%$ & $0.0 \%$ \\
Trade services & $0.5 \%$ & $0.1 \%$ & $0.4 \%$ & $0.6 \%$ & $0.2 \%$ \\
Transport services & $0.1 \%$ & $0.0 \%$ & $0.1 \%$ & $0.1 \%$ & $0.0 \%$ \\
Business services & $0.0 \%$ & $0.0 \%$ & $0.0 \%$ & $0.0 \%$ & $0.0 \%$ \\
Government services & $0.1 \%$ & $0.0 \%$ & $0.1 \%$ & $0.1 \%$ & $0.0 \%$ \\
Personal services & $0.2 \%$ & $0.0 \%$ & $0.2 \%$ & $0.2 \%$ & $0.0 \%$ \\
Total Economy & $2.6 \%$ & $0.2 \%$ & $2.4 \%$ & $2.8 \%$ & $0.4 \%$ \\
\hline Southern Africa Average $\%$ & $(1960 s-2015)$ & & & &
\end{tabular}

\section{Southern Africa Average (1960s-2015)}

Sector

Agriculture

GJR

EJR

Mining

Manufacturing

Utilities

Construction

Trade services

Transport services

Business services

Government services

$\begin{array}{lllll}1.2 \% & 0.2 \% & 1.0 \% & 1.4 \% & 0.4 \%\end{array}$

$\begin{array}{lllll}0.1 \% & 0.1 \% & 0.0 \% & 0.2 \% & 0.2 \%\end{array}$

$\begin{array}{lllll}0.2 \% & 0.1 \% & 0.1 \% & 0.3 \% & 0.2 \%\end{array}$

$\begin{array}{lllll}0.0 \% & 0.0 \% & 0.0 \% & 0.0 \% & 0.0 \%\end{array}$

$\begin{array}{lllll}0.2 \% & 0.1 \% & 0.1 \% & 0.3 \% & 0.2 \%\end{array}$

$\begin{array}{lllll}0.4 \% & 0.1 \% & 0.3 \% & 0.5 \% & 0.2 \%\end{array}$

$\begin{array}{lllll}0.1 \% & 0.0 \% & 0.1 \% & 0.1 \% & 0.0 \%\end{array}$

\begin{tabular}{lllll}
$0.1 \%$ & $0.0 \%$ & $0.1 \%$ & $0.1 \%$ & $0.0 \%$ \\
\hline
\end{tabular}

\begin{tabular}{lllll}
$0.3 \%$ & $0.1 \%$ & $0.2 \%$ & $0.4 \%$ & $0.2 \%$ \\
\hline
\end{tabular}

\begin{tabular}{llllll} 
Total Economy & $2.4 \%$ & $0.2 \%$ & $2.2 \%$ & $2.6 \%$ & $0.4 \%$ \\
\hline
\end{tabular} 
Using the ten-sector dataset of the EASD, Table 3.4 shows that the annual job creation rate of the agriculture sector is 1.2 per cent, a figure that represents 48 per cent of the annual job creation rate in the region's economy over the period 1960s-2015. This is followed by the service sector (aggregating the different service sectors) with an annual job creation rate of 1 per cent, the manufacturing sector with a job creation rate of 0.3 per cent and the non-manufacturing industrial sector (mining, utilities and construction) with a creation rate of 0.1 per cent over the same period. Lewis (1954) argued that structural change, and the associated poverty reduction, is more rapid when agricultural transformation and industrialization occur together. Increasing labor productivity in agriculture implies that fewer jobs are created in the sector, and that as a result labor is released for off-farm economic activities. Industrial hubs or urban growth poles draw this released rural labor into productive use (rural push versus urban pull effects) (Barrett et al, 2017). In the case of Africa, agricultural productivity has remained unchanged since independence (Table 3.2), while at the same time the agricultural sector is creating more jobs despite reducing its valueadded share and shedding fewer workers (Table 3.4 and 3.6). Those workers that have moved have tended to move to the urban sector to engage in informal trading activities rather than to manufacturing. This is also true at the regional level where we observe the same trend. As a result, the rural push, urban pull effects suggested by Lewis (1954) and observed in East Asia in the last century are not observed in Africa, with rural stagnation and informal urban pull effects in Africa leading to a less productive structural transformation compared to the East Asian experience. This trend to some extent has contributed to the limited gains of structural change to productivity growth in the region over the period between 1960s-2015.

Job creation rates in general dominate job destruction rates in all sectors. The average annual job destruction rate in the agricultural sector is 0.3 per cent, considerably lower than the job creation rate. Though job creation is higher than job destruction, it is not sufficient, however, to accommodate the 11 million young workers expected to enter the labor market each year for the next decade in Africa (ILO, 2018).

Table 3.5: LMT (Lilien Index) Decomposition Results Africa (percentages), 1960-2015

\begin{tabular}{|l|cccc|}
\hline Country / Region & Total Economy & Agriculture & Industry & Services \\
\hline All Countries & 3.75 & 1.07 & 2.08 & 2.47 \\
Botswana & 7.72 & 2.47 & 4.97 & 4.61 \\
Burkina Faso & 2.39 & 1.06 & 1.64 & 1.24 \\
Cameroun & 1.13 & 0.36 & 0.35 & 0.99 \\
Ethiopia & 3.76 & 0.60 & 1.71 & 3.13 \\
Ghana & 4.87 & 0.86 & 2.76 & 3.34 \\
Kenya & 3.16 & 1.33 & 1.51 & 2.30 \\
Lesotho & 3.14 & 0.46 & 1.49 & 2.48 \\
Malawi & 4.58 & 0.93 & 2.43 & 3.40 \\
Mauritius & 6.01 & 1.85 & 4.08 & 3.47 \\
Mozambique & 1.84 & 0.46 & 1.26 & 1.09 \\
Namibia & 4.18 & 1.56 & 1.66 & 3.25 \\
Nigeria & 4.95 & 1.46 & 3.01 & 3.10 \\
Rwanda & 2.16 & 0.65 & 1.04 & 1.64 \\
Senegal & 2.96 & 0.85 & 1.66 & 2.15 \\
South Africa & 4.17 & 1.86 & 2.39 & 2.45 \\
Tanzania & 3.79 & 0.76 & 2.02 & 2.82 \\
Uganda & 2.63 & 0.78 & 1.00 & 2.19 \\
Zambia & 4.13 & 0.91 & 2.37 & 3.03 \\
\hline
\end{tabular}

Source: Authors computation based on the Expanded Africa Sector Database (1960-2015). 
Agriculture in Africa is predominantly subsistence based, highly reliant on nature and affected by natural disasters and drought. The relative stability of jobs in agriculture is further shown by the Lilien Index reported in Table 3.5. The dispersion of annual agricultural employment growth is $1.07 \%$ compared with $2.08 \%$ for industry and $2.47 \%$ for services. The sector remains one of the low productivity growth sectors because of its labor-intensive nature. Despite these results for Africa, we do however observe a relatively large (small) average JD (JC) rate and a negative NEG rate of the sector in countries such as Mauritius and South Africa signaling the significant positive structural change that these countries have achieved over the years as they have reallocated excess labor from the agricultural sector to more dynamic and productive sectors ${ }^{73}$. Excess job reallocation (EJR) in the agricultural sector, reported in Table 3.4, is 0.4 per cent, which is the highest of all the sectors reflecting significant underemployment within the agriculture sector. "It also signals the existence of barriers to more efficient allocation of factors of production" (Barrett et al., 2017:14). The underemployment of labor explains the large productivity gap between agriculture and modern market activities.

In the manufacturing sector, the average yearly JC rate is $0.3 \%$. At the same time, about one third of jobs created annually in the sector are on average destroyed between the 1960s and 2015. The sector recorded its highest annual job creation rate $(0.4 \%)$ during the import substitution era. The years from the 1980s through to the year 2000 saw a sizable job destruction rate in the African manufacturing sector and a decline in the job creation rate as can be seen in Table 3.6. De Loecker \& Konings (2006) find a similar result in many post-Soviet countries and attribute it to the downsizing that took place in the countries due to past labor hoarding in the sector. However, in Africa, this coincided with the economic and political crisis witnessed in the region, the introduction of structural adjustment programs and neoliberal policies during this period. In addition to this, and perhaps contributing to an explanation, there is evidence of global deindustrialization (Lavopa \& Szirmai, 2018) and premature de-industrialization in Africa, with many Africa countries reaching their peak and turning point of industrialization at a relatively low per capita income, a level that is a fraction of that at which the advanced economies started to deindustrialize (Cadot et al., 2015; Rodrik, 2015). This trend only reversed during the MDGs era (2000-2015) as the sector recorded an increase in job creation and a decline in job destruction (see Table 3.6). This also coincided with the period in which the region recorded its highest labor productivity growth, with the contribution of structural change to productivity growth increasing to 1.4 per cent (see table 3.3)

In the service sector, trade services generate the highest average annual job creation rate at 0.4 per cent, followed by government and personal services, with an annual job creation rate of 0.2 per cent. The lowest average annual JC rate in the sector is recorded in business services ( 0.1 per cent) over the period 1960s-2015, possibly as a result of the skilled-labor- and capital-intensive nature of the sector making it difficult for the sector to absorb labor released from the other sectors of the economy. As for the manufacturing sector, the highest average annual job creation in the sector, particularly in tradable services (trade, business), is recorded in the MDGs era (2000-2015), the period in which the region recorded its highest labor productivity growth. Overall, the rates of job creation are insufficient, however, to absorb a growing labor force.

The relative high pace of GJR (i.e. the sum of JC and JD) in the service sector, particularly, in trade services gives an indication of the high degree of volatility associated with vulnerable employment growth in the sector. The dispersion of annual employment growth in the sector is $2.47 \%$, the

\footnotetext{
${ }^{73}$ In Mauritius, the average yearly JC and JD rate in the agricultural sector is 0.2 per cent and 0.4 per cent respectively. Average yearly net employment growth of the sector is -0.2 per cent. In South Africa, the average yearly JC and JD rate in the agricultural sector is 0.4 per cent and 0.4 per cent respectively.
} 
highest among the three major sectors. Two factors could explain this. Firstly, the service sector faces high volatility ${ }^{74}$ in product demand in part as a result of rapid changes in fashion, tastes, lifestyles, and technological advancement which is increasingly changing the mode of production and delivery of services in the sector. Secondly, we could deduce that the trade and personal service sectors - where informality is high - seems to have a high GJR, which translates into relatively high fluctuations in employment growth.

Given the observed increased labor market turbulence in Africa, with more jobs created in the low productivity and productivity resistant agricultural sector and in informal, vulnerable low paid jobs in non-tradable services, we further consider whether there are policy responses that may alleviate the impact of labor market turbulence. The next section of the chapter therefore examines the effect of labor market institutions on job reallocation.

\footnotetext{
${ }^{74}$ Volatility is measured using the standard deviation of sectoral value-added shares. Volatility in the agriculture sector is 5.57 and 1.60 in the manufacturing sector. See table A2 in the online appendix for complete results.
} 
Table 3.6: Job Creation, Job Destruction and Job Reallocation in Sub-Sabaran Africa, by Periods

\begin{tabular}{|c|c|c|c|c|c|}
\hline \multicolumn{6}{|c|}{ Import Substitution Era (1960s-1975) } \\
\hline Sector & $\mathrm{JC}$ & JD & NEG & GJR & $\mathrm{EJR}$ \\
\hline Agriculture & $1.8 \%$ & $0.1 \%$ & $1.7 \%$ & $1.9 \%$ & $0.2 \%$ \\
\hline Mining & $0.1 \%$ & $0.0 \%$ & $0.0 \%$ & $0.1 \%$ & $0.1 \%$ \\
\hline Manufacturing & $0.4 \%$ & $0.0 \%$ & $0.4 \%$ & $0.4 \%$ & $0.1 \%$ \\
\hline Utilities & $0.0 \%$ & $0.0 \%$ & $0.0 \%$ & $0.0 \%$ & $0.0 \%$ \\
\hline Construction & $0.2 \%$ & $0.1 \%$ & $0.1 \%$ & $0.2 \%$ & $0.1 \%$ \\
\hline Trade services & $0.3 \%$ & $0.1 \%$ & $0.2 \%$ & $0.4 \%$ & $0.2 \%$ \\
\hline Transport services & $0.1 \%$ & $0.0 \%$ & $0.1 \%$ & $0.1 \%$ & $0.0 \%$ \\
\hline Business services & $0.0 \%$ & $0.0 \%$ & $0.0 \%$ & $0.0 \%$ & $0.0 \%$ \\
\hline Government services & $0.2 \%$ & $0.0 \%$ & $0.2 \%$ & $0.3 \%$ & $0.1 \%$ \\
\hline Personal services & $0.2 \%$ & $0.1 \%$ & $0.2 \%$ & $0.3 \%$ & $0.1 \%$ \\
\hline Total Economy & $3.0 \%$ & $0.0 \%$ & $2.9 \%$ & $3.0 \%$ & $0.1 \%$ \\
\hline \multicolumn{6}{|c|}{ Post Structural Adjustment (1990-2000) } \\
\hline Sector & JC & JD & NEG & GJR & EJR \\
\hline Agriculture & $1.2 \%$ & $0.2 \%$ & $1.0 \%$ & $1.4 \%$ & $0.4 \%$ \\
\hline Mining & $0.0 \%$ & $0.1 \%$ & $0.0 \%$ & $0.1 \%$ & $0.1 \%$ \\
\hline Manufacturing & $0.2 \%$ & $0.1 \%$ & $0.2 \%$ & $0.3 \%$ & $0.1 \%$ \\
\hline Utilities & $0.0 \%$ & $0.0 \%$ & $0.0 \%$ & $0.0 \%$ & $0.0 \%$ \\
\hline Construction & $0.1 \%$ & $0.1 \%$ & $0.1 \%$ & $0.2 \%$ & $0.1 \%$ \\
\hline Trade services & $0.5 \%$ & $0.0 \%$ & $0.5 \%$ & $0.6 \%$ & $0.1 \%$ \\
\hline Transport services & $0.1 \%$ & $0.0 \%$ & $0.1 \%$ & $0.1 \%$ & $0.0 \%$ \\
\hline Business services & $0.1 \%$ & $0.0 \%$ & $0.1 \%$ & $0.1 \%$ & $0.0 \%$ \\
\hline Government services & $0.2 \%$ & $0.0 \%$ & $0.2 \%$ & $0.3 \%$ & $0.1 \%$ \\
\hline Personal services & $0.2 \%$ & $0.1 \%$ & $0.1 \%$ & $0.3 \%$ & $0.1 \%$ \\
\hline Total Economy & $2.3 \%$ & $0.1 \%$ & $2.2 \%$ & $2.4 \%$ & $0.2 \%$ \\
\hline
\end{tabular}

\begin{tabular}{|c|c|c|c|c|c|}
\hline \multicolumn{6}{|c|}{ The Lost Decades (1975-1990) } \\
\hline Sector & $\mathrm{JC}$ & JD & NEG & GJR & EJR \\
\hline Agriculture & $1.8 \%$ & $0.1 \%$ & $1.7 \%$ & $1.9 \%$ & $0.2 \%$ \\
\hline Mining & $0.1 \%$ & $0.0 \%$ & $0.0 \%$ & $0.1 \%$ & $0.1 \%$ \\
\hline Manufacturing & $0.3 \%$ & $0.1 \%$ & $0.2 \%$ & $0.4 \%$ & $0.2 \%$ \\
\hline Utilities & $0.0 \%$ & $0.0 \%$ & $0.0 \%$ & $0.0 \%$ & $0.0 \%$ \\
\hline Construction & $0.2 \%$ & $0.1 \%$ & $0.1 \%$ & $0.2 \%$ & $0.1 \%$ \\
\hline Trade services & $0.4 \%$ & $0.1 \%$ & $0.3 \%$ & $0.4 \%$ & $0.1 \%$ \\
\hline Transport services & $0.1 \%$ & $0.0 \%$ & $0.1 \%$ & $0.1 \%$ & $0.0 \%$ \\
\hline Business services & $0.1 \%$ & $0.0 \%$ & $0.1 \%$ & $0.1 \%$ & $0.0 \%$ \\
\hline Government services & $0.3 \%$ & $0.0 \%$ & $0.3 \%$ & $0.3 \%$ & $0.0 \%$ \\
\hline Personal services & $0.2 \%$ & $0.1 \%$ & $0.2 \%$ & $0.3 \%$ & $0.1 \%$ \\
\hline Total Economy & $3.1 \%$ & $0.1 \%$ & $3.0 \%$ & $3.2 \%$ & $0.2 \%$ \\
\hline \multicolumn{6}{|c|}{ MDGs (2000-2015) } \\
\hline Sector & $\mathrm{JC}$ & $\mathrm{JD}$ & NEG & GJR & EJR \\
\hline Agriculture & $1.2 \%$ & $0.0 \%$ & $1.1 \%$ & $1.2 \%$ & $0.1 \%$ \\
\hline Mining & $0.1 \%$ & $0.0 \%$ & $0.1 \%$ & $0.1 \%$ & $0.0 \%$ \\
\hline Manufacturing & $0.3 \%$ & $0.0 \%$ & $0.3 \%$ & $0.3 \%$ & $0.0 \%$ \\
\hline Utilities & $0.0 \%$ & $0.0 \%$ & $0.0 \%$ & $0.0 \%$ & $0.0 \%$ \\
\hline Construction & $0.2 \%$ & $0.0 \%$ & $0.2 \%$ & $0.2 \%$ & $0.0 \%$ \\
\hline Trade services & $0.9 \%$ & $0.0 \%$ & $0.9 \%$ & $0.9 \%$ & $0.0 \%$ \\
\hline Transport services & $0.1 \%$ & $0.0 \%$ & $0.1 \%$ & $0.1 \%$ & $0.0 \%$ \\
\hline Business services & $0.2 \%$ & $0.0 \%$ & $0.2 \%$ & $0.2 \%$ & $0.0 \%$ \\
\hline Government services & $0.3 \%$ & $0.0 \%$ & $0.3 \%$ & $0.3 \%$ & $0.0 \%$ \\
\hline Personal services & $0.2 \%$ & $0.0 \%$ & $0.2 \%$ & $0.3 \%$ & $0.0 \%$ \\
\hline Total Economy & $3.3 \%$ & $0.0 \%$ & $3.3 \%$ & $3.3 \%$ & $0.0 \%$ \\
\hline
\end{tabular}




\subsection{Job Reallocation and Productivity Growth in Sub-Saharan Africa: The Role of Employment Protection Legislation}

The theoretical model of Aghion \& Howitt (1994) and empirical work of Faggio \& Konings (2003) predict that a higher pace of job reallocation is associated with higher growth. A great deal of labor market flexibility is needed for this process that allows labor resources to be reallocated to sectors where they can

be more productive (Masso et al., 2005). Some studies find that stringent employment protection legislation adversely affects JR which could stifle economic growth (Haltiwanger et al., 2014; Micco \& Pages 2007; Messina \& Vallanti 2007). ${ }^{75}$

As explained by Haltiwanger et al. (2014), standard labor market models predict that besides technology, entry costs and other market driven factors, and the institutional and regulatory apparatus within which sectors operate shape the direction, speed and effectiveness of labor market outcomes (job flows) within these sectors. The general prediction of these models is that stringent employment protection legislation reduces job reallocation (cf. Messina \& Vallanti, 2007; Micco \& Pages, 2007). As positive as this may be for guaranteeing workers job security, productivity growth could be penalized as a result, at least for countries at initial stages of development that demand positive structural change to unleash productivity growth (cf. Hopenhayn \& Rogerson, 1993).

Until now, Africa has not featured in these discussions even though many countries in the region are undergoing structural transformation with job reallocation that is taking place across sectors. But, to what extent do labor market regulations in Africa impact on this job reallocation? The World Bank's 2010 Doing Business (DB) report attributes employment creation and high labor productivity growth to flexible labor market regulations. In a related study UNDP made a case for developing countries to do away with rigid labor market regulations, replacing them with simpler rules while ensuring stricter levels of enforcement (UNDP, 2004; Boni, 2010). In a similar study, Czegledi (2006) finds that regulating the labor market less rigidly but more coherently is associated with higher growth. The extension of $\mathrm{OHADA}^{76}$ to include more member states in the harmonization of business law and labor codes in Africa continues to be a top priority for many donor and development agencies in Africa. Given the above we examine the effect of employment protection legislation (henceforth EPL) on job reallocation.

Before discussing our methodology and results a caveat here is worth highlighting. Most employment relationships in Africa, particularly in Africa are informal. Available statistics indicate that the share of the labor force that earns a living working in the informal sector in Africa is about 72 per cent (Boni, 2010). Working relationships in the informal sector are often based on casual employment and informal employment arrangements. As a consequence, the implications drawn from our analysis may apply to the formal part of the labor market in Africa where working relationships are based on contracts. In the context of Africa this is also due to another kind of employment protection, namely the "closed shop" which protects jobs for the elite of the labor force in manufacturing, government

\footnotetext{
75 On the other hand, some studies, e.g., Vergeer \& Kleinknecht (2011, 2014) and Vergeer et al. (2015) find that high labour turnover reduces productivity growth. According to the authors, "high labour turnover makes firm-sponsored training less attractive and diminishes loyalty and commitment of people" (Vergeer and Kleinknecht 2011: 393). Exiting workers could easily leak tacit knowledge to competitors and harm productivity and innovation in routinized innovation regime sectors (Schumpeter II) where continuous accumulation of knowledge is crucial (cf. Vergeer \& Kleinknecht, 2011). ${ }^{76}$ Organisation for the Harmonization of Business Law in Africa. It was created in 1993 in Port Louis (Mauritius). As at 2010, 16 Member States had joined the OHADA Treaty.
} 
and formal services and locks a huge number of informal workers out of the formal labor market, further reducing labor reallocation (Visagie et al, 2012). In this closed shop agreement, a worker looking for formal employment must first be a member of a trade union before being considered for employment by an employer. The trade union thus becomes the sole agency for employers to recruit workers into their establishments. ${ }^{77}$

For our analysis, we use EPL data from the Fraser Institute's Economic Freedom of the World (EFW) (2000-2015) and use productivity and JR data (2000-2015) from the preceding sections. The EFW compile data from third party sources, such as the International Country Risk Guide (ICRG), the Global Competitiveness Report, and the World Bank's Doing Business Project. An advantage of the EPL index is the transparency and easily replicable nature of the index. ${ }^{78}$ In addition, compared to other indicators that measure labor market regulation in developing economies, the EFW has extended data that tracks employment regulation over time and serves the purpose of this analysis (cf. Haltiwanger et al., (2014). EPL is measured on a scale of 0 to 10, with 10 being the worst (most restrictive).

Figure 3.4: Scatterplot of EPL and Job Reallocation in Africa (2000-2015)

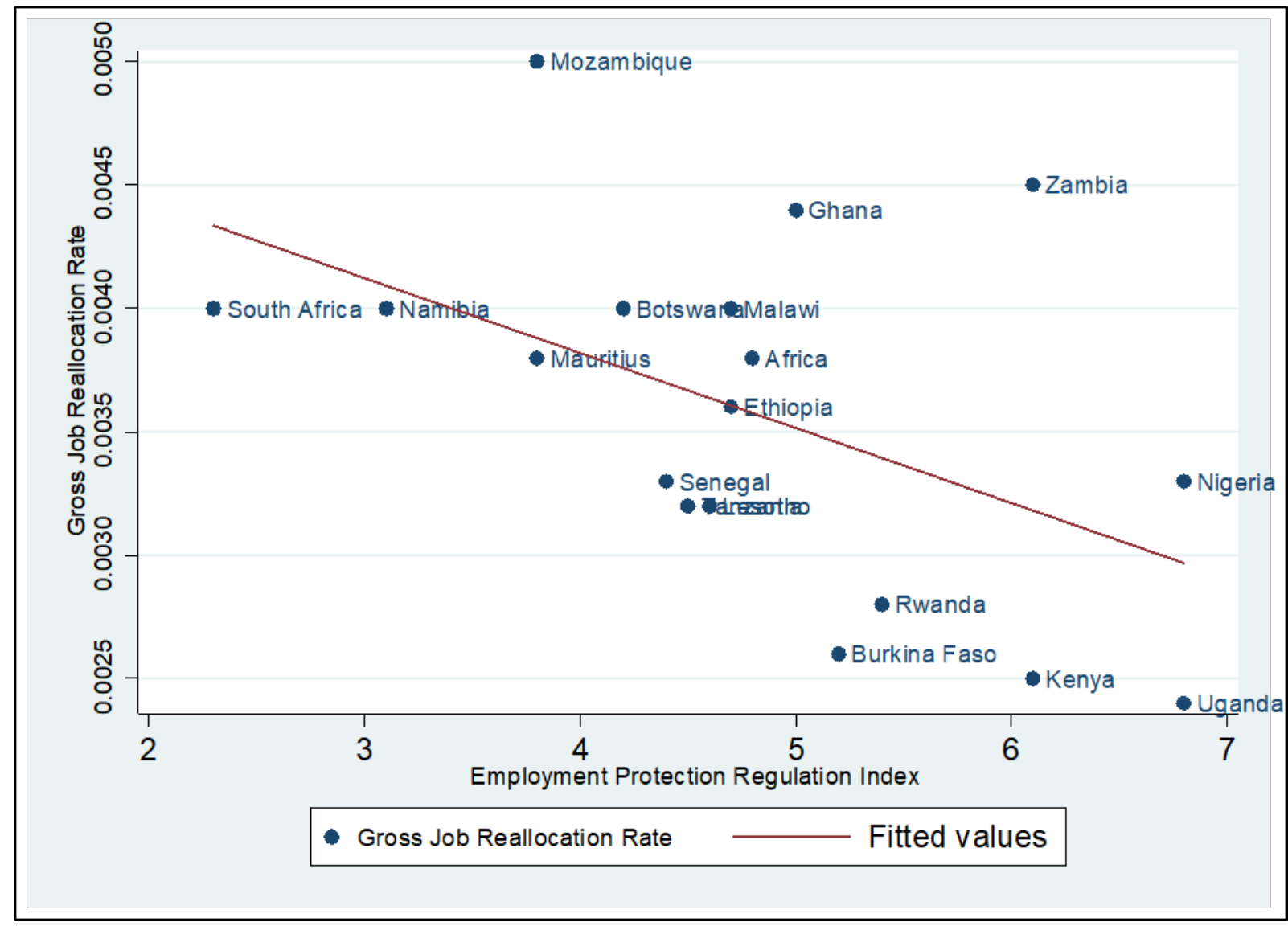

\footnotetext{
${ }^{77}$ http:/ / www.labour.gov.za/DOL/legislation/acts/basic-guides/basic-guide-to-closed-shop-agreements: 3/7/2018. http://www.tonyhealy.co.za/law/11-trade-unions/27-the-return-of-the-closed-shop.html: 3/7/2018.

78 See EFW methodological approach at: https://www.fraserinstitute.org/economic-freedom/approach.
} 
Source: Authors computation based on the Expanded Africa Sector Database and EPL data from Fraser Institute Economic Freedom of the World (EFW). To capture the relationship between EPL and job reallocation, we plot EPL index from $2000-2015$ against gross job reallocation rate in each country for the same period. We observe a negative association between EPL and gross job reallocation rate given by the slope of the best-fit line.

To provide an initial insight, Figure 4 presents a simple scatterplot of job reallocation and EPL, with the plot suggesting a negative relationship between the two, thus providing some support for the argument that high EPL constrains the efforts of job reallocation and positive structural change, making it difficult to reallocate surplus resources into sectors where they could be more productive, penalizing overall productivity growth (Hopenhayn \& Rogerson, 1993). We now proceed to examine this relationship econometrically.

Our empirical strategy follows Haltiwanger et al. (2014), Messina \& Vallanti (2007) and Micco \& Pages (2007) but is modified to suit the purpose of our study. The complete specification yields the following model:

$$
J R_{i t}=\beta_{0}+\beta_{1} E P L_{i t}+\beta_{2} C_{i t}^{\prime}+\gamma_{i}+\varepsilon_{i t}
$$

where $J R$ is gross job reallocation in country $i$ in time $t, E P L_{i t}$ is the index of employment protection legislation, and $C^{\prime}{ }_{i t}$ is a vector of other control variables that includes the stage of the business cycle as measured by changes in GDP growth (Bachmann \& Burda, 2009; Messina \& Vallanti, 2007; Kye, 2008), within-sector labor productivity growth (Diao et al., 2017) and employment growth (Kye, 2008). As explained by the authors of the aforementioned studies, the stage of the business cycle affects job mobility. In recession, job mobility rates tend to fluctuate due to lay-offs and vice versa. In so doing, the level of employment at the industry level tends to rise and fall in tandem with business cycles, though the direction of causality is uncertain (Messina \& Vallanti, 2007). Employment growth affects the job mobility rate by allowing for the creation of employment opportunities (Kye, 2008). As shown by Diao et al. (2017), there is a negative association between productivity growth within sectors and structural change given that wages move in tandem with high productivity growth within a sector. The model also includes country fixed effects $\gamma_{i}$, with $\varepsilon_{i t}$ being the error term. In our analysis, we estimate the models separately for the total economy and for each major sector.

Econometric results are reported in Table 3.7. We find that on average a one point increase in the EPL index significantly decreases job reallocation in the total economy (JR_TE) by 0.26 per cent, by 0.34 per cent in the total service sectors (JR_TS), by 0.43 per cent in market services (JR_MS), by 0.31 per cent in non-market services (JR_NMS), and by 0.44 per cent in the manufacturing sector (JR_MAN), though the impact is not significant in the latter case. These results are in line with the findings of Haltiwanger et al. (2014), Messina \& Vallanti (2007) and Micco \& Pages (2007), and indicate that a more rigid labor market reduces job reallocation which adversely affects the potential for structural change by making it difficult to reallocate surplus labor resources into sectors where they could be more productive.

Other control variables have the expected signs. For instance, having impartial courts and a legal system of high integrity increases job reallocation as it serves as a safeguard for both employers and workers to exercise their right to make justifiable decisions about their business and jobs. Similarly, an increase in within labor productivity growth is associated with lower job reallocation, which implies that when productivity growth of a sector increases, it is less likely for the workers in that sector to move to other sectors (Diao et al, 2017: 16). Employment growth positively and significantly impacts on the job mobility rate. For instance Davis, Haltiwanger, \& Schuh, (1996) find that about 32 to 52 
per cent of job reallocation arises to accommodate the distribution of the labor force to the various sectors as a result of employment growth in the economy.

Table 3.7: The Effect of EPL on Job Reallocation in Africa

\begin{tabular}{|c|c|c|c|c|c|c|}
\hline Variables & $\begin{array}{c}\text { (1) } \\
\text { JR_TE }\end{array}$ & $\begin{array}{c}(2) \\
\text { JR_TS }\end{array}$ & $\begin{array}{c}(3) \\
\text { JR_MS }\end{array}$ & $\begin{array}{c}(4) \\
J R \_N M S\end{array}$ & $\begin{array}{l}(5) \\
J R \_M A N\end{array}$ & $\begin{array}{c}(6) \\
J R \_N M I S \\
\end{array}$ \\
\hline \multirow[t]{2}{*}{ Labor Market Regulations } & $-0.266^{*}$ & $-0.341^{*}$ & $-0.435^{* *}$ & $-0.314^{*}$ & -0.448 & 0.408 \\
\hline & $(0.157)$ & $(0.180)$ & $(0.223)$ & $(0.169)$ & $(0.302)$ & $(0.209)$ \\
\hline \multirow[t]{2}{*}{ Integrity of the legal system } & 0.062 & 0.024 & 0.367 & -0.480 & 0.370 & 0.246 \\
\hline & $(0.131)$ & $(0.218)$ & $(0.257)$ & $(0.224)$ & $(0.269)$ & $(0.210)$ \\
\hline \multirow[t]{2}{*}{ Impartial courts } & $0.175^{* *}$ & $0.202^{* *}$ & $0.270^{* *}$ & -0.041 & 0.180 & 0.109 \\
\hline & $(0.080)$ & $(0.099)$ & $(0.121)$ & $(0.142)$ & $(0.248)$ & $(0.118)$ \\
\hline \multirow[t]{2}{*}{ Productivity Growth (Within) } & -0.017 & -0.015 & -0.017 & -0.022 & $-6.413^{* *}$ & -0.002 \\
\hline & $(0.029)$ & $(0.030)$ & $(0.031)$ & $(0.050)$ & $(2.499)$ & $(0.038)$ \\
\hline \multirow[t]{2}{*}{ Business Cycle } & -0.005 & -0.009 & -0.010 & -0.003 & 0.012 & $-0.024^{*}$ \\
\hline & $(0.006)$ & $(0.007)$ & $(0.007)$ & $(0.009)$ & $(0.019)$ & $(0.012)$ \\
\hline \multirow{2}{*}{ Employment growth } & 1.934 & 3.096 & $5.138^{*}$ & 3.219 & 0.349 & $4.108^{*}$ \\
\hline & $(2.298)$ & $(2.635)$ & $(2.952)$ & $(2.594)$ & $(4.073)$ & (2.097) \\
\hline \multirow[t]{2}{*}{ Constant } & $3.520^{* *}$ & $3.582^{*}$ & 1.291 & $5.985^{* * *}$ & 1.237 & -3.468 \\
\hline & $(1.580)$ & $(1.67)$ & $(2.483)$ & $(1.754)$ & $(3.041)$ & $(2.243)$ \\
\hline Country Effects & Yes & Yes & Yes & Yes & Yes & Yes \\
\hline Industry Size Effects & Yes & Yes & Yes & Yes & Yes & Yes \\
\hline Observations & 194 & 195 & 192 & 188 & 186 & 194 \\
\hline Adj. R-Squared & 0.76 & 0.68 & 0.69 & 0.68 & 0.54 & 0.68 \\
\hline
\end{tabular}

Robust standard errors in parentheses. ${ }^{*} p<0.1,{ }^{* *} p<0.05,{ }^{* * *} p<0.01$. Employment Protection Regulations have limited variation overtime but differ significantly across countries and so we do not include time effects variable. All regressions include weights/size of industry and controls for country specific effects. $\mathrm{JR}=\mathrm{Job}$ reallocation: TE=Total economy: TS=Total service: $\mathrm{MS}=$ Market service: $\mathrm{NMS}=$ Non-market service: MAN=Manufacturing: NMIS= Non-Manufacturing Industrial Sector: Productivity growth within (2000-2015).

\subsection{Conclusion}

This chapter uses the new Expanded Africa Sector Database to combine a standard decomposition of labor productivity with an analysis of labor market turbulence, thus allowing us to study the role of structural change and job reallocation in the economic growth of African countries in the past fifty years. Using both strategies, we examine the relative contribution of structural change and its characteristic labor market outcomes across different countries within three regions of Africa.

The results indicate similar trends to those found in previous studies, but also reveal new trends and insights into long run structural transformation of African economies and sets a new research agenda. Like previous studies (McMillan et al, 2014; de Vries et al, 2015; Daio et al, 2017) we document huge and persistent sectoral productivity gaps in Africa. The employment and value-added shares of agriculture have declined signaling the changing structure of production. However, the service sector is the main recipient of the workers exiting the agricultural sector. While some sub-sectors of services such as business and telecommunication are as dynamic as manufacturing, other sub-sectors such 
trade, government and personal services are only marginally more productive than the agriculture. A shift of resources from agriculture towards these less dynamic sectors means that structural transformation has been weaker than it would have been if resources had shifted to manufacturing or high-tech services.

In contrast to previous studies, our data suggest that productivity of the service sector is higher than previously estimated (Table 3.2). This is due to the structural undercounting of some high-productivity services sub-sectors, such as telecommunications, business services; and, important sectors such as entertainment and the informal sector. ${ }^{79}$

Structural change is also more important than previously estimated (Table 3.3) due again to the undercounting of services in previous data. We have seen a massive exodus of agricultural workers to trade services and a moderate movement to ICT services particularly in tech start-ups. The systematic undercounting resulted in an underestimation of productivity levels, and hence an underestimation of productivity growth due to the reallocation of labor to these services. Aggregate productivity growth due to innovation within sectors is mostly coming from manufacturing and agriculture. However, aggregate productivity due to reallocation of workers is mostly coming from trade and business services (see Table A5). This suggests that apart from manufacturing, dynamic services can play a key role in the transformation of African economies. This is beginning to show in the case of East African economies.

Our productivity decomposition results suggest that the golden era of African labor productivity growth is not the import-substitution era as suggested by de Vries et al (2015), but the period between 2000 and 2015, when the highest productivity growth is achieved. While this may raise some sense of optimism in the recent growth performance of African economies, given the moderate increase in the contribution of structural change to productivity growth in the region, primarily as a result of a slight increase in job creation in manufacturing and business services recorded within the period, the general direction of change of the structure of African economies may not bode well for sustainable growth and poverty reduction in Africa.

Particularly, there is still a strong shift towards services where the highest annual job creation in the sector is in the wholesale and retail trade services (largely informal) and personal and government services due to potentially restrictive opportunities that limit the labor absorption into other dynamic modern market services. The expansion of these non-tradable services has crystallized concerns about the direction of structural change since jobs in these sectors are often temporary or part-time in nature, less well paid and protected, and having few fringe benefits and opportunities for career development. This could increase earnings inequality and stall the expected poverty reduction associated with structural change because business services which is a high-wage service sector is creating fewer opportunities compared with lower-wage non-tradable services.

The labor market institutional arrangements in many countries in Africa have played a significant role

\footnotetext{
${ }^{79}$ For instance, the old GDP estimates of Nigeria used in the ASD ranks Wholesale and Retail trade as the largest component of the service sector, followed by Hotels and Restaurants, and Real Estate. However, the revised GDP used for this research suggest that Telecommunications ranks next to Wholesale and Retail trade. The telecommunication sector is more dynamic than the hospitality sector leading to relatively higher productivity. The revised data includes new activities such as entertainment, research, patents and copyrights in addition to a wider coverage of the informal sector. The correction of the undercounting of these sectors increased the services share of GDP from 23.6\% to $50.2 \%$ (Nigeria Bureau of Statistics, 2014). Kenya, Ghana, Tanzania, Uganda and Zambia all revised their GDP estimates to account for similar undercounting and under-coverage of services.
} 
in these outcomes. We find that rigid labor market institutional arrangements in the region discourage job reallocation, making it difficult to reallocate surplus labor into sectors where they could be more productive, penalizing productivity growth as a result. Although the EASD and job turnover rates cover the entire labor force, i.e., formal and informal workers, the implications drawn from the correlation between labor market institutions and job dynamics may be limited due to the high level of informality in Africa where working relationships are casual. For the region to experience the desired growth enhancing structural change will require not only a high degree of labor market flexibility that will drive this process, but also policies and reforms that will move labor into the formal sector, with a huge number of workers and held-back firms locked in the informal sector due to high entry costs and other regulations.

Due to negative consequences of this 'peculiar' structural change, the chapter sets a new research agenda by arguing that studies on structural transformation in Africa should move beyond a consideration of the extent of structural change and labor productivity to examine labor market outcomes as well. As a first step, we bring this to fruition by examining the labor market turbulence effect of structural change. A clear policy direction from this exercise is that while the main development framework in Africa should hinge on industrialization, complementary policies and strategies should aim at agricultural transformation, improvement in intra-sectoral productivity and employment stability particularly within the service sector bearing in mind the different contexts and specific circumstances of the economies. This could be a potential way to achieve the rapid structural change and poverty reduction predicted by Lewis (1954) and growth with depth as emphasized by ACET (2014:1). 


\subsection{Appendix to chapter 3}

Table A3.1 Sectoral Value-Added Shares

\begin{tabular}{|lcccccc|}
\hline & \multicolumn{7}{c|}{ Real Value-Added Shares (in per cent) } \\
Sector & 1960 & 1975 & 1990 & 2000 & 2010 & 2015 \\
\hline Agriculture & $\mathbf{3 7 . 9}$ & $\mathbf{3 0 . 1}$ & $\mathbf{2 4 . 7}$ & $\mathbf{2 3 . 9}$ & $\mathbf{2 0 . 4}$ & $\mathbf{1 7 . 2}$ \\
Industry & $\mathbf{2 1 . 0}$ & $\mathbf{2 5 . 4}$ & $\mathbf{2 6 . 1}$ & $\mathbf{2 5 . 1}$ & $\mathbf{2 3 . 8}$ & $\mathbf{2 4 . 2}$ \\
Manufacturing & 7.9 & 10.1 & 12.2 & 11.9 & 11.1 & 10.3 \\
Mining & 7.5 & 7.6 & 7.6 & 5.9 & 4.8 & 4.7 \\
Utilities & 0.5 & 1.3 & 1.8 & 2.7 & 2.4 & 2.3 \\
Construction & 5.1 & 6.4 & 4.5 & 4.6 & 5.5 & 6.8 \\
Services & $\mathbf{4 1 . 1}$ & $\mathbf{4 4 . 6}$ & $\mathbf{4 9 . 2}$ & $\mathbf{5 1 . 0}$ & $\mathbf{5 5 . 8}$ & $\mathbf{5 8 . 7}$ \\
Market Services & 29.8 & 30.6 & 31.9 & 34.7 & 40.0 & 42.8 \\
Trade, Restaurant and Hotels & 15.9 & 13.9 & 13.9 & 14.7 & 16.3 & 17.5 \\
Transport, Storage and Communications & 5.7 & 6.5 & 6.1 & 7.0 & 10.4 & 11.2 \\
FIRBS & 8.3 & 10.2 & 11.9 & 12.9 & 13.3 & 14.1 \\
Non-Market Services & 11.3 & 14.0 & 17.2 & 16.4 & 15.8 & 15.9 \\
Government Services & 8.6 & 11.6 & 14.6 & 13.5 & 12.8 & 12.7 \\
Community, Social and Personal Services & 2.7 & 2.4 & 2.7 & 2.8 & 3.0 & 3.2 \\
\hline
\end{tabular}

Table A3.2: Volatility of Value-Added Shares of Sectors

\begin{tabular}{|lcccc|}
\hline Variables & Mean & SD & Min & Max \\
\hline Agriculture & 24.0 & $\mathbf{5 . 5 7}$ & 17.1 & 31.9 \\
Industry & 23.8 & $\mathbf{1 . 1 6}$ & 22.2 & 25.2 \\
Mining & 6.1 & 1.45 & 4.4 & 7.80 \\
Manufacturing & 10.4 & $\mathbf{1 . 6 0}$ & 7.3 & 11.7 \\
Utilities & 1.9 & 0.59 & 1.2 & 2.5 \\
Construction & 5.4 & 0.83 & 4.4 & 6.4 \\
Service & 52.2 & $\mathbf{5 . 7 1}$ & 45.8 & 59.7 \\
Trade, Restaurants and Hotels & 14.2 & 1.65 & 13.0 & 16.8 \\
Transport Storage and Communication & 7.0 & 2.03 & 5.4 & 9.9 \\
FIRBS & 16.2 & 1.30 & 14.5 & 17.7 \\
Government Services & 12.2 & 1.73 & 9.4 & 14.0 \\
Community, Social and Personal & 2.6 & 0.49 & 2.0 & 3.4 \\
Market Services & 37.4 & 4.69 & 33.0 & 44.4 \\
Non-Market Services & 14.8 & 2.04 & 11.70 & 17.1 \\
\hline
\end{tabular}


Table A3.3: Productivity Decomposition Results by Sector (1960-2015)

\begin{tabular}{|lccccc|}
\hline & $\begin{array}{c}\text { Total Productivity } \\
\text { Growth }\end{array}$ & Within & $\begin{array}{c}\text { Between } \\
\text { Static }\end{array}$ & $\begin{array}{c}\text { Between } \\
\text { Dynamic }\end{array}$ & $\begin{array}{c}\text { Structural } \\
\text { Balance }\end{array}$ \\
\hline Total Economy & $1.9 \%$ & $1.0 \%$ & $1.2 \%$ & $-0.3 \%$ & $0.9 \%$ \\
Agriculture & $0.08 \%$ & $0.31 \%$ & $-0.21 \%$ & $-0.02 \%$ & $-0.23 \%$ \\
Mining & $0.06 \%$ & $0.10 \%$ & $0.02 \%$ & $-0.07 \%$ & $-0.04 \%$ \\
Manufacturing & $0.23 \%$ & $0.12 \%$ & $0.13 \%$ & $-0.02 \%$ & $0.11 \%$ \\
Utilities & $0.04 \%$ & $0.01 \%$ & $0.05 \%$ & $-0.02 \%$ & $0.03 \%$ \\
Construction & $0.13 \%$ & $0.02 \%$ & $0.14 \%$ & $-0.04 \%$ & $0.10 \%$ \\
Trade services & $0.29 \%$ & $-0.17 \%$ & $0.52 \%$ & $-0.06 \%$ & $0.46 \%$ \\
Transport services & $0.20 \%$ & $0.13 \%$ & $0.09 \%$ & $-0.02 \%$ & $0.07 \%$ \\
Business services & $0.22 \%$ & $-0.02 \%$ & $0.27 \%$ & $-0.03 \%$ & $0.24 \%$ \\
Government services & $0.27 \%$ & $0.16 \%$ & $0.13 \%$ & $-0.02 \%$ & $0.11 \%$ \\
Personal services & $0.07 \%$ & $0.05 \%$ & $0.04 \%$ & $-0.02 \%$ & $0.02 \%$ \\
\hline
\end{tabular}

Notes: The table shows the productivity decomposition by sector for Africa (18 countries)-unweighted. The sum of the within and structural balance equals total productivity. Structural balance is the sum of static reallocation and dynamic reallocation.

Table A3.4: Productivity Decomposition Results by Country (1960-2015)

\begin{tabular}{|c|c|c|c|c|c|c|}
\hline Country & Period & $\begin{array}{c}\text { Total } \\
\text { Productivity } \\
\text { Growth }\end{array}$ & Within & $\begin{array}{l}\text { Between } \\
\text { Static }\end{array}$ & $\begin{array}{l}\text { Between } \\
\text { Dynamic }\end{array}$ & $\begin{array}{c}\text { Structural } \\
\text { Balance }\end{array}$ \\
\hline \multirow[t]{5}{*}{ Botswana } & $1968-2015$ & $5.5 \%$ & $3.8 \%$ & $3.7 \%$ & $-1.9 \%$ & $1.8 \%$ \\
\hline & 1968-1975 & $14.0 \%$ & $2.6 \%$ & $12.7 \%$ & $-1.2 \%$ & $11.5 \%$ \\
\hline & 1975-1990 & $7.6 \%$ & $6.2 \%$ & $2.9 \%$ & $-1.5 \%$ & $1.4 \%$ \\
\hline & $1990-2000$ & $1.4 \%$ & $2.1 \%$ & $-0.2 \%$ & $-0.5 \%$ & $-0.6 \%$ \\
\hline & $2000-2015$ & $2.3 \%$ & $3.0 \%$ & $2.9 \%$ & $-3.6 \%$ & $-0.7 \%$ \\
\hline \multirow[t]{5}{*}{ Burkina Faso } & $1970-2014$ & $2.9 \%$ & $1.7 \%$ & $1.4 \%$ & $-0.2 \%$ & $1.2 \%$ \\
\hline & $1970-1975$ & $3.4 \%$ & $3.4 \%$ & $0.0 \%$ & $0.0 \%$ & $0.0 \%$ \\
\hline & $1975-1990$ & $4.1 \%$ & $4.2 \%$ & $-0.1 \%$ & $0.0 \%$ & $-0.1 \%$ \\
\hline & $1990-2000$ & $2.9 \%$ & $1.2 \%$ & $1.8 \%$ & $-0.1 \%$ & $1.7 \%$ \\
\hline & $2000-2014$ & $1.6 \%$ & $-1.1 \%$ & $3.2 \%$ & $-0.5 \%$ & $2.8 \%$ \\
\hline \multirow[t]{5}{*}{ Cameroun } & $1965-2015$ & $2.3 \%$ & $1.3 \%$ & $1.1 \%$ & $-0.1 \%$ & $1.0 \%$ \\
\hline & $1965-1975$ & $6.1 \%$ & $6.1 \%$ & $0.1 \%$ & $0.0 \%$ & $0.0 \%$ \\
\hline & $1975-1990$ & $4.1 \%$ & $3.2 \%$ & $0.9 \%$ & $-0.1 \%$ & $0.9 \%$ \\
\hline & $1990-2000$ & $1.8 \%$ & $-1.5 \%$ & $3.6 \%$ & $-0.3 \%$ & $3.3 \%$ \\
\hline & $2000-2015$ & $-1.8 \%$ & $-2.0 \%$ & $0.2 \%$ & $0.0 \%$ & $0.2 \%$ \\
\hline \multirow[t]{4}{*}{ Ethiopia } & $1961-2015$ & $1.3 \%$ & $0.2 \%$ & $1.3 \%$ & $-0.2 \%$ & $1.1 \%$ \\
\hline & $1961-1975$ & $0.4 \%$ & $-0.7 \%$ & $1.1 \%$ & $0.0 \%$ & $1.1 \%$ \\
\hline & $1975-1990$ & $-1.6 \%$ & $-1.7 \%$ & $0.1 \%$ & $0.0 \%$ & $0.1 \%$ \\
\hline & $1990-2000$ & $0.8 \%$ & $-0.5 \%$ & $1.2 \%$ & $0.0 \%$ & $1.2 \%$ \\
\hline
\end{tabular}




\begin{tabular}{|c|c|c|c|c|c|c|}
\hline & 2000-2015 & $5.4 \%$ & $3.4 \%$ & $2.5 \%$ & $-0.6 \%$ & $2.0 \%$ \\
\hline \multirow[t]{5}{*}{ Ghana } & $1960-2015$ & $1.4 \%$ & $1.4 \%$ & $0.2 \%$ & $-0.2 \%$ & $0.0 \%$ \\
\hline & $1960-1975$ & $-1.0 \%$ & $-0.7 \%$ & $-0.2 \%$ & $-0.1 \%$ & $-0.3 \%$ \\
\hline & 1975-1990 & $-1.2 \%$ & $-1.1 \%$ & $-0.1 \%$ & $0.0 \%$ & $-0.1 \%$ \\
\hline & $1990-2000$ & $3.3 \%$ & $2.7 \%$ & $0.6 \%$ & $0.0 \%$ & $0.6 \%$ \\
\hline & $2000-2015$ & $5.1 \%$ & $5.2 \%$ & $0.4 \%$ & $-0.6 \%$ & $-0.1 \%$ \\
\hline \multirow[t]{5}{*}{ Kenya } & 1969-2015 & $0.1 \%$ & $-0.6 \%$ & $0.9 \%$ & $-0.2 \%$ & $0.7 \%$ \\
\hline & $1969-1975$ & $1.5 \%$ & $1.1 \%$ & $0.7 \%$ & $-0.3 \%$ & $0.4 \%$ \\
\hline & $1975-1990$ & $0.5 \%$ & $-0.3 \%$ & $1.1 \%$ & $-0.2 \%$ & $0.8 \%$ \\
\hline & $1990-2000$ & $-2.6 \%$ & $-4.8 \%$ & $2.6 \%$ & $-0.3 \%$ & $2.2 \%$ \\
\hline & 2000-2015 & $0.8 \%$ & $1.2 \%$ & $-0.3 \%$ & $-0.1 \%$ & $-0.4 \%$ \\
\hline \multirow[t]{5}{*}{ Lesotho } & $1970-2015$ & $1.9 \%$ & $0.8 \%$ & $1.3 \%$ & $-0.2 \%$ & $1.1 \%$ \\
\hline & $1970-1975$ & $-2.3 \%$ & $-2.5 \%$ & $0.4 \%$ & $-0.1 \%$ & $0.3 \%$ \\
\hline & 1975-1990 & $1.8 \%$ & $0.9 \%$ & $1.0 \%$ & $-0.1 \%$ & $0.9 \%$ \\
\hline & $1990-2000$ & $4.6 \%$ & $3.4 \%$ & $1.2 \%$ & $-0.1 \%$ & $1.2 \%$ \\
\hline & $2000-2015$ & $1.6 \%$ & $0.0 \%$ & $1.9 \%$ & $-0.3 \%$ & $1.6 \%$ \\
\hline \multirow[t]{5}{*}{ Malawi } & 1966-2015 & $1.2 \%$ & $0.0 \%$ & $1.6 \%$ & $-0.3 \%$ & $1.2 \%$ \\
\hline & 1966-1975 & $3.0 \%$ & $1.8 \%$ & $1.2 \%$ & $0.0 \%$ & $1.2 \%$ \\
\hline & 1975-1990 & $-1.1 \%$ & $-0.7 \%$ & $0.4 \%$ & $-0.7 \%$ & $-0.3 \%$ \\
\hline & $1990-2000$ & $1.4 \%$ & $0.0 \%$ & $1.6 \%$ & $-0.1 \%$ & $1.4 \%$ \\
\hline & $2000-2015$ & $2.4 \%$ & $-0.2 \%$ & $2.9 \%$ & $-0.3 \%$ & $2.6 \%$ \\
\hline \multirow[t]{5}{*}{ Mauritius } & $1970-2015$ & $3.4 \%$ & $2.7 \%$ & $1.2 \%$ & $-0.4 \%$ & $0.7 \%$ \\
\hline & $1970-1975$ & $13.2 \%$ & $11.3 \%$ & $2.6 \%$ & $-0.8 \%$ & $1.8 \%$ \\
\hline & $1975-1990$ & $1.1 \%$ & $0.3 \%$ & $1.3 \%$ & $-0.6 \%$ & $0.7 \%$ \\
\hline & $1990-2000$ & $4.3 \%$ & $3.1 \%$ & $1.3 \%$ & $-0.1 \%$ & $1.2 \%$ \\
\hline & $2000-2015$ & $1.9 \%$ & $1.8 \%$ & $0.4 \%$ & $-0.3 \%$ & $0.1 \%$ \\
\hline \multirow[t]{5}{*}{ Mozambique } & $1970-2015$ & $2.5 \%$ & $2.4 \%$ & $0.3 \%$ & $-0.1 \%$ & $0.2 \%$ \\
\hline & 1970-1975 & $-6.4 \%$ & $-6.4 \%$ & $0.0 \%$ & $0.0 \%$ & $0.0 \%$ \\
\hline & $1975-1990$ & $-2.2 \%$ & $-2.0 \%$ & $0.0 \%$ & $-0.2 \%$ & $-0.2 \%$ \\
\hline & $1990-2000$ & $8.9 \%$ & $9.1 \%$ & $0.0 \%$ & $-0.2 \%$ & $-0.2 \%$ \\
\hline & $2000-2015$ & $5.9 \%$ & $5.1 \%$ & $0.8 \%$ & $0.0 \%$ & $0.8 \%$ \\
\hline \multirow[t]{5}{*}{ Namibia } & $1965-2015$ & $1.3 \%$ & $1.1 \%$ & $0.6 \%$ & $-0.4 \%$ & $0.2 \%$ \\
\hline & $1965-1975$ & $0.4 \%$ & $-0.2 \%$ & $0.7 \%$ & $-0.1 \%$ & $0.6 \%$ \\
\hline & 1975-1990 & $0.6 \%$ & $0.7 \%$ & $0.0 \%$ & $-0.1 \%$ & $-0.1 \%$ \\
\hline & $1990-2000$ & $2.9 \%$ & $2.9 \%$ & $0.5 \%$ & $-0.5 \%$ & $0.1 \%$ \\
\hline & $2000-2015$ & $1.5 \%$ & $1.4 \%$ & $1.1 \%$ & $-0.9 \%$ & $0.2 \%$ \\
\hline
\end{tabular}




\begin{tabular}{|c|c|c|c|c|c|c|}
\hline \multirow[t]{5}{*}{ Nigeria } & $1960-2015$ & $3.0 \%$ & $2.4 \%$ & $0.8 \%$ & $-0.1 \%$ & $0.6 \%$ \\
\hline & $1960-1975$ & $4.6 \%$ & $3.3 \%$ & $1.5 \%$ & $-0.3 \%$ & $1.2 \%$ \\
\hline & $1975-1990$ & $0.5 \%$ & $0.8 \%$ & $-0.1 \%$ & $-0.1 \%$ & $-0.2 \%$ \\
\hline & $1990-2000$ & $0.8 \%$ & $1.2 \%$ & $-0.3 \%$ & $-0.1 \%$ & $-0.4 \%$ \\
\hline & $2000-2015$ & $5.3 \%$ & $3.7 \%$ & $1.6 \%$ & $0.0 \%$ & $1.6 \%$ \\
\hline \multirow[t]{5}{*}{ Rwanda } & $1970-2015$ & $3.5 \%$ & $1.7 \%$ & $1.9 \%$ & $-0.1 \%$ & $1.8 \%$ \\
\hline & $1970-1975$ & $6.5 \%$ & $6.5 \%$ & $0.0 \%$ & $0.0 \%$ & $0.0 \%$ \\
\hline & $1975-1990$ & $-1.1 \%$ & $-2.5 \%$ & $1.7 \%$ & $-0.2 \%$ & $1.5 \%$ \\
\hline & $1990-2000$ & $5.0 \%$ & $4.7 \%$ & $0.3 \%$ & $0.0 \%$ & $0.3 \%$ \\
\hline & $2000-2015$ & $5.9 \%$ & $2.2 \%$ & $3.9 \%$ & $-0.2 \%$ & $3.7 \%$ \\
\hline \multirow[t]{5}{*}{ Senegal } & $1970-2014$ & $-0.7 \%$ & $-1.5 \%$ & $1.0 \%$ & $-0.1 \%$ & $0.9 \%$ \\
\hline & $1970-1975$ & $-2.1 \%$ & $-2.9 \%$ & $0.8 \%$ & $0.0 \%$ & $0.8 \%$ \\
\hline & $1975-1990$ & $-2.7 \%$ & $-3.3 \%$ & $0.7 \%$ & $0.0 \%$ & $0.7 \%$ \\
\hline & $1990-2000$ & $0.9 \%$ & $-0.2 \%$ & $1.2 \%$ & $-0.1 \%$ & $1.1 \%$ \\
\hline & $2000-2014$ & $0.9 \%$ & $-0.1 \%$ & $1.3 \%$ & $-0.3 \%$ & $1.0 \%$ \\
\hline \multirow[t]{5}{*}{ South Africa } & $1960-2015$ & $1.7 \%$ & $0.9 \%$ & $0.9 \%$ & $-0.1 \%$ & $0.8 \%$ \\
\hline & $1960-1975$ & $4.1 \%$ & $2.5 \%$ & $1.6 \%$ & $0.0 \%$ & $1.6 \%$ \\
\hline & $1975-1990$ & $0.0 \%$ & $-1.2 \%$ & $1.3 \%$ & $-0.1 \%$ & $1.2 \%$ \\
\hline & $1990-2000$ & $0.0 \%$ & $0.1 \%$ & $0.2 \%$ & $-0.3 \%$ & $-0.1 \%$ \\
\hline & $2000-2015$ & $2.1 \%$ & $2.0 \%$ & $0.3 \%$ & $-0.2 \%$ & $0.1 \%$ \\
\hline \multirow[t]{5}{*}{ Tanzania } & $1960-2015$ & $2.0 \%$ & $-0.1 \%$ & $2.5 \%$ & $-0.5 \%$ & $2.0 \%$ \\
\hline & $1960-1975$ & $2.1 \%$ & $-0.7 \%$ & $3.9 \%$ & $-1.0 \%$ & $2.8 \%$ \\
\hline & $1975-1990$ & $-0.5 \%$ & $-1.2 \%$ & $0.8 \%$ & $-0.1 \%$ & $0.7 \%$ \\
\hline & $1990-2000$ & $0.7 \%$ & $0.1 \%$ & $0.6 \%$ & $0.0 \%$ & $0.6 \%$ \\
\hline & $2000-2015$ & $5.3 \%$ & $1.7 \%$ & $4.2 \%$ & $-0.6 \%$ & $3.5 \%$ \\
\hline \multirow[t]{5}{*}{ Uganda } & $1960-2015$ & $0.9 \%$ & $-0.3 \%$ & $1.4 \%$ & $-0.2 \%$ & $1.2 \%$ \\
\hline & 1960-1975 & $0.1 \%$ & $-1.1 \%$ & $1.4 \%$ & $-0.2 \%$ & $1.2 \%$ \\
\hline & $1975-1990$ & $1.4 \%$ & $-0.6 \%$ & $2.1 \%$ & $-0.1 \%$ & $2.0 \%$ \\
\hline & $1990-2000$ & $3.2 \%$ & $0.4 \%$ & $3.0 \%$ & $-0.2 \%$ & $2.8 \%$ \\
\hline & $2000-2015$ & $-0.3 \%$ & $0.4 \%$ & $-0.6 \%$ & $-0.1 \%$ & $-0.7 \%$ \\
\hline \multirow[t]{5}{*}{ Zambia } & $1965-2015$ & $-0.7 \%$ & $-0.3 \%$ & $-0.3 \%$ & $-0.1 \%$ & $-0.4 \%$ \\
\hline & $1965-1975$ & $-2.7 \%$ & $-1.1 \%$ & $-1.7 \%$ & $0.0 \%$ & $-1.7 \%$ \\
\hline & $1975-1990$ & $-2.2 \%$ & $-0.2 \%$ & $-2.0 \%$ & $0.0 \%$ & $-2.0 \%$ \\
\hline & $1990-2000$ & $-1.2 \%$ & $-1.3 \%$ & $0.2 \%$ & $-0.1 \%$ & $0.1 \%$ \\
\hline & $2000-2015$ & $2.7 \%$ & $1.0 \%$ & $2.1 \%$ & $-0.3 \%$ & $1.8 \%$ \\
\hline
\end{tabular}




\section{Chapter 4: Productive Efficiency, Technological Change and Catch-up within Africa ${ }^{80}$}

${ }^{80}$ Co-authored with Neil Foster-McGregor and Solomon Owusu. 


\subsection{Introduction and Motivation}

Evidence of cross-country (spatial) externalities is suggestive of the importance of global technological interdependence. Technological advancement in one country depends on the level of technological development in another country (Ertur \& Koch, 2007), with technological spillovers flowing in particular from advanced countries to developing countries. This is due to the fact that advanced countries, particularly the US, are considered to operate on the technology frontier while developing countries, including those in Africa, operate inside the technology frontier (Caselli \& Coleman, 2006; Filippetti \& Peyrache, 2017; Kumar \& Russell, 2002). With technological progress playing a crucial role in the long run growth of countries (Grossman \& Helpman, 1991a; Romer, 1990, 1994), developed countries at the technological frontier rely on R\&D investments to shift the frontiers of knowledge in order to generate long-run growth, while developing countries are able to assimilate technologies already developed in advanced countries to generate growth, especially if they have developed their absorptive capacity to a level that is necessary and sufficient to benefit from existing technologies (Abramovitz, 1986; Cohen \& Levinthal, 1989). The non-rival nature of technology makes this relation feasible as developed countries' investment in new knowledge does not only benefit these advanced countries but also contributes to the global knowledge pool that can spill over to developing countries if conditions allow (Keller, 2004). Endogenous growth models have emphasized that the international spillover of knowledge is a major source of productivity growth in receiving countries. These international spillovers from advanced countries are received in developing countries through human capital interactions, international trade, and foreign direct investment (Borensztein, De Gregorio, \& Lee, 1998; Coe \& Helpman, 1995; Wolfgang Keller, 1998, 2009; Wolfgang Keller \& Yeaple, 2013).

Given the recent pace of technological change and globalization, African countries are expected to adopt, assimilate, and ultimately benefit from technology developed in frontier countries without much friction. Thus, the geographic distance between Africa and frontier countries should not matter for the technology diffusion process if "there is a global pool of technological knowledge or a country's technology level depends on only idiosyncratic non-spatial factors” (Keller, 2002:120). However, the international diffusion of knowledge is not global. Keller (2002) established that the international diffusion of technology is geographically localized in the sense that knowledge gained from R\&D decreases with geographic distance. Thus the "spatial diffusion of technological knowledge may be geographically bounded, so that the stock of knowledge in one region may spill over into other regions with an intensity which decreases with geographical distance" (Basile, Capello, \& Caragliu, 2011:21). "Technology diffusion declines with distance because in equilibrium technology transfer to remote locations is relatively costly, so there is less of it" (Keller, 2009: 59).

Recent exogenous growth models consider technological interdependence between countries by modeling spatial externalities. The implication of the spatially augmented Solow model is that "the stock of knowledge in one country produces externalities that may cross national borders and spill over into other countries with an intensity which decreases with distance"(Ertur \& Koch, 2007). Ertur \& Koch (2007) tested the spatially augmented Solow model and found spatial externalities to be statistically significant.

While geographical proximity is essential for knowledge spillovers, Basile et al. (2011:21) have shown that not all mechanisms underlying knowledge spillovers can be explained by geographical proximity 
alone. Gravity models (Ertur \& Koch, 2007; Keller \& Yeaple, 2013) are often used to capture the spatial dimension of knowledge spillovers, but gravity models do not explain an important component of technological spillover i.e. "the learning processes of agents and contexts". Two countries at the same geographical distance from the technological leader may benefit differently from technology that spills over from the frontier because of the different learning processes and institutional contexts. To capture the learning process in the technology diffusion framework, Basile et al. (2011:21) introduced the concept of relational proximity. Relational proximity is defined as "the similarities of two areas in terms of shared behavioral codes, common culture, mutual trust, sense of belonging and cooperation capabilities." Relational proximity facilitates cooperative learning processes through which knowledge accumulation takes place. Their empirical analysis showed that relational proximity is not only crucial in the knowledge absorption process but that it also complements the positive effect of geographical proximity. Finally, evolutionary theory suggests that technological diffusion is difficult if the technology gap between the frontier and the laggard country is large. Beyond a certain threshold, this technology gap widens over time (Verspagen, 1991). The technology gap between African countries and the US - normally considered in the catch-up literature as the frontier - is huge, persistent, and widening over time.

The peculiar nature of African development presents unique technological challenges. This often requires African-induced innovations. These innovations could facilitate knowledge accumulation and catch-up because of the closeness of African countries in terms of geography, institutions, and the technology gap. For example, because of geography and idiosyncratic reinforcing factors such as institutions, the disease burden of Africa is relatively high compared to other regions. Effective treatment and medicines are, therefore, needed. However, it is estimated that $42 \%$ of detected counterfeit - i.e., substandard or falsified - pharmaceutical drugs occurred in Africa (WHO, 2017). While pharmaceutical counterfeiting is common in all developing countries, the risk of penetration is high for most African countries. Most Food and Drugs Boards (FDBs) and crime units responsible for fighting this crime are not well-equipped to mitigate this public safety risk. As a result, an estimated 64-158 thousand lives are lost annually to malaria alone in Africa due to fake drugs (ENACT, 2018). To crackdown on this crime, mPedigree developed a technological platform that stores pedigree information of pharmaceutical products of participating manufacturers in a central registry and connects this registry to GSM mobile networks so that with a simple short code consumers can verify the authenticity of the drugs or products they are buying. mPedigree observed this peculiar problem in Ghana, but because of the relational proximity - institutional similarity - to other countries, similar levels of penetration of counterfeit pharmaceutical drugs were observed in most African countries. To fight the menace, the technology has been adopted in most African countries and has extended its application to other sectors such as Agro-industries (seeds), textiles, and domestics. In particular, the Nigerian National Agency for Food and Drug Administration and Control (NAFDAC) formed a consortium including mPedigree and other technology companies to roll out the mobile medicine authentication process in Nigeria since 2014.

In relation to the counterfeiting problem, multiple infections are common in Africa. While it is rare to find someone in advanced countries infected with malaria, Hepatitis, Zika, and HIV at the same time, it is common in Africa. In the traditional medical system, a person living with two or more infectious diseases needs to test for each of them in the laboratory separately. In the wake of the rapid spread of 
the Ebola virus in Guinea, Liberia, and Sierra Leone, Doctor $\mathrm{Nyan}^{81}$ developed a rapid diagnostic test that can detect up to seven infections in about ten to forty minutes (Economist, 2017). The batterypowered technology provides a fast and cheap alternative to the traditional laboratory test, which remains expensive to the poor and uninsured. (See the Economist (2017) for other technological innovations induced by specific problems in Africa).

Furthermore, before the mobile money revolution, the majority of Africans were unbanked due to high transaction costs emanating from high levels of perceived risks and information asymmetries for the traditional banking system leading to low levels of financial inclusion. The exclusion of the majority of people from the financial system means they cannot easily smoothen their income and consumption patterns over time, exposing them to potential shocks (Pelletier, Khavul, \& Estrin, 2019). The introduction of the MPesa in Kenya and the subsequent spread of mobile money services across the continent has revolutionized transactions across the continent, with the majority of digital-wallets users being previously unbanked. The unprecedented growth of mobile money services has modernized the banking system and supported rapid financial inclusion. For instance, the growth of mobile financial services has sped up and simplified remittance transactions and supported the growth of e-commerce in a way that would otherwise be impossible in Africa. These are a few examples of peculiar development problems and how African-induced innovations are helping to tackle them.

Given that African countries are geographically and relationally closer to each other than the US and given the huge productivity gap between Africa and the US, this chapter departs from the existing literature and studies technological change and technological catch-up within African by considering catch-up with respect to an African technology leader. We do this using a linear programming technique (i.e. data envelopment analysis (DEA)) to estimate a virtual production frontier for Africa, using this estimate to then construct the productive efficiency of each country relative to the frontier. The dynamic efficiency of each country is examined using the Malmquist productivity index to decompose total productivity growth into technological catch-up (movement toward or away from the frontier) and technological change (i.e., a shift of the frontier over time). One advantage of the DEA over the other usual approach of measuring technology gaps and catch-up relative to some defined frontier is that it defines best practice based on the sample. Unlike Stochastic Frontier Analysis (SFA), DEA does not require any assumption about market structure and functional specification of the production technology.

The analysis shows that Botswana and Mauritius are the only two countries in Africa that have successfully converged to the efficiency ${ }^{82}$ level of the frontier. In 1970, South Africa, Rwanda and Zambia were on the African production possibility frontier. By 2014, Rwanda and Zambia had fallen behind while Botswana and Mauritius had caught up with South Africa. The Malmquist productivity decomposition indicates that productivity convergence of Botswana and Mauritius is driven more by a movement toward the production possibility frontier - i.e., technological catch-up - and less by the shift of the production possibility frontier - i.e., technological change. The productivity growth of

\footnotetext{
${ }^{81}$ Dougbeh Chris Nyan is a Liberian medical doctor, a biomedical research scientist, social activist and inventor.

${ }^{82}$ Efficiency is achieved when the maximum possible number of goods and services are produced with a given amount of inputs. This will occur on the production possibility frontier and the lowest point of the average cost curve of the decisionmaking unit. Productivity on the other hand, is a measure of how efficiently a country (or firm or industry) converts inputs into outputs.
} 
almost all the countries in Africa in our dataset is driven more by improvements in efficiency change or technological catch-up.

To further understand the special role efficiency change (catch-up) played in the convergence of Botswana and Mauritius to the technology leader, we examine whether this process was driven by structural change. To determine the extent to which a transformation in production could contribute to catch-up, we follow the structural approach of Lavopa \& Szirmai (2014) to estimate the annual rate of catch up to the frontier by decomposing relative labor productivity to the frontier into a catch-up rate due to the adoption of best practice within sectors (within), the catch-up rate due to the movement of workers to sectors with a smaller technology gap relative to the frontier (structural change), and due to initial specialization. By doing this, we trace the sectoral origin of aggregate efficiency change. In this estimation, South Africa (SA) is used as the technological frontier for two reasons: First, the DEA analysis indicates that SA has been on the African production possibility frontier since 1970. Second, SA leads the rest of Africa in terms of innovation, intellectual property production, and education (Section Appendix). Successful catch-up to the technology leader (i.e., SA) has huge implications for (transitory) growth and development in Africa, implying a movement from the current average GDP per capita of $\$ 1500$ to a GDP per capita of about $\$ 10000$.

We find that structural change contributes more to technological convergence than the within and specialization effects. The potential explanations for these findings are as follows: the discovery of diamonds in Botswana and the development of an exporting manufacturing sector in Mauritius and subsequent movement of workers to these sectors led to the relatively successful transition of these two countries. Botswana's geographical and relational proximity to SA enabled effective development of the mining and auxiliary sectors since, by 1970, SA had established itself as a global leader in miningrelated technology (Kaplan, 2012). By interacting with SA, Botswana adopted the appropriate technology and best management practices to explore its diamond deposits and launched itself upon a consistent growth path. In Mauritius, conversely, the policies deployed after the creation of the export processing zones (EPZs) in the early 1970s led to successful diversification and catch-up. For instance, duty-free access to capital goods and a raft of tax incentives granted to firms operating within the EPZs acted as subsidies to encourage export-oriented manufacturing. Mining-led and manufacturing-led catch-up in Botswana and Mauritius, respectively, may suggest that catch-up within Africa is a sector-specific phenomenon. This analysis reinforces the argument that developing countries can successfully climb up the income ladder through a two-pronged transformation structural change and technological catch-up (Lavopa \& Szirmai, 2018).

The rest of the chapter is structured as follows. Section 4.2 briefly discusses the datasets used for the analysis. Section 4.3 analyzes efficiency convergence and decomposes dynamic efficiency change in Africa. Section 4.4 decomposes the relative productivity to the frontier and explores the role of structural change in technological catch-up. Section 4.5 concludes.

\subsection{Data Sources and Description}

Data on value added and employment were sourced from the Expanded Africa Sector Database (EASD) presented in Chapter 2. We complement the EASD with capital stock data from the PWT 9.0 database. The EASD is converted from local currencies to international dollars using the 2011 PPPs. We did not use sector-specific PPPs constructed by the GGDC because the sector-specific 
PPPs are not available for the seven newly added countries in the EASD. The capital stock reported in the PWT 9.0 is measured in 2011 PPPs. Using 2011 PPPs to convert value added data therefore gives output and capital input in a single unit.

\subsection{Nonparametric Estimation of Technology gaps in Africa}

DEA is often used to measure the productive efficiency of a set of decision-making units (DMUs) with multiple inputs and outputs by employing standard mathematical linear programming algorithms (Wang \& Lan, 2011; Kumar \& Russel, 2002; Coelli, Prasada, \& Battese, 1998). Originally proposed by Charnes et al. (1978) and later named the CCR model to reflect the acronyms of all the authors (Charnes-Cooper-Rhodes), the DEA approach has been improved and widely used in productivity analysis.

Using a linear programming technique, DEA envelops the dataset under consideration to construct a convex cone or piecewise hull (the technology frontier). The upper boundary of the convex cone represents the best practice (production frontier) and is made up of all technically efficient DMUs (Kumar \& Russel, 2002; Van Dijk \& Szirmai, 2011). By so doing, the DEA approach of measuring productive efficiency constructs a virtual production frontier for the sample of economies and associated efficiency indexes of individual economies. By constructing a virtual production frontier, we can measure how far or close each African economy is to the production frontier and how much inefficient economies need to adjust their production technology to become efficient. All African economies operating below the production frontier are considered technically inefficient as the combination of inputs yields output smaller than what could have been produced. Technically efficient economies operate on the production frontier. Technically efficient economies have an efficiency index of 1, and technically inefficient economies have an efficiency index of less than 1 . The efficiency index could be interpreted as encompassing both technological phenomena as well as the set of institutions and policies deployed in each economy to drive technical change (Kumar \& Russel, 2002).

In summary, DEA has an advantage over standard methods of studying catch-up relative to some defined frontier, which reduces the best-practice frontier to a point and compares other countries to the point in terms of efficient and inefficient utilization of factor supplies (Kumar \& Russel, 2002). Also, unlike standard stochastic frontier analysis (SFA) or econometric estimation of catch-up that assumes the shape of the production function, the nonparametric, data-driven DEA approach requires no specification of the functional form-an advantage DEA has over SFA and econometric approaches. Initially, an assumption about the returns to scale of technology is required, but with advances made in the statistical analysis of DEA, one can choose the appropriate returns to scale of a production technology through a formal statistical test (see test below). Assumptions about free disposability of inputs and outputs are, however, required (Kumar \& Russel, 2002; Van Dijk \& Szirmai, 2011).

\subsubsection{The DEA Model}

We calculate the Farrell (output-based) technical efficiency index of DMUs (countries) by solving the linear programming problem for each observation. We assume output (value added) is produced by two inputs (capital and labor). We also assume free disposability of inputs and outputs. We compute the efficiency indexes under constant returns to scale (CRS), variable returns to scale (VRS) and non- 
increasing returns to scale (NIRS). Suppose there are $J$ countries to be evaluated, given $n$ inputs and $w$ outputs.

The technology set is defined as:

\section{1}

$$
T\left(\theta^{*}\right)=E^{t}\left(L^{t}, K^{t}, Y^{t} \mid C R S\right)=\text { Minimize } \theta \text {, }
$$

Subject to:

$$
\begin{aligned}
& \sum_{j=1}^{J} \lambda_{j} Y_{w j} \geq Y_{W}, \quad w=1, \ldots \ldots \ldots W \\
& \sum_{j=1}^{J} \lambda_{j} L_{j} \leq \theta L_{n}, \quad n=1, \ldots \ldots \ldots N \\
& \sum_{j=1}^{J} \lambda_{j} K_{n j} \leq \theta K_{n}, \quad n=1, \ldots \ldots \ldots N \\
& \lambda_{j} \geq 0, j=1, \ldots . J
\end{aligned}
$$

Where $L_{n j t}, K_{n j t}$ and $Y_{w j t}$ are the labor, capital, and output of each country $j$ in time $t$. The convex cone formed by these column vectors is the technology set $T\left(\theta^{*}\right)$, with $\lambda$ being a $J \times 1$ vector of constants. The $n$ and $w$ inequalities capture the free disposability of inputs and output assumption and represent the $n$th inputs and $w$ th output for DMUs, respectively. The value of $\theta$ that solves the linear program problem gives the technical efficiency index for each country $j$ in time $t .^{83}$ If $\theta^{*}=1$, the DMU is on the frontier, and current inputs cannot be reduced (proportionally). The DMU is below the frontier if $\theta^{*}<1$. Equation (4.1) yields efficiency estimates under a constant returns to scale assumption. Efficiency estimates for other returns to scale specifications can be modeled by altering the constraint on the process operating levels vector, $\lambda_{j}$. For efficiency estimates under variable returns to scale $-E^{t}\left(L^{t}, K^{t}, Y^{t} \mid V R S\right)$ - the convexity constraint $\sum_{j=1}^{J} \lambda_{j}=1$ is imposed, whereas for efficiency estimates under nonincreasing returns to scale - $E^{t}\left(L^{t}, K^{t}, Y^{t} \mid N R S\right)$ - the inequality $\sum_{j=1}^{J} \lambda_{j} \leq 1$ is added to the set of constraints on inputs and output in equation (4.1)

\subsubsection{Nonparametric Test of Returns to Scale}

The returns to scale assumption used to specify the production technology is very important in DEA as efficiency estimates vary under different returns to scale assumptions (see Table 4.3). We, therefore, compute the scale efficiency for each country and test for the returns to scale assumption under which each country is scale efficient. The measures of (radial) technical efficiencies under CRS, NRS, and

\footnotetext{
83 This is from the optimistic DEA point of view since we maximize the efficiency of DMUs within the range of zero to one. In the case of the pessimistic DEA, the efficiency of DMUs is minimized relative to others within a range no less than one. For instance, measuring efficiency using the pessimistic DEA, a DMU will be pessimistically inefficient if the efficiency scores equal one and pessimistically efficient if efficiency score is greater than one (Wang \& Lan, 2011).
} 
VRS returns scale explained above can be used to compute the scale efficiency defined by Färe \& Grosskopf (1985) as follows:

$4.2 \quad S E_{j}^{0}\left(L^{t}, K^{t}, Y^{t}\right)=\frac{E^{t}\left(L^{t}, K^{t}, Y^{t} \mid C R S\right)}{E^{t}\left(L^{t}, K^{t}, Y^{t} \mid V R S\right)}$

$4.3 \quad S E_{j}^{1}\left(L^{t}, K^{t}, Y^{t}\right)=\frac{E^{t}\left(L^{t}, K^{t}, Y^{t} \mid N R S\right)}{E^{t}\left(L^{t}, K^{t}, Y^{t} \mid V R S\right)}$

Where the ratio $S E_{j}^{0}$ measures how close the data point - in our case $-\left(k^{t}, y^{t}\right)^{84}$ is to the maximum productive scale size. If $S E_{j}^{0}\left(L^{t}, K^{t}, Y^{t}\right)=1$, then the data point $\left(k^{t}, y^{t}\right)$ is scale efficient. If $S E_{j}^{0}\left(L^{t}, K^{t}, Y^{t}\right)>1$, the data point $\left(k^{t}, y^{t}\right)$ is scale inefficient because it is either operating on the decreasing portion of the technology, $T\left(\theta^{*}\right)$, i.e. if $S E_{j}^{1}\left(L^{t}, K^{t}, Y^{t}\right)=1$, or on the increasing portion of the technology, $T\left(\theta^{*}\right)$, i.e. if $S E_{j}^{1}\left(L^{t}, K^{t}, Y^{t}\right)>1$.

If the global technology $T\left(\theta^{*}\right)$ in equation (4.1) exhibits CRS, then the VRS estimator is less efficient than the CRS estimator and vice versa (Badunenko \& Mozharovskyi, 2016). To impose the right returns to scale (RTS) assumption, Simar \& Wilson (2002) suggest the following tests:

Test \#1: $H_{0}: T\left(\theta^{*}\right)$ is globally $C R S$ versus $H_{1}: T\left(\theta^{*}\right)$ is $V R S$

If the null hypothesis is rejected, then the following less restrictive test is conducted:

Test \#2: $H_{0}: T\left(\theta^{*}\right)$ is globally $N R S$ versus $H_{1}: T\left(\theta^{*}\right)$ is $V R S$

The test statistic for test \#1 and test \#2 is computed as follows:

$$
\tau_{1}=\sum_{j=1}^{J} S E_{j}^{0}\left(L^{t}, K^{t}, Y^{t}\right) J^{-1}
$$

$$
\tau_{2}=\sum_{j=1}^{J} S E_{j}^{1}\left(L^{t}, K^{t}, Y^{t}\right) J^{-1}
$$

Where $\tau_{1}$ represents the average ratio of the technical efficiencies under CRS technology to technical efficiencies under VRS. If the null hypothesis is true, then the distance between the CRS and VRS frontier is negligible. If the alternative hypothesis is true, then the average ratio of technical efficiencies between both frontiers is significantly different from 1. If the alternative hypothesis is true, then test \#2 is performed. Analogous to test \#1, if the null hypothesis is true, then the mean distance between the NRS and VRS frontiers is statistically indifferent from 1 . If the alternative is true, then the average distance between the NRS and VRS is statistically larger than 1.

A bootstrapping procedure is often used to calculate the test statistic of test \#1 and test \#2. Simar \& Wilson $(2000,2011)$ provide a detailed explanation of the concept and implementation of the bootstrapping technique. The bootstrapping method for output-based efficiency estimates relies on one fundamental testable assumption, namely whether the output-based efficiency estimates are independent of the mix of outputs. In other words, the test shows whether all the countries in the

$84 \frac{K^{t}}{L^{t}}=k^{t}, \frac{Y^{t}}{L^{t}}=y^{t}$ 
sample are similar in terms of technology and characteristics (homogeneous) or are not similar (heterogeneous). If output-based efficiency estimates are independent of the mix of outputs, a homogeneous bootstrap technique is used in the statistical test. If output-based efficiency estimates are dependent on the mix of outputs, a heterogenous bootstrap technique is preferred. The Heterogeneous bootstrap is used in this case since a formal test of independence indicates outputbased measures of technical efficiency are not independent of the mix of outputs (Badunenko \& Mozharovskyi, 2016:256). The test confirms the empirical reality that African countries are different in terms of the adoption and usage of technology as well as other idiosyncratic factors. The test of returns to scale assumption shows that all countries are statistically scale-efficient under constant returns to scale technology in the heterogeneous bootstrap (see Table 4.1). Therefore, the preferred efficiency scores are the ones under constant returns to scale specifications.

Table 4.1: Test of Returns to Scale

\begin{tabular}{|c|c|c|c|c|c|}
\hline \multicolumn{3}{|c|}{ Scale Analysis_-1970 } & \multicolumn{3}{|c|}{ Scale Analysis-2014 } \\
\hline DMU & $\mathrm{SE}$ & $\begin{array}{l}\text { Scale Efficient } \\
\text { under CRS } \\
\text { (Heterogeneous) }\end{array}$ & DMU & $\mathrm{SE}$ & $\begin{array}{l}\text { Scale Efficient } \\
\text { under CRS } \\
\text { (Heterogeneous) }\end{array}$ \\
\hline BWA & 1.12 & scale efficient & BWA & 1.00 & scale efficient \\
\hline BFA & 1.03 & scale efficient & BFA & 1.07 & scale efficient \\
\hline CMR & 1.03 & scale efficient & CMR & 1.00 & scale efficient \\
\hline ETH & 1.16 & scale efficient & ETH & 1.12 & scale efficient \\
\hline GHA & 1.04 & scale efficient & GHA & 1.02 & scale efficient \\
\hline $\mathrm{KEN}$ & 1.21 & scale efficient & $\mathrm{KEN}$ & 1.09 & scale efficient \\
\hline LSO & 1.03 & scale efficient & LSO & 1.66 & scale efficient \\
\hline MWI & 1.00 & scale efficient & MWI & 1.10 & scale efficient \\
\hline MUS & 1.63 & scale efficient & MUS & 1.00 & scale efficient \\
\hline MOZ & 1.03 & scale efficient & MOZ & 1.07 & scale efficient \\
\hline NAM & 1.33 & scale efficient & NAM & 1.01 & scale efficient \\
\hline NGA & 1.32 & scale efficient & NGA & 1.00 & scale efficient \\
\hline RWA & 1.00 & scale efficient & RWA & 1.24 & scale efficient \\
\hline SEN & 1.02 & scale efficient & SEN & 1.07 & scale efficient \\
\hline ZAF & 1.00 & scale efficient & ZAF & 1.02 & scale efficient \\
\hline TZA & 1.19 & scale efficient & TZA & 1.01 & scale efficient \\
\hline UGA & 1.04 & scale efficient & UGA & 1.06 & scale efficient \\
\hline ZMB & 1.00 & scale efficient & ZMB & 1.01 & scale efficient \\
\hline
\end{tabular}

$* \mathrm{SE}=$ statistically scale efficient under CRS

\subsection{Efficiency Results}

In figures 4.1 and 4.2, we analyze the evolution of the distribution of output per worker and capital per worker between 1970 and 2014, respectively. The distribution of output per worker (Figure 4.1) has shifted to the right, implying that labor productivity has improved over the period. The peak of 
the distribution increased from $\$ 3,833$ to $\$ 8,490$ (Table 4.2). While in 1970 there was no country in Africa with the productivity level of $\$ 10,000$ or above, in 2014 , a few countries reported a productivity level close to $\$ 30,000$, a $\$ 20,000$ change in productivity for the countries in the upper end of the distribution. ${ }^{85}$ This transformation in labor productivity could be interpreted as the emergence of lower middle-income countries in the region.

A similar observation is made in Figure 4.2, which shows that in 1970 many countries had a low capital stock and a resultant low capital per worker. By 2014, the distribution of capital per worker in Africa had transformed drastically, with labor having more capital to work with. On average, productive efficiency is unchanged, decreasing slightly from 0.71 to 0.70 (see Table 4.2). However, this average trend in efficiency differs by country.

Figure 4.1: Evolution of Output per worker

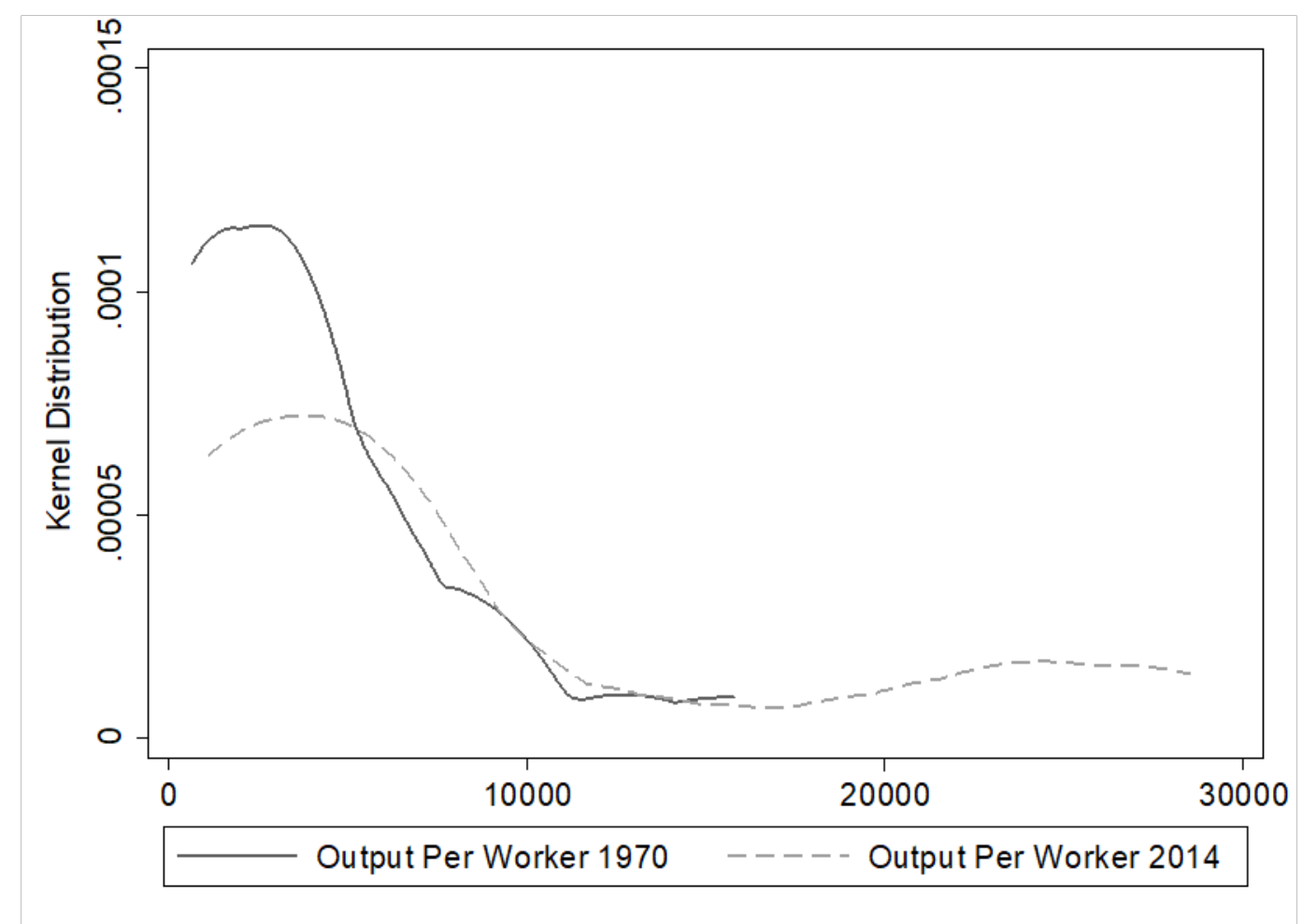

Note: A kernel density plot visualizing the distribution of output per worker in 1970 and 2014 computed from EASD

${ }^{85}$ For purposes of comparison, this compares well with the change in labor productivity in the US, which increased by $\$ 33,712$ - from $\$ 56,616$ in 1970 to $\$ 90,338$ in 2014. 
Figure 4.2: Evolution of Capital per Worker

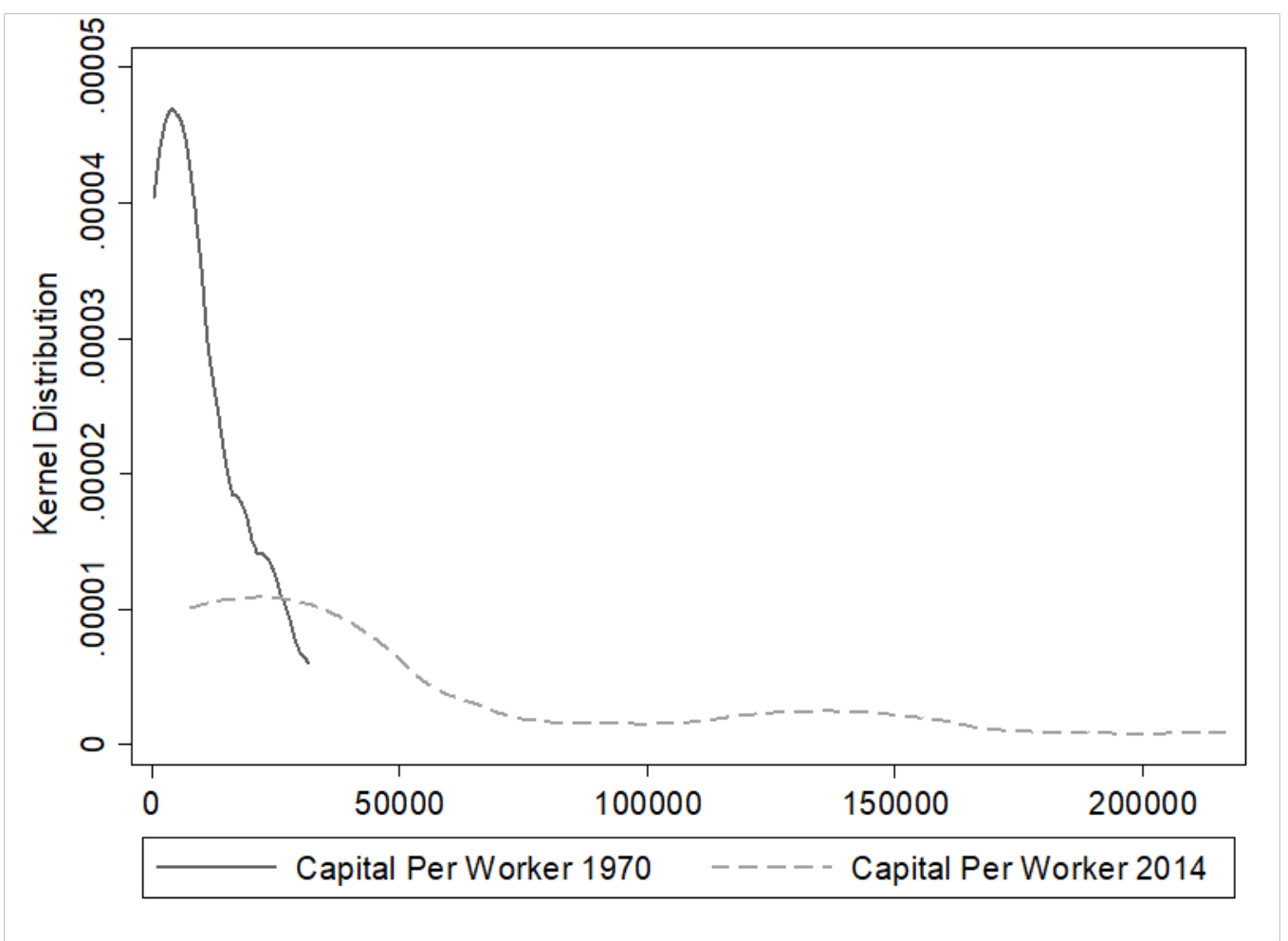

Note: A kernel density plot visualizing the distribution of capital per worker in 1970 and 2014 computed from EASD and PWT 9.0

Table 4.3 reports the radial technical efficiencies by country in 1970 and 2014, respectively. The radial index measures inefficiency in terms of distance to the production frontier, whereas the non-radial measure defines inefficiency in terms of efficient subsets as opposed to the production frontier. For robustness, non-radial measures are also reported in Table A4.3 \& A4.4 in the appendix. The results of both radial and non-radial measures are quantitively and qualitatively the same. In 1970, Rwanda, South Africa, and Zambia were on the production frontier. By 2014, Rwanda and Zambia had fallen behind, with Botswana, Cameroon, Mauritius, and Nigeria joining South Africa as frontier countries. In terms of GDP per worker or GDP per capita, it is only Botswana and Mauritius that have converged to the level of SA. Therefore, it seems surprising to observe that Cameroon and Nigeria are on the production frontier. 
Table 4.2: Descriptive Statistics

\begin{tabular}{lccccc}
\hline Variables & Observation & Mean & SD & Min & Max \\
\hline Output per worker in 1970 & 18 & 3,833 & 3,978 & 650.7 & 15,780 \\
Output per worker in 2014 & 18 & 8,490 & 9,225 & 1,101 & 28,556 \\
Capital per worker in 1970 & 18 & 9,105 & 9,191 & 495.8 & 31,673 \\
Capital per worker in 2014 & 18 & 51,958 & 61,798 & 7,725 & 216,694 \\
Average efficiency index with only labor in 1970 & 18 & 0.292 & 0.307 & 0.0400 & 1 \\
Average efficiency index with only labor in 2014 & 18 & 0.366 & 0.373 & 0.0500 & 1 \\
Average efficiency index with only capital in 1970 & 18 & 0.626 & 0.264 & 0.210 & 1 \\
Average efficiency index with only capital in 2014 & 18 & 0.615 & 0.242 & 0.300 & 1 \\
Average efficiency index with both inputs in 1970 & 18 & 0.709 & 0.246 & 0.220 & 1 \\
Average efficiency index with both inputs in 2014 & 18 & 0.703 & 0.257 & 0.350 & 1 \\
\hline
\end{tabular}

Note: As a standard DEA procedure, the technical efficiency is computed for the beginning period and the end period.

However, in a similar analysis of Kumar \& Russell (2002), Sierra Leone, which is one of the most technologically backward countries in the world, was on the technology frontier with the US. The plausible explanation often stated for these peculiar observations is that the DEA is constructed such that it places a lower boundary on the frontier under the assumption of constant returns technology and as a result it may fail to identify the true but unknown frontier especially at low capital-labor ratios (Kumar \& Russell, 2002).

Table 4.3: Radial Measures of Technical Efficiency for African Countries

\begin{tabular}{l|ccc|ccc}
\hline & \multicolumn{3}{c|}{1970} & \multicolumn{3}{c}{2014} \\
\hline DMU & TErdCRS_LK & TErdNR__LK & TErdVRS_LK & TErdCRS_LK & TErdNR__LK & TErdVRS_LK \\
\hline Botswana & 0.73 & 0.73 & 0.81 & 1.00 & 1.00 & 1.00 \\
Burkina Faso & 0.81 & 0.84 & 0.84 & 0.82 & 0.82 & 0.88 \\
Cameroon & 0.47 & 0.49 & 0.49 & 1.00 & 1.00 & 1.00 \\
Ethiopia & 0.86 & 1.00 & 1.00 & 0.37 & 0.42 & 0.42 \\
Ghana & 0.22 & 0.23 & 0.23 & 0.43 & 0.43 & 0.44 \\
Kenya & 0.44 & 0.53 & 0.53 & 0.70 & 0.76 & 0.76 \\
Lesotho & 0.97 & 0.97 & 1.00 & 0.60 & 0.60 & 1.00 \\
Malawi & 0.52 & 0.52 & 0.52 & 0.35 & 0.35 & 0.39 \\
Mauritius & 0.61 & 0.61 & 1.00 & 1.00 & 1.00 & 1.00 \\
Mozambique & 0.92 & 0.95 & 0.95 & 0.81 & 0.81 & 0.87 \\
Namibia & 0.75 & 0.75 & 1.00 & 0.84 & 0.84 & 0.85 \\
Nigeria & 0.76 & 1.00 & 1.00 & 1.00 & 1.00 & 1.00 \\
Rwanda & 1.00 & 1.00 & 1.00 & 0.81 & 0.81 & 1.00 \\
Senegal & 0.72 & 0.72 & 0.73 & 0.65 & 0.65 & 0.70 \\
South Africa & 1.00 & 1.00 & 1.00 & 1.00 & 1.00 & 1.00 \\
Tanzania & 0.38 & 0.45 & 0.45 & 0.36 & 0.37 & 0.37 \\
Uganda & 0.61 & 0.63 & 0.63 & 0.48 & 0.51 & 0.51 \\
Zambia & 1.00 & 1.00 & 1.00 & 0.43 & 0.43 & 0.43 \\
\hline * TErdCRS = the radial output-based measures of technical efficiency under the assumption of constant returns to scale \\
* TErdNRS $=$ the radial output-based measures of technical efficiency under the assumption of non- increasing returns to scale \\
* TErdVRS = the radial output-based measures of technical efficiency under the assumption of variable returns to scale
\end{tabular}


$* \mathrm{LK}=$ both labor and capital used as inputs.

In our case, while Botswana and Mauritius have the highest capital-labor ratios in our sample, Cameroon and Nigeria have ratios below the average of the sample. In the face of this observation, we conclude that Botswana and Mauritius are the two countries that have robustly converged to the efficiency level of the frontier. All the other countries are either slowly converging or falling away.

\subsection{Dynamic Efficiency in Africa}

The slow rate of technological catch-up is often stated as the main cause of nonconvergence or slow convergence of productivity. For example, in the earlier (mainstream) literature on convergence, the slow diffusion of technology is often cited as the main cause of the slow convergence of productivity (Barro \& Sala-i-Martin, 1997; Mankiw et al., 1992). In the current context, technology is denoted by the state-of-the-art production frontier. A shift in the production frontier denotes technological change, and a movement toward the frontier represents technological catch-up. To understand why some African countries converged to the productivity level of the frontier while others did not, we decompose productivity growth into these two components - technological catch-up and technological change - using the Malmquist Productivity Index (MPI). ${ }^{86}$ The DEA (distance function)-based MPI decomposes productivity changes attributable to changes in efficiency (technological catch-up) and changes in technology (shift of the frontier). In a broader sense, technological catch-up captures changes in a country's productive behavior and performance over time due to policy initiatives. That is, the innovative initiatives of the country that lead to a productive reward. Conversely, technological change denotes general technical progress and the ability of countries to absorb this new knowledge to improve production. The change in efficiency is further decomposed into a pure efficiency and a scale efficiency change. Scale efficiency measures how close the data points of DMUs are to the potentially most productive or the optimal scale size and whether a DMU must reduce or increase its scale while maintaining the best practices it already has.

All assumptions made in constructing the DEA model above when estimating the Farrell (outputbased) technical efficiency index of DMUs apply here. Suppose there are $J$ DMUs to be evaluated given $n$ inputs and $W$ outputs in time periods $t$ and $t+1$ respectively, four indicators of technical efficiencies are required: (1) technical efficiencies at the base-period, $t,(2)$ technical efficiencies at the current-period, $t+1$, and two counterfactuals, (3) potential base-period efficiency of DMUs using current-period technology, (4) potential current-period efficiency of DMUs using base-period technology. We denote inputs of DMUs by $L_{n j t}, K_{n j t}$ and $Y_{w j t}$. The solution of the optimistic DEAbased MPI is given as follows.

Technical efficiencies of DMUs in the base-period $(t)$ :

4.6 $E^{t}\left(L^{t}, K^{t}, Y^{t} \mid C R S\right)=$ Minimise $\theta$,

\footnotetext{
${ }^{86}$ The MPI is originally named after Professor Sten Malmquist, whose idea the MPI is based upon. Originally used to estimate a consumer-based index by Professor Malmquist, Caves et al. (1982) replaced the indifference curve with a technology frontier to define a productivity index. Färe, Grosskopf, \& Lindgren, (1992) made substantial efforts to combine the efficiency measurement of Farrell, (1957), Charnes et al (1978) and the productivity measurement of Caves et al. (1982) to come up with a DEA-based MPI (Wang \& Lan, 2011).
} 
Subject to the following constraints:

$$
\begin{aligned}
& \sum_{j=1}^{J} \lambda_{j} Y_{w j}^{t} \geq Y_{W}^{t}, \quad w=1, \ldots \ldots \ldots, W \\
& \sum_{j=1}^{J} \lambda_{j} L_{n j}^{t} \leq \theta L_{n}^{t}, \quad n=1, \ldots \ldots \ldots, N \\
& \sum_{j=1}^{J} \lambda_{j} K_{n j}^{t} \leq \theta K_{n}^{t}, \quad n=1, \ldots \ldots \ldots, N \\
& \lambda_{j} \geq 0, j=1, \ldots, J
\end{aligned}
$$

Technical efficiencies of DMUs in the current period:

$4.7 E^{t+1}\left(L^{t+1}, K^{t+1}, Y^{t+1} \mid C R S\right)=$ Minimise $\theta$,

Subject to the following constraints:

$$
\begin{aligned}
& \sum_{j=1}^{J} \lambda_{j} Y_{w j}^{t+1} \geq Y_{W}^{t+1}, \quad w=1, \ldots \ldots \ldots, W \\
& \sum_{j=1}^{J} \lambda_{j} L_{n j}^{t+1} \leq \theta L_{n}^{t+1}, \quad n=1, \ldots \ldots \ldots, N \\
& \sum_{j=1}^{J} \lambda_{j} K_{n j}^{t+1} \leq \theta K_{n}^{t+1}, \quad n=1, \ldots \ldots \ldots, N \\
& \lambda_{j} \geq 0, j=1, \ldots, J
\end{aligned}
$$

Technical efficiencies of DMUs in the base-period using current-period technology:

4.8 $E^{t+1}\left(L^{t}, K^{t}, Y^{t} \mid C R S\right)=$ Minimise $\theta$,

Subject to:

$$
\begin{array}{ll}
\sum_{j=1}^{J} \lambda_{j} Y_{w j}^{t+1} \geq Y_{W}^{t}, & w=1, \ldots \ldots \ldots, W \\
\sum_{j=1}^{J} \lambda_{j} L_{n j}^{t+1} \leq \theta L_{n}^{t}, & n=1, \ldots \ldots \ldots, N
\end{array}
$$




$$
\begin{aligned}
& \sum_{j=1}^{J} \lambda_{j} K_{n j}^{t+1} \leq \theta K_{n}^{t}, \quad n=1, \ldots \ldots \ldots, N \\
& \lambda_{j} \geq 0, j=1, \ldots, J
\end{aligned}
$$

Technical efficiencies of DMUs in the current-period using base-period technology:

$$
E^{t}\left(L^{t+1}, K^{t+1}, Y^{t+1} \mid C R S\right)=\text { Minimise } \theta,
$$

Subject to:

$$
\begin{array}{ll}
\sum_{j=1}^{J} \lambda_{j} Y_{w j}^{t} \geq Y_{W}^{t+1}, & w=1, \ldots \ldots \ldots, W \\
\sum_{j=1}^{J} \lambda_{j} L_{n j}^{t} \leq \theta L_{n}^{t+1}, & n=1, \ldots \ldots \ldots, N \\
\sum_{j=1}^{J} \lambda_{j} K_{n j}^{t} \leq \theta K_{n}^{t+1}, & n=1, \ldots \ldots \ldots, N \\
\lambda_{j} \geq 0, j=1, \ldots, J &
\end{array}
$$

As explained above, $E^{t}\left(L^{t}, K^{t}, Y^{t}\right)$ and $E^{t+1}\left(L^{t+1}, K^{t+1}, Y^{t+1}\right)$ measure efficiencies of DMUs in time periods $t$ and $t+1$, respectively, $E^{t}\left(L^{t+1}, K^{t+1}, Y^{t+1}\right)$ denotes efficiencies of DMUs in time $t+1$ using production technology of time $t$ and $E^{t+1}\left(L^{t}, K^{t}, Y^{t}\right)$ efficiencies of DMUs in time $t$ using production technology of time $t+1$ (Wang \& Lan, 2011).

\subsubsection{Malmquist productivity index}

Proposed by Färe, Grosskopf, \& Lindgren, (1992), the resultant Malmquist productivity index that measures productivity changes of DMUs in time periods $t$ and $t+1$ takes the form:

$$
\mathrm{MPI}=\left[\left(\frac{E^{t}\left(L^{t+1}, K^{t+1}, Y^{t+1}\right)}{E^{t}\left(L^{t}, K^{t}, Y^{t}\right)}\right) \times\left(\frac{E^{t+1}\left(L^{t+1}, K^{t+1}, Y^{t+1}\right)}{E^{t+1}\left(L^{t}, K^{t}, Y^{t}\right)}\right)\right]^{\frac{1}{2}}
$$

There is an improvement in productivity growth between time periods $t$ and $t+1$ if MPI (optimistic) is greater than 1. A value of MPI equal to one implies that productivity has stagnated, while a value less than one means that there has been a productivity decline. Färe, Grosskopf, \& Lindgren, (1992) further decomposed the MPI (optimistic) into two separate components.

$$
\mathrm{MPI}=\left(\frac{E^{t}\left(L^{t+1}, K^{t+1}, Y^{t+1}\right)}{E^{t}\left(L^{t}, K^{t}, Y^{t}\right)}\right) \times\left[\left(\frac{E^{t}\left(L^{t}, K^{t}, Y^{t}\right)}{E^{t+1}\left(L^{t}, K^{t}, Y^{t}\right)}\right) \times\left(\frac{E^{t}\left(L^{t+1}, K^{t+1}, Y^{t+1}\right)}{E^{t+1}\left(L^{t+1}, K^{t+1}, Y^{t+1}\right)}\right)\right]^{\frac{1}{2}}
$$

Where the first and second term on the right-hand side represent productivity changes attributable to efficiency change (whether or not a DMU is catching up to the frontier over time) and technology 
change (whether or not the frontier is shifting out over time) respectively. Using both CRS and VRS DEA frontiers to estimate the distance function in Equation (11), technical efficiency is further decomposed into a scale and a pure efficiency change given by:

4.12 Pure Efficiency Change $=\frac{E^{t+1(v r s)}\left(L^{t+1}, K^{t+1}, Y^{t+1}\right)}{E^{t(c r s)}\left(L^{t}, K^{t}, Y^{t}\right)}$

4.13 Scale-Efficiency-Change $=\left[\frac{E^{t+1(v r s)}\left(L^{t+1}, K^{t+1}, Y^{t+1}\right) / E^{t+1(c r s)}\left(L^{t+1}, K^{t+1}, Y^{t+1}\right)}{E^{t+1(v r s)}\left(L^{t}, K^{t}, Y^{t}\right) / E^{t+1(c r s)}\left(L^{t}, K^{t}, Y^{t}\right)} \times\right.$

$\left.\frac{E^{t(v r s)}\left(L^{t+1}, K^{t+1}, Y^{t+1}\right) / E^{t(c r s)}\left(L^{t+1}, K^{t+1}, Y^{t+1}\right)}{E^{t(v r s)}\left(L^{t}, K^{t}, Y^{t}\right) / E^{t(c r s)}\left(L^{t}, K^{t}, Y^{t}\right)}\right]^{1 / 2}$

A country which has a scale efficiency change equal to one means the country is operating at the optimum scale. Based on the statistical test of returns to scale above, we used constant returns to scale technology to estimate the MPI.

\subsubsection{Technological Catch-up Within Africa}

The result of the output based MPI for each of the 18 countries in our sample is reported in Table 4.4. As a standard procedure, the MPI is calculated using five-year intervals because technological change or efficiency change at the country level normally happens in the medium to long term. In confirmation of the existing finding that convergence is primarily driven by technological catch-up, the stellar total productivity growth of Botswana and Mauritius is driven more by technological catchup and less by technological change. Total productivity growth grew by $7 \%$ and $9 \%$ every five years on average in Botswana and Mauritius, respectively, between 1970 and 2014. Of these, technological catch-up accounts for $4 \%$ and $6 \%$ in Botswana and Mauritius, respectively. The MPI also shows that the total productivity of Cameroon and Ghana improved by 3.0 and $1.0 \%$ (quinquennially), respectively. In the case of Cameroon and Ghana, however, all productivity gains were due to improvements in efficiency levels (catch-up). Productivity in all the other countries, either stagnated or declined. Technological catch-up was significant in Cameroon (9\%), Ghana (8\%), Kenya (5\%), and Nigeria $(3 \%)$. However, this, in combination with a negative technical change (i.e. an inability to benefit from the shift in the production frontier), penalized overall total productivity growth. This indicates that faster productivity convergence is possible through a combination of technical progress and technological catch-up. The ability of individual countries to benefit from general technological progress often depends on the level of capitalization of the country. Highly capitalized countries have the infrastructural architecture necessary to gain from the shift in the production frontier (Kumar \& Russell, 2002). Botswana and Mauritius are highly capitalized, and as a result, they gained from the shift of the African production frontier.

The results are very interesting in the sense that while technological progress has contributed positively to productivity growth of these two relatively rich countries, the same cannot be said for the other two relatively poor countries (Cameroon and Ghana) that experienced productivity improvements over the same period but with a technological regression. What this means is that technological progress has disproportionately benefitted relatively rich countries in Africa. This supports the general 
conclusion that wealthy economies have benefitted from technological progress to a greater extent than poor economies (cf. Kumar \& Russel, 2002: 538).

In Figure 4.3, we observe that highly capitalized economies tend to be wealthy economies with high per capita incomes in the context of Africa. In our sample, Botswana, Namibia, Mauritius, and South Africa could be classified as rich African countries given the relatively high per capita incomes of these countries within Africa. The rest of the countries could be classified as poor African countries, given their low per capita incomes. A substantial outward shift in the frontier (technological progress) in Botswana and Mauritius (see figures $4.4 \& 4.5$ ) at high capital-labor ratios (see fig 4.3) means that technological change tends to take place in highly capitalized economies which happen to be relatively wealthy economies. Thus, even in Africa, wealthy economies tend to benefit more from technological change if they are highly capitalized.

Table 4.4: Dynamic Efficiency in Africa

\begin{tabular}{lccccc}
\hline Country & $\begin{array}{c}\text { Total } \\
\text { Productivity } \\
\text { Growth }\end{array}$ & $\begin{array}{c}\text { Technology } \\
\text { Change }\end{array}$ & $\begin{array}{c}\text { Technological } \\
\text { Catch-up } \\
\text { (Efficiency } \\
\text { change) }\end{array}$ & \multicolumn{2}{c}{$\begin{array}{c}\text { Catch-up (Efficiency } \\
\text { Change) }\end{array}$} \\
\cline { 5 - 6 } Botswana & 1.07 & 1.03 & 1.04 & 1.02 & $\begin{array}{c}\text { Scale } \\
\text { Efficiency }\end{array}$ \\
Burkina Faso & 0.98 & 0.98 & 1.00 & 1.01 & 1.01 \\
Cameroon & 1.03 & 0.95 & 1.09 & 1.08 & 1.00 \\
Ethiopia & 0.88 & 0.97 & 0.91 & 0.91 & 1.00 \\
Ghana & 1.01 & 0.94 & 1.08 & 1.08 & 1.00 \\
Kenya & 0.98 & 0.93 & 1.05 & 1.04 & 1.01 \\
Lesotho & 0.91 & 0.96 & 0.95 & 1.00 & 0.95 \\
Malawi & 0.94 & 0.98 & 0.96 & 0.97 & 0.99 \\
Mauritius & 1.09 & 1.04 & 1.06 & 1.00 & 1.06 \\
Mozambique & 0.90 & 0.91 & 0.99 & 0.99 & 1.00 \\
Namibia & 0.97 & 0.96 & 1.01 & 0.98 & 1.03 \\
Nigeria & 0.99 & 0.96 & 1.03 & 1.00 & 1.03 \\
Rwanda & 0.89 & 0.91 & 0.98 & 1.00 & 0.98 \\
Senegal & 0.95 & 0.96 & 0.99 & 0.99 & 0.99 \\
South Africa & 0.99 & 0.99 & 1.00 & 1.00 & 1.00 \\
Tanzania & 0.92 & 0.92 & 1.00 & 0.98 & 1.02 \\
Uganda & 0.94 & 0.96 & 0.97 & 0.98 & 1.00 \\
Zambia & 0.87 & 0.95 & 0.91 & 0.911 & 1.00 \\
\hline
\end{tabular}

*Both L\&K used in Malmquist. Note the effect of efficiency change and technology change is multiplicative. 
Figure 4.3: Output Per Worker 2014 Plotted Against Capital Per Worker 2014

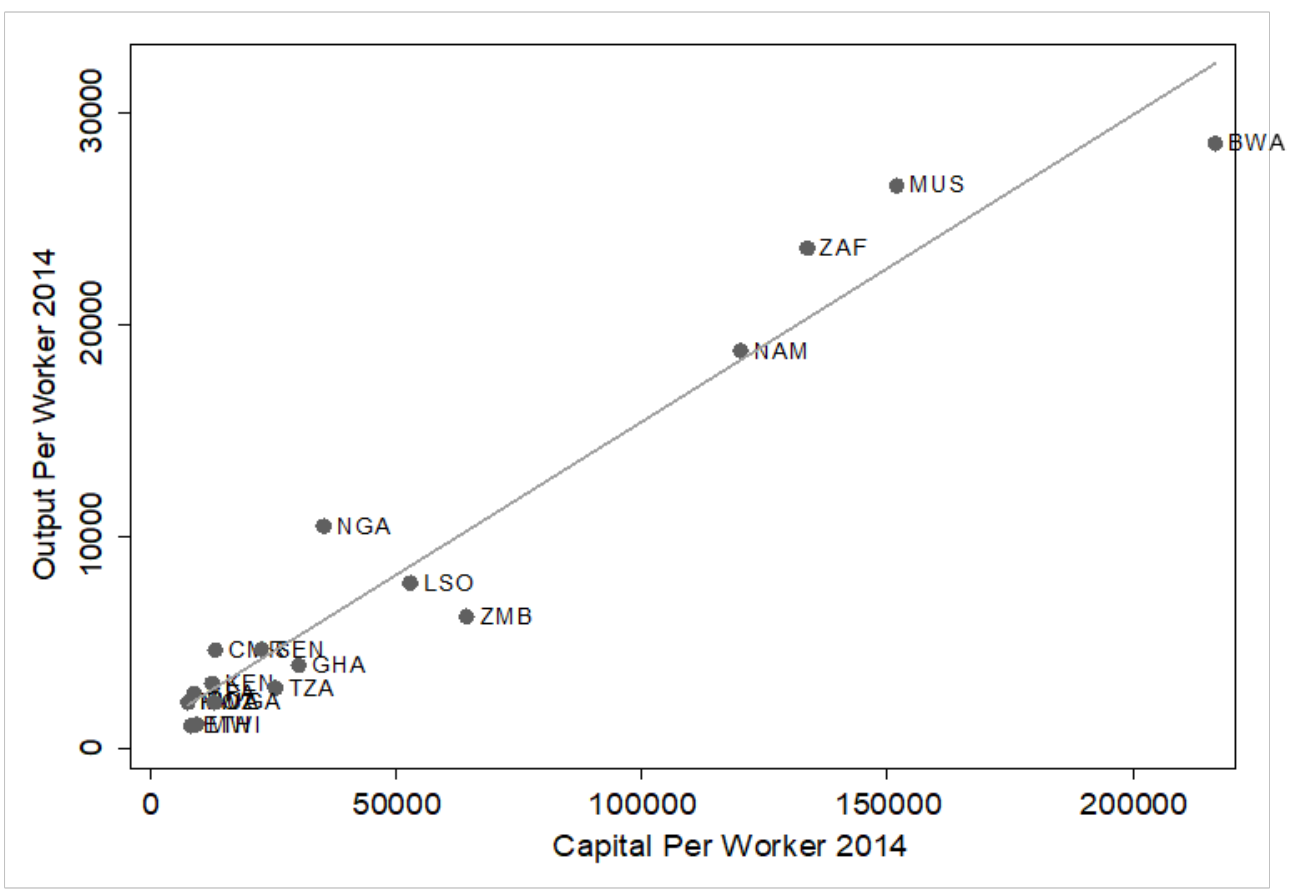

Figure 4.4: Technology Change Between 1970-2014 Plotted Against Output Per Worker 1970

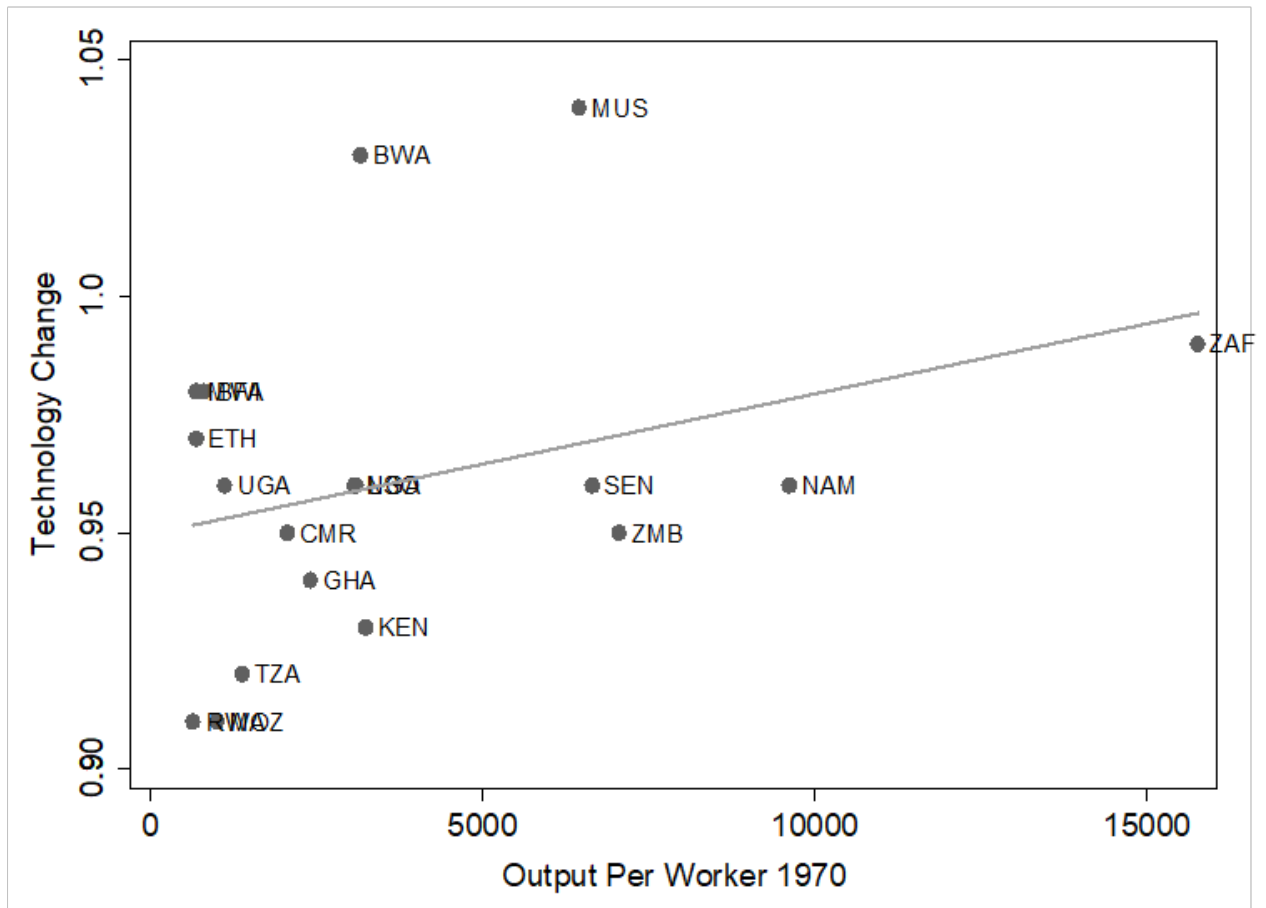


Figure 4.5: Technology Change Between 1970-2014 Plotted Against Output Per Worker 2014

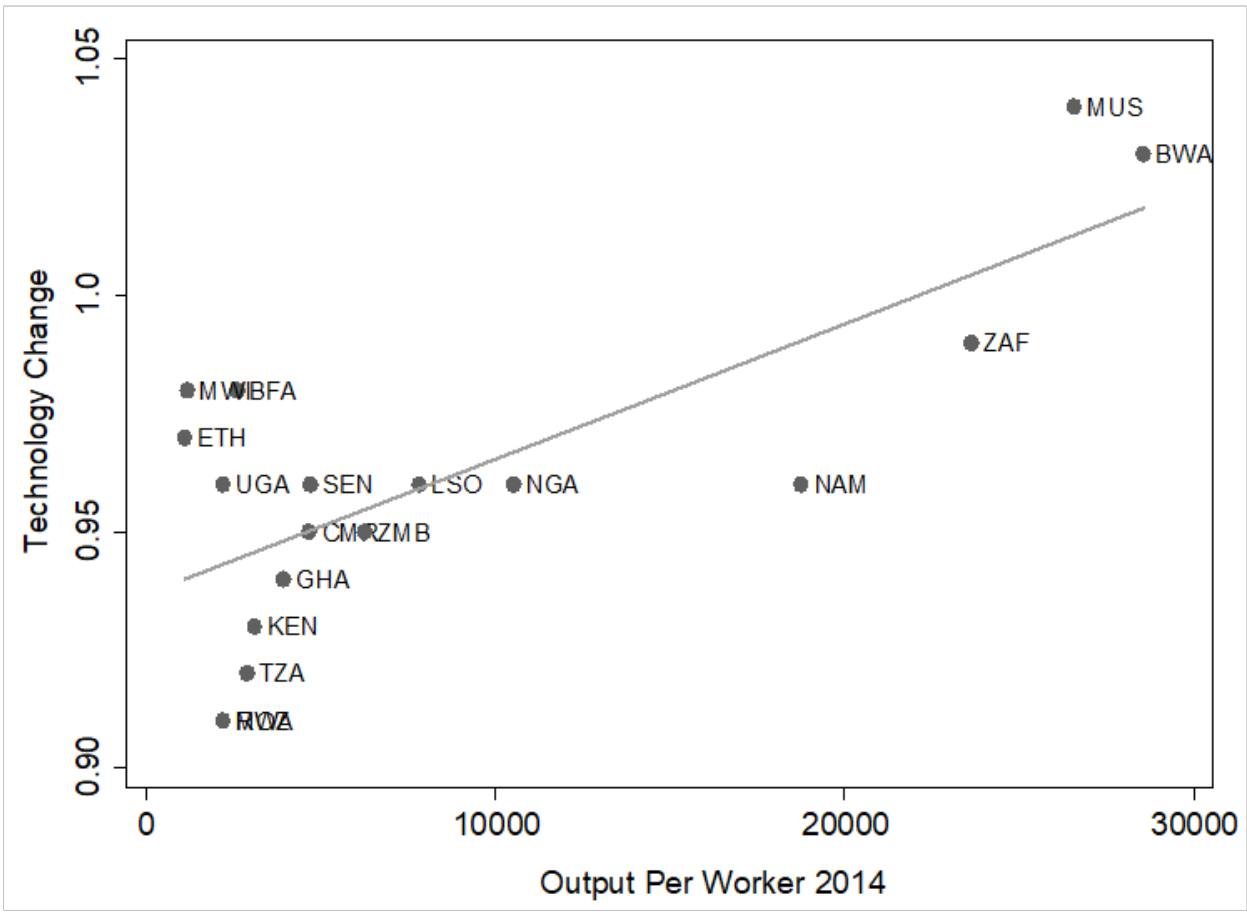

\subsection{Catch-up Within Africa: Is structural change important?}

In the previous section, we established that technological catch-up, on average, has been more important than technological change in productivity convergence within Africa. For example, technological catch-up is the primary factor behind the successful convergence of Botswana and Mauritius. Technological catch-up was also important in countries such as Cameroon, Ghana, Kenya, and Nigeria, although, however, the positive gains from technological catch-up were outweighed by the negative contribution of technological change, slowing down the speed of productivity convergence. The convergence of countries to the productivity frontier through efficiency change and technological change is strongly underpinned by structural shifts of resources (both labor and capital) across sectors. Using a sample of 39 countries between 1973 and 1990, Fagerberg (2000) finds that structural change matters for overall growth and convergence and that countries that have managed to increase their presence in the technologically most progressive industries have experienced higher productivity growth. To understand further the importance of structural change to productivity convergence in Africa, we decompose technological catch-up using a structural shift-share model. This allows us to reflect on the role of structural change in the catch-up of the region. With this approach, we are able to examine if countries in the region are moving resources to sectors where the technology gap with the frontier is lower or decreasing over time.

Since the allocation of resources across sectors involves both labor and capital, the ideal strategy would be to use both inputs in our structural decomposition. However, due to data limitations on sectoral 
capital, we resort to the second-best solution, where we use only labor as inputs in the structural shiftshare model. To this end and within the context of the structural model, we define technological catchup as a process where a country eliminates the labor productivity gap with the frontier by moving workers into sectors with a lower technology gap with the frontier (i.e. a static effect) or a decreasing technology gap with the frontier (i.e., a dynamic effect). For this exercise, we use South Africa as the technological leader for two reasons: South Africa has been on the African technology frontier since 1970 (see section 4.3 DEA results in Table 4.3). Second, South Africa leads the rest of Africa in terms of quality education, innovation, and intellectual property production (see Appendix A for further explanation), this is particularly important for maintaining its technological hegemony in the region.

\subsubsection{Decomposition of Technological Catch-up}

The technology gap is measured as the aggregate labor productivity of each country relative to the aggregate labor productivity of South Africa (SA). This approach allows us to decompose annual catch-up (i.e. the percentage reduction in the technology gap) into an initial specialization effect, a reallocation effect and a within effect. This approach bears a resemblance to the shift-and-share methodology widely used in the literature to study productivity growth. However, this approach focuses on the technology gap instead of productivity growth (Lavopa, 2015).

The approach adopted was developed by Lavopa (2015) to study catch up by decomposing technology gaps in modern market activities within the context of high income and emerging countries. We adopt this approach but focus on aggregate technology gaps within Africa. The aggregate technology gap is postulated as:

$$
\theta_{t}^{i}=\frac{P_{t}^{i}}{P_{t}^{f}}
$$

Where $\theta_{t}^{i}$ is the technology gap of country $i$ in time $t, P_{t}^{i}$ is the aggregate labor productivity of (laggard) country $i$ in time $t$, and $P_{t}^{f}$ is aggregate labor productivity of the frontier country $f$ in time $t$, with SA being the frontier in this case. The aggregate productivity of country $i$ is the sum of the sectoral productivities weighted by their employment shares $\left(s_{k t}^{i}\right)$. This is given as:

$$
4.15 \quad P_{t}^{i}=\frac{Y_{t}^{i}}{E_{t}^{i}}=\sum_{j} \frac{Y_{k t}^{i} E_{k t}^{i}}{E_{k t}^{i} E_{t}^{i}}=\sum_{j} p_{k t}^{i} s_{k t}^{i}
$$

Where $Y$ is value added and $s_{k t}^{i}$ is the employment share of sector $k$ at time $t$. Substituting (4.15) into (4.14) gives:

$$
4.16 \quad \theta_{t}^{i}=\frac{\sum_{k} p_{k t}^{i} s_{k t}^{i}}{P_{t}^{f}}=\sum_{k} \frac{p_{k t}^{i} p_{k t}^{f}}{p_{k t}^{f} p_{t}^{f}} s_{k t}^{i}=\sum_{k} \theta_{k t}^{i} r_{k t}^{f} s_{k t}^{i}
$$

The technology gap of an African country can be measured as the multiplication of the sectoral productivity relative to the frontier $\left(\theta_{k t}^{i}\right)$, the sectoral employment share in the laggard economy $\left(S_{k t}^{i}\right)$, and the sectoral productivity of the frontier country relative to the aggregate frontier productivity $\left(r_{k t}^{f}\right)$ and, as discussed, $r_{k t}^{f}$ is the productivity of a particular sector in the frontier relative to the total 
economy productivity in the frontier. It is a proxy for the technological sophistication of the sector in question. Productivity improves if laggard countries reduce the technology gap with sectors of the frontier with higher $r_{k t}^{f}$. Taking the time difference of (4.16) with 0 and $T$ as initial and final time gives:

$$
4.17 \Delta \theta^{i}=\theta_{T}^{i}-\theta_{0}^{i}=\sum_{k} \theta_{k T}^{i} r_{k T}^{f} s_{k T}^{i}-\sum_{k} \theta_{k 0}^{i} r_{k 0}^{f} s_{k 0}^{i}
$$

Applying the idea of the shift-and-share method and manipulating equation (4.17), we decompose the technology gap into four components that explain the underlying drivers of technological catch-up within Africa as:

$$
4.18 \Delta \theta^{i}=\sum_{k} s_{k 0}^{i} r_{k T}^{f} \Delta \theta_{k}^{i}+\sum_{k} \theta_{k 0}^{i} r_{k T}^{f} \Delta s_{k}^{i}+\sum_{k} r_{k T}^{f} \Delta \theta_{k}^{i} \Delta s_{k}^{i}+\sum_{k} \theta_{k 0}^{i} s_{k 0}^{i} \Delta r_{k}^{f}
$$

The first component of the right-hand side is the sum of each sector's within-sector catch-up term. It is that part of the overall catch-up caused by the reduction of technology gaps at the sectoral level. The reduction of sectoral productivity gaps could be due to the introduction of new technology (e.g., resulting from the adoption of a mix of innovations), changes in organizational structure, downsizing (e.g., shedding surplus labor) or increased competition within a sector. The next two components measure catch-up due to labor reallocation. The first term is the between static reallocation catch-up term. It captures whether workers move to sectors with a smaller or larger technological gap relative to the frontier economy. The reallocation of workers to sectors with a smaller (larger) gap will tend to reduce (increase) the aggregate gap (Lavopa, 2015). The second term is the dynamic reallocation catchup term. It measures the joint effect of changes in both employment shares as well as changes in sectoral technology gaps during the period. It captures whether catch-up is higher or lower in sectors that expand in employment shares. The final term measures the effect of initial specialization. That is the effect of the structure of the economy at the initial period and the changes in the relative sectoral productivity of the frontier. If a country within Africa manages to maintain the initial technology distance with the leading economy and specializes in sectors that are dynamic in the leading economy, the initial specialization term will contribute positively to aggregate catch-up. However, if the technology gap widens, specializing in sectors that are dynamic in the leading economy may not contribute positively to catch up because the positive effect of specialization could be offset by the negative effect of increasing technology distance.

\subsubsection{Long-run Relative Productivity Patterns and Technological Catch-up in Africa}

The long run trend of relative labor productivity to SA across the 17 African countries studied is depicted in Figure 4.6. The clear pattern shown is that three African countries have separated themselves from the rest of Africa with the productivity of Botswana (blue round dot line) and Mauritius (square dot line) converging to and leapfrogging the productivity level of the technology leader. Namibia shows signs of convergence but never really touching the productivity level of the technology leader. The rate of labor productivity growth differs among the three countries mentioned above in relation to South Africa. The annual average productivity growth of South Africa, Botswana, Mauritius, and Namibia between 1970 and 2014 was 1.05\%, 5.2\%, 3.5\%, and 1.8\%, respectively. 
Since Botswana's annual rate of increase has been the fastest in Africa, by 1995, its productivity level had converged with the frontier (i.e., South Africa). This was followed by Mauritius, the second-fastest growing country, whose productivity converged to the productivity level of the frontier in 2000 . Namibia (dashed line) has not been able to catch-up with South Africa, although the technology gap was small in the late 1990s and again by 2014. Another striking observation is that Zambia (green dash-dot line) had very good initial conditions, as measured by the initial technology gap, compared to Botswana and Mauritius. Despite this, Zambia has fallen behind the frontier, with its relative productivity decreasing from 0.66 in 1965 to 0.28 in 2015.

What underlies the successful catch up of Botswana and Mauritius and the relative failure of other countries such as Zambia in Africa? To understand the successful catch-up of Botswana and Mauritius and the falling behind of other African countries from a structural change perspective, we applied the methodology outlined above to the EASD data. We split the entire period into four distinct periods as in Chapter 3. We assess the degree of technological catch-up of the RoA with respect to SA for the entire period (1960s-2015) as well as catch up during each of the sub-periods outlined above. The results are reported in Table 4.5.

Figure 4.6: Relative Labor Productivity as a measure of Technology gap $(S A=1)$

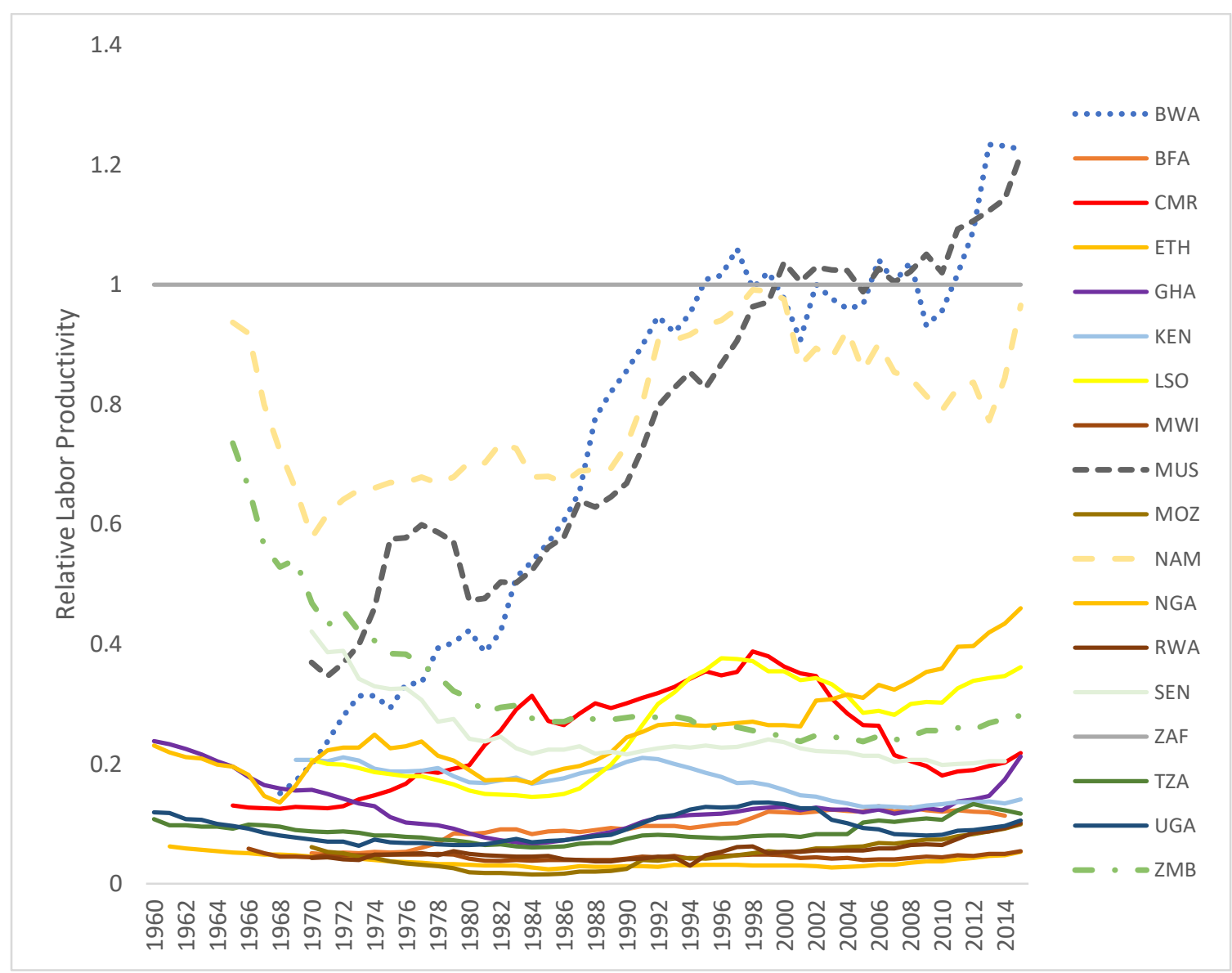


Table 4.5: Decomposition of Technological Catch-up to $S A$

\begin{tabular}{lcccccc}
\hline Catch up to SA & Period & $\begin{array}{c}\text { Catch-Up } \\
\text { Rate }\end{array}$ & Within & $\begin{array}{c}\text { Between } \\
\text { Static }\end{array}$ & $\begin{array}{c}\text { Between } \\
\text { Dynamic }\end{array}$ & $\begin{array}{c}\text { Initial } \\
\text { Specialization }\end{array}$ \\
\hline Rest of Africa (ROA) & $1960-2015$ & $1.0 \%$ & $0.4 \%$ & $1.2 \%$ & $-0.3 \%$ & $-0.4 \%$ \\
& $1960-1975$ & $-0.2 \%$ & $-1.6 \%$ & $1.8 \%$ & $-0.2 \%$ & $-0.2 \%$ \\
& $1975-1990$ & $0.3 \%$ & $0.3 \%$ & $0.6 \%$ & $-0.2 \%$ & $-0.4 \%$ \\
& $1990-2000$ & $2.4 \%$ & $1.9 \%$ & $1.1 \%$ & $-0.1 \%$ & $-0.5 \%$ \\
& $2000-2015$ & $1.1 \%$ & $0.3 \%$ & $1.7 \%$ & $-0.5 \%$ & $-0.3 \%$ \\
\hline
\end{tabular}

Notes: The table reports the decomposition of catch-up (relative labor productivity to SA) into within-sector catch-up, static between-sector catch-up, dynamic between-sector catch-up and initial specialization by period based on the EASD.

The analysis shows that, on average, structural change contributes more to catch up than the within effect for the entire period. The African experience contradicts the observation for high-income countries where the within effect dominates the between effect (see Lavopa, 2015). This implies that most African countries are moving workers to sectors where the technology gap with SA is decreasing over time. We have seen the movement of workers mostly from agriculture to services across Africa, and over time, the productivity of labor in services in the RoA is converging towards that of SA, translating into the dominant reallocation effect. Though, on average, the within effect is not as strong as the between effect, the within effect was stronger than the between effect in the 1990s. The within effect has contributed positively to relative productivity growth in each sub-period except for the import substitution era. The protective policies implemented by most African countries led to inappropriate technology adoption (particularly in State-Owned Enterprises) that stifled innovation and hence technology growth within that period. The initial specialization effect has contributed negatively to technological growth in all periods. This means that most African countries are specializing in sectors where South Africa has not been very dynamic. Since Africa is highly specialized in agriculture, but South Africa is dynamic is mining activities, the initial specialization components tend to contribute negatively to technological catch-up. To summarize, while the within effect and the between effect help the RoA to catch up with SA, the initial specialization effect tends to be a drag on technological catch-up.

\subsubsection{Catch-up by Country}

Of the 17 countries studied in relation to SA, two countries (Botswana and Mauritius) converged to the productivity level of SA, four countries (Kenya, Malawi, Senegal, and Zambia) were found to fall further behind, and the other eleven countries were found to catch up with SA, but at a relatively slow pace (Table 4.6). Why have Botswana and Mauritius been successful while others been unsuccessful in catching-up? We speculate that Botswana's proximity to SA in combination with the discovery of diamonds in the late 1960s and Mauritius's industry-friendly policies adopted in the early 1970s played a significant role in the successful take-off and subsequent catch-up of these two countries.

Immediately after independence in 1966, Botswana discovered a huge diamond reserve. By that time, SA had established itself as a leader in mining-related technology in the sub-region. By interacting with SA, Botswana adopted the appropriate technology and best management practices to exploit its diamond deposits and launch itself upon a consistent growth path. In fact, Botswana's technological 
learning process has been strongly attributed to the "intensity of interactions" with SA as well as "investment and trade linkages to the SA economy" (Yaremye, 2008). Botswana's interactions with SA accounts for more than 70 percent of its capital imports, a major source of technology inflow (Yaremye, 2008).

After establishing a very productive mining sector through its technological interactions with SA, mining sector employment in Botswana increased from about 1000 in 1968 to about 10000 by 1976, or from $1.1 \%$ to $9.6 \%$ of total employment. The reallocation of workers to mining and auxiliary sectors in Botswana led to a rapid catch-up rate of 10.3\% between 1968 and 1975. The between effect was so strong that the countervailing forces of the within and specialization effects did not matter (See Table A4.6 in the Appendix). The strength of the between effect decreased over time, such that by 1990 it had become a drag on productivity growth (see also McCaig, McMillan, \& Jefferis, 2015:6), partly due to the decline of the productive mining sector over time and the lack of diversification into other high productivity sectors.

Hillborn (2008) attempts to explain this more clearly. In 1968, agriculture dominated Botswana's economy, contributing more than $40 \%$ to the country's GDP only to decline to less than 3\% in 2004 . The agriculture sector continues to hold a very modest position in the country in terms of GDP contribution. The mining sector instead expanded, contributing about 8\% of GDP in 1974/75 before expanding to $53 \%$ in $1988 / 89$ only to shrink back again to roughly $35 \%$ in 2002 . Although the industrial sector has grown significantly in relative terms, it is mainly due to the expansion of the mining sector. At the same time, manufacturing maintains a share of around $4 \%$ of GDP, with figures falling in recent years. Some have argued that governments' effort to diversify the economy has failed and has left the economy of Botswana vulnerable in the long run. (Leith 2005:100; Siwawa-Ndai, 1997).

Table 4.6: Catch-up by Country (average annual percentage change)

\begin{tabular}{lcccccc}
\hline Country & Period & $\begin{array}{c}\text { Catch-up } \\
\text { Rate }\end{array}$ & Within & $\begin{array}{c}\text { Between } \\
\text { Static }\end{array}$ & Between Dynamic & $\begin{array}{c}\text { Initial } \\
\text { Specialization }\end{array}$ \\
\hline Botswana & $1968-2015$ & $4.5 \%$ & $3.3 \%$ & $3.7 \%$ & $-1.9 \%$ & $-0.5 \%$ \\
Burkina Faso & $1970-2015$ & $2.0 \%$ & $1.0 \%$ & $1.4 \%$ & $-0.2 \%$ & $-0.3 \%$ \\
Cameroun & $1965-2015$ & $1.4 \%$ & $0.3 \%$ & $1.3 \%$ & $-0.1 \%$ & $-0.1 \%$ \\
Ethiopia & $1961-2015$ & $0.3 \%$ & $-0.6 \%$ & $1.2 \%$ & $-0.2 \%$ & $0.0 \%$ \\
Ghana & $1960-2015$ & $0.8 \%$ & $0.8 \%$ & $0.3 \%$ & $-0.2 \%$ & $-0.1 \%$ \\
Kenya & $1969-2015$ & $-0.8 \%$ & $-1.0 \%$ & $0.9 \%$ & $-0.2 \%$ & $-0.5 \%$ \\
Lesotho & $1970-2015$ & $1.1 \%$ & $0.9 \%$ & $1.3 \%$ & $-0.2 \%$ & $-0.9 \%$ \\
Malawi & $1966-2015$ & $-1.7 \%$ & $-2.6 \%$ & $1.6 \%$ & $-0.4 \%$ & $-0.3 \%$ \\
Mauritius & $1970-2015$ & $2.6 \%$ & $2.4 \%$ & $1.2 \%$ & $-0.4 \%$ & $-0.6 \%$ \\
Mozambique & $1970-2015$ & $1.8 \%$ & $1.8 \%$ & $0.3 \%$ & $-0.1 \%$ & $-0.1 \%$ \\
Namibia & $1965-2015$ & $0.7 \%$ & $1.4 \%$ & $0.5 \%$ & $-0.4 \%$ & $-0.8 \%$ \\
Nigeria & $1960-2015$ & $2.8 \%$ & $2.1 \%$ & $1.2 \%$ & $-0.1 \%$ & $-0.4 \%$ \\
Rwanda & $1970-2015$ & $2.6 \%$ & $0.9 \%$ & $1.9 \%$ & $-0.1 \%$ & $-0.1 \%$ \\
Senegal & $1970-2015$ & $-1.6 \%$ & $-2.1 \%$ & $1.0 \%$ & $-0.1 \%$ & $-0.3 \%$ \\
Tanzania & $1960-2015$ & $0.5 \%$ & $-0.9 \%$ & $2.1 \%$ & $-0.3 \%$ & $-0.3 \%$ \\
Uganda & $1960-2015$ & $0.7 \%$ & $-0.2 \%$ & $1.3 \%$ & $-0.2 \%$ & $-0.2 \%$ \\
Zambia & $1965-2015$ & $-1.3 \%$ & $-0.6 \%$ & $0.0 \%$ & $-0.2 \%$ & $-0.5 \%$ \\
\hline
\end{tabular}


The experience of Mauritius is, however, quite different. After independence in 1968, Mauritius was a monocrop (i.e., sugar) economy, highly vulnerable to terms of trade shocks, and susceptible to potential conflict due to ethnic diversity. These unfavorable conditions led two Nobel laureates ${ }^{87}$ to conclude that the economic future of Mauritius is a predictable dud (Subramanian, 2009). Contrary to this prediction, Mauritius has managed to sustain a high growth rate for over four decades leading to catch-up with the African frontier. The catch-up process in Mauritius was facilitated by reinforcement of both the within and the between effects. Between 1970 and 1975, the catch-up rate was 9.9\%, with $8.4 \%$ of this percentage change being due to technological progress within sectors (Table A4.5). The years 1975-1990 saw the implementation of industrial policies and structural reallocation of resources across sectors in the country.

For this reason, out of the 1 percent productivity growth recorded in the country during this period, structural change contributed 70 percent, whereas the within effect contributed 30 percent (see Mensah et al. 2018). While reallocating resources across sectors, the effective industrial policies that were put in place made sure that over time the efficiency of firms improved, leading to a strong contribution of the within effect and a moderate contribution of the between effect to the country's productivity growth in the periods after 1990. For instance, between 1990 and 2000, productivity growth of the country was 4.3 percent. Out of this, the within effect contributed $3.1 \%$ while the between effect contributed 1.2\%. Between 2000 and 2015, the within effect accounted for nearly all $(1.8 \%)$ of the country's productivity growth of 1.9 percent (Mensah et al. 2018). Overall structural change was important in Mauritius's productivity growth (e.g., moving from sugar to textiles, tourism, finance, etc.) from the late 1970s to 1990, but later on, within effects started to dominate.

The strong within and moderate between effect is explained by the policies deployed after the creation of the export processing zones (EPZ) in the early 1970s. First, duty-free access was granted on all imported inputs. The free import of capital goods that embodied technological knowledge contributed positively to productivity growth and technological spillovers within sectors. Second, a raft of tax incentives was granted to firms operating in the EPZ. This had the same effect as export subsidies in encouraging exports. The effect of tax incentives on the growth of the export sector was complemented by the preferential market access granted by Mauritius' major trading partners, such as the European Economic Area and the USA (Subramanian, 2009). Exporting to the EU and the USA requires product certification that meets the market standards of these countries. To meet these standards, firms operating in an EPZ often adopt technological knowledge and management practices to improve existing production and delivery processes. This resulted in enhanced firm efficiency, and hence a strong within sector technological growth and moderate between effect. In summary, while the between effect created the technological momentum for catch up in Botswana, the within effect was the main driving force behind Mauritius' catch-up.

In contrast to the success of Botswana and Mauritius, the technology gap between Kenya, Malawi, Senegal, Zambia, and the technology leader is widening over time. They are falling behind at an average annual rate of $0.8 \%, 1.7 \%, 1.6 \%$ and $1.3 \%$ respectively (Table 4.6 ). The technology gap between Kenya and SA has increased from 0.79 in 1969 to 0.86 in 2015. That of Malawi has increased marginally from

${ }^{87}$ James Meade and V. S. Naipaul 
0.94 in 1966 to 0.95 in 2015, while Senegal's productivity gap had widened by a third from 0.58 in 1970 to 0.80 in 2014. Finally, the most dramatic free fall of relative productivity is seen in the case of Zambia. Zambia's technology gap has increased from 0.26 in 1965 to 0.72 in 2015 (Figure 4.7).

Although there are country-specific idiosyncratic factors that may explain each country's technological decline, inappropriate technology policies adopted during the import substitution era and the structural adjustment era created an inertia that hampered technology growth. For example, during the importsubstitution period, most governments imposed strict price controls and forced producers to purchase local intermediates input whenever available. This made domestic intermediates more expensive than what is available on the international market. This was exacerbated by foreign exchange controls where approval is required by government agencies before the allocation of foreign exchange needed for the purchase of essential intermediates input. Furthermore, infant industries were protected from competition, and as a result there was no urge to create a market niche through the adoption of efficient production techniques and processes. This set of policies implemented during the IS strategy hampered productivity growth during the era. For example, the relative productivity growth of Kenya, Senegal, and Malawi - three out of the four countries falling behind - decreased by $1.6 \%, 4.9 \%$, and $4.2 \%$ respectively during the import-substitution era.

Most infant industries hardly broke even and consistently survived on the books of central governments. During the period of structural adjustment programs, almost all state-owned enterprises became targets for public sector rationalization. They were cleared off the book of central governments and subsequently collapsed. This caused a massive movement of workers from import substitution industries to the non-wage agricultural sector, the distributive trading sector, and other informal ventures. These sectors offer very little opportunity for technological learning. Finally, except for Botswana and Mauritius, all African countries witnessed political upheavals either during the 1970s, 1980 s, or 1990s, which adversely affected the inflow of technologically embedded FDI into the region.

Figure 4.7: Countries Falling Bebind

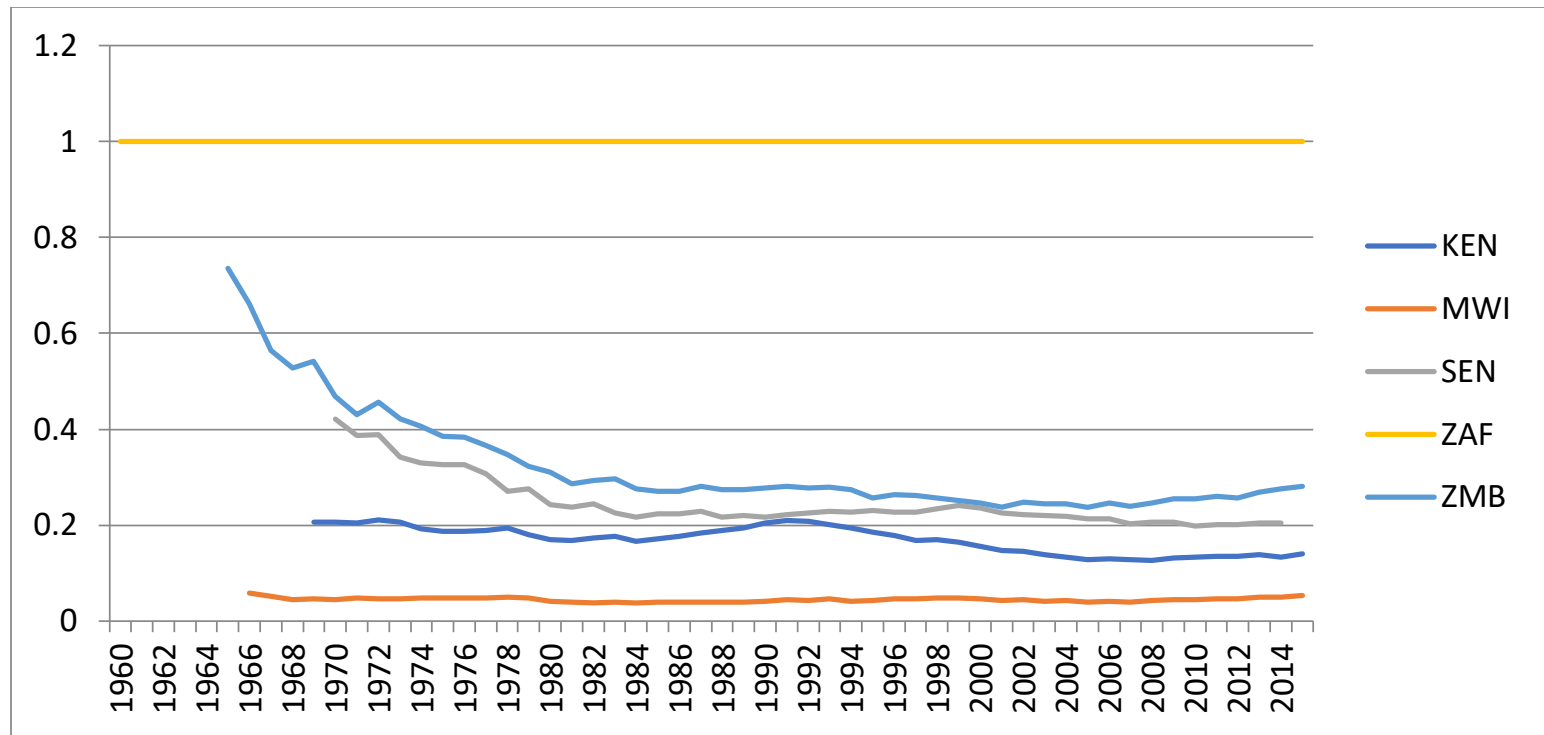

**Note: Malawi and Zambia's data start in the mid-1960s, Kenya's in 1969 and Senegal's in 1970 


\subsection{Conclusion}

Economic systems of Africa present unique technological challenges. This often requires a unique combination of technical knowledge developed in advanced countries or African-induced innovation to surmount the technological challenges. In this chapter, we have examined how African countries are catching-up with the best practice within Africa from a nonparametric perspective. The analysis shows that technological catch-up is an important driver of efficiency convergence within Africa. We further decomposed technological catch-up using a structural model. The results confirmed our conjecture that structural change is an important driver of technological catch-up within Africa. On average, structural change contributed more than half of the annual catch-up rate to the technology leader. However, the average productivity of the Rest of Africa (RoA) has not converged to the productivity level of the technology leader. Botswana and Mauritius are notable exceptions to this general trend. Botswana and Mauritius are the only two countries in Africa that have converged to the productivity level of the frontier. All the other countries have neither converged to the productivity level nor the efficiency level of the technology leader. In the case of Kenya, Malawi, Senegal, and Zambia productivity levels have fallen behind the productivity level of the leading economy. Protectionist policies implemented during the IS era led to the concentration of knowledge production and diffusion and slowed-down the catch-up rate. In this regard, the introduction and implementation of intraregional free trade agreement (AfCFTA) seems to be timely to boost catch-up efforts in the region.

In addition, the average result of the Malmquist productivity decomposition (average of five-year interval period) shows that Africa achieved a productivity decline of -4.0 percent between 1970 and 2014. The decline in productivity growth is almost entirely attributable to lack of technological progress and less to technological catch-up. This contribution of technological regress to the region's productivity decline is primarily driven by the experience of relatively poor countries in the region rather than relatively wealthy and highly capitalized economies in the region. Two important lessons emerged from this exercise. First, successful productivity convergence requires the combination technical progress and technological catch-up. Second, structural change exerts significant influence on the speed of technological convergence. 


\subsection{Appendix to Chapter 4}

\subsubsection{South Africa: A Leader in Education and Innovation}

South Africa is the technological hub of Africa. It is home to world-class academic and research institutions that attract young talent from across Africa. The Times Higher Education (THE) and QS ranking consistently place seven of the top ten African universities in South Africa. The country has consistently been ranked among the most innovative countries in Africa by the Global Innovation Index, and in 2017 was ranked as the most innovative African country. While other highly innovative countries such as Mauritius, Botswana and Nigeria are performing below their level of development, South Africa is performing at a level consistent with its development (Global Innovation Index Report, 2017). Patent data at the US Patent and Trademark Office also shows that South Africa recorded the highest number of (residential) patents applications between 2001 and 2014 in SubSahara Africa (see Table A2 in Appendix).

In addition to its leadership in education and innovation, South Africa has established itself globally in some technological domains - mining-related technology - that are particularly important for Africa. This is important because most of the economies of the other 17 countries in our sample depend heavily on mineral exports. South Africa has developed a globally competitive and advanced technological capacity in "mining equipment and specialist services sector". The share of miningrelated technology patents is higher than other comparator countries which are considered to have technological leadership in mining (Table A1). The share of mining-related technology patents for SA is $4.5 \%$ compared with a global average of $0.54 \%$. The revealed comparative advantage in miningrelated innovations (RCAI) is therefore 8.4, which is higher than that of comparator countries which are considered to be global leaders in mining related technology. "This indicates that South Africa has a very significant global comparative advantage in mining related technology innovation" (Kaplan, 2012: 426).

Table A4.1: SA's Leadership in Mining and Related Services

\begin{tabular}{|c|c|c|c|c|}
\hline \multicolumn{5}{|l|}{ Panel A: Patent Quantity } \\
\hline Country & All Patents & $\begin{array}{l}\text { Mining Technology } \\
\text { Patents }\end{array}$ & Share $(\%)$ & RCAI \\
\hline South Africa & 3151 & 142 & 4.51 & 8.35 \\
\hline United States & $1,587,915$ & 7882 & 0.5 & 0.93 \\
\hline Australia & 16,283 & 311 & 1.9 & 3.52 \\
\hline Canada & 65,580 & 853 & 1.3 & 2.41 \\
\hline \multicolumn{4}{|l|}{ Panel B: Patent Quality } & ----- \\
\hline All countries & All Patents & $\begin{array}{l}\text { Mining-related } \\
\text { tech. patents }\end{array}$ & \multicolumn{2}{|l|}{ Other patents } \\
\hline \multicolumn{5}{|c|}{ Citations received (not truncation corrected) } \\
\hline South Africa & 5.52 & 7.05 & \multicolumn{2}{|l|}{5.44} \\
\hline United States & 8.52 & 6.99 & \multicolumn{2}{|l|}{8.53} \\
\hline Australia & 5.39 & 4.15 & \multicolumn{2}{|l|}{5.41} \\
\hline Canada & 6.60 & 4.70 & \multicolumn{2}{|l|}{6.72} \\
\hline Average & 6.53 & 5.73 & \multicolumn{2}{|l|}{6.53} \\
\hline \multicolumn{5}{|c|}{ Citations received (truncation corrected) } \\
\hline South Africa & 7.95 & 9.01 & \multicolumn{2}{|l|}{7.90} \\
\hline
\end{tabular}




\begin{tabular}{|llll|}
\hline United States & 14.13 & 9.97 & 14.16 \\
Australia & 9.41 & 6.16 & 9.47 \\
Canada & 11.43 & 6.91 & 11.49 \\
Average & 10.73 & 8.01 & 10.76 \\
\hline
\end{tabular}

Source: Kaplan (2012)

Note: The table show the number of patents and mining related patents granted at the USPTO 1976-2006; South Africa and Comparator Countries. RCAI is ratio of the share of mining related patent granted to the average global share of mining related patents granted. "The truncation-correction refers to the fact that it takes time for citations to arrive. Older patents will naturally have more citations than younger ones. A truncation correction allows for a 'fairer' comparison between samples of patents with different age distributions"

\section{Table A4.2: Ranking of Universities, Innovation, and Intellectual Properties in Africa}

\begin{tabular}{|c|c|c|c|c|c|}
\hline QSRanking & Univeristy & Country & THE Ranking & University & Country \\
\hline 1 & Universityof Cape Town & South Africa & 1 & UniversityofCape Town & South Afica \\
\hline 2 & Stellenbosch Uhiversity & South Afica & 2 & University of the Witvatersrand & South Afica \\
\hline 3 & Universtyof the Witvatersrand & South Afica & 3 & Stelenbosch University & South Afica \\
\hline 4 & The American of University in Caio & Egspt & 4 & UniversityofKwaZulu-Natal & South Afica \\
\hline 5 & Cairo University & Egypt & 5 & Makerere University & Uganda \\
\hline 6 & UniversityofPretoria & South Afica & 6 & The American Uhiverstyin Cairo & Egypt \\
\hline 7 & Universty of Johamesburg & South Africa & 7 & Beni-Suef Uhiversity & Egypt \\
\hline 8 & An shams University & Egspt & 8 & University of Johannesburg & South Africa \\
\hline 9 & Rhodes University & South Africa & 9 & UniverstyofPrebra & South Afica \\
\hline 10 & UniversityofKwaZulu-Natal & South Afica & 10 & Uhiversity of the Western Cape & South Africa \\
\hline \multicolumn{3}{|c|}{ PanelB:Innovation } & \multicolumn{3}{|c|}{ Panel C: Patents } \\
\hline$\underset{2 n 17}{\text { GlIRank }}$ & Innovation Score & Country & Rank & Number of Paterts Applications (2001-2014) & Country \\
\hline 1 & 35.80 & South Afica & 1 & 2060 & South Afica \\
\hline 2 & 34.80 & Maurifus & 2 & 287 & Maurifus \\
\hline 3 & 32.70 & Morocco & 3 & 75 & Seychelles \\
\hline 4 & 31.00 & Kenya & 4 & 57 & Kenya \\
\hline 5 & 30.00 & Botswana & 5 & 36 & Noer \\
\hline 6 & 28.00 & Tarzania & 6 & 33 & Ngeria \\
\hline 7 & 27.90 & Namibia & 7 & 23 & Cote Dlvaire \\
\hline 8 & 27.40 & Rwanda & 8 & 18 & Cameroon \\
\hline 9 & 27.10 & Senegal & 9 & 13 & Gabon \\
\hline 10 & 27.00 & Uganda & 10 & 12 & Namiba \\
\hline
\end{tabular}

Source: The Times Higher Education and QS Ranking; Global Innovation Index Report (2017); and USPTO. Note: The ranking of IP excludes North Africa. 
Figure A4.1: Decomposition of Productivity Growth, Technology and Efficiency Indexes: Africa Period Averages: 1970-2014

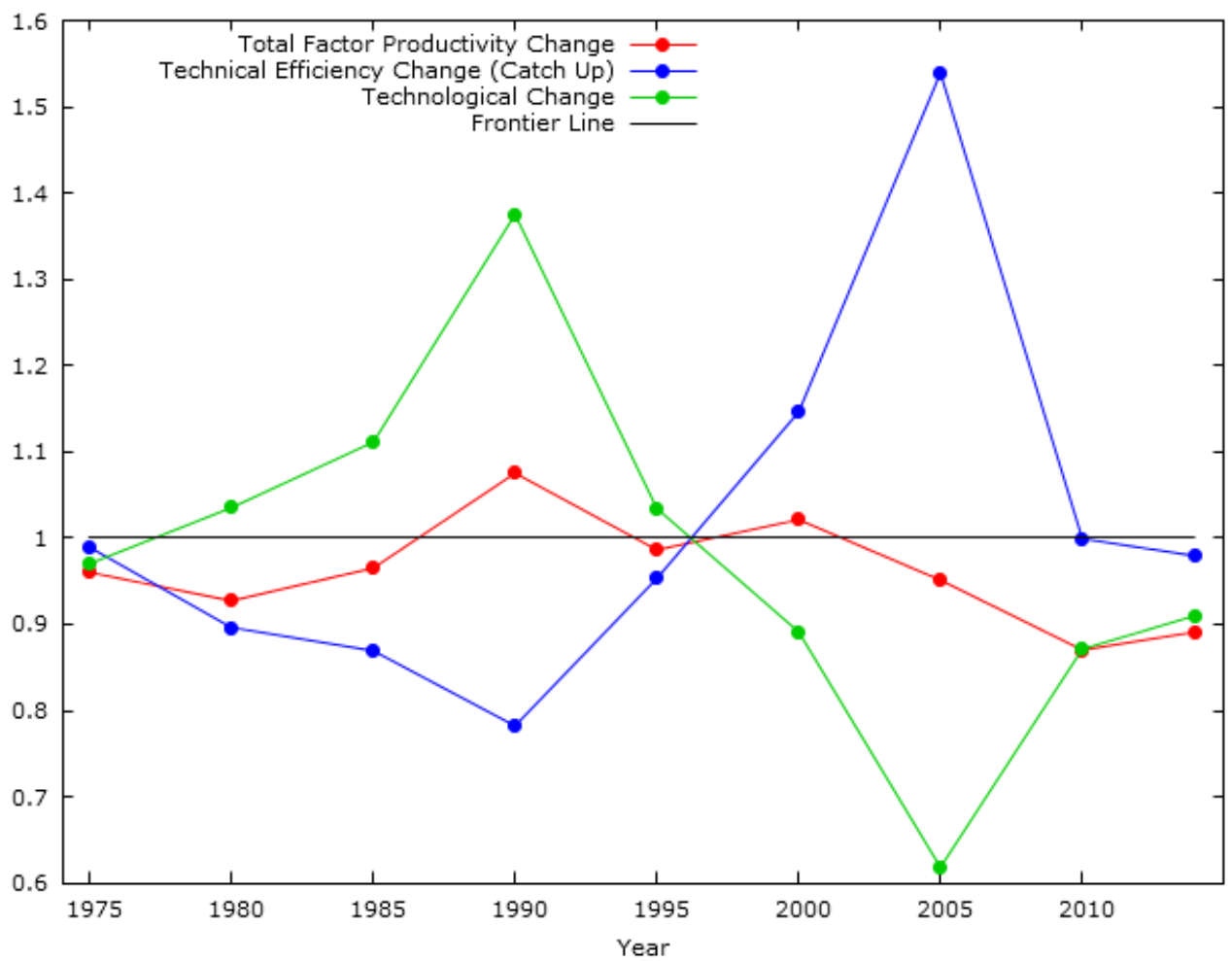

\subsubsection{Robustness Checks of Efficiency Measures}

Table A4.3: The Nonradial (Slack Based Measures) for Technical Efficiency for DMUs-1970

\begin{tabular}{|c|c|c|c|c|c|c|c|c|c|}
\hline $\mathrm{DMU}$ & $\begin{array}{c}\text { TEnrCRS } \\
\text { _LK }\end{array}$ & $\begin{array}{c}\text { TEnrNRS } \\
\text { _LK }\end{array}$ & $\begin{array}{c}\text { TEnrVRS } \\
\text { _LK }\end{array}$ & $\begin{array}{c}\text { TEnrCRS } \\
\_L\end{array}$ & $\begin{array}{c}\text { TEnrNRS } \\
\_L\end{array}$ & $\begin{array}{c}\text { TEnrVRS } \\
\_L\end{array}$ & $\begin{array}{c}\text { TEnrCRS } \\
\_K\end{array}$ & $\begin{array}{c}\text { TEnrNRS } \\
\_\mathrm{K}\end{array}$ & $\begin{array}{c}\text { TEnrVRS } \\
\_K\end{array}$ \\
\hline BFA & 0.81 & 0.84 & 0.84 & 0.05 & 0.05 & 0.05 & 0.61 & 0.75 & 0.75 \\
\hline CMR & 0.47 & 0.49 & 0.49 & 0.13 & 0.13 & 0.13 & 0.27 & 0.44 & 0.44 \\
\hline ETH & 0.86 & 1.00 & 1.00 & 0.04 & 0.07 & 0.07 & 0.74 & 1.00 & 1.00 \\
\hline GHA & 0.22 & 0.23 & 0.23 & 0.15 & 0.15 & 0.16 & 0.09 & 0.21 & 0.21 \\
\hline LSO & 0.97 & 0.97 & 1.00 & 0.20 & 0.20 & 1.00 & 0.56 & 0.56 & 1.00 \\
\hline MWI & 0.52 & 0.52 & 0.52 & 0.04 & 0.04 & 0.05 & 0.35 & 0.43 & 0.43 \\
\hline MUS & 0.61 & 0.61 & 1.00 & 0.41 & 0.41 & 1.00 & 0.27 & 0.34 & 0.34 \\
\hline MOZ & 0.92 & 0.95 & 0.95 & 0.06 & 0.06 & 0.07 & 0.67 & 0.84 & 0.84 \\
\hline SEN & 0.72 & 0.72 & 0.73 & 0.42 & 0.42 & 0.46 & 0.33 & 0.56 & 0.56 \\
\hline ZAF & 1.00 & 1.00 & 1.00 & 1.00 & 1.00 & 1.00 & 0.38 & 1.00 & 1.00 \\
\hline TZA & 0.38 & 0.45 & 0.45 & 0.09 & 0.09 & 0.09 & 0.22 & 0.43 & 0.43 \\
\hline
\end{tabular}




\begin{tabular}{llllllllll} 
UGA & 0.61 & 0.63 & 0.63 & 0.07 & 0.07 & 0.07 & 0.38 & 0.52 & 0.52 \\
ZMB & 1.00 & 1.00 & 1.00 & 0.45 & 0.45 & 0.48 & 0.54 & 0.88 & 0.88 \\
\hline
\end{tabular}

* TEnrdCRS = tenonradial output-based measures of technical efficiency under assumption of constant returns to scale

* TEnrdNRS = tenonradial output-based measures of technical efficiency under assumption of non- increasing returns to scale

* TEnrdVRS $=$ tenonradial output-based measures of technical efficiency under assumption of variable returns to scale

* LK = both labor and capital used; $\mathrm{L}=$ only labor used; $\mathrm{K}=$ only capital used

Table A4.4: The Nonradial-Slack Based Measures for Technical Efficiency for DMUs—2014

\begin{tabular}{lccccccccc}
\hline DMU & $\begin{array}{c}\text { TEnrCRS } \\
\text { LLK }\end{array}$ & $\begin{array}{c}\text { TEnrNRS } \\
\text { LK }\end{array}$ & $\begin{array}{c}\text { TEnrVRS } \\
\text { _LK }\end{array}$ & $\begin{array}{c}\text { TEnrCRS } \\
\text { _L }\end{array}$ & $\begin{array}{c}\text { TEnrNRS } \\
\text { _L }\end{array}$ & $\begin{array}{c}\text { TEnrVRS } \\
\text { _L }\end{array}$ & $\begin{array}{c}\text { TEnrCRS } \\
\text { KK }\end{array}$ & $\begin{array}{c}\text { TEnrNRS } \\
\text { K }\end{array}$ & \multicolumn{2}{c}{ TEnrVRS } \\
BW
\end{tabular}

* TEnrdCRS = tenonradial output-based measures of technical efficiency under assumption of constant returns to scale

$*$ TEnrdNRS $=$ tenonradial output-based measures of technical efficiency under assumption of non- increasing returns to scale

* TEnrdVRS = tenonradial output-based measures of technical efficiency under assumption of variable returns to scale

* LK = both labor and capital used; $\mathrm{L}=$ only labor used; $\mathrm{K}=$ only capital used 
Figure A4. 2: Relative Labor Productivity as a measure of Technology gap: US $A==1$

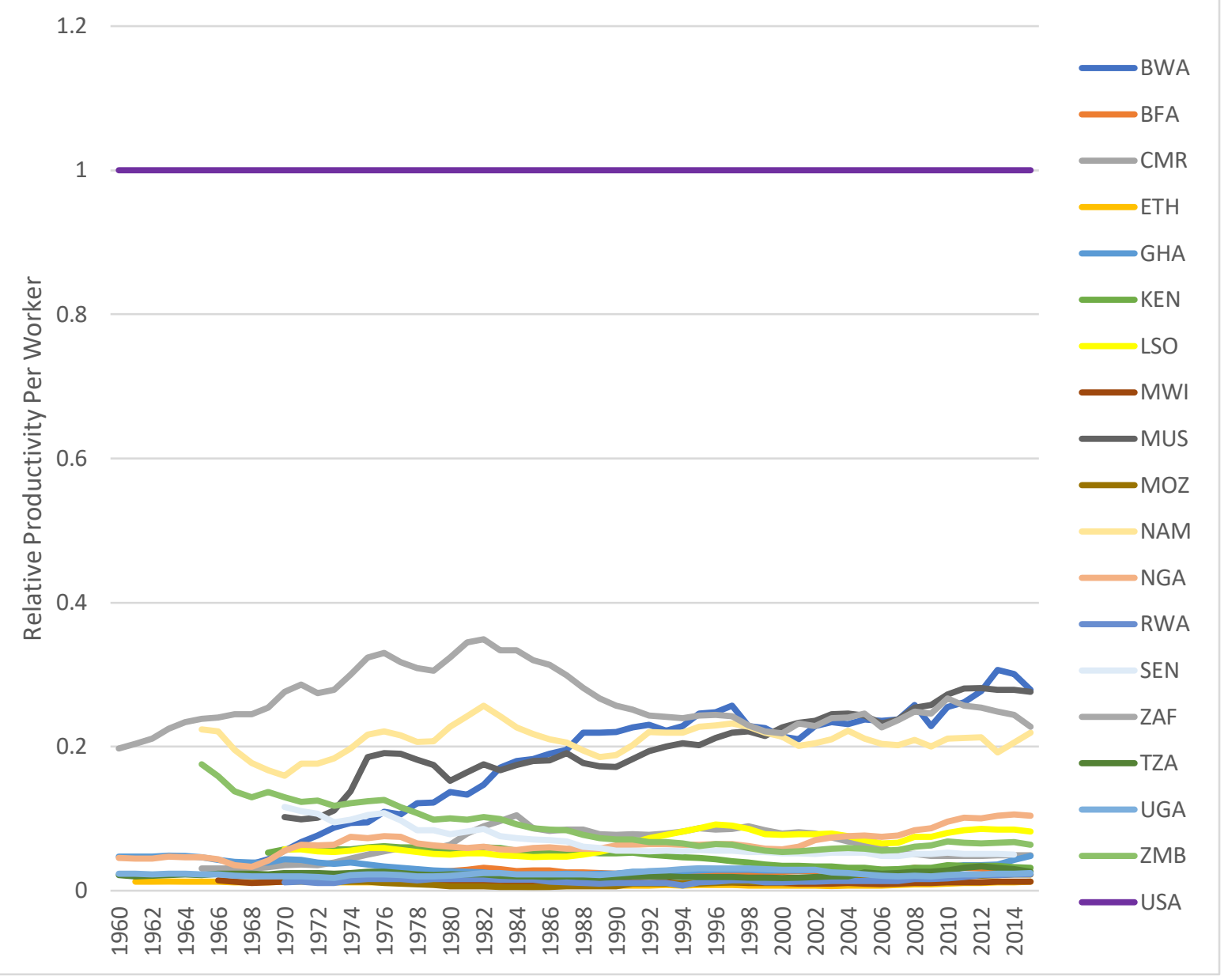

4.8.3. Decomposition of catch-up by country and period

Table A4.5: Decomposition of Catch Up to SA for Whole Period and Sub-Periods

\begin{tabular}{|ccccccc|}
\hline Country/Region & Period & $\begin{array}{c}\text { Total Catch } \\
\text { Up Rate }\end{array}$ & Within & $\begin{array}{c}\text { Between } \\
\text { Static }\end{array}$ & $\begin{array}{c}\text { Between } \\
\text { Dynamic }\end{array}$ & $\begin{array}{c}\text { Initial } \\
\text { Specialization }\end{array}$ \\
\hline Rest of Africa (ROA) & $1960-2015$ & $1.0 \%$ & $0.4 \%$ & $1.2 \%$ & $-0.3 \%$ & $-0.4 \%$ \\
& $1960-1975$ & $-0.2 \%$ & $-1.6 \%$ & $1.8 \%$ & $-0.2 \%$ & $-0.2 \%$ \\
& $1975-1990$ & $0.3 \%$ & $0.3 \%$ & $0.6 \%$ & $-0.2 \%$ & $-0.4 \%$ \\
& $1990-2000$ & $2.4 \%$ & $1.9 \%$ & $1.1 \%$ & $-0.1 \%$ & $-0.5 \%$ \\
& $2000-2015$ & $1.1 \%$ & $0.3 \%$ & $1.7 \%$ & $-0.5 \%$ & $-0.3 \%$ \\
Botswana & & & & & & $-0.5 \%$ \\
& $1960-2015$ & $4.5 \%$ & $3.3 \%$ & $3.7 \%$ & $-1.9 \%$ & $-0.8 \%$ \\
& $1968-1975$ & $10.3 \%$ & $-0.1 \%$ & $12.7 \%$ & $-1.4 \%$ & $-1.9 \%$ \\
& $1975-1990$ & $7.7 \%$ & $8.3 \%$ & $2.9 \%$ & $-1.6 \%$ & $-0.3 \%$ \\
& $1990-2000$ & $1.4 \%$ & $0.7 \%$ & $-0.2 \%$ & $-0.4 \%$ & $-0.2 \%$ \\
& $2000-2015$ & $0.8 \%$ & $1.6 \%$ & $2.9 \%$ & $-3.5 \%$ & $-0.3 \%$
\end{tabular}




\begin{tabular}{|c|c|c|c|c|c|c|}
\hline & $1970-1975$ & $0.3 \%$ & $0.2 \%$ & $0.0 \%$ & $0.0 \%$ & $0.1 \%$ \\
\hline & $1975-1990$ & $4.1 \%$ & $4.1 \%$ & $-0.1 \%$ & $0.0 \%$ & $0.1 \%$ \\
\hline & $1990-2000$ & $2.9 \%$ & $2.2 \%$ & $1.8 \%$ & $-0.1 \%$ & $-1.0 \%$ \\
\hline & $2000-2015$ & $-0.4 \%$ & $-2.9 \%$ & $3.2 \%$ & $-0.5 \%$ & $-0.2 \%$ \\
\hline \multirow[t]{5}{*}{ Cameroun } & 1965-2015 & $1.4 \%$ & $0.3 \%$ & $1.3 \%$ & $-0.1 \%$ & $-0.1 \%$ \\
\hline & 1965-1975 & $3.2 \%$ & $2.9 \%$ & $0.0 \%$ & $0.0 \%$ & $0.3 \%$ \\
\hline & 1975-1990 & $4.8 \%$ & $4.3 \%$ & $1.1 \%$ & $0.0 \%$ & $-0.7 \%$ \\
\hline & $1990-2000$ & $1.9 \%$ & $-2.1 \%$ & $4.0 \%$ & $-0.4 \%$ & $0.5 \%$ \\
\hline & $2000-2015$ & $-3.2 \%$ & $-3.2 \%$ & $0.2^{\circ} \%$ & $0.0 \%$ & $-0.2^{\circ} \%$ \\
\hline \multirow[t]{5}{*}{ Ethiopia } & 1961-2015 & $0.3 \%$ & $-0.6 \%$ & $1.2 \%$ & $-0.2 \%$ & $0.0 \%$ \\
\hline & 1961-1975 & $-3.8 \%$ & $-4.6 \%$ & $0.6 \%$ & $-0.1 \%$ & $0.2 \%$ \\
\hline & 1975-1990 & $-1.5 \%$ & $-2.3 \%$ & $0.1 \%$ & $0.0 \%$ & $0.8 \%$ \\
\hline & 1990-2000 & $0.7 \%$ & $0.3 \%$ & $1.2 \%$ & $0.0 \%$ & $-0.8 \%$ \\
\hline & $2000-2015$ & $3.9 \%$ & $2.4 \%$ & $2.5 \%$ & $-0.6 \%$ & $-0.5 \%$ \\
\hline \multirow[t]{5}{*}{ Ghana } & 1960-2015 & $0.8 \%$ & $0.8 \%$ & $0.3 \%$ & $-0.2 \%$ & $-0.1 \%$ \\
\hline & 1960-1975 & $-4.9 \%$ & $-5.2 \%$ & $0.3 \%$ & $-0.1 \%$ & $0.1 \%$ \\
\hline & 1975-1990 & $-1.0 \%$ & $-1.1 \%$ & $-0.1 \%$ & $0.1 \%$ & $0.1 \%$ \\
\hline & $1990-2000$ & $3.3 \%$ & $3.1 \%$ & $0.6 \%$ & $0.0 \%$ & $-0.3 \%$ \\
\hline & $2000-2015$ & $3.6 \%$ & $4.1 \%$ & $0.4 \%$ & $-0.6 \%$ & $-0.3 \%$ \\
\hline \multirow[t]{5}{*}{ Kenya } & 1969-2015 & $-0.8 \%$ & $-1.0 \%$ & $0.9 \%$ & $-0.2 \%$ & $-0.5 \%$ \\
\hline & 1969-1975 & $-1.6 \%$ & $-1.6 \%$ & $0.7 \%$ & $-0.2 \%$ & $-0.5 \%$ \\
\hline & 1975-1990 & $0.6 \%$ & $-0.1 \%$ & $1.1 \%$ & $-0.2 \%$ & $-0.2 \%$ \\
\hline & $1990-2000$ & $-2.6 \%$ & $-3.7 \%$ & $2.6 \%$ & $-0.3 \%$ & $-1.1 \%$ \\
\hline & $2000-2015$ & $-0.7 \%$ & $0.0 \%$ & $-0.3 \%$ & $-0.1 \%$ & $-0.4 \%$ \\
\hline \multirow[t]{5}{*}{ Lesotho } & 1970-2015 & $1.1 \%$ & $0.9 \%$ & $1.3 \%$ & $-0.2 \%$ & $-0.9 \%$ \\
\hline & 1970-1975 & $-5.2 \%$ & $-4.5 \%$ & $0.4 \%$ & $-0.1 \%$ & $-0.9 \%$ \\
\hline & 1975-1990 & $1.9 \%$ & $1.8 \%$ & $1.0 \%$ & $0.0 \%$ & $-0.8 \%$ \\
\hline & 1990-2000 & $4.7 \%$ & $5.0 \%$ & $1.2 \%$ & $-0.1 \%$ & $-1.5 \%$ \\
\hline & $2000-2015$ & $0.1 \%$ & $-1.0 \%$ & $1.9 \%$ & $-0.3 \%$ & $-0.5 \%$ \\
\hline \multirow[t]{5}{*}{ Malawi } & 1966-2015 & $-1.7 \%$ & $-2.6 \%$ & $1.6 \%$ & $-0.4 \%$ & $-0.3 \%$ \\
\hline & 1966-1975 & $1.0 \%$ & $-0.5 \%$ & $1.6 \%$ & $-0.1 \%$ & $0.0 \%$ \\
\hline & 1975-1990 & $-7.7 \%$ & $-6.9 \%$ & $0.4 \%$ & $-0.8 \%$ & $-0.3 \%$ \\
\hline & $1990-2000$ & $1.4 \%$ & $0.5 \%$ & $1.6 \%$ & $-0.1 \%$ & $-0.5 \%$ \\
\hline & $2000-2015$ & $1.0 \%$ & $-1.3 \%$ & $2.9 \%$ & $-0.4 \%$ & $-0.3 \%$ \\
\hline \multirow[t]{2}{*}{ Mauritius } & 1970-2015 & $2.6 \%$ & $2.4 \%$ & $1.2 \%$ & $-0.4 \%$ & $-0.6 \%$ \\
\hline & 1970-1975 & $9.9 \%$ & $8.4 \%$ & $2.6 \%$ & $-0.9 \%$ & $-0.3 \%$ \\
\hline
\end{tabular}




\begin{tabular}{|c|c|c|c|c|c|c|}
\hline & $1975-1990$ & $1.2 \%$ & $1.1 \%$ & $1.3 \%$ & $-0.6 \%$ & $-0.6 \%$ \\
\hline & $1990-2000$ & $4.3 \%$ & $4.2 \%$ & $1.3 \%$ & $0.0 \%$ & $-1.1 \%$ \\
\hline & $2000-2015$ & $0.4 \%$ & $0.4 \%$ & $0.4 \%$ & $-0.3 \%$ & $-0.2 \%$ \\
\hline \multirow[t]{5}{*}{ Mozambique } & $1970-2015$ & $1.8 \%$ & $1.8 \%$ & $0.3 \%$ & $-0.1 \%$ & $-0.1 \%$ \\
\hline & $1970-1975$ & $-9.2 \%$ & $-10.0 \%$ & $0.0 \%$ & $0.0 \%$ & $0.8 \%$ \\
\hline & 1975-1990 & $-1.9 \%$ & $-1.7 \%$ & $0.0 \%$ & $-0.2 \%$ & $0.0 \%$ \\
\hline & $1990-2000$ & $9.2 \%$ & $9.8 \%$ & $0.0 \%$ & $-0.1 \%$ & $-0.5 \%$ \\
\hline & $2000-2015$ & $4.3 \%$ & $3.8 \%$ & $0.8 \%$ & $0.0 \%$ & $-0.3 \%$ \\
\hline \multirow[t]{5}{*}{ Namibia } & $1965-2015$ & $0.7 \%$ & $1.4 \%$ & $0.5 \%$ & $-0.4 \%$ & $-0.8 \%$ \\
\hline & $1960-1975$ & $-0.9 \%$ & $0.2 \%$ & $0.4 \%$ & $-0.2 \%$ & $-1.3 \%$ \\
\hline & $1975-1990$ & $0.6 \%$ & $1.7 \%$ & $0.0 \%$ & $-0.1 \%$ & $-1.0 \%$ \\
\hline & $1990-2000$ & $3.0 \%$ & $3.4 \%$ & $0.5 \%$ & $-0.3 \%$ & $-0.7 \%$ \\
\hline & $2000-2015$ & $0.1 \%$ & $0.4 \%$ & $1.1 \%$ & $-1.0 \%$ & $-0.4 \%$ \\
\hline \multirow[t]{5}{*}{ Nigeria } & $1960-2015$ & $2.8 \%$ & $2.1 \%$ & $1.2 \%$ & $-0.1 \%$ & $-0.4 \%$ \\
\hline & $1960-1975$ & $8.1 \%$ & $3.7 \%$ & $5.5 \%$ & $0.1 \%$ & $-1.2 \%$ \\
\hline & $1975-1990$ & $0.7 \%$ & $2.0 \%$ & $-0.1 \%$ & $-0.1 \%$ & $-1.1 \%$ \\
\hline & $1990-2000$ & $0.8 \%$ & $0.6 \%$ & $-0.3 \%$ & $-0.1 \%$ & $0.6 \%$ \\
\hline & $2000-2015$ & $3.8 \%$ & $2.4 \%$ & $1.6 \%$ & $-0.1 \%$ & $-0.1 \%$ \\
\hline \multirow[t]{5}{*}{ Rwanda } & $1970-2015$ & $2.6 \%$ & $0.9 \%$ & $1.9 \%$ & $-0.1 \%$ & $-0.1 \%$ \\
\hline & $1970-1975$ & $3.3 \%$ & $1.3 \%$ & $0.0 \%$ & $0.0 \%$ & $2.0 \%$ \\
\hline & $1975-1990$ & $-1.0 \%$ & $-3.4 \%$ & $1.7 \%$ & $-0.2 \%$ & $0.8 \%$ \\
\hline & $1990-2000$ & $4.9 \%$ & $6.8 \%$ & $0.3 \%$ & $0.0 \%$ & $-2.2 \%$ \\
\hline & $2000-2015$ & $4.4 \%$ & $1.0 \%$ & $3.9 \%$ & $-0.3 \%$ & $-0.3 \%$ \\
\hline \multirow[t]{5}{*}{ Senegal } & $1970-2015$ & $-1.6 \%$ & $-2.1 \%$ & $1.0 \%$ & $-0.1 \%$ & $-0.3 \%$ \\
\hline & $1970-1975$ & $-4.9 \%$ & $-6.1 \%$ & $0.8 \%$ & $-0.1 \%$ & $0.4 \%$ \\
\hline & $1975-1990$ & $-2.6 \%$ & $-2.9 \%$ & $0.7 \%$ & $0.0 \%$ & $-0.4 \%$ \\
\hline & $1990-2000$ & $0.9 \%$ & $0.6 \%$ & $1.2 \%$ & $-0.1 \%$ & $-0.8 \%$ \\
\hline & $2000-2015$ & $-1.1 \%$ & $-1.9 \%$ & $1.3 \%$ & $-0.3 \%$ & $-0.1 \%$ \\
\hline \multirow[t]{5}{*}{ Tanzania } & $1960-2015$ & $0.5 \%$ & $-0.9 \%$ & $2.1 \%$ & $-0.3 \%$ & $-0.3 \%$ \\
\hline & $1960-1975$ & $-2.4 \%$ & $-5.1 \%$ & $3.3 \%$ & $-0.5 \%$ & $-0.1 \%$ \\
\hline & $1975-1990$ & $-0.3 \%$ & $-1.0 \%$ & $0.8 \%$ & $-0.1 \%$ & $-0.1 \%$ \\
\hline & $1990-2000$ & $0.7 \%$ & $1.1 \%$ & $0.6 \%$ & $-0.1 \%$ & $-0.9 \%$ \\
\hline & $2000-2015$ & $2.7 \%$ & $-0.1 \%$ & $3.7 \%$ & $-0.6 \%$ & $-0.3 \%$ \\
\hline \multirow[t]{3}{*}{ Uganda } & $1960-2015$ & $0.7 \%$ & $-0.2 \%$ & $1.3 \%$ & $-0.2 \%$ & $-0.2 \%$ \\
\hline & $1960-1975$ & $-1.8 \%$ & $-3.4 \%$ & $1.6 \%$ & $-0.3 \%$ & $0.2 \%$ \\
\hline & $1975-1990$ & $1.9 \%$ & $-0.4 \%$ & $1.8 \%$ & $0.0 \%$ & $0.5 \%$ \\
\hline
\end{tabular}




\begin{tabular}{ccccccc|} 
& $1990-2000$ & $4.0 \%$ & $1.9 \%$ & $3.0 \%$ & $-0.2 \%$ & $-0.6 \%$ \\
\hline \multirow{3}{*}{ Zambia } & & $-1.4 \%$ & $0.0 \%$ & $-0.4 \%$ & $-0.2 \%$ & $-0.7 \%$ \\
& $1965-2015$ & $-1.3 \%$ & $-0.6 \%$ & $0.0 \%$ & $-0.2 \%$ & $-0.5 \%$ \\
& $1965-1975$ & $-4.2 \%$ & $-2.2 \%$ & $-0.1 \%$ & $0.0 \%$ & $-1.9 \%$ \\
& $1975-1990$ & $-2.1 \%$ & $1.5 \%$ & $-2.0 \%$ & $-0.1 \%$ & $-1.5 \%$ \\
& $1990-2000$ & $-1.2 \%$ & $-2.7 \%$ & $0.2 \%$ & $0.0 \%$ & $1.3 \%$ \\
& $2000-2015$ & $0.8 \%$ & $-0.6 \%$ & $1.9 \%$ & $-0.4 \%$ & $-0.1 \%$ \\
\hline
\end{tabular}

Table A4.6: Decomposition of Catch Up to USA for Whole Period and Sub-Periods

\begin{tabular}{|c|c|c|c|c|c|c|}
\hline Country/Region & Period & $\begin{array}{l}\text { Total Catch } \\
\text { Up Rate }\end{array}$ & Within & $\begin{array}{l}\text { Between } \\
\text { Static }\end{array}$ & $\begin{array}{l}\text { Between } \\
\text { Dynamic }\end{array}$ & $\begin{array}{c}\text { Initial } \\
\text { Specialization }\end{array}$ \\
\hline \multirow[t]{5}{*}{ Africa } & $1960-2015$ & $0.9 \%$ & $-0.5 \%$ & $1.2 \%$ & $-0.3 \%$ & $0.5 \%$ \\
\hline & 1960-1975 & $2.6 \%$ & $1.0 \%$ & $1.7 \%$ & $-0.2 \%$ & $-0.1 \%$ \\
\hline & 1975-1990 & $-0.3 \%$ & $-1.3 \%$ & $0.7 \%$ & $-0.2 \%$ & $0.6 \%$ \\
\hline & $1990-2000$ & $0.9 \%$ & $-0.9 \%$ & $1.1 \%$ & $-0.2 \%$ & $0.9 \%$ \\
\hline & $2000-2015$ & $1.3 \%$ & $-0.1 \%$ & $1.6 \%$ & $-0.5 \%$ & $0.3 \%$ \\
\hline \multirow[t]{5}{*}{ Botswana } & 1960-2015 & $4.5 \%$ & $2.7 \%$ & $3.7 \%$ & $-1.9 \%$ & $-0.1 \%$ \\
\hline & $1968-1975$ & $13.5 \%$ & $3.2 \%$ & $12.7 \%$ & $-1.0 \%$ & $-1.4 \%$ \\
\hline & 1975-1990 & $6.7 \%$ & $4.4 \%$ & $2.9 \%$ & $-1.4 \%$ & $0.7 \%$ \\
\hline & $1990-2000$ & $0.1 \%$ & $0.4 \%$ & $-0.2 \%$ & $-0.5 \%$ & $0.3 \%$ \\
\hline & $2000-2015$ & $1.0 \%$ & $2.3 \%$ & $2.9 \%$ & $-3.7 \%$ & $-0.5 \%$ \\
\hline \multirow[t]{5}{*}{ Burkina Faso } & $1970-2015$ & $1.9 \%$ & $0.1 \%$ & $1.4 \%$ & $-0.2 \%$ & $0.6 \%$ \\
\hline & $1970-1975$ & $2.7 \%$ & $3.3 \%$ & $0.0 \%$ & $0.0 \%$ & $-0.6 \%$ \\
\hline & 1975-1990 & $3.2 \%$ & $2.6 \%$ & $-0.1 \%$ & $0.0 \%$ & $0.7 \%$ \\
\hline & $1990-2000$ & $1.5 \%$ & $-1.1 \%$ & $1.8 \%$ & $-0.1 \%$ & $1.0 \%$ \\
\hline & $2000-2015$ & $0.4 \%$ & $-2.9 \%$ & $3.2 \%$ & $-0.5 \%$ & $0.6 \%$ \\
\hline \multirow[t]{5}{*}{ Cameroun } & $1965-2015$ & $1.3 \%$ & $-0.7 \%$ & $1.3 \%$ & $-0.1 \%$ & $0.8 \%$ \\
\hline & $1965-1975$ & $6.2 \%$ & $5.5 \%$ & $0.0 \%$ & $0.0 \%$ & $0.7 \%$ \\
\hline & 1975-1990 & $3.9 \%$ & $2.0 \%$ & $1.1 \%$ & $-0.1 \%$ & $0.9 \%$ \\
\hline & $1990-2000$ & $0.6 \%$ & $-4.2 \%$ & $4.0 \%$ & $-0.4 \%$ & $1.3 \%$ \\
\hline & $2000-2015$ & $-3.1 \%$ & $-3.8 \%$ & $0.2 \%$ & $0.0 \%$ & $0.5 \%$ \\
\hline \multirow[t]{5}{*}{ Ethiopia } & $1961-2015$ & $0.2 \%$ & $-1.7 \%$ & $1.2 \%$ & $-0.2 \%$ & $0.9 \%$ \\
\hline & 1961-1975 & $-1.0 \%$ & $-2.8 \%$ & $0.6 \%$ & $0.0 \%$ & $1.2 \%$ \\
\hline & $1975-1990$ & $-2.4 \%$ & $-3.6 \%$ & $0.1 \%$ & $0.0 \%$ & $1.0 \%$ \\
\hline & $1990-2000$ & $-0.6 \%$ & $-3.0 \%$ & $1.2 \%$ & $0.0 \%$ & $1.3 \%$ \\
\hline & $2000-2015$ & $4.0 \%$ & $1.5 \%$ & $2.5 \%$ & $-0.6 \%$ & $0.5 \%$ \\
\hline
\end{tabular}




\begin{tabular}{|c|c|c|c|c|c|c|}
\hline \multirow[t]{5}{*}{ Ghana } & $1960-2015$ & $0.6 \%$ & $-0.3 \%$ & $0.3 \%$ & $-0.2 \%$ & $0.9 \%$ \\
\hline & 1960-1975 & $-2.0 \%$ & $-2.7 \%$ & $0.3 \%$ & $0.0 \%$ & $0.4 \%$ \\
\hline & $1975-1990$ & $-2.0 \%$ & $-2.9 \%$ & $-0.1 \%$ & $0.0 \%$ & $1.0 \%$ \\
\hline & $1990-2000$ & $1.9 \%$ & $0.2 \%$ & $0.6 \%$ & $0.0 \%$ & $1.1 \%$ \\
\hline & $2000-2015$ & $3.7 \%$ & $3.0 \%$ & $0.4 \%$ & $-0.5 \%$ & $0.8 \%$ \\
\hline \multirow[t]{5}{*}{ Kenya } & $1969-2015$ & $-1.0 \%$ & $-2.1 \%$ & $0.9 \%$ & $-0.2 \%$ & $0.5 \%$ \\
\hline & 1969-1975 & $1.0 \%$ & $0.4 \%$ & $0.7 \%$ & $-0.3 \%$ & $0.2 \%$ \\
\hline & $1975-1990$ & $-0.3 \%$ & $-1.7 \%$ & $1.1 \%$ & $-0.2 \%$ & $0.5 \%$ \\
\hline & $1990-2000$ & $-3.9 \%$ & $-6.8 \%$ & $2.6 \%$ & $-0.4 \%$ & $0.7 \%$ \\
\hline & $2000-2015$ & $-0.5 \%$ & $-0.5 \%$ & $-0.3 \%$ & $-0.1 \%$ & $0.4 \%$ \\
\hline \multirow[t]{5}{*}{ Lesotho } & $1970-2015$ & $0.8 \%$ & $-0.4 \%$ & $1.3 \%$ & $-0.2 \%$ & $0.1 \%$ \\
\hline & $1970-1975$ & $-2.9 \%$ & $-2.9 \%$ & $0.4 \%$ & $-0.1 \%$ & $-0.2 \%$ \\
\hline & 1975-1990 & $0.9 \%$ & $0.0 \%$ & $1.0 \%$ & $-0.1 \%$ & $0.0 \%$ \\
\hline & $1990-2000$ & $3.2 \%$ & $2.0 \%$ & $1.2 \%$ & $-0.2 \%$ & $0.1 \%$ \\
\hline & $2000-2015$ & $0.3 \%$ & $-1.5 \%$ & $1.9 \%$ & $-0.3 \%$ & $0.2 \%$ \\
\hline \multirow[t]{5}{*}{ Malawi } & 1966-2015 & $0.4 \%$ & $-1.5 \%$ & $1.6 \%$ & $-0.4 \%$ & $0.6 \%$ \\
\hline & 1966-1975 & $3.9 \%$ & $1.9 \%$ & $1.6 \%$ & $0.0 \%$ & $0.4 \%$ \\
\hline & $1975-1990$ & $-1.9 \%$ & $-2.0 \%$ & $0.4 \%$ & $-0.8 \%$ & $0.5 \%$ \\
\hline & $1990-2000$ & $0.1 \%$ & $-2.3 \%$ & $1.6 \%$ & $-0.2 \%$ & $1.0 \%$ \\
\hline & $2000-2015$ & $1.1 \%$ & $-2.0 \%$ & $2.9 \%$ & $-0.3 \%$ & $0.5 \%$ \\
\hline \multirow[t]{5}{*}{ Mauritius } & $1970-2015$ & $2.3 \%$ & $1.2 \%$ & $1.2 \%$ & $-0.4 \%$ & $0.4 \%$ \\
\hline & $1970-1975$ & $12.5 \%$ & $10.9 \%$ & $2.6 \%$ & $-0.9 \%$ & $-0.1 \%$ \\
\hline & 1975-1990 & $0.2 \%$ & $-1.1 \%$ & $1.3 \%$ & $-0.6 \%$ & $0.5 \%$ \\
\hline & $1990-2000$ & $2.9 \%$ & $0.9 \%$ & $1.3 \%$ & $-0.1 \%$ & $0.8 \%$ \\
\hline & $2000-2015$ & $0.6 \%$ & $0.5 \%$ & $0.4 \%$ & $-0.3 \%$ & $0.0 \%$ \\
\hline \multirow[t]{5}{*}{ Mozambique } & $1970-2015$ & $1.4 \%$ & $0.5 \%$ & $0.3 \%$ & $-0.1 \%$ & $0.7 \%$ \\
\hline & $1970-1975$ & $-7.0 \%$ & $-6.9 \%$ & $0.0 \%$ & $0.0 \%$ & $-0.1 \%$ \\
\hline & 1975-1990 & $-3.0 \%$ & $-3.7 \%$ & $0.0 \%$ & $-0.2 \%$ & $0.8 \%$ \\
\hline & $1990-2000$ & $7.5 \%$ & $6.6 \%$ & $0.0 \%$ & $-0.2 \%$ & $1.1 \%$ \\
\hline & $2000-2015$ & $4.6 \%$ & $3.1 \%$ & $0.8 \%$ & $0.0 \%$ & $0.7 \%$ \\
\hline \multirow[t]{5}{*}{ Namibia } & $1965-2015$ & $0.6 \%$ & $0.6 \%$ & $0.5 \%$ & $-0.4 \%$ & $-0.1 \%$ \\
\hline & 1960-1975 & $1.9 \%$ & $2.1 \%$ & $0.4 \%$ & $-0.2 \%$ & $-0.3 \%$ \\
\hline & 1975-1990 & $-0.2 \%$ & $0.2 \%$ & $0.0 \%$ & $-0.1 \%$ & $-0.3 \%$ \\
\hline & $1990-2000$ & $1.6 \%$ & $1.3 \%$ & $0.5 \%$ & $-0.4 \%$ & $0.2 \%$ \\
\hline & $2000-2015$ & $0.2 \%$ & $-0.1 \%$ & $1.1 \%$ & $-0.9 \%$ & $0.1 \%$ \\
\hline Nigeria & $1960-2015$ & $2.7 \%$ & $1.2 \%$ & $1.2 \%$ & $0.0 \%$ & $0.3 \%$ \\
\hline
\end{tabular}




\begin{tabular}{|c|c|c|c|c|c|c|}
\hline & $1960-1975$ & $11.4 \%$ & $6.3 \%$ & $5.5 \%$ & $0.1 \%$ & $-0.4 \%$ \\
\hline & $1975-1990$ & $-0.3 \%$ & $-0.1 \%$ & $-0.1 \%$ & $-0.1 \%$ & $0.0 \%$ \\
\hline & $1990-2000$ & $-0.5 \%$ & $-1.2 \%$ & $-0.3 \%$ & $0.0 \%$ & $1.1 \%$ \\
\hline & $2000-2015$ & $4.0 \%$ & $1.9 \%$ & $1.6 \%$ & $0.0 \%$ & $0.5 \%$ \\
\hline \multirow[t]{5}{*}{ Rwanda } & $1970-2015$ & $2.4 \%$ & $-0.3 \%$ & $1.9 \%$ & $-0.2^{\%} \%$ & $0.9 \%$ \\
\hline & $1970-1975$ & $5.9 \%$ & $6.0 \%$ & $0.0 \%$ & $0.0 \%$ & $-0.1 \%$ \\
\hline & $1975-1990$ & $-1.9 \%$ & $-4.9 \%$ & $1.7 \%$ & $-0.2 \%$ & $1.5 \%$ \\
\hline & $1990-2000$ & $3.7 \%$ & $2.5 \%$ & $0.3 \%$ & $0.0 \%$ & $0.9 \%$ \\
\hline & $2000-2015$ & $4.6 \%$ & $0.4 \%$ & $3.9 \%$ & $-0.3 \%$ & $0.5 \%$ \\
\hline \multirow[t]{5}{*}{ Senegal } & $1970-2015$ & $-1.7 \%$ & $-3.2 \%$ & $1.0 \%$ & $-0.2 \%$ & $0.6 \%$ \\
\hline & $1970-1975$ & $-2.7 \%$ & $-3.7 \%$ & $0.8 \%$ & $0.0 \%$ & $0.2 \%$ \\
\hline & $1975-1990$ & $-3.5 \%$ & $-5.0 \%$ & $0.7 \%$ & $0.0 \%$ & $0.8 \%$ \\
\hline & $1990-2000$ & $-0.4 \%$ & $-2.5 \%$ & $1.2 \%$ & $-0.1 \%$ & $1.0 \%$ \\
\hline & $2000-2015$ & $-0.3 \%$ & $-1.6 \%$ & $1.3 \%$ & $-0.3 \%$ & $0.3 \%$ \\
\hline \multirow[t]{5}{*}{ South Africa } & $1960-2015$ & $0.0 \%$ & $-0.7 \%$ & $0.7 \%$ & $-0.2 \%$ & $0.1 \%$ \\
\hline & $1960-1975$ & $2.9 \%$ & $2.2 \%$ & $1.1 \%$ & $0.0 \%$ & $-0.4 \%$ \\
\hline & $1975-1990$ & $-0.9 \%$ & $-2.2 \%$ & $1.3 \%$ & $-0.1 \%$ & $0.1 \%$ \\
\hline & $1990-2000$ & $-1.3 \%$ & $-1.6 \%$ & $0.2 \%$ & $-0.2 \%$ & $0.4 \%$ \\
\hline & $2000-2015$ & $0.3 \%$ & $0.2 \%$ & $0.2 \%$ & $-0.3 \%$ & $0.2 \%$ \\
\hline \multirow[t]{5}{*}{ Tanzania } & $1960-2015$ & $0.5 \%$ & $-1.9 \%$ & $2.1 \%$ & $-0.3 \%$ & $0.6 \%$ \\
\hline & $1960-1975$ & $0.4 \%$ & $-2.9 \%$ & $3.3 \%$ & $-0.3 \%$ & $0.4 \%$ \\
\hline & $1975-1990$ & $-1.3 \%$ & $-2.7 \%$ & $0.8 \%$ & $-0.1 \%$ & $0.7 \%$ \\
\hline & $1990-2000$ & $-0.6 \%$ & $-2.3 \%$ & $0.6 \%$ & $-0.1 \%$ & $1.1 \%$ \\
\hline & $2000-2015$ & $3.0 \%$ & $-0.5 \%$ & $3.7 \%$ & $-0.6 \%$ & $0.4 \%$ \\
\hline \multirow[t]{5}{*}{ Uganda } & $1960-2015$ & $0.6 \%$ & $-1.2 \%$ & $1.3 \%$ & $-0.2 \%$ & $0.7 \%$ \\
\hline & $1960-1975$ & $1.1 \%$ & $-1.2 \%$ & $1.6 \%$ & $-0.3 \%$ & $0.9 \%$ \\
\hline & $1975-1990$ & $0.9 \%$ & $-1.7 \%$ & $1.8 \%$ & $-0.1 \%$ & $0.8 \%$ \\
\hline & $1990-2000$ & $2.6 \%$ & $-1.2 \%$ & $3.0 \%$ & $-0.3 \%$ & $1.1 \%$ \\
\hline & $2000-2015$ & $-1.2 \%$ & $-0.8 \%$ & $-0.4 \%$ & $-0.1 \%$ & $0.2 \%$ \\
\hline \multirow[t]{5}{*}{ Zambia } & $1965-2015$ & $-1.4 \%$ & $-1.3 \%$ & $0.0 \%$ & $-0.2 \%$ & $0.1 \%$ \\
\hline & $1965-1975$ & $-1.5 \%$ & $0.3 \%$ & $-0.1 \%$ & $0.0 \%$ & $-1.6 \%$ \\
\hline & $1975-1990$ & $-3.0 \%$ & $-0.8 \%$ & $-2.0 \%$ & $-0.1 \%$ & $-0.1 \%$ \\
\hline & $1990-2000$ & $-2.5 \%$ & $-3.9 \%$ & $0.2 \%$ & $-0.1 \%$ & $1.3 \%$ \\
\hline & $2000-2015$ & $1.1 \%$ & $-0.8 \%$ & $1.9 \%$ & $-0.4 \%$ & $0.3 \%$ \\
\hline
\end{tabular}




\section{Chapter 5: Is Africa Deindustrializing?}




\subsection{Introduction}

Without question, Africa is the least industrialized region of the world, mostly dependent on the export of primary commodities and imports of manufactures. Some observers argue that Africa has not only failed to industrialize but also that it faces the risk of premature deindustrialization. For example, Rodrik (2016) argues the region ${ }^{88}$, which could potentially become the next leader in labor-intensive manufacturing, is surprisingly deindustrializing prematurely in employment and output. The peak of the manufacturing share in both employment and output is lower than the lowest level of any other region. Tregenna (2015:15) characterized this as 'pre-industrialization deindustrialization' because there has not been any real industrialization before deindustrialization began. Page (2012) also documents that Africa has deindustrialized in three dimensions: relative size - the manufacturing share of employment or output, diversity - the variety of manufactured goods a country produces, and sophistication - the relative knowledge intensity of the manufactured goods a country produces.

At the same time, the emergence of new technologies such as automation, artificial intelligence (AI), and information communication technology (ICT) suggests that the traditional industrialization path of development is increasingly becoming difficult for late industrializers. The potential for Africa to become the next labor-intensive manufacturing powerhouse is threatened by recent advancements in artificial intelligence and automation, which could remove the labor cost advantage and actively discourage the labor intensity of manufacturing. With Google establishing an Artificial Intelligence Lab in Ghana, the use of robots in Africa in the near future is more of a reality than a possibility. Conversely, this technological progress, mainly, the rapid spread of ICT and changes in transport costs has led to the emergence of certain services which have similar properties to manufacturing, opening a new pathway for services-driven structural transformation in Africa (Newfarmer et al., 2018).

The critical nature of this phenomenon has motivated a series of theoretical ${ }^{89}$ and empirical ${ }^{90}$ studies into the trends and underlying causes of deindustrialization in general. In Africa, in particular, individuals ${ }^{91}$ and organizations ${ }^{92}$ have been involved in the broader study of structural change. One resonating conclusion from these studies is that structural change in Africa is (informal) servicesdriven, raising the question of deindustrialization in the region. While there is agreement on the patterns of deindustrialization in other regions of the world, there is no consensus in the case of Africa, partly because of the limited sectoral data on Africa countries. For example, Diao et al. (2017), based on the same dataset Rodrik (2016) used, argue that it is difficult to conclude that Africa is

\footnotetext{
${ }^{88}$ Without Mauritius in the sample of 11 countries. Namely, Botswana, Ethiopia, Ghana, Kenya, Malawi, Nigeria, Senegal South Africa, and Tanzania.

89 See Acemoglu \& Guerrieri, 2008; Alvarez-Cuadrado, Van Long, \& Poschke, 2017; Comin, Lashkari, \& Mestieri, 2015; Foellmi \& Zweimüller, 2008; Kongsamut, Rebelo, \& Xie, 2001; Ngai \& Pissarides, 2007; Rodrik, 2016.

90 See Rowthorn \& Ramaswamy, 1997; Saeger, 1997; Rowthorn \& Coutts, 2004, 2013; R. Rowthorn \& Ramaswamy, 1999; Kollmeyer, 2009; van Neuss, 2018.

${ }^{91}$ See, for example, Diao, Harttgen, \& McMillan, 2017; Diao \& McMillan, 2018; Diao, McMillan, \& Rodrik, 2017; Diao, McMillan, \& Wangwe, 2018; Mccaig, McMillan, \& Jefferis, 2015; M. S. McMillan \& Harttgen, 2014; McMillan \& Rodrik, 2011; McMillan, Rodrik \& Verduzco-Gallo, 2014; de Vries, Timmer, \& de Vries, 2015; Rodrik, 2018.

92 ACET produces the Africa Transformation report; GGDC maintains the Africa Sector Database, UNU-WIDER initiated the Learning to Compete project (L2C) and Jobs, Poverty, and Structural Change in Africa projects; World BankAFRCE initiated the Industrializing for Jobs in Africa project. The AfDB, AFREXIM Bank, and UNECA have strong pillars on industrialization and produce reports on structural change and industrialization in Africa on a regular basis.
} 
deindustrializing. Among the many issues raised in their research is the representativeness of the sample of countries in the Africa Sector Database (ASD) used by Rodrik. The ASD, they argued, covers 11 relatively rich African countries in Africa with better educational, health, and nutritional outcomes. In Chapter 2, we expanded the ASD to include seven relatively poor countries in Africa. Using the Expanded Africa Sector Database (EASD), Naudé (2019) strongly argues that manufacturing is resurging in Africa. A recent study by the World Bank using data on a sample of 41 Africa countries further shows that there is no evidence in support of the widespread view that Africa is deindustrializing prematurely (Nguimkeu \& Zuefact, 2019). ${ }^{93}$

The existing debate is either based on a limited sample of countries (Rodrik, 2016) or a heavily unbalanced panel with data on as many as seven countries starting from the 2000s only (see Nguimkeu \& Zuefact, 2019). In this chapter, we provide extensive evidence on the patterns of deindustrialization using multiple databases that cover all countries in Sub-Saharan Africa over a similar timespan, providing a complete picture of manufacturing performance in Africa. The major aim of the chapter is to reassess Rodrik's(2016) result using a larger sample of countries. This chapter contributes to the limited but essential discussion on the patterns, causes, and consequences of (de)industrialization in Africa in the last six decades. First, it re-examines the evidence on the trends of deindustrialization in Africa. Second, it examines the factors responsible for the manufacturing employment outcomes in Africa.

The analysis elicits several findings of long-run manufacturing performance in Africa based on a sample of 46 countries for real value added and 18 countries for employment. Key among these findings are: (1) There is little evidence in support of the general view that Africa is deindustrializing prematurely by relative size. (2) While there is no evidence in support of the premature deindustrialization thesis for a typical African country in our sample, manufacturing performance in Africa is generally disappointing. For instance, the manufacturing share of employment increased from about 5\% in 1960 to about 7\% in 2015. (3) We document significant heterogeneity across different geographical groups, with southern African countries, in particular, experiencing rapid deindustrialization since the 1980s. The analysis shows that several factors account for these outcomes with preferences, technological progress, and international trade playing an important role. In particular, while trade among Africa countries has played a limited role in the industrialization of the continent, exporting to advanced countries increases manufacturing employment shares, but importing, in general, has adverse effects on employment shares. The negative effect is more substantial for imports coming from other developing countries outside Africa. The rest of the chapter is organized as follows: Section 5.2 discusses methods, data sources, and indicators of deindustrialization; Section 5.3 discusses patterns and trends of deindustrialization in Africa; Section 5.4 provides statistical evidence on deindustrialization in Africa; Section 5.5 discusses the key drivers of manufacturing performance; and Section 5.6 concludes.

\subsection{Methods and Data Sources}

The methodologies and the datasets used to answer the two distinct, but related, research questions are discussed in this section. First, we describe the methods and the a priori expectations. Second, we

\footnotetext{
93 This sample covers value added on 41 countries with several time gaps and covers employment on only 11 countries.
} 
describe the measures and sources of the dependent variable, followed by a description of the independent variables.

\subsubsection{Models and a priori expectations}

To show whether Africa is deindustrializing or not, we consider simultaneously the income effect, population effect and country-specific idiosyncratic factors that may affect the degree of industrialization in the long run. Over the course of development - i.e., as income and population increases - manufacturing activities are expected to have an inverted U-shape relationship with income per capita. To delineate the development effect from the time trend, this section follows Rodrik (2016) by including income per capita, population, and their quadratic terms in the model. The basic econometric model is stated as:

$$
\begin{aligned}
\text { Manshare }_{i t}= & \beta_{0}+\beta_{1} \ln Y_{i t}+\beta_{2}(\ln Y)_{i t}^{2}+\beta_{3} \ln \text { pop }_{i t}+ \\
& \beta_{4}(\ln p o p)_{i t}^{2}+\gamma D u m m y_{t}+\alpha_{i}+\varepsilon_{i t}
\end{aligned}
$$

Where Manshare $_{i t}$ is the manufacturing share of employment or output of country $i$ at time $t, \beta_{0}$ is the constant, $\ln Y$ and $(\ln Y)^{2}$ are the natural logarithm of per capita income and its squared value, $\ln p o p$ and $(\ln p o p)^{2}$ are the natural logarithm of population and its squared value and $\alpha_{i}$ are country fixed-effects that take into account any time-invariant country-specific features such as geography, endowments, and history that generate a varying degree of industrialization across different countries relative to the baseline conditions. After controlling for income, population, and country-specific fixed effects, we capture the patterns of industrialization over time using period dummies (Dummy $)$ for the different episodes of development in Africa: the import substitution era (1960-1975), Lost decades (1976-1989), Post-Structural Adjustment Programs (SAPs) era (1990-1999), and the MDGs era (20002015). The estimated coefficients of the period dummies show the degree of (de)industrialization of each period relative to the control period (import-substitution era). As mentioned in Chapter 3, the periods are defined according to the centrality of industrialization within the prevailing national development plan. The ISI era is used as the benchmark period because it is usually referred to as the golden era of industrialization driven by import-substitution and nationalist aspirations for rapid development.

To further understand the underlying drivers of manufacturing outcomes in Africa, we estimate a variant of the models of Kollmeyer (2009) and van Neuss (2018). These models follow the tradition of Chenery (1960). In addition to the variables in 5.1, we include key independent variables and other control variables that have the potential to drive industrial development in the current context of globalization. The model is explicitly stated as follows:

$$
\begin{gathered}
\text { Manshare }_{i t}=\alpha_{0}+\beta_{1} \ln Y_{i t}+\beta_{2}(\ln Y)_{i t}^{2}+\beta_{3} \ln p o p_{i t}+\beta_{4}(\ln p o p)_{i t}^{2}+\alpha_{1} U B P_{i t}+ \\
\alpha_{2} I T_{i t}+\delta C V_{i t}^{\prime}+\alpha_{i}+\gamma_{t}+\varepsilon_{i t}
\end{gathered}
$$


Where $U B P$ is is the unbalanced labor productivity growth which captures cross-sector differences in labor productivity, IT is international trade in manufactures, $C V^{\prime}$ stands for other control variables, $\gamma_{t}$ represents time fixed effects and $\varepsilon$ the idiosyncratic error term. In equation 5.2, we replace the period dummies with time fixed effect to account for the change occuring across time but common to all countries in year t. Our model is similar to the models of Kollmeyer (2009) and van Neuss (2018) but not comparable in the sense that in addition to per capita income, we control for population to account for the fact that the size of the domestic market is essential for industrial development.

A large domestic market is indicative of a large potential demand, although this will depend upon the level of income i.e., for a given level of income, a higher population is associated with a larger market. All else equal therefore, we expect a rising population to increase the demand for manufactures, with manufacturing firms responding by producing more manufactures at a lower cost per unit, generating scale economies. As the unit cost of manufactures falls, firms become more competitive domestically and internationally leading to further increases in demand and higher employment demand. Thus, we expect a positive relationship between population and manufacturing output/employment. However, beyond a certain threshold, population growth becomes a drag on manufacturing development (Malthus trap). From a classical Malthusian perspective, if agricultural technology is not well developed (as in many Africa countries), beyond a certain critical level of population when population growth outpaces the growth of agricultural output, agricultural consumption per capita will be lower than the subsistence level, industry will be denied critical raw materials, theoretically leading to a breakdown of the growth process (Zhou, 2009).

The level of income has long been recognized as a key driver of structural change. According to Engel's law and Bell's Law, structural change is driven by changes in the structure of demand resulting from changes in real income. Particularly, Engel's law states that as income increases, the share of income spent on agricultural products decreases. Bell (1976) argues that at the early stages of development, the proportion of income spent on manufactures will increase but during the postindustrial phase of development, there will be a secular shift of demand from manufactures to services. Recent literature on structural change shows that the process of the reallocation of economic activity across sectors is partly driven by changes in the structure of demand resulting from changes in real income (van Neuss, 2018, 2019). Theoretically, structural change driven by non-homothetic tastes is modelled using the Stone-Geary utility function, which generates non-linear Engel curves. In this framework, the marginal rate of substitution (budget share) between different goods varies as income increases, inducing some activity reallocation towards the sectors which meet higher-order needs (van Neuss, 2019). The extended version of Engel's law shows that the budget share spent on manufacturing goods increases during initial stages of development then stabilizes, and eventually falls beyond a certain level of per capita income. Therefore, we expect an inverted U-shape relationship 
between per capita income and the manufacturing output/employment share. Structural change induced by changes in real income is often described as 'preference-driven structural change.' 94

Another primary cause of employment deindustrialization is rapid technological progress, which induces differential patterns of productivity growth at the sectoral level. The classical studies show that productivity gains in manufacturing exceed productivity gains in services because manufacturing often involves standardized and repetitive processes, which can easily be automated or mechanized, and this leads to a decline in the manufacturing share of employment. If the productivity gap between the manufacturing and non-manufacturing sectors continuously persists, and the pattern of demand among these sectors is constant, then employment growth should shrink in the manufacturing sector and expand in the non-manufacturing sector (Kollmeyer, 2009a). Furthermore, Baumol (1967), through the idea of the 'cost disease' hypothesis, argued that cross-sector differences in technology drive the reallocation of economic activities across sectors. The cost disease hypothesis states that labor moves from sectors characterized by a relatively high rate of technical progress - dynamic sectors - to stagnant sectors, increasing the cost burden of the economy. Manufacturing is considered the progressive sector, whereas the service sector is characterized as the non-progressive sector.

Ngai \& Pissarides (2007) provide a more persuasive premise and generalization to Baumol's cost disease hypothesis, showing that the reallocation of labor to a stagnant sector depends on the elasticity of substitution in demand between manufacturing goods and non-manufacturing goods. If the elasticity of substitution is less than one - i.e., if the consumers' relative choice over the consumption of manufacturing goods changes by less than the change in relative price - technological progress in manufactures leads to a decline in the employment share of manufacturing. If the elasticity of substitution is greater than one, the manufacturing share of labor is increasing in technological progress in manufacturing. In this case, while technological progress in manufacturing reduces employment, a technology-induced reduction in the relative price of manufacturing creates a more than proportionate increase in demand for manufactures, so the net effect is a growth in employment. Most empirical evidence supports a negative relationship between technological progress and employment in manufacturing. However, Nordhaus( 2005), using sectoral data for the US economy, argued that rapid technological progress leads to employment growth in manufacturing because international competition reduces the market price of manufacturing goods, which in turn stimulates greater demand. In this case, the price effect creates more jobs than the technology effect displaces.

Rodrik (2016) shows that the effect of technological progress in manufacturing is not only mediated through the elasticity of substitution in demand between manufactures and non-manufactures but also the ratio of (domestic) supply to demand in manufacturing. In a case where the ratio is less than one - i.e., where the country is a large net importer of manufacturing goods - technological progress in manufacturing may increase manufacturing employment even if demand for manufactures is inelastic. If the proportion of domestic supply in total consumption (of manufactures) is low, the effect of

\footnotetext{
94 The preceding paragraphs discuss how income and population relate to both manufacturing output and employment. In answering our second research question (i.e. equation 5.2) we focus on manufacturing employment only. This is because "the employment-based measure of deindustrialization is, by far, the most studied in the scientific literature. This is likely due to the fact that manufacturing employment is the most visible measure of the size of manufacturing in any country, the one that tends to drive public perceptions of the issue" (van Neuss, 2019: 50).
} 
technological progress in domestic manufacturing on relative prices is also low, compared to a country where the proportion of domestic supply in total consumption is high. As a result, for small open economies like many African countries, technological progress in manufacturing can lead to higher manufacturing output and employment.

Conversely, importing manufacturing goods to meet excess domestic demand can transfer the technology effect on relative prices elsewhere on domestic manufacturing employment, leading to a situation known as 'imported deindustrialization'. Technological progress in China, the EU, and the US - Africa's major trading partners - has made manufactured imports relatively cheaper than domestic goods, rendering the domestic manufacturing sector less competitive. Therefore for technological progress in (domestic) manufacturing to boost employment in African countries, the relative productivity growth in manufacturing must exceed the reduction in the relative price of manufactures on the world market (Rodrik, 2016). Most African countries in our sample are net importers of manufactures, so whether the domestic technology effect or imported deindustrialization effect will dominate is a matter of empirics.

Another driver of manufacturing employment is international trade. In the literature, economic globalization is implicated in the deindustrialization of advanced countries. It was at the core of the debate when deindustrialization coincided with unfavorable labor market developments in the North, with the fear being that trade with the South creates structural unemployment, drives a wedge between wages of skilled and unskilled labor, and contracts the absolute and relative manufacturing share of employment in the North (Saeger, 1997). This called for policy coordination to protect the manufacturing sector from low-wage competitors in the South. The theoretical basis for this debate is rooted in the framework of Frobel, Heinrichs, \& Kreye (1980) which shows the evolving relationship between economic globalization and the patterns of manufacturing employment in the global North and South. During much of the industrial age, world trade patterns followed the classical international division of labor, in which developing countries specialized in the production of primary products and advanced countries specialized in the production of finished goods, creating a dynamic manufacturing sector in the North. However, these existing world trade patterns changed in the late 1960s creating a phenomenon described by Frobel, Heinrichs, \& Kreye (1980) as the "new international division of labor". The new international division of labor involves the globalization of manufacturing supply chains, with multinational firms reducing production costs by relocating routine manufacturing jobs to the South, where wages are generally lower. This was made possible by the emergence of new technology such as ICT, which reduced barriers associated with geographic distance (Kollmeyer, 2009). Africa has not featured prominently in these discussions except for the argument of Page (2012) that the geographic shift (net relocation) of production from (out of) Africa was consistently negative between 1990 and 2005, resulting in a fall of manufactured exports. This is beginning to change with the reallocation of Chinese jobs to the garment sector of Ethiopia, for example.

A related theoretical literature has shown that under certain conditions, international trade spurs industrial development through technology spillover (Grossman \& Helpman, 1991a; Romer, 1990). Trade allows the import of intermediates, which often embody technological knowledge. By accessing intermediate inputs and machinery through trade, developing countries are able to build their 
manufacturing capabilities initially through reverse engineering and incremental innovation, before moving to the production of more sophisticated goods. The intensity of learning opportunities offered by intermediate inputs often depends on the technological distance from trading partners, with learning and spillover effects being stronger when trading partners share similar production capabilities (Amighini \& Sanfilippo, 2014). Conversely, it is argued that nascent industries in developing countries are not able to exploit economies of scale to the same extent as trade competitors, with premature exposure of these industries to international competition potentially destroying industries in the South (Chang, 2003). This argument stems from the logic that trade leads developing countries to specialize according to their comparative advantage on sectors with poor dynamic learning externalities, and that as a result developing countries may suffer dynamic losses from free trade. The infant-industry argument is, however, based on the assumption that there exist in these countries traditional technology with growth potential. The prevalence of traditional technology with poor growth potential in developing countries breaks down the infant-industry logic (Sauré, 2007).

The other (control) variables often cited as important drivers of industrialization are the real exchange (RER) rate, human capital, foreign direct investment (FDI), and fixed domestic capital. The index of (RER) undervaluation is the ratio of the price of tradable goods to non-tradable goods. Undervaluation increases the price of the tradable sector (manufacturing sector) relative to the nontradable sector. This enhances the relative profitability of the tradable sector and causes it to expand (Rodrik, 2008). The stock of human capital affects a country's specialization patterns. For African countries, improvements in the quality of human capital could change their specialization patterns from the production of primary commodities towards knowledge-intensive manufactured goods. FDI is an important source of employment creation either directly or indirectly through technology transfer particularly if it is channeled to the tradable sector. FDI increases manufacturing employment directly by creating jobs that did not exist in the manufacturing sector of the host country especially if it involves greenfield investment. The direct job creation is often higher if the greenfield investment goes to labor intensive sectors such as manufacturing (Jenkins, 2006; Jude \& Silaghi, 2016). FDI can also affect the manufacturing labor demand of host countries indirectly through both competition effects and the spillover effects. On the one hand, if FDI entry creates competitive pressure that crowds-out domestic firms, the labor intensity of the receiving industries might be negatively affected (Mencinger, 2003). On the other hand, if foreign subsidiaries of multinational firms source locally, demand addressed to upstream sectors could increase, thus stimulating employment (Javorcik, 2004). Similarly, the efficient allocation of domestic investment should increase the relative size of the manufacturing sector, provided it is targeted at the tradable sector.

\subsubsection{Data sources}

The sectoral data for the measurement of the relative size of manufacturing - defined as the manufacturing share of employment or output - come from three main sources: the Africa Sector Database which is integrated into the GGDC 10-sector database (Timmer et al., 2015), the Expanded Africa Sector Database (Mensah \& Szirmai, 2018) and the UN National Accounts: Analysis of Main Aggregates database. Based on these datasets, we measure deindustrialization using three indicators: 
the manufacturing share of total employment, the manufacturing share of real value added, and the manufacturing share of nominal value added. In the context of the existing debate, we show trends in all three shares, although our focus is on employment and real value added since nominal value added conflates movements in quantities and prices, making both movements inseparable.

Income and population data are sourced from the Maddison Project Database (Bolt, Inklaar, de Jong, \& van Zanden, 2018), which provide information on income per capita (in 2011 US\$) and population for all countries in the sample. We measure the technology-induced effect on manufacturing employment using the indicator of unbalanced productivity growth, which measures cross-sector differences in labor productivity growth. Unbalanced productivity growth (UBP) is the ratio of labor productivity in manufacturing to labor productivity in services. Following the existing literature on deindustrialization, we use UBP to capture the idea of Baumol's cost disease hypothesis. UBP is computed using data on real value added (converted to 2011 PPP) and employment from EASD. The third explanatory variable aims at capturing the effect of international trade on manufacturing employment. Many studies use variables such as the terms of trade, the degree of openness to trade, import penetration, or the trade balance (total or in manufacturing) to capture the effect of foreign trade on manufacturing employment. We follow the approach of Kollmeyer (2009) and van Neuss (2018) to disaggregate trade flows into exports (and imports) to (and from) Africa, the North, and the South. The North is defined as Europe and North America whereas the South is defined as Middle East and North Africa, Asia, Central and South America, and Oceania, with some adjustments. We adjust the North and South classification by moving Australia, New Zealand, Israel, Japan, and South Korea to the North, and by moving Mexico and Turkey to the South. The classification is essential because the potential benefits that countries get from imported inputs depend on the technological distance with trade partners. For the export side, the distinction is important because there are a number of studies that have found a strong relationship between the country-of-destination characteristics and export performance (e.g. Baldwin \& Harrigan, 2011). There are number of reasons why manufacturing firms exporting to the US and EU may generate a differential employment impact than countries exporting to African countries only, for example. According to the income preference hypothesis, higher income countries prefer more knowledge-intensive goods, therefore countries exporting to advanced countries may learn more than countries exporting to neighboring African countries. Even when the technology intensity of goods being exported to advanced countries, developing countries, and other African countries are the same however, product certification and market standards differ. As a result, firms exporting to advanced economies adopt the best production techniques and management practices to improve existing production and delivery processes. The resulting efficiency may lead to a differential employment effect. Furthermore, there is strong evidence that manufacturing goods from the North and the South embody different factor intensities. Consistent with the work of Kollmeyer (2009) and van Neuss (2018), trade in manufactures is defined as imports and exports in standard international trade classification (SITC) 5 to 8. Trade data are obtained from the World Trade Flows database (Feenstra et al., 2005) for the period 1962-2000 and the BACI database for the period 2001-2015. We reclassify the BACI dataset from HS6 to SITC4 using a trade concordance table. We then expressed the value of imports and exports as a percentage of total manufacturing value added instead of total value added or GDP to avoid the potential distortion that the increasing share of services in Africa may introduce to the variables. 
Our measure of undervaluation follows the index of Rodrik (2008), which measures the domestic price level adjusted for the Balassa-Samuelson effect. We use data on exchange rates (XR) and PPP from the Penn World Tables version 9.1 to compute the real exchange rate (RXR). ${ }^{95}$ We adjust for the Balassa-Samuelson effect by controlling for GDP per capita $\left(Y_{i t}\right)$ and time fixed effects $\left(\gamma_{t}\right){ }^{96}$ The estimated coefficient of GDP per capita is -0.20 , indicating that as income increases by $10 \%$ the real exchange rate falls by $2.0 \%$ in Africa. The results show a strong Balassa-Samuelson effect. Finally, the index of undervaluation is computed as the difference between the actual real exchange rate and the Balassa-Samuelson-adjusted rate. ${ }^{97}$

Data on net FDI inflows is taken from UNCTAD and expressed in its natural logarithm. Data on the stock of human capital is taken from the Penn World Tables version 9.1. Finally, fixed capital as a percentage of GDP is taken from World Development Indicators.

\subsubsection{Estimation strategy}

The estimation of the econometric model (5.1) stated above to investigate the presence or otherwise of deindustrialization in Africa may suffer from two main problems. First, since the manufacturing share of employment or output is bounded (fractional response variable), the linear fixed effects model - i.e. equation 5.3 - may suffer similar drawbacks as linear probability models (LPM). Therefore, Nguimkeu \& Zuefact (2019) suggest the use of a fixed-effects fractional logit model for studying deindustrialization. However, fixed effects are generally not consistent in nonlinear models such as logit. Treating $\alpha_{i}$ as a parameter to be estimated in a maximum likelihood framework is usually not consistent as the number of cross-sectional unit $(i)$ grows with the time period $(t)$ fixed. This is known as the incidental parameters problem. Fixed effects fractional logit models yield consistent results only if cross-sectional units are fixed and the number of years per unit approaches infinity. The gold standard in estimating a consistent and robust fractional response specification is the method developed by Papke \& Wooldridge (2008), which relies on the Chamberlain-Mundlak method. The method as developed and applied by Papke \& Wooldridge (2008) is limited to balanced panels. Furthermore, Papke \& Wooldridge (2008:130), in the same paper, remark that "It seems evident that, for estimating the marginal effect of a given percentage change in [the independent variable], the difference between linear and nonlinear models is not important." Since we are interested in the marginal effects, particularly of the period dummies, we applied the fixed-effects linear panel estimator (with panel-corrected standard errors for robust inference) to the above specification.

The second econometric challenge is that the usual test of a hump-shaped relationship between the manufacturing share of employment or output and per capita income may not be appropriate. In the literature that tests for the presence of an inverted U-shaped relationship between manufacturing activities and per capita income, the most common approach includes a quadratic term for income in a standard regression. Once the coefficient on income is positive and significant, and the coefficient of the quadratic term is negative and significant and, in addition, the estimated turning point is within the data range, it is common to argue for the presence of an inverted U-shaped relationship. Lind \&

\footnotetext{
${ }^{95} \ln (R X R)_{i t}=\ln \left(X R_{i t} / P P P_{i t}\right)$

${ }^{96} \ln (R X R)_{i t}=\alpha+\beta \ln Y_{i t}+\gamma_{t}+\varepsilon_{i t}$

${ }^{97} \operatorname{lnUnd}_{v a}=\ln (R X R)_{i t}-\ln (\widehat{R X R})_{l t}$
} 
Mehlum (2010) have, however, shown that this criterion used for testing for the presence or otherwise of a U-shaped relationship is too weak. It is particularly problematic because when the true relationship is non-monotone over a small range of data but monotone over most of the data range, imposing a quadratic specification will yield an extremum point (Lind \& Mehlum, 2010:110). Therefore to identify a true inverted U-shape relationship between manufacturing activities and per capita income over relevant data values, the test must identify whether the relationship is increasing at low values within this interval and decreasing at high values within the interval. We, therefore, used the FE estimator (with panel-corrected standard errors for robust inference) in combination with the Lind \& Mehlum appropriate $U$ test to examine the degree of deindustrialization or otherwise in Africa. ${ }^{98}$

Finally, we also adopt a fixed-effects specification to study the drivers of manufacturing employment in Africa (i.e., model 5.2). The choice of a fixed-effects framework is based on two reasons: First, the Hausman test shows that the unique errors are correlated with the model's regressors. Second, the fixed effects framework eliminates time-invariant confounding factors, estimating the coefficient on each regressor using only the within-country variation (Mummolo \& Peterson, 2018). This allows us to emphasize the 'within' effect of each of the key independent variables, namely the impact of changes in preferences, technology, and trade in manufacturing performance within countries. This approach is preferred when evaluating the relative importance of the key factors of deindustrialization for policy purposes. We further estimate the fixed effect model with panel-corrected standard errors suggested by Beck \& Katz (1995).

\subsection{Patterns and Trends of Deindustrialization}

\subsubsection{Evidence on the Changing Structure of the World Economy}

To motivate our analysis of Africa, we show the evolution of the structure of employment with respect to per capita income in the world. A long-standing observation is that the structure of production changes in the process of development (Lewis, 1954; Rostow, 1960). Kuznets (1973), in his Nobel Prize speech, referred to structural change as one of the main features of modern economic growth. At the early stages of development, countries are characterized by the preponderance of agricultural production, where most people live in the countryside and are mostly preoccupied with subsistence farming. The agricultural share of the labor force and national income is very high during this stage of development. At later stages of development, the industry share of the labor force and national income rises to a point and then declines, while the services share of labor and income increases monotonically. Figure 5.1, panels A-D, depicts this path of economic development in the last six decades. In Figure 5.1, Panel A, the agriculture share of total employment is as high as $90 \%$ at lower levels of income. However, as income increases, the proportion of the labor force in agriculture declines exponentially throughout the entire path of economic development.

Generally, the fraction of the labor force in agriculture continues to fall around the world, although the size of the share significantly differs even among developing regions. For example, while the agriculture share of employment is declining in Africa (blue diamonds), it is still high when compared

${ }^{98}$ See similar approach in Nguimkeu \& Zuefact (2019) 
with other regions. Three views explain the declining trend of the agricultural employment share: the labor push hypothesis, the labor pull hypothesis, and the subsistence constraint hypothesis. The labor push hypothesis states that the combination of improvements in farm technology and less-than-unity income elasticity of demand for food releases the agrarian workforce to other sectors as income increases (Caselli \& Coleman, 2001; Matsuyama, 1992). The labor pull hypothesis states that it is faster productivity growth in the modern sector due to advances in industrial technology that induces more workers in the agricultural sector to relocate to the modern industrial sector. Complementing the labor push hypothesis is the subsistence constraint hypothesis, which states that if a country consumes neither more nor less of the subsistence level of agricultural products ${ }^{99}$, then the fraction of labor in agriculture is directly proportional to the subsistence level of consumption and inversely proportional to the level of productivity in agriculture. This implies that when agricultural productivity is low, more workers are required to produce the minimum subsistence consumption and vice versa.

Alvarez-Cuadrado \& Poschke (2011) explore the historical experiences of 12 countries using data from the $19^{\text {th }}$ century onwards and show that technological progress in manufacturing - the pull effect was the main driver of the de-agriculturalization of today's industrialized countries until 1920. However, productivity improvements in agriculture - the push effect - is the primary driver of structural change after the 1960s. The implication is that advances in industrial technology are essential for successful structural transformation at the early stages of development. However, industrial growth in Africa in the last five decades has been disappointing (Newfarmer et al., 2018). In contrast to the experience of earlier industrializers, recent evidence further suggests that the de-agriculturalization of Africa - depicted in Figure 5.2, panel A - is linked to improvements in agricultural productivity (Diao et al., 2018). Evidence on the subsistence constraint hypothesis indicates that this simple characterization alone explains as much as $90 \%$ of the decline in agricultural employment shares in some countries since the 1960s (see Üngör, 2013). The intuition and the empirical results of the subsistence constraint hypothesis further support the earlier indication that agricultural productivity has played a fundamental role in the structural transformation of the world in the last six decades.

While improvements in agricultural technology free more workers globally, the sectors in which the workers are moving into explains regional differences in catching up with the productivity level of the frontier. For example, the aggregate productivity level of East Asia was 15\% of the US level in 1963. East Asian productivity reached $70 \%$ of the US level by 2010. The productivity of Latin American was $35 \%$ of the US level in 1963 but shrank to $25 \%$ by 2010 . One stylized fact associated with the divergence between these two regions is that whereas a significant proportion of workers initially relocated to manufacturing industries, and later, to dynamic services in East Asia, the fraction of the workforce in manufacturing has been declining while the fraction of the workforce in domestic trade and personal services has been rising in Latin America since the 1960s. The sectoral heterogeneity, particularly the differential rate of labor productivity growth in the sectors receiving most workers, explains the divergence of the two regions (Üngör, 2017). The experience of Africa is no different from Latin America. The structural change of Africa has mostly been marked by informal tertiarization where workers are relocating from the traditional agricultural sector to informal trading activities with aggregate productivity of most countries below 15\% of US productivity (see chapter 4).

${ }^{99}$ The minimum subsistence good is a satiation point. 
Figure 5.1, panels B and C, further show that the manufacturing and the industry share of employment has followed a hump-shaped trajectory throughout development. The increasing phase of the manufacturing/industry employment trajectory is known as industrialization, while the decreasing phase is known as deindustrialization. Despite the commonly observed patterns of structural change especially with respect to de-agriculturalization and tertiarization, it is clear from Figure 5.1, panels B $\& C$, that countries and regions achieved different levels of industrial development at the same level of per capita income. While the predicted values of the agriculture and services shares of employment at each level of per capita income tend to fit the observed data quite well, the predicted values of the manufacturing share of employment at each level of per capita income do not fit the data so well. The highest manufacturing employment shares that countries reached before beginning to deindustrialize has fallen over time.

At the national level, unbalanced productivity growth - labor productivity in manufacturing grows much faster than in non-manufacturing - has led to the fear that technology is taking away global manufacturing jobs. Evidence suggests that while manufacturing jobs are declining at the country level for former industrialized and some newly industrializing countries, the world as a whole has not deindustrialized (Felipe \& Mehta, 2016). The near constancy of the global manufacturing share of employment and output since the 1970s is explained by the globalization of manufacturing supply chains. Thus, while technology is driving value added per worker to grow much faster than aggregate productivity within countries, global labor productivity in manufacturing is not growing faster than global aggregate labor productivity because rapid productivity growth within countries is offset by the negative geographic shift, namely the continual shift of manufacturing jobs from higher productivity countries and regions to lower productivity countries and regions (Felipe \& Mehta, 2016). 


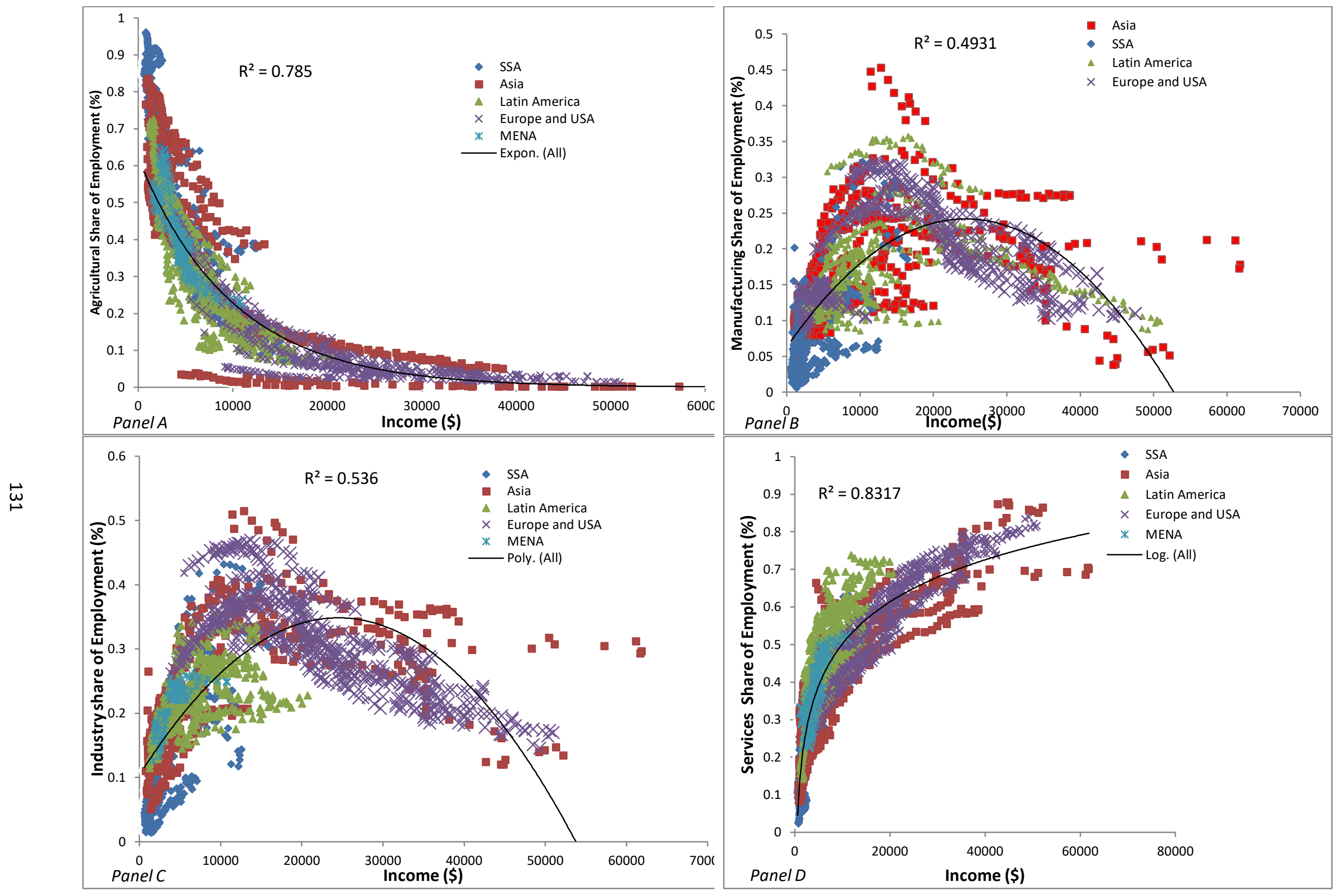

Figure 5.1: Evolution of sectoral employment shares in the world

Sectoral shares of employment and the level per capita income on a sample of 49 countries in the World. Based on data from the GGDC 10-sector database, the Expanded Africa Sector Database and the Maddison project database. 

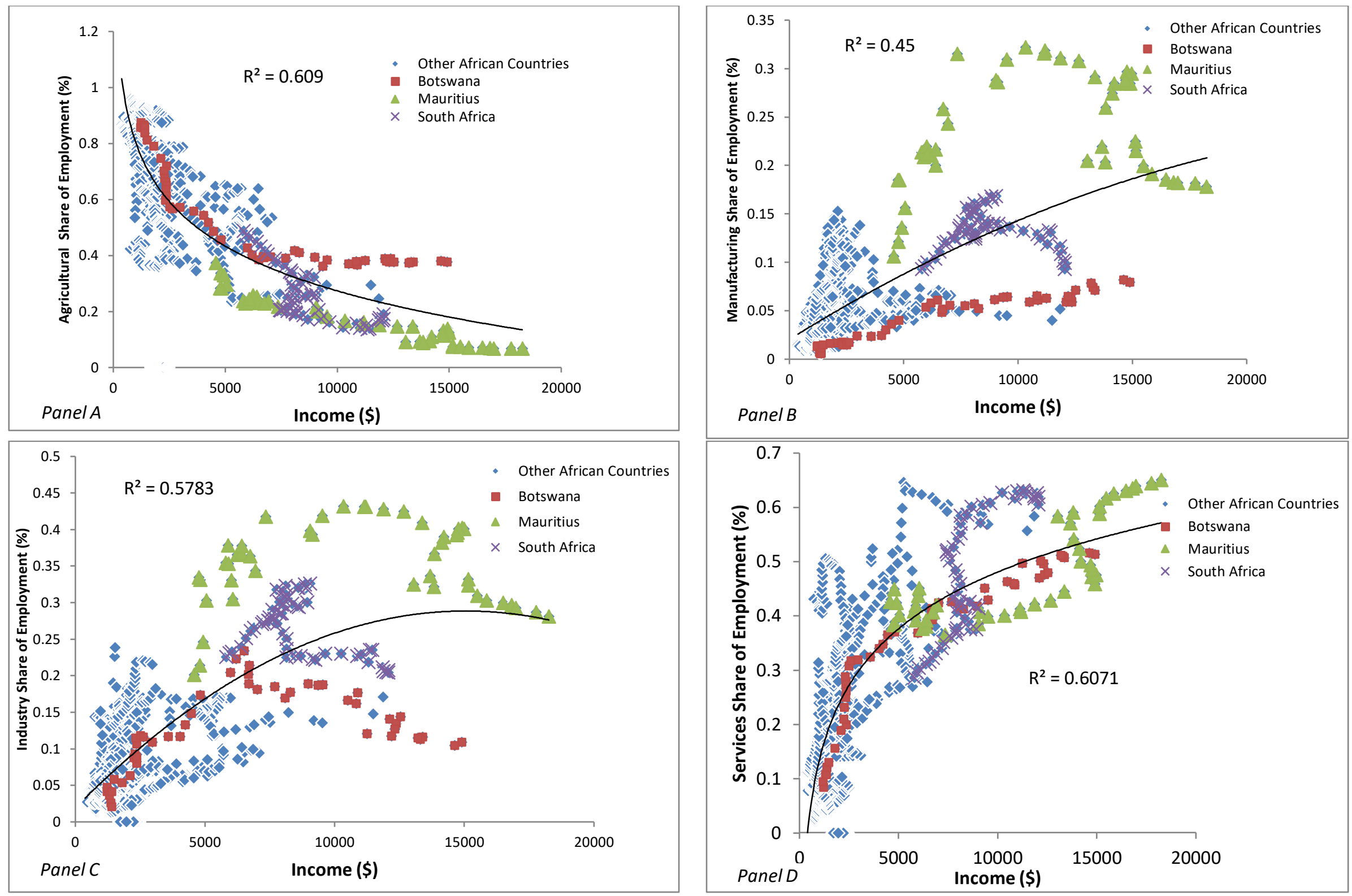

Figure 5.2: Evolution of sectoral employment shares in the Sub-Saharan Africa

Sectoral shares of employment and the level per capita income on a sample of 18 countries in Africa. Based on data from the Expanded Africa Sector Database and the Maddison project database. 
Deindustrialization has been a key feature of advanced economies since the 1960s because of rapid technological progress, which induces differential patterns of productivity growth at the industry level. National experiences are marked by varying degrees of intensity of deindustrialization. For example, while the manufacturing share of employment in the US has steadily declined from about 25 percent in the 1950s to less than 10 percent in 2010, the manufacturing share of valued-added has remained roughly the same. In the United Kingdom, conversely, the manufacturing employment share decreased from about 30 percent in the 1970s to about 10 percent in 2010, with the manufacturing share in total value added also falling from about 25 percent to 15 percent (Timmer et al., 2015). On theoretical grounds, the structural shift of factors of production from manufacturing industries to services in developed countries is expected. At a high level of development (post-industrial phase), it is expected that the rate of technological progress and accompanying income level will induce a secular shift from the production of physical goods to the provision of services. What is unexpected and unwelcome is the 'supposed' deindustrialization of Africa.

\subsubsection{Is Africa Deindustrializing?}

There is a widespread view that Africa is deindustrializing prematurely since the manufacturing share of employment and output peaks at income levels that are much lower than those at which former industrialized and newly industrializing economies reached before deindustrializing (Rodrik, 2016; Tregenna, 2015). However, recent evidence suggests that this view within the context of limited data needs to be reconsidered (Diao et al., 2017; Naudé, 2019; Nguimkeu \& Zuefact, 2019). Figure 5.2, panel $\mathrm{B}$, shows that the manufacturing share of total employment is yet to peak in Africa. This section aims to examine whether Africa has truly deindustrialized using a new database that covers about $80 \%$ GDP in Africa. We explore the trends of deindustrialization since the 1960s. We begin our analysis by graphically summarizing the trends in the manufacturing share of employment and value added in Africa.

Figure 5.3 depicts the patterns of manufacturing shares in employment in Africa and three sub-regions since the 1960s. For Africa as a whole, the manufacturing share of employment has marginally increased from less than $5 \%$ in 1960 to more than $7 \%$ by 2015 . However, the results differ markedly by sub-region. In Southern Africa, there has been a relatively sharp decline in employment shares from $11 \%$ in 1960 to $5.5 \%$ in 2015. In West Africa, the employment share increased from $4.2 \%$ in 1960 to about $6.5 \%$ in 2015 but this is lower than the $7.5 \%$ achieved in 1976, suggesting deindustrialization in the more recent period. In East Africa, there is an incredible increase in the manufacturing share from around $1 \%$ to $9 \%$. There is some evidence to indicate that the rapid expansion of employment in manufacturing is mainly driven by micro, small and medium size firms (MSMEs) that operate outside the formal sector in some East African countries (Diao, Kweka, et al., 2018; Diao, Magalhaes, \& Mcmillan, 2018).

Figure 5.4 shows the evolution of the manufacturing share of real value added in Africa and the three sub-regions. In terms of value-added there is a rapid decline in the shares after 1982 (except for East Africa where the manufacturing share continues to increase till 1997 and does not decline much thereafter). The manufacturing share of value-added peaks at around $23 \%$ for Southern Africa, 18\% 
for Africa as a whole, and 16.5\% for West Africa. The peaks are comparable to the manufacturing share of output in the UK and China in the 1980s. ${ }^{100}$

The sample used in figures 3 and 4 is limited to the 18 countries for which data is available with no coverage of Central Africa. To extend our coverage of manufacturing output to as many countries in Africa as possible, we use the UN National Accounts: Analysis of Main Aggregates database. The database covers 46 countries in Africa, including nine countries in Central Africa from 1970 to 2016. Following the AU regional classification, we further sub-divided the sample by sub-region. Figure 5.5 shows the evolution of the manufacturing share in value added by sub-region. In contrast to the wholesale conclusion that Africa is deindustrializing, Figure 5.5 reveals significant heterogeneity across the four sub-regions. While Southern Africa is experiencing a decreasing trend, the manufacturing value added shares of Eastern Africa and Central Africa are increasing over time. For example, the manufacturing share in value added in Southern Africa decreased from 20\% in 1970 to about 10\% in 2016 whereas the share of Eastern Africa changes by about the same magnitude but in the opposite direction, increasing from about $11 \%$ in 1970 to $18 \%$ in 2016. Though the manufacturing share in value added of Central Africa is spiky, it shows an upward trend throughout the entire period, increasing from about $10 \%$ in 1970 to $16 \%$ in 2016. West Africa seems to be the only region that has witnessed a differing trend during the period of study. The manufacturing share of output decreased slowly from 1970 until the mid-1980s before picking up and increasing rapidly until the 1990s when it started falling drastically again. It, however, shows an upward trend since 2010.

Figure 5.3: Manufacturing share of employment by sub-region over time
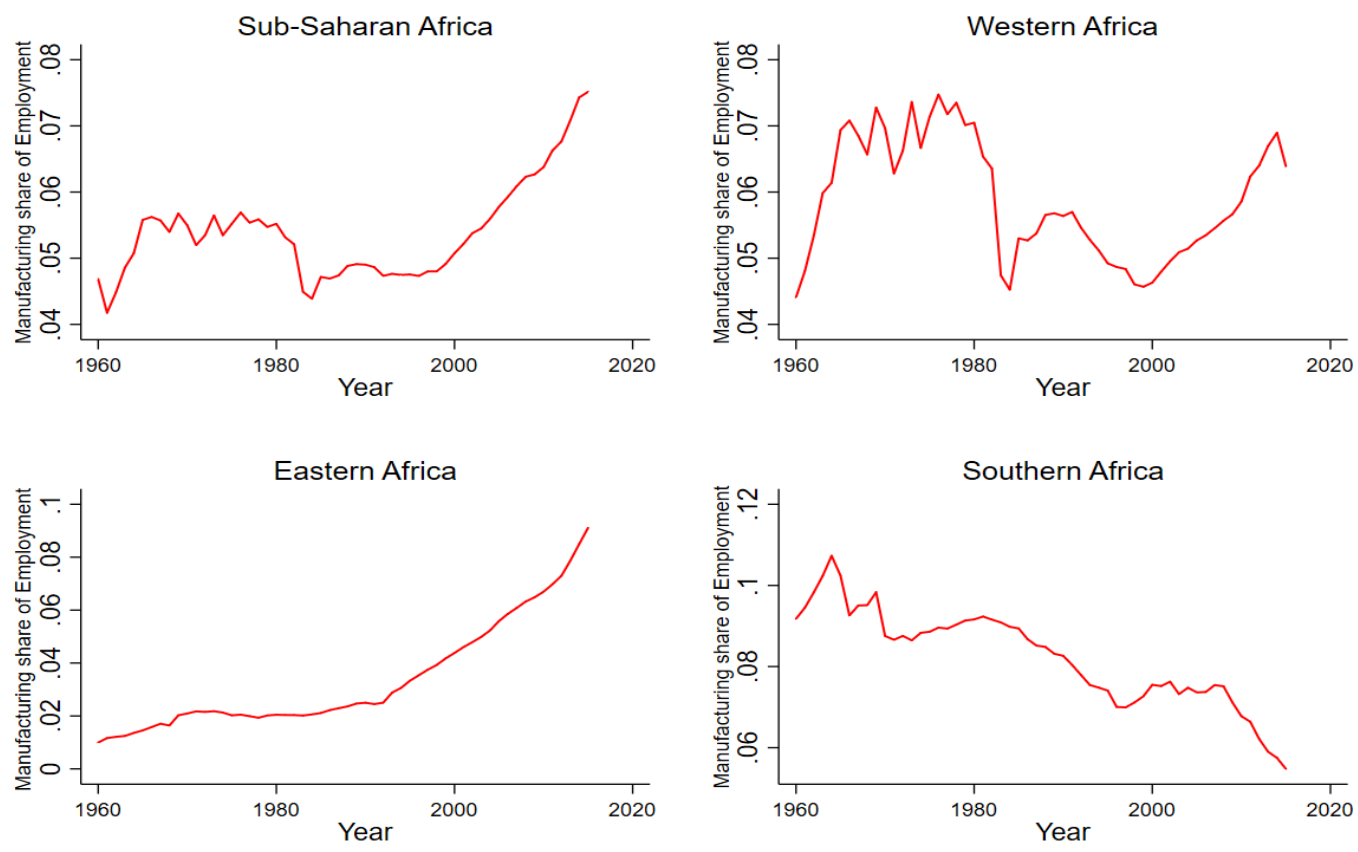

Notes: Manufacturing share of employment trends in Africa, Western Africa, Eastern Africa, and Southern Africa based on the Expanded Africa Sector Database (Mensah and Szirmai, 2018). The regional employment shares are constructed

${ }^{100}$ However, the absolute size of manufacturing and total value added are significantly lower in the case of Africa. 
as the ratio of total manufacturing employment of the region to the total employment of the region, which is equivalent to the weighted averages of manufacturing shares across countries.

Figure 5.4: Manufacturing share of real value added by sub-region over time
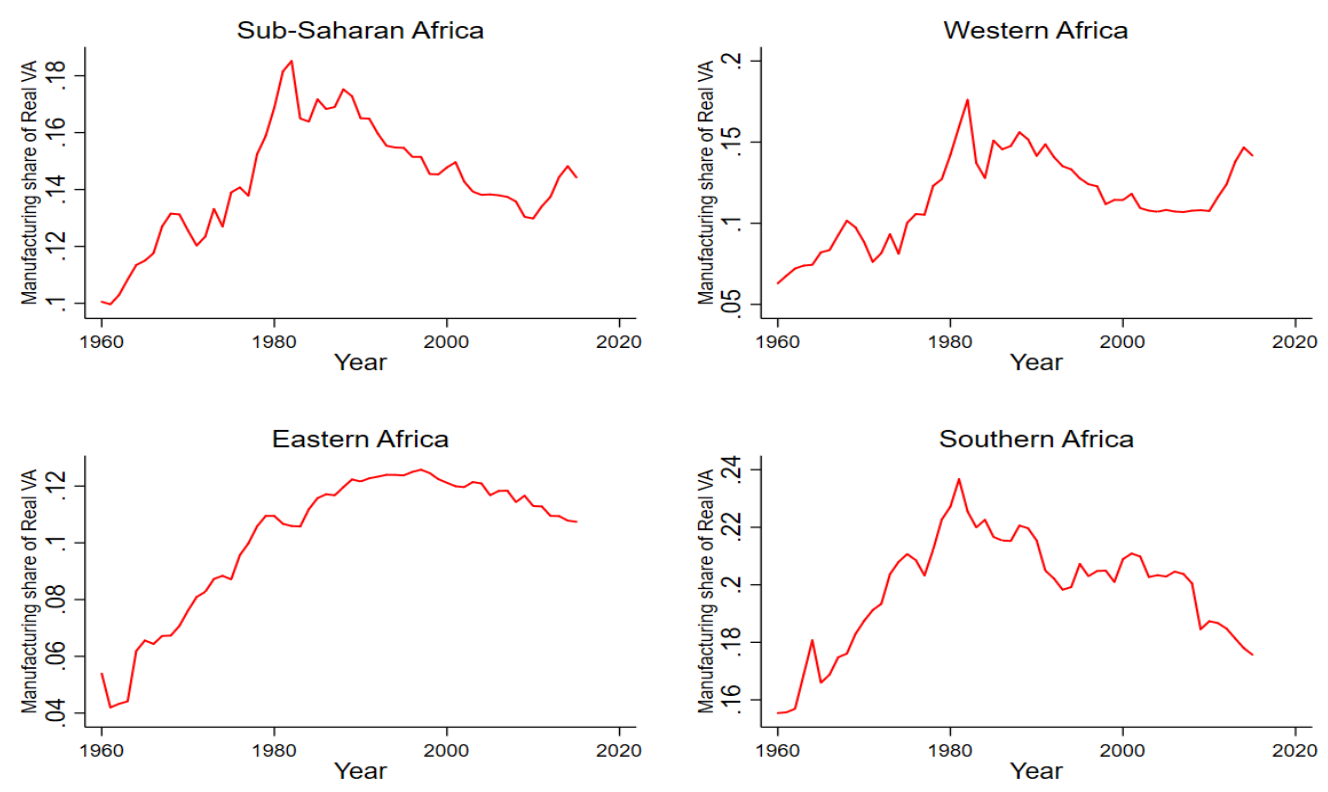

Notes: Manufacturing share of Real Value Added in Africa, Western Africa, Eastern Africa, and Southern Africa computed from the Expanded Africa Sector Database (Mensah and Szirmai, 2018). The regional real value added shares are constructed as the ratio of total manufacturing real value added (in PPP \$) of the region to the total real value added (in PPP \$) of the region, which is equivalent to the weighted averages of manufacturing shares across countries.

\subsection{Empirical Analysis of Deindustrialization}

The previous section provided an overview of the trends in the relative size of manufacturing indicators without considering simultaneously the income effect, population effect, and countryspecific idiosyncratic factors that may affect the degree of industrialization in the long run. As explained above, over the course of development - i.e., as income and population increases manufacturing activities are expected to have an inverted U-shape relationship with income per capita. This section provides statistical evidence on deindustrialization after delineating the development effect using equation 5.1 .

Our baseline results are based on the EASD. For robustness and broader coverage, we supplement this data with the GGDC Africa sector database and the UN National Accounts database. Table 5.1 reports estimated results based on the baseline data. The table further shows the results without Mauritius $^{101}$ in the sample and results for the industry shares. Our focus is on real measures - the manufacturing share of employment and real value added - although in the context of the existing debate, we also report results for nominal value added. After controlling for income, demographic

101 Mauritius is excluded following Rodrik (2016) to test the conjecture that countries with a high share of manufactured exports tend to bias the typical trend of industrialization. 
trends, and country fixed-effects, the estimated coefficients of the period dummies are insignificant and negligible in terms of the magnitude for all periods relative to the ISI period. The Lind \& Mehlum test suggests that the true relationship between the manufacturing share of employment and per capita income is an increasing monotone. The relationship is increasing at lower and higher values of income per capita within the relevant data range with a constant slope.

Figure 5.5: Trends of manufacturing share in value added by sub-region
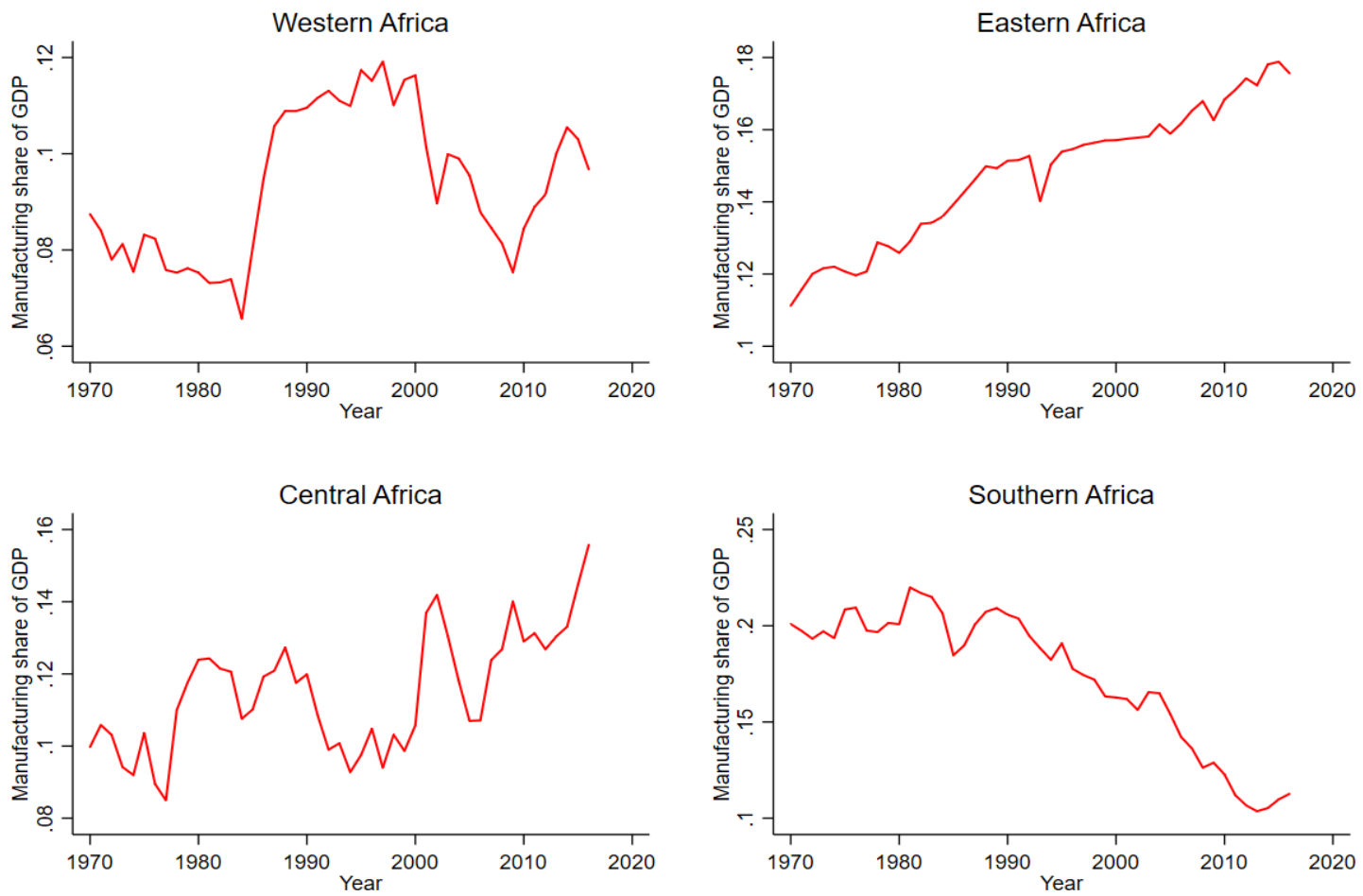

Notes: Trends of manufacturing share of total value added in Western Africa, Eastern Africa, Central Africa, and Southern Africa computed from the UN National Accounts: Analysis of Main Aggregates Database. The construction of the shares follows a similar approach to that in Figure 5.4.

For the nominal and real value added shares, the results show that the coefficients of the period dummies are postive and significant over time. In contrast to the trends in Figure 5.4, the trend of the manufacturing share of real value added show a positive and significant effect over time. Clearly, this does not mean that African countries have not experienced a reduction in the manufacturing share of output. Instead, it suggests that the general downward direction since 1982 (in Figure 5.3) is explained by income and demographic trends with no deindustrialization left to be explained. This is confirmed by the Lind \& Mehlum U test, which shows the presence of an inverted U-shaped relationship between real manufacturing value added and per capita income, with a turning point of around \$7400 (2011 US dollars). When Mauritius is excluded from the sample, the coefficients of the period dummies show a negative and significant effect in the case of the manufacturing share of employment, suggesting employment deindustrialization. Continuous deindustrialization would imply that the negative coefficient gets bigger (in absolute value) over time, however, the negative coefficient of the period dummy of the MDGs is smaller (in absolute value) than the post-SAP period, suggesting that 
there has been much deindustrialization after the 1990s. Specifically, conditional on income, population, and country-specific idiosyncratic factors, the manufacturing share of employment is $0.7 \%$ lower in the lost decades, $1.1 \%$ lower in the period after SAPs, and $0.9 \%$ lower in the MDGs era compared with the ISI era. However, the manufacturing share of real output is $3.3 \%$ higher in the lost decades, $4.9 \%$ higer in the period after SAPs, and 5.2\% higher in the MDGs era compared to the ISI era. The opposite trends of employment and real output shares suggest increasing manufacturing labor productivity in Africa (we return to this issue in Section 5.5).

Table 5.2 reports the estimated results based on the same dataset Rodrik (2016) used. For the full sample, there is no evidence of deindustrialization in Africa. However, once we exclude Mauritius, we find similar trends deindustrialization reported by Rodrik (2016). ${ }^{102}$ The Lind and Mehlum test, however, rejects the presence of an inverse U-shaped relationship between the manufacturing share of employment or output and per capita income. Thus the relationship between manufacturing activities and per capita income is monotonic with confidence intervals suggesting a wide range of possible extremum points. The results in Table 5.1 and Table 5.2 indicate that the evidence of deindustrialization in Africa is not as robust as Rodrik (2016) presented. Albeit, the result is still limited to a small fraction of countries in Africa - 18 countries in Table 5.1 and 11 countries in Table 5.2 with no coverage of Central Africa.

To cover as many countries as possible, we used the UN National Accounts: Analysis of Main Aggregates database. The UN dataset does not include most years of the ISI period; hence the period 1970-79 is used as the benchmark period. As a consequence, we cannot define the lost decades as in the previous estimation, with the 1980s therefore used in place of the lost decades. However, the postSAPs (1990-99) and MDGs (2000-2015) periods are defined as previously. The results based on the UN database are reported in Table 5.3. The estimated coefficients of the period dummies are not statistically significant for the nominal manufacturing share of value added. For the real manufacturing share of value added, the estimated coefficient is $1.2 \%$ higher in the $1980 \mathrm{~s}$ than the $1970 \mathrm{~s}, 2.0 \%$ higher in the post-SAPs period than the 1970s, but there is no statistically significant difference between the estimated shares in the MDGs era and the 1970s. For the industry share of output, estimated coefficients of the period dummies are not statistically significant. The results suggest that Africa is not deindustrializing. However, there has not been any significant industrial development since the 1970s.

Rodrik (2016) argues that when Mauritius, a high exporter of manufacturing goods, is excluded from the sample, all three measures of industrialization ${ }^{103}$ show a declining trend in Africa. We, therefore, follow the approach of Nguimkeu \& Zuefact (2019) to classify countries as intensive exporters of manufacturing in Africa if manufactured exports in the total volume of exports exceed $50 \%$. The following countries were identified as intensive manufacturing exporters in Africa: Botswana, Lesotho, Eswatini, Cape Verde, and Mauritius. In our analysis, we excluded the intensive manufacturing exporters from the sample to test the conjecture that Africa is deindustrializing when intensive exporters of manufacturing are excluded from the sample. In contrast to Rodrik's results, our analysis for the restricted sample rejects the conjecture that Africa is deindustrializing when exporters of

\footnotetext{
102 The coefficients of income and population and their square values is however different from Rodrik's. We use the latest version of the Maddison database while Rodrik uses the 2009 version updated with information from WDI

103 Manufacturing share of employment, nominal value added, and real value added.
} 
manufacturing are excluded from the sample. In particular, the real manufacturing share of output is $1.3 \%$ higher in the 1980s than the $1970 \mathrm{~s}, 2.1 \%$ higher in the post-SAPs era than the $1970 \mathrm{~s}$, and $0.9 \%$ higher in the MDGs era than 1970s. The Lind and Mehlum test further shows that the true relationship between real manufacturing in value added and per capita income is not concave but monotonic, increasing in income.

The results on the manufacturing share of output in tables 5.1, 5.2, and 5.3 present evidence on the varying degree of industrialization in Africa. The different geographical coverage of the tables and the different corresponding estimated coefficients of the period dummies are suggestive of the significance of geographic differences in manufacturing performance. Figure 4 further suggests that estimating the model using data for all countries may conceal essential differences in the pattern of industrialization across sub-regions. We explore this further by dividing the sample and estimating the model according to the African Union (AU)sub-regional boundaries. The results for the sub-regional analysis are presented in Table 5.4. The results highlight noticeable regional differences. For both the nominal and real manufacturing share of value added, while East Africa is industrializing, Southern Africa is deindustrializing. The estimated coefficients of the period dummies for East Africa are positive and significantly different from the control period. The results show that the real manufacturing share of value added is $1.5 \%$ higher in the $1980 \mathrm{~s}$ than the $1970 \mathrm{~s}, 3.6 \%$ higher in the post-SAPs period than the 1970s, and 3.1\% higher in the MDGs era than in the 1970s. Conversely, the estimated coefficients on the period dummies for Southern Africaare negative and statistically significant. The manufacturing share in Southern Africa is 1.7\% lower in the 1980s than the 1970s, $1.9 \%$ lower in the post-SAPs era than the 1970s, and 2.1\% lower in the MDGs era than the 1970s. The appropriate U-curve test further confirms that the true relationship between the manufacturing share of output and per capita income is monotone in East Africa, but concave in South Africa with a turning point of $\$ 8394$ (2011 US dollars). For West Africa, the real manufacturing share of value added is $2.5 \%$ lower in the MDGs era than in the 1970s. But for the other periods, there was no statistically significant difference between the shares and the control period. The Lind \& Mehlum test suggests the presence of a strong inverted U-shaped relationship between manufacturing activities and per capita income. For Central Africa, we do not find evidence for changes in manufacturing shares over time.

We do not find convincing and robust evidence in support of the general view that Africa is deindustrializing prematurely (by relative size). Manufacturing employment shares do not follow an inverse U-shape relationship. Conditional on income, population, and country-specific fixed effects, manufacturing output shares show positive and statistically significant trends over time. When we increase the coverage of countries to almost all countries in Africa, the results suggest that Africa is not deindustrializing, although there has not been any significant industrial development since the 1970s. This result masks important regional differences. A sub-regional analysis shows that East Africa is industrializing, whereas Southern Africa is the only region that seems to be deindustrializing. 
Table 5.1: Evidence on Deindustrialization in Sub-Saharan Africa (EASD)

\begin{tabular}{|c|c|c|c|c|c|c|c|c|c|}
\hline \multirow{3}{*}{ Panel A: Reg. Estimates } & \multicolumn{3}{|c|}{ Sub-Saharan Africa } & \multicolumn{3}{|c|}{ Sub-Saharan Africa excl. MUS ${ }^{104}$} & \multicolumn{3}{|c|}{ Sub-Saharan Africa } \\
\hline & EMP & Nom VA & Real VA & EMP & Nom VA & Real VA & EMP & Nom VA & Real VA \\
\hline & Manshare & Manshare & Manshare & Manshare & Manshare & Manshare & Indshare & Indshare & Indshare \\
\hline \multirow[t]{2}{*}{ Per capita Income (ln) } & 0.021 & $0.181 * * *$ & $0.206^{* * *}$ & $0.034 * *$ & $0.257 * * *$ & $0.219 * * *$ & $0.161 * * *$ & $0.580 * * *$ & $0.770^{* * *}$ \\
\hline & $(0.031)$ & $(0.037)$ & $(0.035)$ & $(0.015)$ & $(0.048)$ & $(0.040)$ & $(0.043)$ & $(0.066)$ & $(0.062)$ \\
\hline \multirow[t]{2}{*}{ Per capita Income-squared (ln) } & -0.000 & $-0.011 * * *$ & $-0.012^{* * *}$ & -0.001 & $-0.016^{* * *}$ & $-0.013 * * *$ & $-0.008^{* * *}$ & $-0.030 * * *$ & $-0.043 * * *$ \\
\hline & $(0.002)$ & $(0.002)$ & $(0.002)$ & $(0.001)$ & $(0.003)$ & $(0.003)$ & $(0.003)$ & $(0.004)$ & $(0.004)$ \\
\hline \multirow[t]{2}{*}{ Population (ln) } & 0.010 & $0.135^{* * *}$ & $-0.039 * *$ & $0.036^{* * *}$ & $0.158^{* * *}$ & $-0.031 *$ & 0.013 & $-0.193 * * *$ & $-0.278 * * *$ \\
\hline & $(0.009)$ & $(0.023)$ & $(0.016)$ & $(0.007)$ & $(0.023)$ & $(0.017)$ & $(0.015)$ & $(0.034)$ & $(0.038)$ \\
\hline \multirow[t]{2}{*}{ Population-squared (ln) } & 0.000 & $-0.009 * * *$ & 0.001 & $-0.001 *$ & $-0.010 * * *$ & 0.000 & $0.002^{* * *}$ & $0.007 * * *$ & $0.011 * * *$ \\
\hline & $(0.000)$ & $(0.001)$ & $(0.001)$ & $(0.000)$ & $(0.001)$ & $(0.001)$ & $(0.001)$ & $(0.001)$ & $(0.002)$ \\
\hline \multirow[t]{2}{*}{ Lost decades } & -0.001 & $0.038^{* * *}$ & $0.032^{* * *}$ & $-0.007 * * *$ & $0.034^{* * *}$ & $0.033^{* * *}$ & $-0.011 * * *$ & $0.045^{* * *}$ & $0.038^{* * *}$ \\
\hline & $(0.002)$ & $(0.005)$ & $(0.004)$ & $(0.001)$ & $(0.005)$ & $(0.004)$ & $(0.003)$ & $(0.008)$ & $(0.006)$ \\
\hline \multirow[t]{2}{*}{ Post SAPs } & -0.000 & $0.053^{* * *}$ & $0.051 * * *$ & $-0.011 * * *$ & $0.043 * * *$ & $0.049 * * *$ & $-0.016^{* * *}$ & $0.074 * * *$ & $0.073^{* * *}$ \\
\hline & $(0.003)$ & $(0.009)$ & $(0.007)$ & $(0.002)$ & $(0.008)$ & $(0.006)$ & $(0.004)$ & $(0.011)$ & $(0.010)$ \\
\hline \multirow[t]{2}{*}{ MDGs } & -0.003 & $0.044 * * *$ & $0.051 * * *$ & $-0.009 * * *$ & $0.036 * * *$ & $0.052 * * *$ & $-0.028 * * *$ & $0.043^{* * *}$ & $0.054 * * *$ \\
\hline & $(0.004)$ & $(0.011)$ & $(0.009)$ & $(0.003)$ & $(0.010)$ & $(0.008)$ & $(0.006)$ & $(0.014)$ & $(0.012)$ \\
\hline \multirow[t]{2}{*}{ Intercept } & -0.225 & $-1.216^{* * *}$ & $-0.624 * * *$ & $-0.371 * * *$ & $-1.596 * * *$ & $-0.700 * * *$ & $-0.813^{* * *}$ & $-1.350 * * *$ & $-1.557 * * *$ \\
\hline & $(0.150)$ & $(0.183)$ & $(0.168)$ & $(0.066)$ & $(0.229)$ & $(0.190)$ & $(0.198)$ & $(0.248)$ & $(0.313)$ \\
\hline \multicolumn{10}{|l|}{ Panel B: U Test } \\
\hline \multirow[t]{2}{*}{ Slope at LB of Income (ln) } & $0.020^{* * *}$ & $0.056^{* * *}$ & $0.069 * * *$ & $0.018^{* * *}$ & $0.069 * * *$ & $0.070^{* * *}$ & $0.065^{* * *}$ & $0.225^{* * *}$ & $0.260 * * *$ \\
\hline & $(0.007)$ & $(0.010)$ & $(0.010)$ & $(0.004)$ & $(0.012)$ & $(0.010)$ & $(0.009)$ & $(0.019)$ & $(0.015)$ \\
\hline \multirow[t]{2}{*}{ Slope at UB of Income (ln) } & $0.020 * * *$ & $-0.026 * * *$ & $-0.021 * * *$ & $0.008^{* *}$ & $-0.055^{* * *}$ & $-0.028 * * *$ & 0.002 & -0.009 & $-0.075^{* * *}$ \\
\hline & $(0.010)$ & $(0.009)$ & $(0.008)$ & $(0.004)$ & $(0.013)$ & $(0.010)$ & $(0.015)$ & $(0.016)$ & $(0.019)$ \\
\hline \multirow[t]{2}{*}{$\mathrm{U}$ test statistic } & & 3.022 & 2.661 & & 4.368 & 2.803 & & 0.572 & 3.948 \\
\hline & & {$[0.001]$} & {$[0.004]$} & & {$[0.000]$} & {$[0.003]$} & & {$[0.284]$} & {$[0.000]$} \\
\hline Extremum point & & 8.563 & 8.909 & 13.00 & 8.067 & 8.706 & 9.942 & 9.659 & 8.945 \\
\hline In 2011 US\$ & & 5236.11 & 7397.00 & & 3251.45 & 6039.06 & & 15657.01 & 7659.07 \\
\hline 95\%CI, Fieller Method & $(-\infty, 9.93)$ & $(8.27,9.09)$ & $(8.63,9.45)$ & $(-4.69, \infty)$ & $(7.89,8.37)$ & $(8.42,9.28)$ & $(8.82,16.21)$ & $(9.25,10.30)$ & $(8.68,9.29)$ \\
\hline Country FE & Yes & Yes & Yes & Yes & Yes & Yes & Yes & Yes & Yes \\
\hline No. of Countries & 18 & 18 & 18 & 17 & 17 & 17 & 18 & 18 & 18 \\
\hline Observations & 918 & 970 & 930 & 872 & 914 & 884 & 918 & 970 & 930 \\
\hline R-Squared & 0.878 & 0.714 & 0.804 & 0.833 & 0.700 & 0.779 & 0.900 & 0.745 & 0.756 \\
\hline
\end{tabular}

Panel-corrected standard errors are in parentheses and p-values in square brackets. Estimations are based on the Expanded Africa Sector Database (Mensah \& Szirmai, 2018). U test is based on Lind \& Mehlum (2010). LB, and UB denote lower boundary, and upper boundary, respectively. Significance levels: * $\mathrm{p}<.10$, $* *$ p $<0.05, * * *$ $\mathrm{p}<.01$. The Fieller Method follows an inverse test to construct confidence intervals for the ratio of normally distributed statistics. For the U-test this method is preferred to the Delta method. 
Table 5.2: Evidence on Deindustrialization in Sub-Saharan Africa (GGDC Africa Sector Database)

\begin{tabular}{|c|c|c|c|c|c|c|c|c|c|}
\hline \multirow{3}{*}{ Panel A: Reg. Estimates } & \multicolumn{3}{|c|}{ Sub-Saharan Africa } & \multicolumn{3}{|c|}{ Sub-Saharan Africa excl. MUS } & \multicolumn{3}{|c|}{ Sub-Saharan Africa } \\
\hline & EMP & Nom VA & Real VA & EMP & Nom VA & Real VA & EMP & Nom VA & Real VA \\
\hline & Manshare & Manshare & Manshare & Manshare & Manshare & Manshare & Indshare & Indshare & Indshare \\
\hline \multirow[t]{2}{*}{ Per capita Income (ln) } & $-0.120 * * *$ & -0.081 & 0.003 & $-0.043^{* *}$ & 0.094 & $0.077 * *$ & $0.151 * *$ & $0.515^{* * *}$ & $0.498^{* * *}$ \\
\hline & $(0.043)$ & $(0.050)$ & $(0.029)$ & $(0.021)$ & $(0.061)$ & $(0.032)$ & $(0.062)$ & $(0.123)$ & $(0.120)$ \\
\hline \multirow[t]{2}{*}{ Per capita Income-sq. (ln) } & $0.009 * * *$ & $0.005^{*}$ & 0.001 & $0.003 * * *$ & -0.006 & $-0.004 *$ & $-0.007 *$ & $-0.024 * * *$ & $-0.022^{* * *}$ \\
\hline & $(0.003)$ & $(0.003)$ & $(0.002)$ & $(0.001)$ & $(0.004)$ & $(0.002)$ & $(0.004)$ & $(0.007)$ & $(0.007)$ \\
\hline \multirow[t]{2}{*}{ Population (ln) } & 0.010 & $0.277^{* * *}$ & $-0.064 * * *$ & $0.060^{* * *}$ & $0.321 * * *$ & $-0.035^{*}$ & $0.072^{* * *}$ & $-0.124 * *$ & $-0.465^{* * *}$ \\
\hline & $(0.015)$ & $(0.029)$ & $(0.021)$ & $(0.009)$ & $(0.032)$ & $(0.018)$ & $(0.021)$ & $(0.055)$ & $(0.070)$ \\
\hline \multirow[t]{2}{*}{ Population-squared (ln) } & 0.000 & $-0.014 * * *$ & $0.004 * * *$ & $-0.001 * * *$ & $-0.015^{* * *}$ & $0.003^{* * *}$ & $-0.002 *$ & $0.009 * * *$ & $0.026 * * *$ \\
\hline & $(0.001)$ & $(0.002)$ & $(0.001)$ & $(0.000)$ & $(0.002)$ & $(0.001)$ & $(0.001)$ & $(0.003)$ & $(0.004)$ \\
\hline \multirow[t]{2}{*}{ Lost decades } & 0.002 & $0.011 * *$ & $0.007 * *$ & $-0.009 * * *$ & 0.003 & 0.004 & -0.002 & 0.008 & 0.003 \\
\hline & $(0.003)$ & $(0.005)$ & $(0.003)$ & $(0.003)$ & $(0.005)$ & $(0.004)$ & $(0.004)$ & $(0.010)$ & $(0.011)$ \\
\hline \multirow[t]{2}{*}{ Post SAPs } & 0.002 & -0.011 & 0.001 & $-0.019 * * *$ & $-0.028 * * *$ & -0.006 & -0.003 & -0.008 & -0.023 \\
\hline & $(0.005)$ & $(0.008)$ & $(0.005)$ & $(0.004)$ & $(0.008)$ & $(0.006)$ & $(0.008)$ & $(0.017)$ & $(0.019)$ \\
\hline \multirow[t]{2}{*}{ MDGs } & -0.004 & $-0.034 * * *$ & $-0.020 * * *$ & $-0.019 * * *$ & $-0.052 * * *$ & $-0.026 * * *$ & $-0.020 * *$ & $-0.069 * * *$ & $-0.088 * * *$ \\
\hline & $(0.007)$ & $(0.010)$ & $(0.007)$ & $(0.006)$ & $(0.011)$ & $(0.008)$ & $(0.010)$ & $(0.020)$ & $(0.024)$ \\
\hline \multirow[t]{2}{*}{ Intercept } & 0.328 & $-0.903^{* * *}$ & 0.184 & $-0.187^{*}$ & $-1.778^{* * *}$ & -0.230 & $-1.061 * * *$ & $-1.713^{* * *}$ & -0.113 \\
\hline & $(0.214)$ & $(0.225)$ & $(0.160)$ & $(0.097)$ & $(0.285)$ & $(0.150)$ & $(0.287)$ & $(0.581)$ & $(0.609)$ \\
\hline \multicolumn{10}{|l|}{ Panel B: U Test } \\
\hline \multirow[t]{2}{*}{ Slope at LB of Income (ln) } & -0.005 & -0.011 & $0.020 * * *$ & -0.001 & 0.015 & $0.030 * * *$ & $0.066^{* * *}$ & $0.203 * * *$ & $0.216^{* * *}$ \\
\hline & $(0.007)$ & $(0.012)$ & $(0.007)$ & $(0.004)$ & $(0.013)$ & $(0.006)$ & $(0.011)$ & $(0.030)$ & $(0.027)$ \\
\hline \multirow[t]{2}{*}{ Slope at UB of Income (ln) } & $0.078^{* * *}$ & $0.040 * *$ & $0.033^{* * *}$ & $0.034 * * *$ & $-0.042 *$ & -0.004 & 0.004 & -0.023 & 0.012 \\
\hline & $(0.019)$ & $(0.018)$ & $(0.011)$ & $(0.008)$ & $(0.025)$ & $(0.013)$ & $(0.027)$ & $(0.041)$ & $(0.045)$ \\
\hline \multirow[t]{2}{*}{ U test statistic } & 0.746 & 0.879 & & & 1.205 & 0.297 & & 0.571 & \\
\hline & {$[0.228]$} & {$[0.190]$} & & & [0.114] & {$[0.383]$} & & {$[0.284]$} & \\
\hline Extremum point & 6.695 & 7.361 & & 6.198 & 7.639 & 10.520 & 11.353 & 10.557 & 11.298 \\
\hline In 2011 US $\$$ & 808.43 & 1572.95 & & 491.61 & 2076.78 & 37036.62 & 85227.83 & 38463.27 & 80686.66 \\
\hline 95\%CI, Fieller Method & $(5.15,7.11)$ & $(-\infty, 17.1)$ & $(-\infty, 13.93)$ & $(1.58,7.02)$ & $(-\infty, \infty)$ & $(-30.6, \infty)$ & $(-10.9, \infty)$ & $(9.68,13.63)$ & $(9.95,17.67)$ \\
\hline Country FE & Yes & Yes & Yes & Yes & Yes & Yes & Yes & Yes & Yes \\
\hline No. of Countries & 11 & 11 & 11 & 10 & 10 & 10 & 11 & 11 & 11 \\
\hline Observations & 524 & 565 & 530 & 481 & 512 & 487 & 524 & 565 & 530 \\
\hline R-Squared & 0.908 & 0.759 & 0.918 & 0.891 & 0.741 & 0.909 & 0.931 & 0.790 & 0.805 \\
\hline
\end{tabular}

$\mathrm{U}$ test is based on Lind \& Mehlum (2010). LB, and UB denote lower boundary, and upper boundary, respectively. Significance levels: $*$ p $<.10, * *$ p $<0.05, * * *$ p $<.01$.

The Fieller Method follows an inverse test to construct confidence intervals for the ratio of normally distributed statistics. For the U-test this method is preferred to the

Delta method. 
Table 5.3: Evidence on Deindustrialization in Sub-Saharan Africa (UN Database)

\begin{tabular}{|c|c|c|c|c|c|c|c|c|}
\hline \multirow{3}{*}{ Panel A: Reg. Estimates } & \multicolumn{4}{|c|}{ Sub-Saharan Africa } & \multicolumn{4}{|c|}{ Sub-Saharan Africa excl. HEC } \\
\hline & Nom VA & Real VA & Nom VA & Real VA & Nom VA & Real VA & Nom VA & Real VA \\
\hline & Manshare & Manshare & Indshare & Indshare & Manshare & Manshare & Indshare & Indshare \\
\hline \multirow[t]{2}{*}{ Per capita Income (ln) } & $-0.050 * * *$ & $0.136^{* * *}$ & -0.041 & 0.067 & $-0.102^{* * *}$ & $0.118^{* * *}$ & $-0.156^{* * *}$ & -0.025 \\
\hline & $(0.018)$ & $(0.026)$ & $(0.049)$ & $(0.049)$ & $(0.021)$ & $(0.027)$ & $(0.052)$ & $(0.051)$ \\
\hline \multirow[t]{2}{*}{ Per capita Income-squared (ln) } & $0.004 * * *$ & $-0.006^{* * *}$ & $0.009 * * *$ & 0.003 & $0.007 * * *$ & $-0.005^{* * *}$ & $0.017 * * *$ & $0.010^{* * *}$ \\
\hline & $(0.001)$ & $(0.002)$ & $(0.003)$ & $(0.003)$ & $(0.001)$ & $(0.002)$ & $(0.003)$ & $(0.003)$ \\
\hline \multirow[t]{2}{*}{ Population (ln) } & $0.086^{* * *}$ & $0.132^{* * *}$ & $0.046^{* *}$ & $0.096^{* * *}$ & $0.069 * * *$ & $0.121 * * *$ & $0.054 * * *$ & $0.122^{* * *}$ \\
\hline & $(0.010)$ & $(0.011)$ & $(0.021)$ & $(0.023)$ & $(0.009)$ & $(0.010)$ & $(0.021)$ & $(0.022)$ \\
\hline \multirow[t]{2}{*}{ Population-squared (ln) } & $-0.005^{* * *}$ & $-0.009 * * *$ & -0.000 & $-0.006^{* * *}$ & $-0.004 * * *$ & $-0.008^{* * *}$ & -0.001 & $-0.008^{* * *}$ \\
\hline & $(0.000)$ & $(0.000)$ & $(0.001)$ & $(0.001)$ & $(0.000)$ & $(0.001)$ & $(0.001)$ & $(0.001)$ \\
\hline \multirow[t]{2}{*}{$1980 \mathrm{~s}$} & 0.003 & $0.012^{* * *}$ & -0.006 & 0.009 & -0.001 & $0.013^{* * *}$ & -0.010 & 0.010 \\
\hline & $(0.003)$ & $(0.003)$ & $(0.007)$ & $(0.007)$ & $(0.003)$ & $(0.003)$ & $(0.007)$ & $(0.007)$ \\
\hline \multirow[t]{2}{*}{ Post SAPs } & 0.004 & $0.020 * * *$ & -0.005 & 0.016 & -0.004 & $0.021 * * *$ & -0.005 & $0.023 * *$ \\
\hline & $(0.005)$ & $(0.004)$ & $(0.010)$ & $(0.010)$ & $(0.004)$ & $(0.004)$ & $(0.011)$ & $(0.010)$ \\
\hline \multirow[t]{2}{*}{ MDGs } & -0.007 & 0.006 & $-0.027 * *$ & -0.011 & $-0.016 * * *$ & $0.009 *$ & -0.022 & -0.000 \\
\hline & $(0.006)$ & $(0.006)$ & $(0.014)$ & $(0.013)$ & $(0.006)$ & $(0.005)$ & $(0.015)$ & $(0.014)$ \\
\hline \multirow[t]{2}{*}{ Intercept } & $-0.191 * *$ & $-1.154 * * *$ & -0.122 & $-0.689 * * *$ & 0.084 & $-1.022 * * *$ & 0.277 & $-0.496 * *$ \\
\hline & $(0.087)$ & $(0.131)$ & $(0.232)$ & $(0.251)$ & $(0.093)$ & $(0.130)$ & $(0.233)$ & $(0.252)$ \\
\hline \multicolumn{9}{|l|}{ Panel B: U Test } \\
\hline \multirow[t]{2}{*}{ Slope at LB of Income (ln) } & -0.009 & $0.079 * * *$ & $0.046^{* *}$ & $0.097 * * *$ & $-0.031 * * *$ & $0.072 * * *$ & 0.009 & $0.075^{* * *}$ \\
\hline & $(0.008)$ & $(0.011)$ & $(0.018)$ & $(0.018)$ & $(0.009)$ & $(0.011)$ & $(0.019)$ & $(0.019)$ \\
\hline \multirow[t]{2}{*}{ Slope at UB of Income (ln) } & $0.041 * * *$ & 0.010 & $0.149^{* * *}$ & $0.132^{* * *}$ & $0.053^{* * *}$ & $0.018^{* *}$ & $0.208^{* * *}$ & $0.195^{* * *}$ \\
\hline & $(0.006)$ & $(0.008)$ & $(0.021)$ & $(0.020)$ & $(0.007)$ & $(0.008)$ & $(0.024)$ & $(0.023)$ \\
\hline \multirow[t]{2}{*}{$\mathrm{U}$ test statistic } & 1.136 & & & & 3.634 & & & \\
\hline & {$[0.128]$} & & & & {$[0.000]$} & & & \\
\hline Extremum point & 5.939 & 11.588 & 2.325 & -11.137 & 7.063 & 12.627 & 4.619 & 1.253 \\
\hline In 2011 US $\$$ & 379.76 & & & & 1168.79 & & & \\
\hline 95\% CI, Fieller Method & $(3.38,6.82)$ & $(10.42,15.22)$ & $(-10.62,4.57)$ & $(-\infty, 25.48)$ & $(6.36,7.45)$ & $(10.85,21.21)$ & $(2.66,5.50)$ & $(-9.86,3.77)$ \\
\hline Country FE & Yes & Yes & Yes & Yes & Yes & Yes & Yes & Yes \\
\hline No. of Countries & 46 & 46 & 46 & 46 & 41 & 41 & 41 & 41 \\
\hline Observations & 2157 & 2157 & 2157 & 2157 & 1922 & 1922 & 1922 & 1922 \\
\hline R-Squared & 0.703 & 0.783 & 0.736 & 0.827 & 0.680 & 0.785 & 0.755 & 0.850 \\
\hline
\end{tabular}

Panel-corrected standard errors are in parentheses and p-values in square brackets. Estimations are based on the UN National Accounts: Analysis of Main Aggregate Database. U test is based on Lind \& Mehlum (2010). HEC, LB, and UB denote high exporting countries, lower boundary, and upper boundary, respectively. Significance levels: ${ }^{*} \mathrm{p}<.10,{ }^{* *} \mathrm{p}<0.05,{ }^{* * *} \mathrm{p}<.0$. The Fieller Method follows an inverse test to construct confidence intervals for the ratio of normally distributed statistics. For the U-test this method is preferred to the Delta method. 
Table 5.4: Evidence on Deindustrialization by Sub-region (UN Database)

\begin{tabular}{|c|c|c|c|c|c|c|c|c|}
\hline Panel A: Reg. Estimates & $\begin{array}{l}\text { Western } \\
\text { Africa } \\
\text { Nom. } \\
\text { Manshare }\end{array}$ & $\begin{array}{l}\text { Eastern } \\
\text { Africa } \\
\text { Nom. } \\
\text { Manshare }\end{array}$ & $\begin{array}{l}\text { Central } \\
\text { Africa } \\
\text { Nom. } \\
\text { Manshare }\end{array}$ & $\begin{array}{l}\text { Southern } \\
\text { Africa } \\
\text { Nom. } \\
\text { Manshare }\end{array}$ & $\begin{array}{l}\text { Western } \\
\text { Africa } \\
\text { Real } \\
\text { Manshare }\end{array}$ & $\begin{array}{c}\text { Eastern } \\
\text { Africa } \\
\text { Real } \\
\text { Manshare }\end{array}$ & $\begin{array}{c}\text { Central } \\
\text { Africa } \\
\text { Real } \\
\text { Manshare }\end{array}$ & $\begin{array}{l}\text { Southern } \\
\text { Africa } \\
\text { Real } \\
\text { Manshare }\end{array}$ \\
\hline Per capita Income (ln) & $\begin{array}{c}0.176^{* * *} \\
(0.047)\end{array}$ & $\begin{array}{c}0.142^{* * *} \\
(0.051)\end{array}$ & $\begin{array}{c}-0.220^{* * *} \\
(0.036)\end{array}$ & $\begin{array}{c}0.162^{* *} \\
(0.069)\end{array}$ & $\begin{array}{c}0.194 * * * \\
(0.047)\end{array}$ & $\begin{array}{l}0.081^{*} \\
(0.046)\end{array}$ & $\begin{array}{c}0.370^{* * *} \\
(0.055)\end{array}$ & $\begin{array}{c}0.242^{* * *} \\
(0.043)\end{array}$ \\
\hline Per capita Income-squared (ln) & $\begin{array}{c}-0.011 * * * \\
(0.003)\end{array}$ & $\begin{array}{c}-0.007 * * \\
(0.003)\end{array}$ & $\begin{array}{c}0.014 * * * \\
(0.002)\end{array}$ & $\begin{array}{c}-0.009 * * \\
(0.004)\end{array}$ & $\begin{array}{c}-0.015^{* * *} \\
(0.003)\end{array}$ & $\begin{array}{l}-0.003 \\
(0.003)\end{array}$ & $\begin{array}{c}-0.019 * * * \\
(0.003)\end{array}$ & $\begin{array}{c}-0.013^{* * *} \\
(0.003)\end{array}$ \\
\hline Population (ln) & $\begin{array}{c}0.010 \\
(0.024)\end{array}$ & $\begin{array}{c}0.053^{* * *} \\
(0.011)\end{array}$ & $\begin{array}{c}-0.089 * * * \\
(0.028)\end{array}$ & $\begin{array}{c}0.562^{* * *} \\
(0.053)\end{array}$ & $\begin{array}{c}0.098^{* * *} \\
(0.037)\end{array}$ & $\begin{array}{l}-0.015 \\
(0.011)\end{array}$ & $\begin{array}{c}0.377 * * * \\
(0.060)\end{array}$ & $\begin{array}{c}0.336 * * * \\
(0.049)\end{array}$ \\
\hline Population-squared (ln) & $\begin{array}{l}-0.000 \\
(0.001)\end{array}$ & $\begin{array}{c}-0.006^{* * *} \\
(0.001)\end{array}$ & $\begin{array}{c}0.006^{* * *} \\
(0.001)\end{array}$ & $\begin{array}{c}-0.034 * * * \\
(0.003)\end{array}$ & $\begin{array}{c}-0.005^{* *} \\
(0.002)\end{array}$ & $\begin{array}{l}-0.001 \\
(0.000)\end{array}$ & $\begin{array}{c}-0.025^{* * *} \\
(0.003)\end{array}$ & $\begin{array}{c}-0.020 * * * \\
(0.002)\end{array}$ \\
\hline $1980 \mathrm{~s}$ & $\begin{array}{l}-0.001 \\
(0.004)\end{array}$ & $\begin{array}{c}0.015^{* * *} \\
(0.003)\end{array}$ & $\begin{array}{c}0.000 \\
(0.005)\end{array}$ & $\begin{array}{c}-0.016^{*} \\
(0.008)\end{array}$ & $\begin{array}{c}0.001 \\
(0.006)\end{array}$ & $\begin{array}{c}0.015^{* * *} \\
(0.004)\end{array}$ & $\begin{array}{c}0.002 \\
(0.009)\end{array}$ & $\begin{array}{c}-0.017 * * * \\
(0.006)\end{array}$ \\
\hline Post SAPs & $\begin{array}{c}0.017 * * * \\
(0.006)\end{array}$ & $\begin{array}{c}0.030 * * * \\
(0.006)\end{array}$ & $\begin{array}{l}-0.003 \\
(0.008)\end{array}$ & $\begin{array}{c}-0.010^{* * *} \\
(0.003)\end{array}$ & $\begin{array}{l}-0.009 \\
(0.008)\end{array}$ & $\begin{array}{c}0.036 \text { *** } \\
(0.007)\end{array}$ & $\begin{array}{l}-0.000 \\
(0.014)\end{array}$ & $\begin{array}{c}-0.019 * * \\
(0.008)\end{array}$ \\
\hline MDGs & $\begin{array}{c}0.005 \\
(0.009)\end{array}$ & $\begin{array}{c}0.028^{* * * *} \\
(0.008)\end{array}$ & $\begin{array}{l}-0.008 \\
(0.013)\end{array}$ & $\begin{array}{c}-0.020 * * * \\
(0.006)\end{array}$ & $\begin{array}{c}-0.025^{* *} \\
(0.011)\end{array}$ & $\begin{array}{c}0.031 * * * \\
(0.009)\end{array}$ & $\begin{array}{l}-0.008 \\
(0.019)\end{array}$ & $\begin{array}{c}-0.021 * * \\
(0.010)\end{array}$ \\
\hline Intercept & $\begin{array}{c}-0.621 * * * \\
(0.231)\end{array}$ & $\begin{array}{c}-0.713^{* * *} \\
(0.198)\end{array}$ & $\begin{array}{c}1.288^{* * *} \\
(0.222)\end{array}$ & $\begin{array}{c}-2.921 * * * \\
(0.404)\end{array}$ & $\begin{array}{c}-0.963^{* * *} \\
(0.273)\end{array}$ & $\begin{array}{l}-0.284^{*} \\
(0.162)\end{array}$ & $\begin{array}{c}-2.908^{* * *} \\
(0.357)\end{array}$ & $\begin{array}{c}-2.459 * * * \\
(0.324)\end{array}$ \\
\hline Panel B: U Test & & & & & & & & \\
\hline Slope at LB of Income (ln) & $\begin{array}{c}0.065^{* * *} \\
(0.016)\end{array}$ & $\begin{array}{c}0.069 * * * \\
(0.020)\end{array}$ & $\begin{array}{c}-0.078^{* * *} \\
(0.016)\end{array}$ & $\begin{array}{c}0.073 * * * \\
(0.027)\end{array}$ & $\begin{array}{c}0.052^{* * *} \\
(0.015)\end{array}$ & $\begin{array}{c}0.052^{* * *} \\
(0.017)\end{array}$ & $\begin{array}{c}0.186^{* * *} \\
(0.025)\end{array}$ & $\begin{array}{c}0.111 * * * \\
(0.017)\end{array}$ \\
\hline Slope at UB of Income (ln) & $\begin{array}{c}-0.068^{* * *} \\
(0.023)\end{array}$ & $\begin{array}{l}-0.019 \\
(0.018)\end{array}$ & $\begin{array}{c}0.091 * * * \\
(0.011)\end{array}$ & $\begin{array}{c}-0.033^{*} \\
(0.023)\end{array}$ & $\begin{array}{c}-0.118^{* * *} \\
(0.025)\end{array}$ & $\begin{array}{c}0.017 \\
(0.017)\end{array}$ & $\begin{array}{c}-0.034^{* *} \\
(0.015)\end{array}$ & $\begin{array}{c}-0.046^{* * * *} \\
(0.017)\end{array}$ \\
\hline $\mathrm{U}$ test statistic & $\begin{array}{c}2.980 \\
{[0.001]}\end{array}$ & $\begin{array}{c}1.060 \\
{[0.145]}\end{array}$ & $\begin{array}{c}4.980 \\
{[0.000]}\end{array}$ & $\begin{array}{c}1.450 \\
{[0.074]}\end{array}$ & $\begin{array}{c}3.35 \\
{[0.000]}\end{array}$ & & $\begin{array}{c}2.28 \\
{[0.012]}\end{array}$ & $\begin{array}{c}2.74 \\
{[0.003]}\end{array}$ \\
\hline $\begin{array}{l}\text { Extremum point } \\
\text { In } 2011 \text { US } \$ \\
95 \% \text { CI, Fieller Method }\end{array}$ & $\begin{array}{c}7.752 \\
2327.12 \\
(7.32,8.60) \\
\end{array}$ & $\begin{array}{c}9.500 \\
13346.21 \\
(8.71,16.73) \\
\end{array}$ & $\begin{array}{c}7.612 \\
2021.95 \\
(7.14,7.93) \\
\end{array}$ & $\begin{array}{c}8.921 \\
7485.80 \\
(8.24,17.29) \\
\end{array}$ & $\begin{array}{c}6.680 \\
796.274 \\
(6.10,7.05) \\
\end{array}$ & $\begin{array}{c}13.64 \\
842457.07 \\
(1.67, \infty) \\
\end{array}$ & $\begin{array}{c}9.834 \\
18648.95 \\
(9.38,10.57) \\
\end{array}$ & $\begin{array}{c}9.035 \\
8394.29 \\
(8.56,9.97) \\
\end{array}$ \\
\hline Country FE & Yes & Yes & Yes & Yes & Yes & Yes & Yes & Yes \\
\hline No. of Countries & 16 & 10 & 9 & 11 & 16 & 10 & 9 & 11 \\
\hline Observations & 752 & 470 & 423 & 512 & 752 & 474 & 423 & 512 \\
\hline R-Squared & 0.747 & 0.849 & 0.643 & 0.724 & 0.741 & 0.827 & 0.879 & 0.818 \\
\hline
\end{tabular}

Panel-corrected standard errors are in parentheses and p-values in square brackets. Estimations are based on the UN National Accounts: Analysis of Main Aggregate Database. U test is based on Lind \& Mehlum (2010). LB and UB denote lower boundary, and upper boundary, respectively. Significance levels: $*$ p $<0.10, * *$ p $<0.05$, $* * *$ $\mathrm{p}<0.01$. The Fieller Method follows an inverse test to construct confidence intervals for the ratio of normally distributed statistics. For the U-test this method is preferred to the Delta method. 


\subsection{The deep drivers of manufacturing performance in Africa}

Our baseline data (EASD) show that conditional on income, population, and country-specific idiosyncratic factors, the manufacturing share of employment is declining while the manufacturing share of output is increasing. These opposing trends point to a potential productivity effect. To understand this trend and other underlying drivers of manufacturing outcomes in Africa, we estimate model 5.2, examining the marginal effect of the key as well as other independent variables on the manufacturing share of employment in Africa. Table 5.5 presents the regression results. Column 1 shows the estimated coefficients of the key independent variables, Column 2 shows the estimated coefficients of all independent variables except trade, and Column 3 shows the result for all regressors. The results are qualitatively and quantitatively consistent across the three models. Our preferred model is model 3. As expected, the coefficients on internal factors except for income - i.e., population, and relative labor productivity growth - are statistically significant and exhibit the expected signs. The results show a U-shaped relationship between manufacturing share of employment and per capita income, suggesting that in Africa, conditional all other variables in the model, as income increases, it induces the reallocation of labor from the manufacturing sector of Africa. However, beyond a certain level of income, the growing affluence of consumers induces reallocation of labor into manufacturing. This is inconsistent with Bell's Law and the extended Engel's law where changes in the marginal rate of substitution (budget share) between the manufacturing and non-manufacturing sector initially induces the reallocation of activity in favor of the manufacturing sector. However, our results are consistent with existing studies on Africa which control for some of the key variables used in our model. For example, our results corroborate the results of Mijiyawa (2017), who finds a U-shape relationship between the manufacturing share of GDP and per capita income in Africa. The U-shape relationship between manufacturing activities and per capita income characterizes less competitive countries in a highly competitive and globalized world (ibid).

Population shows an inverted U-shape relationship with the manufacturing share of employment. There is no doubt that population, a proxy for the size of domestic market, is important for the industrialization of Africa. However, in African countries that are populated by poor consumers, beyond a certain level of population, the negative 'size' effect seems to dominate the positive scale economies.

The results further show that there is a negative relationship between technological progress in manufacturing relative to services and manufacturing employment in Africa. Thus, relatively faster productivity growth in the manufacturing sector shrinks manufacturing employment in Africa, confirming the Baumol's cost disease hypothesis. Two reinforcing reasons may explain this result. First, manufacturing goods are traded through global value chains (GVCs) which also acts as a channel for the diffusion of skilled-biased technologies in developing countries (Rodrik, 2018b). However, the diffusion of these technologies adversely affects manufacturing employment in developing countries by replacing less skilled workers. As explained above, manufacturing goods exported to international markets embodies higher knowledge intensity and standards, which requires less manual work leading to the use of labor-saving technologies such as automation or mechanization. In the context of Africa, our result is consistent with the recent study of Pahl et al. (2019), who show that technological change through the GVC participation has a negative effect on manufacturing jobs in emerging African countries. 
Table 5.5: Deep Drivers of Manufacturing Employment Shares in Africa, 1970-2015

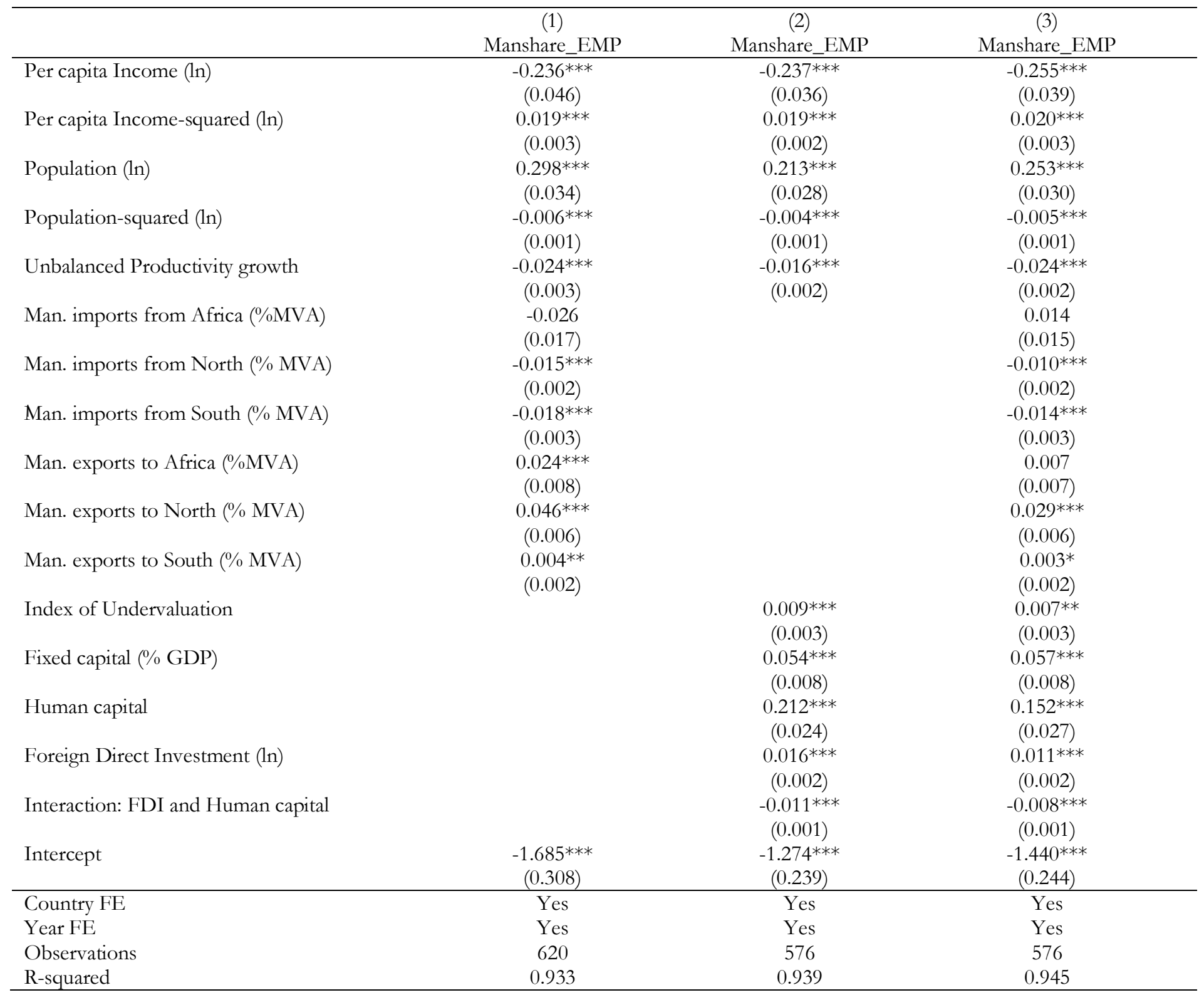

Notes: Panel-corrected Standard errors in parentheses. Estimations are based EASD. Significance level: ${ }^{*} \mathrm{p}<.10,{ }^{* *}$ $\mathrm{p}<0.05, * * * \mathrm{p}<.01$

Second, as price takers on the world market, African countries may have imported the negative effect of technological progress from abroad. After the SAPs, most African countries liberalized their trade regimes resulting in a significant surge in trade inflows. At the same time, technological progress reduced the relative prices of manufacturing goods on the world market. Examination of the underlying data shows that there was a marginal increase in the relative labor productivity of manufacturing, but this was not sufficient to counteract the magnitude of the reduction in the 
relative price of manufacturing from elsewhere. ${ }^{105}$ The net effect is a shrinkage in manufacturing employment.

The variables intended to capture the contribution of international trade on relative manufacturing employment in Africa - manufactured exports and imports - exhibit the expected sign in model 1 and model 3. The only difference is that once we control for the other variables in model 3 the magnitude of the estimated coefficients reduces. Manufactured exports from other African countries, the global South and global North as a percentage of manufacturing output correlate positively with the manufacturing employment share. The role of manufactured exports to Africa is not statistically significant once we control for other factors (model 3), however, indicating the limited role that intra-African trade has played in building the productive capacity of the continent. The share of intra-African exports as a percentage of total African exports was 17 percent in 2017 compared to 59 percent in Asia, 69 percent in Europe, and 31 percent in North America (Songwe, 2019). It is projected that the successful implementation of the African Continental Free Trade Area (AfCFTA) will double the size of the manufacturing sector and create 14 million jobs in Africa by 2025 (Signé, 2018). The AfCFTA is promising for industrialization since recent evidence suggests that manufactured goods, which are more knowledge-intensive compared to primary products, make up 42 percent of intra-African exports compared to $15 \%$ of extra-regional exports (Songwe, 2019). This means AfCFTA will not only boost the size of industry but may also facilitate knowledge transfer and catch-up within Africa, as shown by the catch-up analysis in Chapter 4 .

Manufactured imports from the North and the South correlate negatively with relative manufacturing employment, with the coefficient of imports from the South being bigger than the coefficient on imports from the North in absolute value. This suggests that the competition effect is stronger than the spillover effect. After the SAPs, most African countries opened their borders to trade. After hiding behind protective walls for decades, the domestic industry was not able to compete on cost with the South and on quality with the North after trade liberalization. As a result, they imported employment deindustrialization. The statistically significant coefficient of imports is, however, lower than exports, indicating that economic globalization increases relative manufacturing employment in Africa than it decreases.

The coefficient of the index of undervaluation is positive and statistically significant. This means that competitive exchange rates will make the tradable sector more profitable, increasing the relative size of manufacturing by acting as a subsidy to remove distortions created by weak contracting institutions and market failures. Our result is consistent with the empirical findings of McMillan, Rodrik, \& Verduzco-Gallo (2014) where overvaluation of currencies through disinflationary monetary policy and foreign aid inflows inhibits structural change. It is also consistent with the theoretical predictions of Diao \& McMillan (2018), where assumptions about a country's dependence on foreign aid inflows for infrastructure development could cause real exchange rate appreciation making the open modern sector less competitive. The stock of human capital is positively correlated with the share of manufacturing employment. Improving the quality of education and training in Africa is essential for producing knowledge-intensive goods. Domestic investment has a significant effect on relative manufacturing employment. FDI is also an important conduit for industrialization through knowledge transfer. In our model, FDI has a statistically strong effect on manufacturing employment. However, manufacturing FDI tends to flow into

${ }^{105}$ Using data from EASD to calculate the change in relative manufacturing labor productivity of Africa and the GDDC 10-sector database to calculate the change in the relative price of manufacturing in China and the North (the major trading partners of African countries). 
low-income countries where the human capital stock and wages tend to be low, creating a negative interaction effect. In our model, we measure this indirect effect by interacting FDI with the stock of human capital. The results show that FDI indirectly displaces manufacturing jobs in Africa. This is consistent with the observation that manufacturing FDI tends to flow into low-income countries with low-skilled labor and wages.

\subsection{Conclusion}

Deindustrialization is a key feature of structural change around the world. While there is no debate about evidence on deindustrialization in Latin America and developed countries, the evidence on the pattern of deindustrialization in Africa is inconclusive. The representativeness and the coverage of the samples used in previous analyses often form the crux of the debate. This chapter provides extensive evidence on deindustrialization in Africa, using carefully constructed data and other reliable sources. We find that the evidence on deindustrialization is sensitive to sample size. If we replicate the results of Rodrik (2016) with data for the 11 African countries in the 10-sector database of GGDC, we find similar patterns. However, if we increase the sample size from 11 to 18 and 45, different patterns and trends emerge. For the sample of 18 countries in the EASD, conditional on income, population, and country fixed effects, we observe employment deindustrialization and output industrialization in Africa. When we increase the sample to cover all countries in (Sub-Saharan) Africa, we do not find evidence of (output) deindustrialization neither do we find evidence of industrialization, however. Therefore, the appropriate characterization of the evidence for a typical African country is industrial stagnation, not premature deindustrialization. We, however, document significant sub-regional heterogeneity with East Africa industrializing and Southern Africa deindustrializing. Based on the results of the drivers of the deindustrialization, we argue that the deindustrialization of Southern Africa is preferenceinduced whereas the significant industrialization of Eastern Africa is trade-induced. Higher levels of income in Southern Africa and higher levels of manufacturing exports observed in Eastern Africa explain the sub-regional heterogeneity.

In addition to investigating the patterns of deindustrialization, we examine the underlying drivers of the declining manufacturing employment trend (in Table 5.5). We found that income (squared) and population are significant positive correlates of manufacturing employment, indicating that purchasing power and the size of the domestic market are essential for the industrial development of Africa. Our analysis further shows that technical progress, through the price-taker mechanism, has had a negative effect on relative manufacturing employment, suggesting that African countries may have imported negative technology effects on employment from abroad. While international trade, in general, creates more manufacturing jobs than it displaces in Africa, intra-regional trade has played a limited role in the industrial development of the continent. Our results underscore a number of important policy options for African economies to overcome the pervasive industrial stagnation. First, the results show that FDI and domestic investment are essential for the industrial development of the continent. Strategies to attract manufacturing FDI should be a key policy priority for many African countries, taking into consideration the different contexts. For example, relatively high-income countries like Botswana, Mauritius, and South Africa, where wages are high and the industrial structure is capital-intensive, are less attractive for greenfield manufacturing investments looking for low-wage countries. For such countries, relying on FDI for industrial 
development is a less viable strategy, therefore targeted domestic investment would be more important. Most African countries are low-cost countries with young populations, therefore attracting greenfield investment into the manufacturing sector is critical. However, some of the low-cost countries are endowed with natural resources and are vulnerable to Dutch disease. Other countries artificially overvalue their currencies through disinflationary monetary policy, making them less competitive in international markets. For these countries, in addition to attracting manufacturing FDI, implementing competitiveness polices such as undervaluation of domestic currencies could boost industrialization.

Second, imports from both the North and South have negative effect on relative manufacturing employment suggesting that the competition effect is stronger than the spillover effect in the context of Africa. African countries can offset the negative effect through competition policies such as subsidies and local content laws that have minimum requirements for the procurement of locals and services, local employment opportunities, technology, and skill transfer, etc.

Finally, as the results of the drivers show, promoting manufacturing exports is important for the industrial development of the continent. In that sense, reducing trade frictions within Africa and expanding intra-regional trade through the AfCFTA is timely for the structural transformation of the region. 


\subsection{Appendix to Chapter 5}

Baseline results with decadal dummies instead of the period dummies used throughout the thesis.

Table A5.1: Evidence on Deindustrialization in Sub-Sabaran Africa (EASD)

\begin{tabular}{|c|c|c|c|c|c|c|c|c|c|}
\hline \multirow{3}{*}{ Panel A: Reg. Estimates } & \multicolumn{3}{|c|}{ Sub-Saharan Africa } & \multicolumn{3}{|c|}{ Sub-Saharan Africa excl. MUS } & \multicolumn{3}{|c|}{ Sub-Saharan Africa } \\
\hline & EMP & Nom VA & Real VA & EMP & Nom VA & Real VA & EMP & Nom VA & Real VA \\
\hline & Manshare & Manshare & Manshare & Manshare & Manshare & Manshare & Indshare & Indshare & Indshare \\
\hline \multirow[t]{2}{*}{ Per capita Income (ln) } & 0.015 & $0.196^{* * *}$ & $0.208^{* * *}$ & $0.033^{* *}$ & $0.249 * * *$ & $0.214^{* * *}$ & $0.147 * * *$ & $0.593^{* * *}$ & $0.769 * * *$ \\
\hline & $(0.031)$ & $(0.036)$ & $(0.034)$ & $(0.014)$ & $(0.046)$ & $(0.039)$ & $(0.042)$ & $(0.065)$ & $(0.062)$ \\
\hline \multirow[t]{2}{*}{ Per capita Income-squared (ln) } & 0.000 & $-0.012 * * *$ & $-0.012^{* * *}$ & -0.001 & $-0.015^{* * *}$ & $-0.012 * * *$ & $-0.007 * *$ & $-0.031 * * *$ & $-0.043^{* * *}$ \\
\hline & $(0.002)$ & $(0.002)$ & $(0.002)$ & $(0.001)$ & $(0.003)$ & $(0.002)$ & $(0.003)$ & $(0.004)$ & $(0.004)$ \\
\hline \multirow[t]{2}{*}{ Population (ln) } & $0.017^{*}$ & $0.104 * * *$ & $-0.055^{* * *}$ & $0.045^{* * *}$ & $0.128 * * *$ & $-0.045^{* * *}$ & $0.030 * *$ & $-0.219 * * *$ & $-0.287 * * *$ \\
\hline & $(0.010)$ & $(0.023)$ & $(0.016)$ & $(0.007)$ & $(0.023)$ & $(0.016)$ & $(0.015)$ & $(0.033)$ & $(0.038)$ \\
\hline \multirow[t]{2}{*}{ Population-squared (ln) } & 0.000 & $-0.009 * * *$ & 0.001 & $-0.001 * *$ & $-0.010^{* * *}$ & 0.000 & $0.002^{* * *}$ & $0.007 * * *$ & $0.011^{* * *}$ \\
\hline & $(0.000)$ & $(0.001)$ & $(0.001)$ & $(0.000)$ & $(0.001)$ & $(0.001)$ & $(0.001)$ & $(0.001)$ & $(0.002)$ \\
\hline \multirow[t]{2}{*}{$1970 \mathrm{~s}$} & $-0.005^{* *}$ & $0.034 * * *$ & $0.022 * * *$ & -0.003 & $0.032 * * *$ & $0.023 * * *$ & $-0.018^{* * *}$ & $0.022 * * *$ & $0.026 * * *$ \\
\hline & $(0.002)$ & $(0.005)$ & $(0.004)$ & $(0.002)$ & $(0.004)$ & $(0.004)$ & $(0.004)$ & $(0.007)$ & $(0.006)$ \\
\hline \multirow[t]{2}{*}{$1980 \mathrm{~s}$} & $-0.009 * *$ & $0.067 * * *$ & $0.052 * * *$ & $-0.013^{* * *}$ & $0.061^{* * *}$ & $0.052^{* * *}$ & $-0.031 * * *$ & $0.068^{* * *}$ & $0.057 * * *$ \\
\hline & $(0.003)$ & $(0.007)$ & $(0.005)$ & $(0.003)$ & $(0.006)$ & $(0.005)$ & $(0.005)$ & $(0.009)$ & $(0.008)$ \\
\hline \multirow[t]{2}{*}{$1990 \mathrm{~s}$} & $-0.009 *$ & $0.083^{* * *}$ & $0.070 * * *$ & $-0.017 * * *$ & $0.073^{* * *}$ & $0.068^{* * *}$ & $-0.039 * * *$ & $0.094 * * *$ & $0.091 * * *$ \\
\hline & $(0.005)$ & $(0.009)$ & $(0.007)$ & $(0.003)$ & $(0.009)$ & $(0.007)$ & $(0.006)$ & $(0.013)$ & $(0.011)$ \\
\hline \multirow[t]{2}{*}{$2000 \mathrm{~s}$} & $-0.013^{* *}$ & $0.082^{* * *}$ & $0.075^{* * *}$ & $-0.016^{* * *}$ & $0.073^{* * *}$ & $0.076^{* * *}$ & $-0.056^{* * *}$ & $0.068^{* * *}$ & $0.076^{* * *}$ \\
\hline & $(0.006)$ & $(0.011)$ & $(0.009)$ & $(0.004)$ & $(0.011)$ & $(0.009)$ & $(0.008)$ & $(0.016)$ & $(0.014)$ \\
\hline \multirow[t]{2}{*}{ Intercept } & -0.245 & $-1.095^{* * *}$ & $-0.537 * * *$ & $-0.416^{* * *}$ & $-1.394 * * *$ & $-0.594 * * *$ & $-0.864 * * *$ & $-1.252 * * *$ & $-1.492 * * *$ \\
\hline & $(0.152)$ & $(0.180)$ & $(0.163)$ & $(0.065)$ & $(0.222)$ & $(0.182)$ & $(0.200)$ & $(0.245)$ & $(0.312)$ \\
\hline \multicolumn{10}{|l|}{ Panel B: U Test } \\
\hline \multirow[t]{2}{*}{ Slope at LB of Income (log) } & $0.019 * * *$ & $0.059 * * *$ & $0.069 * * *$ & $0.018^{* * *}$ & $0.067 * * *$ & $0.069 * * *$ & $0.062 * * *$ & $0.228^{* * *}$ & $0.260 * * *$ \\
\hline & $(0.007)$ & $(0.010)$ & $(0.009)$ & $(0.004)$ & $(0.012)$ & $(0.010)$ & $(0.009)$ & $(0.019)$ & $(0.016)$ \\
\hline \multirow[t]{2}{*}{ Slope at UB of Income (log) } & $0.021 * * *$ & $-0.031 * * *$ & $-0.021 * * *$ & $0.008^{*}$ & $-0.052 * * *$ & $-0.026 * * *$ & 0.006 & -0.012 & $-0.075^{* * *}$ \\
\hline & $(0.010)$ & $(0.009)$ & $(0.008)$ & $(0.004)$ & $(0.012)$ & $(0.009)$ & $(0.015)$ & $(0.016)$ & $(0.019)$ \\
\hline \multirow[t]{2}{*}{$\mathrm{U}$ test statistic } & & 3.630 & 2.736 & & 4.293 & 2.727 & & 0.740 & 3.905 \\
\hline & & {$[0.000]$} & {$[0.003]$} & & {$[0.000]$} & {$[0.003]$} & & {$[0.229]$} & {$[0.000]$} \\
\hline Extremum point & -24.288 & 8.454 & 8.894 & 12.721 & 8.106 & 8.732 & 10.204 & 9.614 & 8.940 \\
\hline In 2011 US\$ & & 4694.44 & 7295.15 & & 3315.79 & 6195.68 & & 14967.58 & 7628.01 \\
\hline $95 \% \mathrm{CI}$, Fieller Method & $(-\infty, 10.15)$ & $(8.19,8.87)$ & $(8.62,9.42)$ & $(-5.36, \infty)$ & $(7.90,8.41)$ & $(8.43,9.33)$ & $(8.89,20.70)$ & $(9.21,10.23)$ & $(8.68,9.29)$ \\
\hline Country FE & Yes & Yes & Yes & Yes & Yes & Yes & Yes & Yes & Yes \\
\hline No. of Countries & 18 & 18 & 18 & 17 & 17 & 17 & 18 & 18 & 18 \\
\hline Observations & 918 & 970 & 930 & 872 & 914 & 884 & 918 & 970 & 930 \\
\hline R-Squared & 0.878 & 0.731 & 0.812 & 0.835 & 0.714 & 0.786 & 0.902 & 0.747 & 0.756 \\
\hline
\end{tabular}

Panel-corrected standard errors are in parentheses and p-values in square brackets. Estimations are based on the Expanded Africa Sector Database (Mensah \& Szirmai, 2018). U test is based on Lind \& Mehlum (2010). LB, and UB denote lower boundary, and upper boundary, respectively. Significance levels: * $\mathrm{p}<.10, * * \mathrm{p}<0.05, * * * \mathrm{p}<.01$. The Fieller Method follows an inverse test to construct confidence intervals for the ratio of normally distributed statistics. For the U-test this method is preferred to the Delta method. 
6 Chapter 6. Reforms and productivity growth in developing countries: Inter or intra -allocative efficiency channel? ${ }^{106}$

${ }^{106}$ Co-authored with Maty Konte and Wilfred Kouame 


\subsection{Introduction}

A long-standing observation in economics is that large differences in productivity is the dominant source of the differences in living standards across countries (Restuccia \& Rogerson, 2017). A recent study suggests that labor productivity is the most important source of GDP per capita in some developing countries (Foster-McGregor \& Verspagen, 2016). The rate at which labor productivity grows at the aggregate level depends on two components: the intra-sectoral component (within effect) and the inter-sectoral component (between effect), also known as structural change. The former indicates the average growth rate of labor productivity within the sectors of an economy, and the latter measures the growth rate of labor productivity due to the movement of labor across the sectors of an economy. Differences in patterns of structural change explain much of the variation in total labor productivity growth among developing regions. For instance, many Asian countries have successfully undergone deep structural change that boosted labor productivity while most African and Latin American countries have recorded relatively low labor productivity growth, mostly driven by within-sector productivity growth (McMillan et al., 2014). This raises the question of why some countries have higher labor productivity growth and a more dynamic shift of labor across sectors than others.

A growing literature has identified misallocation as an important source of aggregate productivity differences across countries ( e.g., Bartelsman et al., 2013; Hsieh \& Klenow, 2009; Restuccia \& Rogerson, 2008). Misallocation arises from frictions or structural rigidities that prevent the efficient allocation of resources. The frictions that drive cross-country differences in productivity and allocative efficiency include among others entry barriers (Ciccone \& Papaioannou, 2008), labor market distortions (Haltiwanger et al., 2014), trade restrictions (Revenga, 1997; Wacziarg \& Wallack, 2004), credit frictions (Bai, Carvalho, \& Phillips, 2018), financial market distortions (McKinnon \& Pill, 1998; Shaw, 1973), market power (De Loecker et al., 2020)and monopoly power (Cheremukhin et al., 2017). A related literature has also identified structural reforms as important determinants of economic performance and labor productivity growth by engendering an efficient reallocation of resources such as labor by reducing rigidities that exist in markets (Adamopoulos \& Restuccia, 2019; Bourlè et al., 2013; Casu et al., 2013; Prati et al., 2013). In developing countries where a series of structural reforms have been implemented over the last decades, there is little evidence on the impacts of these reforms on labor productivity growth (Dabla-Norris et al., 2016; Kouamé \& Tapsoba, 2019). Most importantly, these few studies do not assess how these effects are distributed between the intra and inter-sectoral components, masking the allocative efficiency channels through which reforms affect labor productivity growth.

This chapter fills the gap in the literature by analyzing the impact of financial sector, product markets, and trade reforms on labor productivity growth and exploring whether these reforms affect labor productivity growth by inducing a more efficient reallocation of resources either within sectors or across sectors or both. In doing so, this chapter is the first attempt to quantify how labor productivity growth effects of financial sector, product markets, and trade reforms are distributed between the within and the between components in developing countries. It is often argued that the persistent inter-sectoral productivity gaps across countries (Duarte \& Restuccia, 2010; Gollin et al., 2014) and within countries (McMillan et al., 2014) are caused by structural rigidities that prevent the efficient allocation of resources within and across sectors. Also, 
differences in sectoral productivity relate to market failures or government failures, such as observable policy distortions introduced in many developing countries during the importsubstitution era. Therefore, structural reforms are expected to improve inter and intra-sectoral allocative efficiency, and hence productivity growth, more rapidly in developing countries (see, for example, the Berg's report, World Bank, 1981). Theoretically, trade reforms induce a more efficient allocation of resources within sectors ala Melitz (2003) and between sectors in response to changes in relative prices ala Ricardo and Heckscher-Ohlin models. Product market reforms increases competition in product markets, reduces mark-ups and generate allocative, dynamic and productive efficiencies (Nicodeme \& Sauner-Leroy, 2007). Financial sector reforms affect productivity through the efficient allocation of financial resources (Schumpeter, 1912) (see Section 2).

For our analysis, we merge the structural reform dataset from Prati et al. (2013) with labor productivity data computed from sectoral data from the GGDC 10-Sector Database and the Expanded Africa Sector Database. ${ }^{107}$ The data cover the period 1975-2005 and includes all the developing countries for which data on reforms, value-added, and employment are available. We employ the shift-share method used in McMillan \& Rodrik (2011) to decompose labor productivity growth into the intra-sectoral and the inter-sectoral components. To minimize possible causality bias between reforms and labor productivity growth, we measure reforms at the beginning of each period. We control for country and time fixed-effects and cluster standard errors within countries. We run a number of robustness checks adding various control variables, estimating a dynamic panel data model to correct for possible endogeneity bias, estimating a five years labor productivity growth model and testing for heterogeneity effects using distance to the technological frontier.

We find that product markets and trade reforms - in a particular trade, the current account, and electricity and telecommunications (henceforth network) reforms - are positively associated with the growth rates of labor productivity. Similarly, financial sector reforms-such as domestic finance, banking, and securities reforms - have positive and statistically significant effects on the growth rate of labor productivity. However, the magnitude of the coefficients decreases as the country reduces the productivity gap with the technology leader. Thus, countries that are further away from the technology leader tend to benefit more from structural reforms than countries closer to the technology frontier. This evidence corroborates the empirical findings of DablaNorris et al. (2016), who found that the positive impact of reforms on productivity growth increases with productivity distance from the technology frontier.

Looking at the different components of the growth rate of labour productivity, structural reforms affect the within and the structural change components differently. In fact, most of the financial sector, product markets, and trade reforms have positive effects on the within component but have no significant effects on the structural change component of labor productivity growth. In terms of the distribution of the contribution of the effects of reforms on the growth rate of labor productivity, we find that the contribution of the effects of structural reforms arising from the within component accounts for between 76 percent and 96 percent of the overall productivity

${ }^{107}$ Countries are classified as developing based on the World Bank country classification. 
effect ${ }^{108}$ depending on the measure of reforms we consider. The contribution that comes from the structural change component thus varies between 4 percent and 24 percent, with a negative contribution observed in most cases. This implies that structural reforms work mostly through the intra-allocative efficiency channel but not through the inter-allocative efficiency channel. That is, structural reforms induce an efficient reallocation of resources within sectors but not across sectors. Our results are consistent with the argument that many developing countries had structural adjustment programs without structural change (Page, 2012).

The chapter adds to the limited literature on the impact of reforms on productivity in developing countries. To the best of our knowledge, Dabla-Norris et al. (2016) is a unique chapter examining the impact of reforms on productivity in 108 emerging markets and developing countries at the macroeconomic level. The authors find that the positive impact of reforms on productivity growth depends on the distance to the productivity technology frontier. However, they did not explore the distributional effects of reforms between the within and the between components. ElFayoumi et al. (2018) focus on structural reforms and sectoral labor reallocation, neglecting the effect of reforms on intra-sectoral allocative efficiency. At the microeconomic level, the recent chapter by Kouamé \& Tapsoba (2019) is among the few studies to assess the impact of structural reforms on firm-level productivity in developing countries. Alternative microeconomic evidence includes Amiti \& Konings (2007), Arnold et al. (2016), Eslava et al. (2004), and Topalova \& Khandelwal (2011). These studies adopt a country case study approach by focusing mainly on China, Colombia, India, and Indonesia and find a positive impact of structural reforms on productivity. Our chapter differs from those chapters mentioned above by focusing on the impact of reforms on productivity growth in developing countries at the macroeconomic level, where existing evidence is needed, but limited. Second, to the best of our knowledge, this study is the first to examine how structural reforms affect both within and structural change components of productivity growth and evaluates the relative importance of reforms on both components.

The remainder of the chapter is structured as follows: Section 6.2 discusses the theoretical mechanisms through which reforms may affect the between and within effects differently; Section 6.3 describes the datasets; Section 6.4 discusses descriptive statistics and the empirical strategy; Section 6.5 reports and discusses the estimation results; and Section 6.6 presents concluding remarks.

\subsection{Theoretical mechanisms}

In most of the theoretical literature, the link between reforms and productivity are indirect and often act through specific channels. In this section, we discuss some of these channels, particularly, how trade reforms, product market reforms, and financial market reforms may affect productivity growth either through the between effect or within effect.

\subsubsection{Trade reforms}

Trade reforms are reforms that reduce or eliminate frictions and costs that affect the free movement of goods and services across countries. From classical models of trade such as Ricardo's 108 The only exception is agriculture reform, for which the contribution is equally distributed between the within and
the structural change components, but its effect on the growth rate of labor productivity is not significant. 
theory of comparative advantage to 'new' new trade theory (NNTT), such as the seminal work of Melitz (2003), increasing the degree of openness to trade has implication on the allocation of resources within and across sectors. In classical models, a country gains from trade by moving resources to the sector that the country has a comparative advantage in. Countries specialize in different economic activities based on their relative differences in technology - in Ricardo's model - and factor endowments - in the Heckscher-Ohlin model. In both models, trade liberalization induces a reallocation of resources across sectors in response to changes in relative prices. In new trade theories (NTT) with increasing returns to scale, trade liberalization leads to the agglomeration of production in certain geographic locations, which can act as growth poles because of the existence of agglomeration economies in these locations leading to observable sectoral change at the country level (Wacziarg \& Wallack, 2004). This is especially the case when there are existing complementary spatial industrial policies that influence the location choice of firms (Newman \& Page, 2017). In the endogenous growth models with increasing returns to scale where trade openness facilitates the transmission of technology and impacts upon long-run growth (Grossman \& Helpman, 1991b), reductions in trade frictions may affect the intersectoral shifts of resources if the transfer of technology affects the modern and traditional sectors differently. By inducing the reallocation of resources across sectors, trade reforms can affect labor productivity growth through the structural change component.

Another set of models demonstrates how trade liberalization affects intra-industry productivity growth without necessarily changing the specialization patterns of countries and hence structural change. In NNTT and NTT models with heterogeneous firms, differentiated products, and increasing returns to scale, trade occurs within narrowly defined sectors, inducing a reallocation of resources towards more productive firms within the same industry. For example, Melitz (2003) specifies a model with imperfect competition and heterogeneous firms in which trade liberalization leads to a shift of resources towards more productive firms within industries. In this model, more competitive and productive firms expand in the domestic market, and some enter the international market. Trade compels less productive firms to exit the market, reallocating market shares to the internationally competitive firms. The process leads to an increase in intra-industry productivity, even when productivity does not grow within firms. To be clear, if the traded goods are laborintensive, then increased intra-industry trade may induce structural change or even changes in the international organization of production (see Antras, 2003, for example). However, the immediate implication of the model is increased intra-industry productivity growth. Consistent with these theoretical predictions, Pavcnik (2002), in a study of Chilean manufacturing plants, found that trade liberalization improves within-plant productivity for the plants in the import-competing sector. From the study, aggregate productivity improvement is mostly due to the reallocation of resources from less to more efficient plants.

Furthermore, pro-competitive models have shown that trade liberalization can be beneficial to a country without necessarily involving the pattern of specialization. This is known in the literature as the pro-competitive effects of trade liberalization. For example, Melitz \& Ottaviano (2008), integrating the different modeling structures under NTT, demonstrated that trade liberalization reduces mark-ups, at least in the short run, highlighting the potential pro-competitive effects associated with trade liberalization. For a particular sector where high-mark-up firms are many, and low-mark-up firms are few, a reduction in mark-ups decreases the inefficiency in the allocation 
of resources within that sector and hence the within component of aggregate productivity growth. In similar models based on imperfect competition within a dynamic Cournot-Nash framework, trade liberalization can have a pro-competitive effect on output without necessarily relying on changes in the pattern of comparative advantage (Wacziarg, 1997; Wacziarg \& Wallack, 2004). The key implication of the pro-competitive models of trade is that gains from trade are possible without necessarily inducing structural change.

\subsubsection{Product markets reforms}

Product market reforms remove impediments to the proper functioning of products markets by increasing competition among producers of goods and services. Nicodeme \& Sauner-Leroy (2007) argue that product market reforms affect productivity through three indirect mechanisms: allocative efficiency, productive efficiency, and dynamic efficiency. First, product market reforms such as deregulation of agricultural markets and liberalization of the telecommunication sector, eliminate unnecessary government interventions, barriers to entry, and open up markets. This will increase competition in the market and reduce economic rents such as mark-ups. For example, it is expected that agricultural reforms improve price incentives, affecting farm profitability, inducing a supply response, and hence productivity growth and sometimes agricultural commercialization if land tenure system permits. While the immediate supply response generates productivity growth within the agricultural sector, the commercialization of production, which often involves mechanization and adoption of new farming technologies, rapidly increases agricultural productivity. Since agricultural productivity is inversely related with the share of the labor force in agriculture, agricultural commercialization may reduce the number of people employed in the agricultural sector, inducing an intersectoral movement of labor. We expect agricultural reforms to have a stronger effect on the within component, rather than the structural change component, especially in developing countries where the supply response to changes in price incentives is immediate but agricultural commercialization happens in the medium to long term and often depends on land and labor markets institutions.

Second, product market liberalization increases competition, forcing firms to allocate available resources efficiently by reducing or eliminating underutilization of factors of production such as labor and capital. By removing entry barriers and costs, product market competition supports the creation of new enterprises and business growth and increases the speed of diffusion of new technologies and production techniques. By increasing the intensity of competition, product market reforms actively encourage the spread of ideas, the adoption of better production techniques, technology spillovers, increasing technical and productive efficiency, and hence productivity growth. Another channel through which product market reforms increase productive efficiency relates to agency costs. Competitive pressures incentivize managers and workers to reduce slack and increase worker efforts, increasing production efficiency. Finally, product market reforms affect productivity through dynamic efficiency or the Schumpeterian engine of growth. Schumpeterian models emphasize that competition reduces economic rents. It is natural for individual firms to accrue rents and market power. Due to the fear of losing economic rents, firms have great incentives to innovate. Conversely, new endogenous growth models find that competition increases the incentives to innovate to escape competition. There is evidence that at lower and higher levels of competition, innovation activity is low (Aghion et al., 2005). The 
empirical relationship between competition and innovation is an inverted U-shape. In addition, the absorptive capacity and the type of industry will influence the incentives for innovation (Nicodeme \& Sauner-Leroy, 2007).

In summary, agricultural reforms such as the dismantling of agricultural marketing boards, privatization of state-owned companies that monopolized agricultural trade, the removal of price controls, and the removal of exchange rate restrictions to promote exports may create price incentives and induce productivity growth within the agricultural sector. However, this may also lead to agricultural commercialization and mechanization if land tenure system permits. With the inverse relationship between mechanization and the share labor force in agriculture, agricultural reforms can generate a between effect conditional on land and labor institutions. Similarly, we expect network reforms to increase efficiency and reduce mark-ups in electricity and telecommunications markets. Depending on the heterogeneity of mark-ups across sectors and interconnectedness of the deregulated sector to other sectors of the economy, the allocative efficiency effect of product market reforms will increase aggregate productivity growth either through the reallocation of resources across or within sectors. Especially with the rise of mobile money services in many developing countries, a competitive telecommunication sector will have effects beyond its boundaries. However, we expect a stronger within effect from product market reforms. This is because product market reforms may generate allocative and productive efficiency in the short term and dynamic efficiency in the long term. We expect dynamic efficiency to induce structural change. On balance, product market reforms will generate stronger within effects than structural change, at least in the short run.

\subsubsection{Financial markets reforms}

The main role of financial institutions is to facilitate the efficient allocation of resources in an economy. Schumpeter (1912) argued that financial institutions have the ability to identify entrepreneurs with prospects and can, therefore, help channel resources to their most productive uses. A well-functioning financial system can identify and fund firms with the highest probability of initiating new products and processes, boosting the rate of technological innovation in an economy. Therefore, it has been recognized that a well-functioning financial sector is a precondition for the efficient allocation of resources and potential long-run economic growth (Levine, 1997, 1999). Allocative efficiency is often associated with a more unfettered - liberalized and deregulated - financial system. However, financial sectors of developing countries are often described as repressive, with excess control and interference from the state. Financial sector reforms - mostly through structural adjustment loans - aim to remove the systemic repressions and restrictions on the price and quantity of credit, boost productivity growth by generating higher levels of domestic investment and encourage a more efficient allocation of capital within and across sectors (Dabla-Norris et al., 2016; Graham, 1996). Notably, there is an indication that financial liberalization improves allocative efficiency by allowing investment funds to go to firms with a higher marginal return to capital (Galindo, Schiantarelli, \& Weiss, 2007). For within-sector productivity growth, financial reforms lower the cost of credit, allowing financially constrained firms to access capital and produce at a more efficient level. Furthermore, it enables the financing of new machinery, the adoption of new production techniques, and innovation within industries. For example, evidence at the firm level indicates that financial reforms in Eastern European 
countries increased aggregate productivity through a more efficient allocation of capital withinindustry by $10 \%$ to $16 \%$ (Larrain \& Stumpner, 2017).

Conversely, financial reforms affect structural change by inducing the reallocation of capital and investment to more productive industries. For instance, there is an indication that well-developed financial systems increase investment more in growing industries and decrease investment more in declining industries compared to less-developed financial systems (Wurgler, 2000). The efficiency with which capital is allocated across industries is also inversely related to the extent of state ownership in the economy (ibid). Furthermore, there is evidence that countries with welldeveloped financial markets have relatively high correlated intersectoral growth rates (structural change) and respond better to global opportunities (Fisman \& Love, 2004). This evidence implies that by removing restrictions and state interference, financial reforms may also boost productivity growth through structural change.

\subsection{Data}

\subsubsection{The structural reforms data}

To measure structural reforms, we employ the dataset on real sector reforms and financial sector reforms from Prati et al. (2013). ${ }^{109}$ Compared to existing structural reforms datasets in the literature, this database has the advantage of covering more than 90 countries across the world with a long-time series dimension. The chapter makes use of different indexes of real and financial sector reforms. For the real sector reforms, we employ indicators related to the openness to international trade and product market liberalization. Openness to international trade is measured over two dimensions: (i) the average tariff rate and (ii) the restrictions on current account transactions that include payments and receipts on exports and imports of goods and services. Restrictions on current account transactions measure restrictions on the proceeds from trade transactions, rather than on the underlying transactions as several countries use in practice restrictions on trade proceeds as a type of trade restriction. In the context of theoretical discussions, we expect trade reforms to affect productivity growth positively, but whether this will work either through the between effect or within effect or both cannot be determined, a priori. We use each dimension of the openness to international trade individually in the regressions.

Product market reforms are agricultural sector reforms and the degree of liberalization in the telecommunication and electricity markets (network sector reforms). Agricultural sector reforms measure the extent of public intervention in the market of the country's main agricultural export commodity, the presence of export marketing boards, and the incidence of administrated prices. The degree of liberalization in the telecommunication and electricity markets accounts for the existence of an independent regulator, and the extent of competition in the provision of the services. The regressions will include the indexes of agricultural sector reforms and liberalization in the network sector separately.

The indicators of financial reforms derived from Abiad et al. (2008) include two main indexes. The first index measures the degree of domestic financial liberalization which is an average of six sub-

\footnotetext{
${ }^{109}$ See the online supplemental materials of Prati et al (2013) for the list of countries covered by this database and the detailed information on the methodology employed.
} 
indices: (i) credit controls accounting for subsidized lending and directed credit, (ii) interest rate controls such as floors and ceilings, (iii) competition restrictions related to entry barriers and limits on number of bank branches, (iv) the importance of state ownership, (v) the quality of banking supervision and regulation, and (vi) the degree of legal restrictions on the development of domestic bonds and equity markets and the existence of independent regulators. Of the six sub-indices, the first five sub-indices document reforms in the banking system while the sixth captures securities sector reforms. Our strategy will consist of introducing the aggregate domestic financial liberalization index and two separate indexes of reforms in the banking system and securities sector. The second index of financial sector reform captures the degree of external capital account liberalization. This is an average of two sub-indicators measuring the intensity of restrictions on residents and nonresidents in moving capital in and out of a country. The external capital account liberalization index captures a broad set of restrictions on financial transactions for residents and non-residents and the use of multiple exchange rates. In the regressions, we include the aggregate index of external capital account liberalization and two separate indices of capital account liberalization for residents and non-residents. As in the original database, all (normalized) reform indicators range between 0 and 1, with a higher value corresponding to a higher degree of liberalization in the associated sector. Consistent with the theoretical discussion, we expect the domestic financial liberalization variable to affect both between and within effects through the efficient allocation of capital and investments. Financial openness may also affect productivity by improving domestic allocative efficiency, by allowing countries to effectively share risks and invest in riskier but high-return firms/sectors (e.g., see the model of Obstfeld, 1994). We expect external financial liberalization to affect productivity through both the between and within channels.

\subsubsection{Sectoral Indicators data}

To analyze the effect of reforms on productivity growth, and the within and structural change components, we use the Groningen Growth and Development Center (GGDC) 10-sector database (M. Timmer et al., 2015) and the Expanded Africa Sector Database (EASD) (Mensah and Szirmai, 2018). These datasets have been widely used to analyze productivity across time and space because of their coverage and reliability. The GGDC 10-sector database provides long-run harmonized sectoral data on nominal value added, real value added, and employment for ten broad sectors of the economy in 42 countries mostly from the 1960s to 2010. Of the 42 countries, 11 countries are in Africa, 11 countries are in Asia, 2 countries in MENA, 9 countries are in Latin America, and 8 countries are in Europe and the USA. We complemented this dataset with the EASD, which updates value added and employment data for the 11 existing African countries. EASD also extends the coverage of the data to 7 new countries in Africa, increasing our sample to 49 countries. Of the 49 countries, 8 countries in Europe, along with Hong Kong-China, Japan, Singapore, South Korea, and the USA are classified as developed countries. Our analysis is based on the remaining 36 developing countries.

Using this dataset, we apply the shift-share methodology to decompose labor productivity growth in developing countries. As mentioned above, labor productivity in a country can grow in two ways; either within sectors due to innovation, capital accumulation, and a more efficient allocation of resources across plants or through the movement of workers from low-productivity sectors to high-productivity sectors. 
Aggregate labor productivity growth is defined as the weighted sum of sectoral productivity, with the weights being the employment shares, that is:

$$
q_{t}=\sum_{i} q_{i t} s_{i t}
$$

where $q_{i t}$ is labor productivity of sector $i$ in time $t$ given by $q_{i t}=Q_{i t} /_{i t}, Q_{i t}$ being sector $i$ 's real value added and $l_{i t}$ being the number of persons employed in sector $i$ at time $t$. Real value added (volume) is used to measure the growth of output per worker because the nominal value added conflates movement in quantities and prices. $s_{i t}$ is the sectoral employment share defined as the ratio of each sector's employment to the total employment of the economy at time $t$. Given the above, many researchers have decomposed labor productivity growth between time $(t)$ and $(0)$ using variant forms of the shift-share method. ${ }^{110}$ In this chapter, we take inspiration from Rodrik and McMillan (2011) to decompose aggregate labor productivity growth. The approach is given as:

$$
\dot{q}=\frac{\Delta q}{q^{0}}=\sum_{i=1}^{N}\left[\frac{q_{i}^{t}-q_{i}^{0}}{q^{0}}\right] s_{i}^{0}+\sum_{i=1}^{N}\left[\frac{\left(s_{i}^{t}-s_{i}^{0}\right) q_{i}^{t}}{q^{0}}\right]
$$

The first term on the right-hand side is the within effect, and the second term is the reallocation effect (structural change). The within effect measures average productivity growth within the sectors of an economy due to the adoption of new production techniques, innovation, and improvements in intra-sectoral allocative efficiency and productive efficiency. The reallocation effect measures productivity growth mainly due to the improvement in intersectoral allocative efficiency i.e. the movement of labor from lower productivity sectors to higher productivity sectors.

\subsubsection{Descriptive Statistics}

This section discusses the variation in reform indices, the patterns of labor productivity growth, and structural change in developing countries over time. Figure 6.1 and Figure 6.2 show the evolution of the (five-year average) indices of product markets reforms and financial markets reforms, respectively, since 1975. For the real sector, reforms related to trade has been more pronounced than reforms related to agriculture and electricity and telecommunications. This is consistent with the observation that structural adjustment programs in products markets were mostly preoccupied with trade openness. In addition, we observe that the distribution of the trade liberalization index narrows over time, indicating that most countries further liberalized their trade regimes. Countries in the sample also underwent deep financial liberalization. We observe a strong variation over time in the domestic financial sector reforms and its two components - banking and securities markets as well as the financial openness index (capital accounts index). The strong financial liberalization observed in developing countries may be explained by the fact that the SAPs or most IMF programs are highly contingent on recipient's commitment to financial and fiscal reforms.

110 see for example Fabricant, 1942; McMillan, Rodrik \& Verduzco-Gallo, 2014; Vries, Timmer, \& Vries, 2015. 

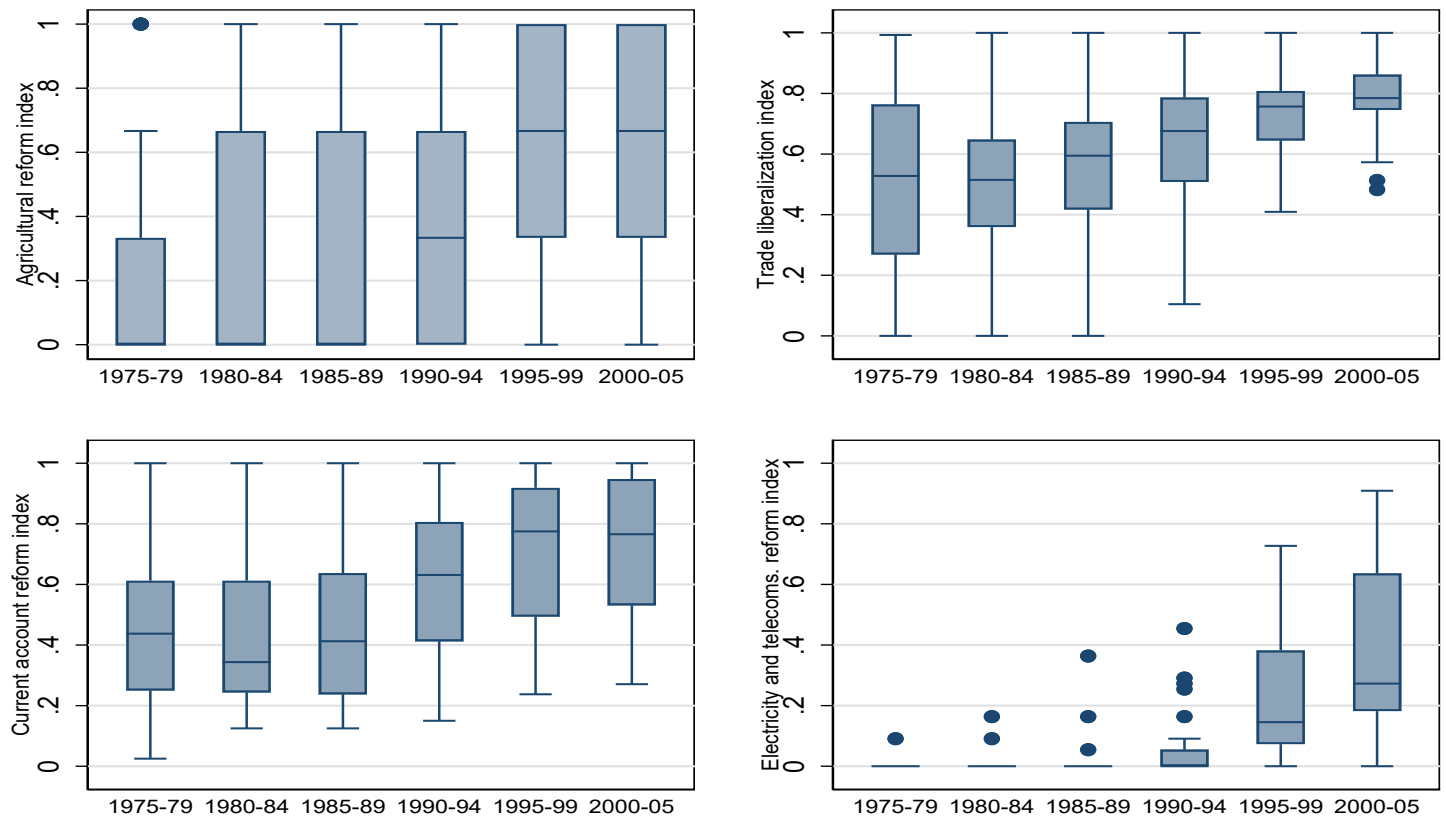

Notes: Authors' calculation based on Prati et al. (2013). Higher values indicate higher degree of liberalization.

Figure 6.2. Financial markets Reforms
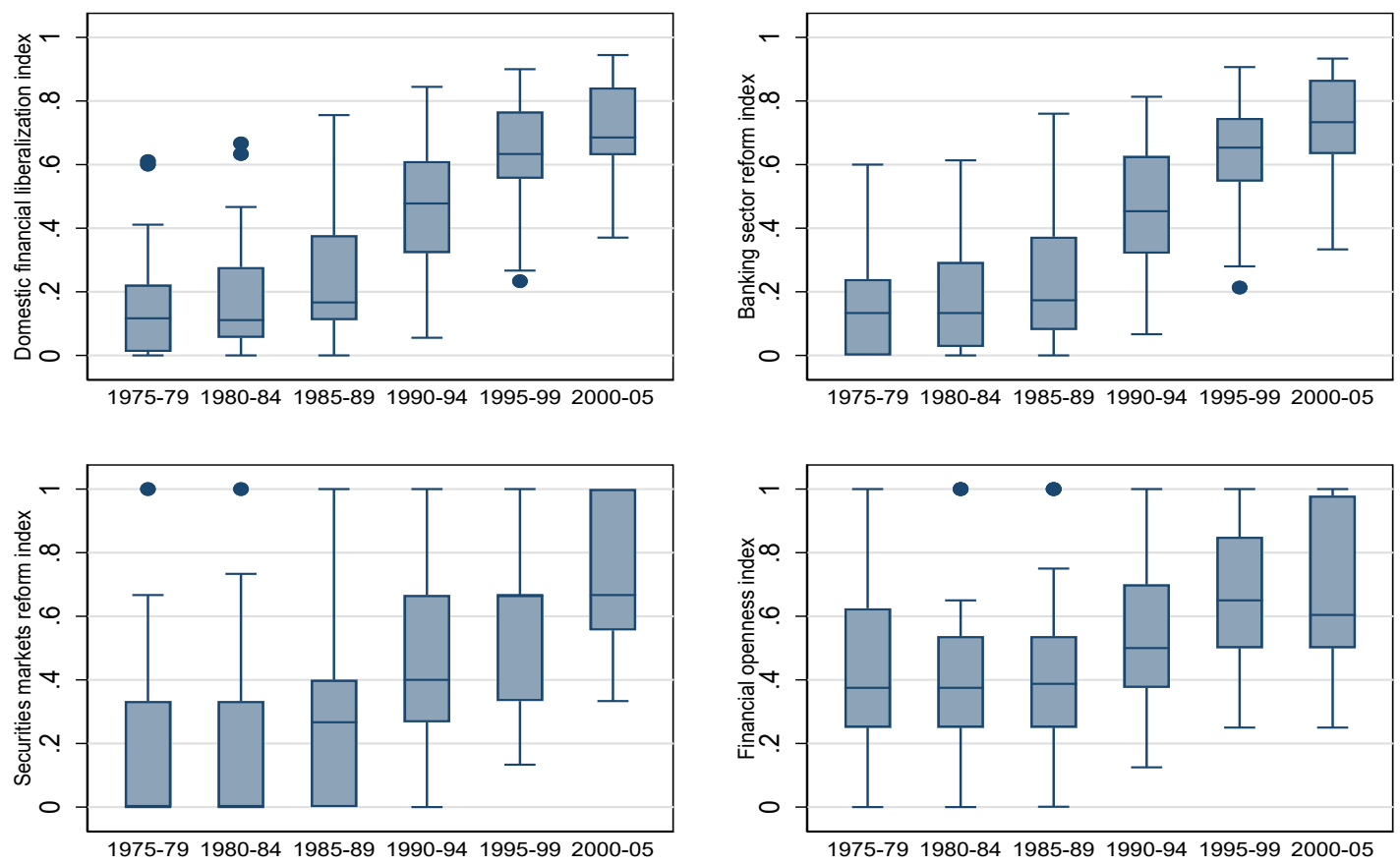

Notes: Authors' calculation based on Prati et al. (2013). Higher values indicate higher degree of liberalization

Tables 6.1 and 6.2 show the results of the decomposition exercise by region and country, respectively. Table 6.1 confirms regional differences in labor productivity growth, highlighting the potential differences in allocative and productive efficiency. For example, the highest labor productivity growth is observed in Asia, where productivity grew by about 3.5\% per annum on 
average. In contrast, productivity growth decreased by about $0.2 \%$ per annum on average in Latin America due to weak productivity growth within sectors. Productivity grew by $1.4 \%$ in Africa with structural change contributing as much as the within effect. There is also heterogeneity in productivity growth of the countries within each region. The highest degree of heterogeneity is observed in Africa with a standard deviation (SD) of 6.5\%. For example, productivity growth is as high as $4.6 \%$ in Botswana but as low as $-0.1 \%$ in Ethiopia over the same period (see Table 2). The observed productivity gaps between Asian and non-Asian developing countries are welldocumented in the literature. For example, Timmer et al. (2014) find similar productivity patterns and show that while structural change in Asia is characterized by a reallocation of labor towards sectors that experience both above-average productivity level and above-average productivity growth, in Africa and Latin America resources move toward sectors with above-average productivity but below-average productivity growth, resulting in dynamic productivity losses. McMillan et al. (2014) find a similar productivity difference and argue that the difference in aggregate labor productivity growth between Asian economies and non-Asian economies is due to different patterns of structural change. Relating these findings to the speed of transition from one income level to another, Foster-McGregor and Verspagen (2016) show that the high level of labor productivity growth helped Asian countries to transition faster from one income level to another, when compared with non-Asian countries.

Table 6.1: Annual Labor Productivity Growth by Region (\%), 1975-2005

\begin{tabular}{lcccc}
\hline Region & $\begin{array}{c}\text { Mean } \\
\text { (Within) }\end{array}$ & $\begin{array}{c}\text { Mean (Structural } \\
\text { Change) }\end{array}$ & $\begin{array}{c}\text { Mean (LP } \\
\text { Growth) }\end{array}$ & $\begin{array}{c}\text { SD (LP } \\
\text { Growth) }\end{array}$ \\
\hline SS Africa & 0.7 & 0.7 & 1.4 & 6.5 \\
Asia & 2.9 & 0.6 & 3.5 & 1.8 \\
Latin America & -0.8 & 0.7 & -0.2 & 4.8 \\
MENA & 1.5 & 0.7 & 2.2 & 5.2 \\
\hline
\end{tabular}

Source: Authors' calculation based on the GGDC 10-sector database and Expanded Africa Sector Database. Figures are unweighted averages across countries within each region. Due to approximation (rounding up), the components may not be exactly equal to total productivity growth in this table.

\subsection{Estimation model}

Our estimation strategy follows closely the empirical strategy of Prati et al (2013). The main difference between this chapter and the paper of Prati et al. (2013) is that our dependent variables are the growth rate of labor productivity and its two components (the within effect and structural change) whereas their dependent variable is the growth rate of GDP per capita. Our main baseline model is an OLS model where we control for country and time fixed-effects and cluster standard errors at the level of the country. In some of the estimations, we control for a number of variables that have been previously identified in the literature as being determinants of labor productivity growth. We also estimate a GMM model to correct for possible endogeneity that may exist in the data. Our three main dependent variables are the growth rate of labor productivity, and both the within and structural change components of labor productivity growth. We first estimate the effects of real and financial sector reforms on the growth rate of labor productivity between time 
$\mathrm{t}-1$ and $\mathrm{t}$. As explained above, the reform indices range from 0 to 1 with higher values indicating a higher degree of liberalization. The estimating equation is given as follows:

\section{3 $\operatorname{Ln}\left(\right.$ Productivity $\left._{i t}\right)-\operatorname{Ln}\left(\right.$ Productivity $\left._{i t-1}\right)=\beta_{0}+\beta_{1} \operatorname{Ln}\left(\right.$ Productivity $\left._{i t-1}\right)+$ $\beta_{2}$ Reforms $_{i t-1}+\beta_{3} X_{i t-1}+\sigma_{i}+\tau_{t}+\varepsilon_{i t}$}

Table 6.2: Average Annual Labor Productivity Growth by Country (\%), 1975-2005

\begin{tabular}{|c|c|c|c|c|}
\hline Region & Country & Within Effect & Structural Change & LP Growth \\
\hline \multirow[t]{18}{*}{ 1. SSA } & Botswana & 4.2 & 0.3 & 4.6 \\
\hline & Burkina Faso & 2.6 & 1.0 & 3.6 \\
\hline & Cameroon & 0.6 & 1.6 & 2.2 \\
\hline & Ethiopia & -0.8 & 0.7 & -0.1 \\
\hline & Ghana & 0.3 & 0.1 & 0.5 \\
\hline & Kenya & -1.5 & 0.9 & -0.6 \\
\hline & Lesotho & 1.1 & 0.9 & 2.0 \\
\hline & Malawi & -0.7 & 0.8 & 0.2 \\
\hline & Mauritius & 2.4 & 0.7 & 3.1 \\
\hline & Mozambique & 2.6 & 0.1 & 2.7 \\
\hline & Namibia & 1.4 & 0.2 & 1.6 \\
\hline & Nigeria & 1.6 & -0.1 & 1.5 \\
\hline & Rwanda & 0.5 & 1.4 & 1.9 \\
\hline & Senegal & -1.8 & 1.1 & -0.7 \\
\hline & South Africa & 0.1 & 0.6 & 0.7 \\
\hline & Tanzania & 0.4 & 1.1 & 1.6 \\
\hline & Uganda & -0.7 & 1.8 & 1.1 \\
\hline & Zambia & -0.2 & -0.9 & -1.0 \\
\hline \multirow[t]{7}{*}{ 2. $\quad$ Asia } & China & 5.5 & 1.1 & 6.6 \\
\hline & India & 1.4 & 1.1 & 2.5 \\
\hline & Indonesia & 1.3 & 1.1 & 2.4 \\
\hline & Malaysia & 4.6 & -1.1 & 3.5 \\
\hline & Philippines & 0.6 & 0.3 & 1.0 \\
\hline & Taiwan & 4.7 & -0.3 & 4.4 \\
\hline & Thailand & 2.2 & 1.7 & 3.8 \\
\hline \multirow[t]{9}{*}{ 3. Latin America } & Argentina & 0.4 & -0.5 & -0.1 \\
\hline & Bolivia & -1.4 & 1.3 & -0.1 \\
\hline & Brazil & -1.2 & 1.1 & 0.0 \\
\hline & Chile & 1.7 & 0.4 & 2.0 \\
\hline & Colombia & -0.6 & 0.6 & 0.0 \\
\hline & Costa Rica & -1.0 & 1.0 & 0.0 \\
\hline & Mexico & -1.5 & 1.0 & -0.5 \\
\hline & Peru & -1.7 & 0.8 & -0.9 \\
\hline & Venezuela & -2.3 & 0.4 & -1.9 \\
\hline \multirow[t]{2}{*}{ 4. $\quad$ MENA } & Egypt & 2.6 & 0.7 & 3.3 \\
\hline & Morocco & 0.4 & 0.6 & 1.0 \\
\hline
\end{tabular}


Source: Authors' calculation based on the GGDC 10-sector database and Expanded Africa Sector Database. Due to approximation (rounding up), the components may not be exactly equal to total productivity growth in this table.

The dependent variable, $\operatorname{Ln}\left(\right.$ Productivity $\left._{i t}\right)-\operatorname{Ln}\left(\right.$ Productivity $\left._{i t-1}\right)$, is the annual growth rate of labor productivity for country $i$ at time $t$. The key parameter of interest is $\beta_{2}$ which measures the effect of a given reform on the growth rate of labor productivity. Because different types of reforms may yield different outcomes, it is important to use the disaggregated indicators. Following the work of Prati et al. (2013), we enter the different real and financial sector reforms individually in the model because of the high correlation between the reform variables. In some of our specifications, we include additional control variables, $X$, that include the growth rate of the population, endowments of human capital, as well as an indicator of the quality of institutions. Country and time fixed effects are captured by $\sigma_{i}$ and $\tau_{\mathrm{t}}$, respectively.

The novelty in this chapter is to analyze the effect of reforms on the within and the structural change components of the growth rate of labor productivity. The linear OLS model allows us to effectively regress reforms on the within component and the structural change component as a means of decomposing the effect of reforms into an intra-sectoral allocative efficiency channel and an inter-sectoral allocative efficiency channel, respectively. The estimating equations are given as follows:

6.4 Within $_{i t}=\alpha_{0}+\alpha_{1} \operatorname{Ln}\left(\right.$ Productivity $\left._{i t-1}\right)+\alpha_{2}$ Reforms $_{i t-1}+\alpha_{3} X_{i t-1}+\tau_{t}+\sigma_{i}+\mu_{i t}$

6. 5 Structural_change $_{i t}=\delta_{0}+\delta_{1} \operatorname{Ln}\left(\right.$ Productivity $\left._{i t-1}\right)+\delta_{2}$ Reforms $_{i t-1}+\delta_{3} X_{i t-1}+\tau_{t}+$ $\sigma_{i}+\vartheta_{i t}$

That is, because the estimation models are linear and the dependent variable in equation (6.3) is the sum of the dependent variables in equations (6.4) and (6.5), hence we can write:

$$
\beta_{2}=\alpha_{2}+\delta_{2}
$$

With this expression, we can determine the fraction of the effect of reforms on labor productivity growth that comes through the within component and the fraction that comes from the structural change component. The advantage of this approach is that it provides comparable cross-country evidence on the effect of reforms on within-sector productivity growth and structural change, contrary to the anecdotal argument about the potential effect of adjustment programs on the structural transformation of developing countries. In addition, this approach avoids the pitfall of a lack of comparability of cross-country firm level data that characterizes some micro-level evidence ( Landesmann \& Foster-McGregor, 2021).

For robustness, we employ the dynamic panel method proposed by Arellano \& Bond (1991) to correct for possible endogeneity in the estimation of the effects of reforms on labor productivity growth. Particularly, the use of the lagged dependent variable as regressor in the above equations violates the strict exogeneity assumption because the lagged dependent variable and the general error term are likely to be correlated, as a result, the fixed-effect OLS estimator is likely to produce inconsistent results. The Arellano-Bond (AB) GMM estimator deals with the endogeneity by taking the first difference of equation 6.3 to remove country-specific unobserved heterogeneity and using lags of the dependent variable as instruments. However, the AB GMM is nonlinear and 
does not allow us to quantify the distributional effect of structural reforms between the within effect and the structural change effect because, with the GMM, the dependent variable in equation (6.3) is labor productivity in level, which cannot be decomposed into within and between components.

\subsection{Results and Discussion}

\subsubsection{Reforms and Aggregate Labor productivity growth}

We start our discussion of the results with Table 6.3, where we regress the real and financial sector reforms on the growth rate of labor productivity controlling for the lagged level of labor productivity and country and time fixed effects. We also cluster the standard errors at the country level to correct for correlation that may occur among observations within countries. Similar to the paper of Prati et al. (2013), our baseline model does not include additional controls because of the high correlation between variables but as robustness checks we include some control variables in a separate model.

The results show that trade reforms, and electricity and telecommunications liberalization have positive and statistically significant effects on the growth rate of labor productivity. The result of trade reforms is consistent with expectations of classical trade theory or 'new' new trade theory where trade liberalization could increase labor productivity growth either through specialization according to comparative advantage or provides new opportunities for profits only to the most productive firms, allowing them to pay the entry costs of exporting. As the productive firms expand due to new market opportunities from trade, they increase demand for labor, increasing real wages and forcing the least productive firms to exit, inducing a more efficient allocation of resources within sectors. Similarly, electricity and telecommunications liberalization could increase productivity by increasing competition that leads to a reduction in marks-ups and market power, hence a more efficient allocation of resources within or across sectors. The statistically insignificant effect of agricultural reforms is consistent with existing findings that showed that the effect of agricultural reforms on key outcomes such as agricultural production and modern input usage had not met expectations in some developing countries. For example, Kherallah et al. (2000) find that following reforms in the agricultural sector, the average growth rate of agricultural production per capita and modern input use was negative in Africa in the 1980s and 1990s.

For financial sector reforms, we find that reforms in domestic finance, banking, and securities have positive and statistically significant effects on the growth rate of labor productivity, confirming the intermediary role that the financial sector plays in the efficient allocation of productive investments (Schumpeter, 1912). Contrary to domestic financial reforms, external capital account liberalization does not have significant effects on labor productivity growth in the linear model. Our results are similar to Rodrik (1998), who found no growth effect of general capital account liberalization. While it is possible that capital account openness could lead to an inflow of investible funds, a lower cost of capital, and increases in productive investments, there is also the risk of the Dutch disease effect which could render the tradable sector uncompetitive. The findings in Table 6.3 highlight that in general real and financial sector reforms have increased the growth rate of labor productivity in developing countries. This confirms previous research that shows a positive relationship between real and financial sector reforms and economic growth (Prati et al., 2013), 
labor productivity growth (Dabla-Norris et al., 2016), and firm productivity growth (Kouamé \& Tapsoba, 2019).

Table 6.4 reports results from the AB GMM estimation. The results further emphasize that real and financial sector reforms have positive and statistically significant effects on the growth rate of labor productivity. In addition, the estimated coefficients of the AB GMM model are higher than the ones obtained with our baseline model. In Table 6.5, we include additional control variables to our baseline model. These variables are the growth rate of population, a measure of human capital and the stock of physical capital as a share of GDP. All these variables are in natural logarithm. We also include the measure of constraints on the executive from Polity IV to capture the quality of institutions. The estimation results show that most of the reform variables that were significant in the baseline model are still significant in this model. However, the level of significance of the real sector reforms has decreased. It is worth noting that many of the additional controls are highly correlated. We add them to test the robustness of the results. However, for the rest of the analysis, we will follow Prati et al (2013) to use our baseline model that only controls for initial productivity level and country and time fixed effects.

\subsubsection{Intra-sectoral or Intersectoral Reallocation?}

The key question we are interested in this chapter is whether structural reforms affect labor productivity growth by inducing a more efficient reallocation of resources within sectors, across sectors or both. We investigate the effects of reforms on these two channels of labor productivity growth using our baseline specification, which controls for country and time fixed-effects, and the initial level of labor productivity. The estimation results using the within component as dependent variable are reported in Table 6.6. Trade reforms have a sizable and significant effect on withinsector productivity growth, confirming some of the predictions of "new' new trade theory and pro-competitive models of trade, particularly, the idea that countries can still gain from trade without necessarily changing their specialization patterns. Electricity and telecommunications liberalization have positive and statistically significant effects on within-sector productivity growth. By increasing the intensity of competition, product market reforms may have encouraged the spread of ideas, the adoption of better production techniques, technology spillovers, increasing technical and productive efficiency and hence productivity growth within sectors. Again, agricultural reforms have no effect on the within effect, in contrast to the expectation that agricultural reforms will create price incentives, induce a supply response, and increase agricultural productivity growth. The lack of productivity growth within the sector may affect essential input supply to other industries, and as demonstrated by Gollin (2009), agricultural productivity growth is necessary for aggregate productivity growth, hence the insignificant effect on the aggregate within effect. Another way to think about the result is that agricultural reforms may not be relevant beyond the agricultural sector itself, hence the limited aggregate within-sector productivity. For example, Table 6.14 reports the effect of all reform indices on sectoral labor productivity growth. The Table shows that while all other reform indices are relevant beyond agriculture, agricultural reforms have no significant effect on the labor productivity of industry and services. This result may reflect how agricultural reforms are measured in the Prati et al. (2013:948) database. In the database, agricultural reform is narrowly defined as "the extent of public intervention in the market of each country's main agricultural export commodity. It includes the presence of export marketing boards and the incidence of administered prices." For example, the main agricultural export commodity of Ghana is cocoa. Structural reforms in the cocoa sector may not have any effect on 
other sectors such as the textile industry and telecommunications. A broader measure that includes input and output markets of agricultural products as well as agricultural land reforms may capture the agricultural effect on aggregate within effect more precisely.

All the domestic financial sector reforms are significant and have the expected sign on the within effect. There are many ways through which financial sector reforms may have positively affected within-sector productivity growth. Financial liberalization improves allocative efficiency by allowing investment funds to go to firms with a higher marginal return to capital (Galindo et al., 2007). For within-sector productivity growth, financial reforms lower the cost of credit, allowing financially constrained firms to access capital and produce at a more efficient level. Furthermore, it enables the financing of new machinery, the adoption of new production techniques and innovation within industries. Our results are consistent with the empirical findings and theoretical predictions of Larrain \& Stumpner (2017). However, easing restrictions on external capital has little effect (non-residents) or no effect (resident) on within-sector productivity growth. The weak effect of financial openness relates to the benefits and costs of internal capital flows. Easing capital account restrictions could generate inflows such as FDI that can facilitate the transfer of foreign technological knowledge, encourage competition and financial sector development. It also helps firms to insulate themselves against risk by diversification, potentially generating growth within sectors. Conversely, there are increasing risks associated with the fluctuations of internal capital flows such as sudden reversals associated with investor sentiments and the Dutch disease effect.

Table 6.7 shows the results of the effects of reforms on the structural change component. The estimated coefficients on both real and financial sector reforms are all insignificant. While these insignificant effects on structural change are expected from reforms such as agricultural reforms, at least in the short run, for some reforms such as trade reforms, the zero effect on structural change is surprising. Traditional trade theory predicts that countries gain from trade liberalization through specialization in areas of comparative advantage, and through changes in relative prices, which induce structural change. However, our results should be interpreted with caution since some structural change effect of reforms are conditional on land and labor market institutions and may also be realized in the long term. For example, if trade liberalization allows firms to import cheaper capital and intermediates inputs but firing and hiring costs are still high, firms will adopt more capital intensive methods of production and favor a process of creative destruction (Pariboni \& Tridico, 2019), where the Schumpeterian engine of innovation generates productivity growth within sectors but not structural change due to lack of labor flexibilization. However, we do not have data on land and labor market reforms to test some of these mechanisms. As a second-best solution, we examine long-run effects of reforms on labor productivity growth and its two components. Presumably, in countries where land reforms and labor market reforms are complementary to the reforms we have considered, the structural change effects of the various institutional reforms should be realized after five years. Tables 6.12 and 6.13 show that the effect of reforms on productivity growth after five years is positive and statistically significant and works mainly through the within-sector effect but not through structural change.

Overall, the results of the analysis have shown that structural reforms have increased the growth rate of labor productivity, mainly through the within component. Structural reforms work by increasing dynamic efficiency, productive efficiency (i.e. operating at a more efficient level due to 
competition, and allocative efficiency (i.e. inducing a more efficient reallocation of resources within sectors). However, reforms do not induce structural change in developing countries.

In Table 6.8 we decompose the contribution of the effect of reforms on the growth rate of labor productivity that comes through the within component and through the structural change component. Among the real sector reforms, current account reform is the one that has the highest effect on labor productivity growth arising through the within component. In fact, more than 96\% of the effect of current account reforms on the growth rate of labor productivity comes through the within component, with just 3.6\% coming from the structural change/between component. These values are around $88 \%$ and $12 \%$ for trade and electricity and telecommunications reforms. Agriculture is the only real sector reform for which there is an equal contribution through the within and structural change components, but the previous table has shown that agriculture reforms did not have any significant effects on any of the dependent variables.

Turning now to the financial sector reforms, we find that domestic finance, banking, and securities reforms have roughly $89 \%$ of their effects on the growth rate of labor productivity coming from the within component and only around 11\% from the structural change/between component. Looking at reforms on capital and resident and non-resident capital reforms, we find that they also record higher contributions through the within component than the structural change.

\subsubsection{Distance to the frontier}

One of the key findings of the nascent literature on the effects of reforms on economic performance is that the effect may depend on the distance to the technological frontier. For instance, Prati et al (2013) and Dabla-Norris et al (2016) have shown that countries that are far from the technological frontier benefit more from some structural reforms than other reforms, for example. The obvious reason is that the closer a country is to the frontier, the closer is its allocative efficiency, dynamic efficiency, and productive efficiency to that of the frontier. As a result, reforms that aim to improve these productivity mechanisms, may not positively affect countries closer to the frontier as much as countries which are far away from the frontier. Using an interaction terms, we test if closeness to the technological frontier increases or decreases the effect of reforms on the growth rate of labor productivity and its sub-components. Following, the literature we consider the US as the country with the highest technology. For each country and year, we compute the technological distance as the ratio of the labor productivity of the country to the labor productivity of the US. A ratio lower than one indicates that the country is below the technological frontier and a ratio equal one means that the country has reached the technological frontier.

In the estimations, we remove the initial level of productivity and include the variable distance to the technological frontier along with its interaction with each reform variable. Table 6.9 presents the results using the growth rate of labor productivity as the dependent variable. For real sector reforms, we find positive signs on the estimated coefficients of the variable reforms and negative signs on the interaction terms, but they are statistically significant only for the current account reform variable. This indicates that current account reforms have a positive effect on the growth rate of labor productivity, but this effect reduces as countries approach the technological frontier. This is because the closer the country's productivity is to the US, the freer its trade regime may be, 
therefore easing restrictions on the current account may not generate significant trade grains compared to countries far away from the productivity level of US. For financial sector reforms domestic finance, banking, and securities reforms - the results show positive and statistically significant effects on labor productivity but negative and statistically significant coefficients on the interaction with the distance to the frontier. Results for current account reforms are found to be similar. Generally, financial sector reforms have positive effects on labor productivity growth but that diminishes with proximity to the technology leader. From this table we can conclude that countries that are far from the technological frontier benefit more from structural reforms than countries closer to the technology leader.

Finally, we investigate if distance to the technological frontier also matters for the effects of reforms on the within and structural change components. The results for both components are reported in tables 6.10 and 6.11, respectively. As for the previous estimations, we find that current account, domestic finance, banking, and securities reforms all have positive effects on the within component, but these effects decline as the productivity gap with the technological frontier reduces. Table 6.11 repeats the same exercise using the structural change component as the dependent variable. Most of the estimated coefficients are not significant but we find in a few cases a positive sign on the coefficient of reforms and a negative sign on the interaction term between real sector reforms and technological distance to the US, although the level of significance is $10 \%$.

\subsection{Concluding remarks}

It is widely recognized that productivity is an important determinant of countries' economic performance in the long run. Understanding which policies raise productivity growth in developing countries is essential given the low level of productivity in these countries. This chapter adds to the limited literature on the impacts of structural reforms on productivity growth in low and lowmiddle income countries and pays particular attention to how reforms affect both within-sector effect and the movement of labor across sectors of the economy i.e., structural change. The empirical analysis combines the dataset on structural reforms from Prati et al (2013) with a sectoral database from GGDC 10-sector database and EASD to compute productivity growth and structural change. Our findings show that financial sector reforms have greater effects on the growth rate of labor productivity than real sector reforms. However, reforms affect the within and the structural change contributions differently. Financial sector reforms have positive effects on the within component of the productivity growth rate. In contrast, the different reforms have either a negative effect or no effect on structural change. The results show that reforms affect growth in developing countries mostly by inducing within-sector productivity growth but not structural change, further providing empirical support for the argument that many developing countries had structural adjustments programs without structural change (Page, 2012). Our analysis demonstrates that market-oriented reforms alone will not be able to deliver structural change in developing countries; therefore, there is prima facie rational for complementary industrial policies.

The analysis in this chapter suggests a number of future research avenues. Most of the reform indicators are narrowly defined. For example, agricultural reform covers the markets of each country's main agricultural commodity exports. This sector may have no or limited linkages with other sectors of the economy, therefore the agricultural reform indicator in this research may not be relevant beyond the leading commodity sector. The trade reform indicator also does not cover 
non-tariff barriers. Given that different indicators of trade openness are uncorrelated (Pritchett, 1996), moving beyond tariffs may have some implications for the results reported. Broadening the reform measures and examining how they may affect labor productivity growth, but also its components, is an important area for future research.

Furthermore, while this chapter considers the linear effect of reform on structural change, there is the possibility that the effect of reforms on structural change is nonlinear. As explained above, some reforms may induce sectoral reallocation of resources if they are complemented with appropriate land institutions and less rigid labor markets. Interacting land and labor market institutions may capture some of these mechanisms. However, we do not have data on land and labor market institutions. Further research should consider some of these possible nonlinear effects. 
Table 6.3: Reforms and labor productivity growth

\begin{tabular}{|c|c|c|c|c|c|c|c|c|c|c|}
\hline Dependent variable & (1) & (2) & (3) & (4) & (5) & (6) & (7) & (8) & (9) & (10) \\
\hline \multicolumn{11}{|l|}{$\operatorname{LnProd}(t)-\operatorname{LnProd}(t-1)$} \\
\hline Real sector reforms & & & & & & & & & & \\
\hline Trade $(\mathrm{t}-1)$ & $\begin{array}{c}0.024^{* *} \\
(0.011)\end{array}$ & & & & & & & & & \\
\hline Current_account $(\mathrm{t}-1)$ & & $\begin{array}{c}0.028^{* *} \\
(0.013)\end{array}$ & & & & & & & & \\
\hline Agriculture(t-1) & & & $\begin{array}{c}0.005 \\
(0.009)\end{array}$ & & & & & & & \\
\hline Network(t-1) & & & & $\begin{array}{c}0.019 * * \\
(0.008)\end{array}$ & & & & & & \\
\hline \multicolumn{11}{|l|}{ Financial sector reforms } \\
\hline Domestic_finance(t-1) & & & & & $\begin{array}{c}0.022^{* *} \\
(0.009)\end{array}$ & & & & & \\
\hline Banking(t-1) & & & & & & $\begin{array}{c}0.020^{* *} \\
(0.009)\end{array}$ & & & & \\
\hline Securities(t-1) & & & & & & & $\begin{array}{c}0.022^{* * *} \\
(0.008)\end{array}$ & & & \\
\hline Capital(t-1) & & & & & & & & $\begin{array}{c}0.014 \\
(0.010)\end{array}$ & & \\
\hline Capital_resident $(t-1)$ & & & & & & & & & $\begin{array}{c}0.007 \\
(0.009)\end{array}$ & \\
\hline Capital_nonresident(t-1) & & & & & & & & & & $\begin{array}{c}0.013 \\
(0.008)\end{array}$ \\
\hline $\operatorname{LnProd}(\mathrm{t}-1)$ & $\begin{array}{c}-0.066^{* * * *} \\
(0.015)\end{array}$ & $\begin{array}{c}-0.040^{* *} \\
(0.018)\end{array}$ & $\begin{array}{l}-0.032 \\
(0.019)\end{array}$ & $\begin{array}{l}-0.024 \\
(0.016)\end{array}$ & $\begin{array}{c}-0.040^{* * *} \\
(0.012)\end{array}$ & $\begin{array}{c}-0.039 * * * \\
(0.012)\end{array}$ & $\begin{array}{c}-0.040^{* * *} \\
(0.013)\end{array}$ & $\begin{array}{c}-0.037 * * \\
(0.016)\end{array}$ & $\begin{array}{c}-0.036^{* *} \\
(0.017)\end{array}$ & $\begin{array}{c}-0.036 * * \\
(0.016)\end{array}$ \\
\hline Constant & $\begin{array}{c}0.661 * * * \\
(0.146)\end{array}$ & $\begin{array}{c}0.393 * * \\
(0.178)\end{array}$ & $\begin{array}{c}0.326 \\
(0.199)\end{array}$ & $\begin{array}{c}0.242 \\
(0.164)\end{array}$ & $\begin{array}{c}0.400^{* * *} \\
(0.122)\end{array}$ & $\begin{array}{c}0.395^{* * *} \\
(0.121)\end{array}$ & $\begin{array}{c}0.401 * * * \\
(0.136)\end{array}$ & $\begin{array}{c}0.373 * * \\
(0.166)\end{array}$ & $\begin{array}{c}0.367 * * \\
(0.172)\end{array}$ & $\begin{array}{c}0.367 * * \\
(0.167)\end{array}$ \\
\hline Observations & 1,025 & 1,075 & 1,034 & 1,051 & 913 & 913 & 913 & 1,075 & 1,075 & 1,075 \\
\hline Number of countries & 34 & 32 & 31 & 31 & 28 & 28 & 28 & 32 & 32 & 32 \\
\hline R-squared & 0.193 & 0.161 & 0.163 & 0.128 & 0.152 & 0.152 & 0.154 & 0.154 & 0.152 & 0.154 \\
\hline Country FE & YES & YES & YES & YES & YES & YES & YES & YES & YES & YES \\
\hline Period FE & YES & YES & YES & YES & YES & YES & YES & YES & YES & YES \\
\hline
\end{tabular}


Table 6.4: Reforms and labor productivity growth, GMM

\begin{tabular}{|c|c|c|c|c|c|c|c|c|c|c|}
\hline $\begin{array}{l}\text { Dependent variable } \\
\operatorname{LnProd}(\mathrm{t})-\operatorname{Ln} \operatorname{Prod}(\mathrm{t}-1)\end{array}$ & $(1)$ & $(2)$ & (3) & $(4)$ & $(5)$ & $(6)$ & $(7)$ & $(8)$ & (9) & $(10)$ \\
\hline \multicolumn{11}{|l|}{ Real sector reforms } \\
\hline Trade(t-1) & $\begin{array}{l}0.051 * * \\
(0.025)\end{array}$ & & & & & & & & & \\
\hline Current_account(t-1) & & $\begin{array}{c}0.082^{* * *} \\
(0.022)\end{array}$ & & & & & & & & \\
\hline Agriculture(t-1) & & & $\begin{array}{l}0.041 * * \\
(0.019)\end{array}$ & & & & & & & \\
\hline $\operatorname{Network}(\mathrm{t}-1)$ & & & & $\begin{array}{c}0.059 * * \\
(0.026)\end{array}$ & & & & & & \\
\hline \multicolumn{11}{|l|}{ Financial sector reforms } \\
\hline Domestic_finance(t-1) & & & & & $\begin{array}{l}0.100^{* *} \\
(0.041)\end{array}$ & & & & & \\
\hline Banking(t-1) & & & & & & $\begin{array}{l}0.097 * * \\
(0.039)\end{array}$ & & & & \\
\hline Securities (t-1) & & & & & & & $\begin{array}{c}0.070^{* * *} \\
(0.027)\end{array}$ & & & \\
\hline Capital(t-1) & & & & & & & & $\begin{array}{c}0.079 * * * \\
(0.022)\end{array}$ & & \\
\hline Capital_resident $(t-1)$ & & & & & & & & & $\begin{array}{c}0.062^{* * *} \\
(0.017)\end{array}$ & \\
\hline Capital_nonresident(t-1) & & & & & & & & & & $\begin{array}{c}0.074 * * * \\
(0.023)\end{array}$ \\
\hline LNProd(t-1) & $\begin{array}{c}0.932^{* * *} \\
(0.048)\end{array}$ & $\begin{array}{c}0.921 * * * \\
(0.029)\end{array}$ & $\begin{array}{c}0.936^{* * *} \\
(0.031)\end{array}$ & $\begin{array}{c}0.924 * * * \\
(0.047)\end{array}$ & $\begin{array}{c}0.750^{* * *} \\
(0.070)\end{array}$ & $\begin{array}{c}0.756^{* * *} \\
(0.066)\end{array}$ & $\begin{array}{c}0.830^{* * *} \\
(0.063)\end{array}$ & $\begin{array}{c}0.941^{* * *} \\
(0.028)\end{array}$ & $\begin{array}{c}0.957 * * * \\
(0.028)\end{array}$ & $\begin{array}{c}0.948^{* * *} \\
(0.027)\end{array}$ \\
\hline Observations & 991 & 1,043 & 1,003 & 1,020 & 885 & 885 & 885 & 1,043 & 1,043 & 1,043 \\
\hline Number of countries & 34 & 32 & 31 & 31 & 28 & 28 & 28 & 32 & 32 & 32 \\
\hline Country FE & YES & YES & YES & YES & YES & YES & YES & YES & YES & YES \\
\hline Period FE & YES & YES & YES & YES & YES & YES & YES & YES & YES & YES \\
\hline AR (1) Test P-value & 0.013 & 0.005 & 0.000 & 0.001 & 0.001 & 0.001 & 0.005 & 0.005 & 0.005 & 0.005 \\
\hline AR (2) Test P-value & 0.700 & 0.341 & 0.166 & 0.218 & 0.276 & 0.281 & 0.151 & 0.394 & 0.385 & 0.404 \\
\hline Hansen Test P-value & 0.644 & 0.727 & 0.806 & 0.776 & 0.815 & 0.821 & 0.789 & 0.680 & 0.736 & 0.657 \\
\hline
\end{tabular}

Notes: Robust standard errors clustered within countries in parentheses. ${ }^{* * *} \mathrm{p}<0.01,{ }^{* *} \mathrm{p}<0.05,{ }^{*} \mathrm{p}<0.1$. 
Table 6.5: Reforms and labor productivity growth with additional control variables

\begin{tabular}{|c|c|c|c|c|c|c|c|c|c|c|}
\hline $\begin{array}{l}\text { Dependent variable } \\
\operatorname{LnProd}(t)-\operatorname{LnProd}(t-1)\end{array}$ & (1) & (2) & (3) & (4) & (5) & (6) & (7) & (8) & (9) & $(10)$ \\
\hline \multicolumn{11}{|l|}{ Real sector reforms } \\
\hline Trade(t-1) & $\begin{array}{l}0.022^{*} \\
(0.012)\end{array}$ & & & & & & & & & \\
\hline Current_account(t-1) & & $\begin{array}{l}0.030^{*} \\
(0.017)\end{array}$ & & & & & & & & \\
\hline Agriculture(t-1) & & & $\begin{array}{l}-0.004 \\
(0.011)\end{array}$ & & & & & & & \\
\hline Network(t-1) & & & & $\begin{array}{c}0.022 \\
(0.014)\end{array}$ & & & & & & \\
\hline \multicolumn{11}{|l|}{ Financial sector reforms } \\
\hline Domestic_finance(t-1) & & & & & $\begin{array}{c}0.049 * * \\
(0.018)\end{array}$ & & & & & \\
\hline Banking $(\mathrm{t}-1)$ & & & & & & $\begin{array}{c}0.041 * * \\
(0.017)\end{array}$ & & & & \\
\hline Securities $(\mathrm{t}-1)$ & & & & & & & $\begin{array}{c}0.046^{* * *} \\
(0.013)\end{array}$ & & & \\
\hline Capital(t-1) & & & & & & & & $\begin{array}{c}0.011 \\
(0.014)\end{array}$ & & \\
\hline Capital_resident(t-1) & & & & & & & & & $\begin{array}{c}0.004 \\
(0.011)\end{array}$ & \\
\hline Capital_nonresident(t-1) & & & & & & & & & & $\begin{array}{c}0.008 \\
(0.012) \\
\end{array}$ \\
\hline LnProd(t-1) & $\begin{array}{c}-0.070 * * * \\
(0.016)\end{array}$ & $\begin{array}{c}-0.038^{* *} \\
(0.018)\end{array}$ & $\begin{array}{l}-0.037 \\
(0.022)\end{array}$ & $\begin{array}{l}-0.017 \\
(0.018)\end{array}$ & $\begin{array}{c}-0.030 * * \\
(0.014)\end{array}$ & $\begin{array}{c}-0.030^{* *} \\
(0.014)\end{array}$ & $\begin{array}{c}-0.031 * * \\
(0.015)\end{array}$ & $\begin{array}{c}-0.039 * * \\
(0.018)\end{array}$ & $\begin{array}{c}-0.039 * * \\
(0.019)\end{array}$ & $\begin{array}{r}-0.039 * * \\
(0.019)\end{array}$ \\
\hline lnpop_growth(t-1) & $\begin{array}{c}0.030 \\
(0.199)\end{array}$ & $\begin{array}{c}0.004 \\
(0.233)\end{array}$ & $\begin{array}{l}-0.672 \\
(0.556)\end{array}$ & $\begin{array}{l}-0.517 \\
(0.473)\end{array}$ & $\begin{array}{l}-0.490 \\
(0.693)\end{array}$ & $\begin{array}{l}-0.537 \\
(0.687)\end{array}$ & $\begin{array}{l}-0.292 \\
(0.640)\end{array}$ & $\begin{array}{c}0.015 \\
(0.235)\end{array}$ & $\begin{array}{c}0.009 \\
(0.239)\end{array}$ & $\begin{array}{c}0.017 \\
(0.236)\end{array}$ \\
\hline ln_humanCapital(t-1) & $\begin{array}{c}0.014 \\
(0.028)\end{array}$ & $\begin{array}{l}-0.005 \\
(0.031)\end{array}$ & $\begin{array}{c}0.032 \\
(0.031)\end{array}$ & $\begin{array}{l}-0.020 \\
(0.040)\end{array}$ & $\begin{array}{l}-0.081 \\
(0.061)\end{array}$ & $\begin{array}{l}-0.069 \\
(0.060)\end{array}$ & $\begin{array}{l}-0.071 \\
(0.052)\end{array}$ & $\begin{array}{c}0.016 \\
(0.030)\end{array}$ & $\begin{array}{c}0.022 \\
(0.027)\end{array}$ & $\begin{array}{c}0.018 \\
(0.030)\end{array}$ \\
\hline ln_capital/GDP(t-1) & $\begin{array}{l}-0.011 \\
(0.032)\end{array}$ & $\begin{array}{c}0.001 \\
(0.027)\end{array}$ & $\begin{array}{c}-0.035^{*} \\
(0.018)\end{array}$ & $\begin{array}{l}-0.028 \\
(0.019)\end{array}$ & $\begin{array}{l}-0.030 \\
(0.025)\end{array}$ & $\begin{array}{l}-0.030 \\
(0.025)\end{array}$ & $\begin{array}{l}-0.031 \\
(0.024)\end{array}$ & $\begin{array}{l}-0.004 \\
(0.029)\end{array}$ & $\begin{array}{l}-0.005 \\
(0.029)\end{array}$ & $\begin{array}{l}-0.005 \\
(0.029)\end{array}$ \\
\hline Xconst $(t-1)$ & $\begin{array}{c}0.001 \\
(0.002)\end{array}$ & $\begin{array}{c}0.000 \\
(0.001)\end{array}$ & $\begin{array}{l}-0.000 \\
(0.002)\end{array}$ & $\begin{array}{c}0.001 \\
(0.002)\end{array}$ & $\begin{array}{c}0.000 \\
(0.002)\end{array}$ & $\begin{array}{c}0.000 \\
(0.002)\end{array}$ & $\begin{array}{l}-0.000 \\
(0.002)\end{array}$ & $\begin{array}{l}-0.000 \\
(0.002)\end{array}$ & $\begin{array}{c}0.000 \\
(0.002)\end{array}$ & $\begin{array}{c}0.000 \\
(0.002)\end{array}$ \\
\hline Constant & $\begin{array}{c}0.735^{* * *} \\
(0.203) \\
\end{array}$ & $\begin{array}{c}0.375 \\
(0.235) \\
\end{array}$ & $\begin{array}{c}0.550^{* *} \\
(0.263)\end{array}$ & $\begin{array}{c}0.346 \\
(0.236) \\
\end{array}$ & $\begin{array}{c}0.535^{* *} \\
(0.206)\end{array}$ & $\begin{array}{c}0.526 * * \\
(0.208)\end{array}$ & $\begin{array}{c}0.535^{* *} \\
(0.218)\end{array}$ & $\begin{array}{l}0.403^{*} \\
(0.237) \\
\end{array}$ & $\begin{array}{l}0.407^{*} \\
(0.239) \\
\end{array}$ & $\begin{array}{c}0.402 \\
(0.240) \\
\end{array}$ \\
\hline Observations & 985 & 1,038 & 980 & 995 & 874 & 874 & 874 & 1,038 & 1,038 & 1,038 \\
\hline No. of countries & 34 & 32 & 31 & 31 & 28 & 28 & 28 & 32 & 32 & 32 \\
\hline R-squared & 0.195 & 0.159 & 0.179 & 0.139 & 0.166 & 0.163 & 0.166 & 0.153 & 0.152 & 0.153 \\
\hline Country FE & YES & YES & YES & YES & YES & YES & YES & YES & YES & YES \\
\hline Period FE & YES & YES & YES & YES & YES & YES & YES & YES & YES & YES \\
\hline
\end{tabular}


Table 6.6: Reforms and within component

\begin{tabular}{|c|c|c|c|c|c|c|c|c|c|c|}
\hline $\begin{array}{l}\text { Dependent variable } \\
\text { Within }\end{array}$ & (1) & (2) & (3) & (4) & (5) & (6) & (7) & (8) & (9) & (10) \\
\hline \multicolumn{11}{|l|}{ Real sector reforms } \\
\hline Trade(t-1) & $\begin{array}{c}0.028^{* * *} \\
(0.010)\end{array}$ & & & & & & & & & \\
\hline Current_account(t-1) & & $\begin{array}{l}0.027 * * \\
(0.011)\end{array}$ & & & & & & & & \\
\hline Agriculture(t-1) & & & $\begin{array}{c}0.003 \\
(0.007)\end{array}$ & & & & & & & \\
\hline Network(t-1) & & & & $\begin{array}{c}0.022^{* * *} \\
(0.008)\end{array}$ & & & & & & \\
\hline \multicolumn{11}{|l|}{ Financial sector reforms } \\
\hline Domestic_finance(t-1) & & & & & $\begin{array}{c}0.025^{* * *} \\
(0.008)\end{array}$ & & & & & \\
\hline Banking $(\mathrm{t}-1)$ & & & & & & $\begin{array}{c}0.023^{* * *} \\
(0.008)\end{array}$ & & & & \\
\hline Securities $(\mathrm{t}-1)$ & & & & & & & $\begin{array}{c}0.025^{* * *} \\
(0.008)\end{array}$ & & & \\
\hline Capital(t-1) & & & & & & & & $\begin{array}{l}0.020^{*} \\
(0.010)\end{array}$ & & \\
\hline Capital_resident(t-1) & & & & & & & & & $\begin{array}{l}0.010 \\
(0.008)\end{array}$ & \\
\hline Capital_nonresident(t-1) & & & & & & & & & & $\begin{array}{c}0.019^{* *} \\
(0.009) \\
\end{array}$ \\
\hline LNProd(t-1) & $\begin{array}{c}-0.069 * * * \\
(0.015)\end{array}$ & $\begin{array}{c}-0.040 * * \\
(0.019)\end{array}$ & $\begin{array}{l}-0.033 \\
(0.021)\end{array}$ & $\begin{array}{l}-0.025 \\
(0.017)\end{array}$ & $\begin{array}{c}-0.044^{* * * *} \\
(0.012)\end{array}$ & $\begin{array}{c}-0.043 * * * \\
(0.012)\end{array}$ & $\begin{array}{c}-0.044 * * * \\
(0.013)\end{array}$ & $\begin{array}{c}-0.038^{* *} \\
(0.017)\end{array}$ & $\begin{array}{l}-0.036^{*} \\
(0.018)\end{array}$ & $\begin{array}{r}-0.037^{* *} \\
(0.017)\end{array}$ \\
\hline Constant & $\begin{array}{c}0.690^{* * *} \\
(0.147)\end{array}$ & $\begin{array}{c}0.397 * * \\
(0.187)\end{array}$ & $\begin{array}{c}0.340 \\
(0.212)\end{array}$ & $\begin{array}{l}0.259 \\
(0.171)\end{array}$ & $\begin{array}{c}0.445^{* * *} \\
(0.125)\end{array}$ & $\begin{array}{c}0.440^{* * *} \\
(0.123)\end{array}$ & $\begin{array}{c}0.446 * * * \\
(0.136)\end{array}$ & $\begin{array}{c}0.381 * * \\
(0.173)\end{array}$ & $\begin{array}{c}0.374 * * \\
(0.181)\end{array}$ & $\begin{array}{c}0.374^{* *} \\
(0.173)\end{array}$ \\
\hline Observations & 1,025 & 1,075 & 1,034 & 1,051 & 913 & 913 & 913 & 1,075 & 1,075 & 1,075 \\
\hline Number of countries & 34 & 32 & 31 & 31 & 28 & 28 & 28 & 32 & 32 & 32 \\
\hline R-squared & 0.196 & 0.162 & 0.164 & 0.131 & 0.165 & 0.164 & 0.166 & 0.157 & 0.155 & 0.157 \\
\hline Country FE & YES & YES & YES & YES & YES & YES & YES & YES & YES & YES \\
\hline Period FE & YES & YES & YES & YES & YES & YES & YES & YES & YES & YES \\
\hline
\end{tabular}


Table 6.7: Reforms and structural change

\begin{tabular}{|c|c|c|c|c|c|c|c|c|c|c|}
\hline $\begin{array}{l}\text { Dependent variable } \\
\text { Between component }\end{array}$ & (1) & (2) & (3) & (4) & (5) & (6) & (7) & (8) & (9) & (10) \\
\hline \multicolumn{11}{|l|}{ Real sector reforms } \\
\hline Trade(t-1) & $\begin{array}{l}-0.004 \\
(0.006)\end{array}$ & & & & & & & & & \\
\hline Current_account $(\mathrm{t}-1)$ & & $\begin{array}{c}0.001 \\
(0.006)\end{array}$ & & & & & & & & \\
\hline Agriculture(t-1) & & & $\begin{array}{c}0.003 \\
(0.005)\end{array}$ & & & & & & & \\
\hline Network(t-1) & & & & $\begin{array}{l}-0.003 \\
(0.006)\end{array}$ & & & & & & \\
\hline \multicolumn{11}{|l|}{ Financial sector reforms } \\
\hline Domestic_finance(t-1) & & & & & $\begin{array}{l}-0.003 \\
(0.006)\end{array}$ & & & & & \\
\hline Banking(t-1) & & & & & & $\begin{array}{l}-0.003 \\
(0.006)\end{array}$ & & & & \\
\hline Securities(t-1) & & & & & & & $\begin{array}{l}-0.003 \\
(0.006)\end{array}$ & & & \\
\hline Capital(t-1) & & & & & & & & $\begin{array}{l}-0.006 \\
(0.008)\end{array}$ & & \\
\hline Capital_resident(t-1) & & & & & & & & & $\begin{array}{l}-0.003 \\
(0.006)\end{array}$ & \\
\hline Capital_nonresident(t-1) & & & & & & & & & & $\begin{array}{l}-0.006 \\
(0.007)\end{array}$ \\
\hline LNProd(t-1) & $\begin{array}{l}-0.029 \\
(0.056)\end{array}$ & $\begin{array}{l}-0.004 \\
(0.049)\end{array}$ & $\begin{array}{l}-0.014 \\
(0.053)\end{array}$ & $\begin{array}{l}-0.017 \\
(0.051)\end{array}$ & $\begin{array}{l}-0.045 \\
(0.061)\end{array}$ & $\begin{array}{l}-0.045 \\
(0.061)\end{array}$ & $\begin{array}{l}-0.045 \\
(0.061)\end{array}$ & $\begin{array}{l}-0.009 \\
(0.049)\end{array}$ & $\begin{array}{l}-0.007 \\
(0.049)\end{array}$ & $\begin{array}{l}-0.007 \\
(0.047)\end{array}$ \\
\hline Constant & $\begin{array}{l}-0.029 \\
(0.056)\end{array}$ & $\begin{array}{l}-0.004 \\
(0.049)\end{array}$ & $\begin{array}{l}-0.014 \\
(0.053)\end{array}$ & $\begin{array}{l}-0.017 \\
(0.051)\end{array}$ & $\begin{array}{l}-0.045 \\
(0.061)\end{array}$ & $\begin{array}{l}-0.045 \\
(0.061)\end{array}$ & $\begin{array}{l}-0.045 \\
(0.061)\end{array}$ & $\begin{array}{l}-0.009 \\
(0.049) \\
\end{array}$ & $\begin{array}{l}-0.007 \\
(0.049)\end{array}$ & $\begin{array}{l}-0.007 \\
(0.047)\end{array}$ \\
\hline Observations & 1,025 & 1,075 & 1,034 & 1,051 & 913 & 913 & 913 & 1,075 & 1,075 & 1,075 \\
\hline Number of countries & 34 & 32 & 31 & 31 & 28 & 28 & 28 & 32 & 32 & 32 \\
\hline R-squared & 0.081 & 0.079 & 0.079 & 0.078 & 0.075 & 0.075 & 0.075 & 0.081 & 0.080 & 0.082 \\
\hline Country FE & YES & YES & YES & YES & YES & YES & YES & YES & YES & YES \\
\hline Period FE & YES & YES & YES & YES & YES & YES & YES & YES & YES & YES \\
\hline
\end{tabular}

Table 6.8: Decomposition

\begin{tabular}{lccc}
\hline & Within component & (structural change) & Total \\
\hline Real sector reforms & & & \\
Trade & $+87.5^{* * *}$ & $|-12.5|$ & 100 \\
Current_account & $+96.4^{* *}$ & +3.6 & 100 \\
Agriculture & +50.0 & +50.0 & 100 \\
Network & $+88.0^{* * *}$ & $|-12.0|$ & 100 \\
Financial sector reforms & & & \\
Domestic_finance & $+89.3^{* * *}$ & $|-10.7|$ & 100 \\
Banking & $+88.5^{* * *}$ & $|-11.5|$ & 100 \\
Securities & $+89.3^{* * *}$ & $|-10.7|$ & 100 \\
Capital & $+76.9^{*}$ & $|-23.1|$ & 100 \\
Capital_resident & +76.9 & $|-23.1|$ & 100 \\
Capital_nonresident & $+76.0 * *$ & $|-24.0|$ & 100 \\
\hline
\end{tabular}


Table 6.9: Reforms and labor productivity growth with distance to the technological frontier

\begin{tabular}{|c|c|c|c|c|c|c|c|c|c|c|}
\hline Dependent variable & (1) & (2) & (3) & (4) & (5) & (6) & (7) & (8) & (9) & $(10)$ \\
\hline Dist_front $(\mathrm{t}-1)$ & $\begin{array}{c}-0.797 * * * \\
(0.180)\end{array}$ & $\begin{array}{c}-0.381 * \\
(0.206)\end{array}$ & $\begin{array}{l}-0.469 \\
(0.279)\end{array}$ & $\begin{array}{l}-0.357 \\
(0.217)\end{array}$ & $\begin{array}{c}-0.529 * * * \\
(0.139)\end{array}$ & $\begin{array}{c}-0.527 * * * \\
(0.140)\end{array}$ & $\begin{array}{c}-0.515^{* * *} \\
(0.135)\end{array}$ & $\begin{array}{l}-0.383 \\
(0.226)\end{array}$ & $\begin{array}{c}-0.420^{*} \\
(0.228)\end{array}$ & $\begin{array}{l}-0.376 \\
(0.239)\end{array}$ \\
\hline \multicolumn{11}{|l|}{ Real sector reforms } \\
\hline Trade $(\mathrm{t}-1)$ & $\begin{array}{c}0.138 \\
(0.091)\end{array}$ & & & & & & & & & \\
\hline Dist_front $(\mathrm{t}-1) * \operatorname{Trade}(\mathrm{t}-1)$ & $\begin{array}{l}-0.154 \\
(0.111)\end{array}$ & & & & & & & & & \\
\hline Current_account(t-1) & & $\begin{array}{c}0.313^{* * *} \\
(0.110)\end{array}$ & & & & & & & & \\
\hline Dist_front $(\mathrm{t}-1) *$ Current_account $(\mathrm{t}-1)$ & & $\begin{array}{c}-0.361 * * * \\
(0.128)\end{array}$ & & & & & & & & \\
\hline Agriculture(t-1) & & & $\begin{array}{c}0.124 \\
(0.086)\end{array}$ & & & & & & & \\
\hline Dist_front $(\mathrm{t}-1)^{*}$ Agriculture $(\mathrm{t}-1)$ & & & $\begin{array}{l}-0.152 \\
(0.097)\end{array}$ & & & & & & & \\
\hline Network(t-1) & & & & $\begin{array}{c}0.152 \\
(0.243)\end{array}$ & & & & & & \\
\hline Dist_front $(\mathrm{t}-1) * \operatorname{Network}(\mathrm{t}-1)$ & & & & $\begin{array}{l}-0.165 \\
(0.280)\end{array}$ & & & & & & \\
\hline
\end{tabular}

\section{Financial sector reforms}

Domestic_finance(t-1)

Dist_front $(\mathrm{t}-1) *$ Domestic_finance(t-1)

$0.279 * * *$

$(0.087)$

$-0.322 * * *$

$(0.103)$

Banking(t-1)

Dist_front $(\mathrm{t}-1) * \operatorname{Banking}(\mathrm{t}-1)$

Securities(t-1)

Dist_front $(\mathrm{t}-1) * \operatorname{Securities}(\mathrm{t}-1)$

Capital(t-1)

Dist_front $(\mathrm{t}-1) *$ Capital $(\mathrm{t}-1)$

Capital_resident $(\mathrm{t}-1)$

Dist_front(t-1)*Capital_resident(t-1)

$0.255^{* * *}$

(0.083)

$-0.297 * * *$

(0.098)

$0.338^{* * *}$

(0.097)

$-0.380 * * *$

(0.113)

0.282

(0.209)

$-0.332$

(0.241)

(0.148)

$-0.233$

(0.172)

Capital_nonresident(t-1)

Dist_front $(\mathrm{t}-1) *$ Capital_nonresident(t-1)

\begin{tabular}{|c|c|c|c|c|c|c|c|c|c|c|}
\hline Constant & $\begin{array}{c}0.721 * * * \\
(0.162)\end{array}$ & $\begin{array}{l}0.354^{*} \\
(0.185) \\
\end{array}$ & $\begin{array}{l}0.436^{*} \\
(0.255) \\
\end{array}$ & $\begin{array}{c}0.324 \\
(0.197) \\
\end{array}$ & $\begin{array}{c}0.484 * * * \\
(0.127)\end{array}$ & $\begin{array}{c}0.483^{* * *} \\
(0.128) \\
\end{array}$ & $\begin{array}{c}0.468^{* * *} \\
(0.121)\end{array}$ & $\begin{array}{l}0.356^{*} \\
(0.202) \\
\end{array}$ & $\begin{array}{l}0.388^{*} \\
(0.204) \\
\end{array}$ & $\begin{array}{r}0.350 \\
(0.214) \\
\end{array}$ \\
\hline Observations & 983 & 1,032 & 991 & 1,008 & 871 & 871 & 871 & 1,032 & 1,032 & 1,032 \\
\hline No. of countries & 33 & 31 & 29 & 29 & 27 & 27 & 27 & 31 & 31 & 31 \\
\hline R-squared & 0.202 & 0.177 & 0.174 & 0.130 & 0.169 & 0.168 & 0.173 & 0.165 & 0.162 & 0.163 \\
\hline Country FE & YES & YES & YES & YES & YES & YES & YES & YES & YES & YES \\
\hline Period FE & YES & YES & YES & YES & YES & YES & YES & YES & YES & YES \\
\hline
\end{tabular}


Table 6.10: Reforms and within effect with distance to the technological frontier

\begin{tabular}{|c|c|c|c|c|c|c|c|c|c|c|}
\hline $\begin{array}{l}\text { Dependent variable } \\
\text { Within }\end{array}$ & (1) & (2) & (3) & (4) & (5) & (6) & (7) & (8) & (9) & (10) \\
\hline Dist_front & $\begin{array}{c}-0.853^{* * * *} \\
(0.190)\end{array}$ & $\begin{array}{l}-0.409^{*} \\
(0.224)\end{array}$ & $\begin{array}{l}-0.485 \\
(0.294)\end{array}$ & $\begin{array}{l}-0.363 \\
(0.224)\end{array}$ & $\begin{array}{c}-0.564^{* * * *} \\
(0.131)\end{array}$ & $\begin{array}{c}-0.562^{* * * *} \\
(0.133)\end{array}$ & $\begin{array}{c}-0.556 * * * \\
(0.124)\end{array}$ & $\begin{array}{l}-0.382 \\
(0.229)\end{array}$ & $\begin{array}{l}-0.426^{*} \\
(0.234)\end{array}$ & $\begin{array}{l}-0.362 \\
(0.238)\end{array}$ \\
\hline \multicolumn{11}{|l|}{ Real sector reforms } \\
\hline Trade $(\mathrm{t}-1)$ & $\begin{array}{c}0.055 \\
(0.095)\end{array}$ & & & & & & & & & \\
\hline Dist_front $(\mathrm{t}-1) * \operatorname{Trade}(\mathrm{t}-1)$ & $\begin{array}{l}-0.047 \\
(0.112)\end{array}$ & & & & & & & & & \\
\hline Current_account $(\mathrm{t}-1)$ & & $\begin{array}{l}0.243^{* *} \\
(0.099)\end{array}$ & & & & & & & & \\
\hline Dist_front $(\mathrm{t}-1) *$ Current_account $(\mathrm{t}-1)$ & & $\begin{array}{c}-0.276^{* *} \\
(0.117)\end{array}$ & & & & & & & & \\
\hline Agriculture(t-1) & & & $\begin{array}{c}0.034 \\
(0.066)\end{array}$ & & & & & & & \\
\hline Dist_front $(\mathrm{t}-1) *$ Agriculture $(\mathrm{t}-1)$ & & & $\begin{array}{l}-0.046 \\
(0.075)\end{array}$ & & & & & & & \\
\hline Network(t-1) & & & & $\begin{array}{c}0.162 \\
(0.172)\end{array}$ & & & & & & \\
\hline Dist_front $(\mathrm{t}-1) * \operatorname{Network}(\mathrm{t}-1)$ & & & & $\begin{array}{l}-0.173 \\
(0.201)\end{array}$ & & & & & & \\
\hline \multicolumn{11}{|l|}{ Financial sector reforms } \\
\hline Domestic_finance(t-1) & & & & & $\begin{array}{c}0.212 * * * \\
(0.076)\end{array}$ & & & & & \\
\hline Dist_front $(\mathrm{t}-1) *$ Domestic_finance $(\mathrm{t}-1)$ & & & & & $\begin{array}{c}-0.238^{* *} \\
(0.088)\end{array}$ & & & & & \\
\hline Banking(t-1) & & & & & & $\begin{array}{c}0.192^{* *} \\
(0.073)\end{array}$ & & & & \\
\hline Dist_front $(\mathrm{t}-1) *$ Banking $(\mathrm{t}-1)$ & & & & & & $\begin{array}{c}-0.217^{* *} \\
(0.085)\end{array}$ & & & & \\
\hline Securities $(\mathrm{t}-1)$ & & & & & & & $\begin{array}{c}0.273 * * * \\
(0.092)\end{array}$ & & & \\
\hline Dist_front $(\mathrm{t}-1) * \operatorname{Securities}(\mathrm{t}-1)$ & & & & & & & $\begin{array}{c}-0.300^{* * *} \\
(0.106)\end{array}$ & & & \\
\hline Capital(t-1) & & & & & & & & $\begin{array}{c}0.284 \\
(0.187)\end{array}$ & & \\
\hline Dist_front $(\mathrm{t}-1)^{*}$ Capital(t-1) & & & & & & & & $\begin{array}{l}-0.328 \\
(0.216)\end{array}$ & & \\
\hline Capital_resident(t-1) & & & & & & & & & $\begin{array}{c}0.179 \\
(0.118)\end{array}$ & \\
\hline Dist_front $(\mathrm{t}-1) *$ Capital_resident $(\mathrm{t}-1)$ & & & & & & & & & $\begin{array}{l}-0.210 \\
(0.139)\end{array}$ & \\
\hline Capital_nonresident(t-1) & & & & & & & & & & $\begin{array}{r}0.276 \\
(0.188)\end{array}$ \\
\hline Dist_front $(\mathrm{t}-1) *$ Capital_nonresident $(\mathrm{t}-1)$ & & & & & & & & & & $\begin{array}{l}-0.319 \\
(0.217)\end{array}$ \\
\hline Constant & $\begin{array}{c}0.766^{* * *} \\
(0.172) \\
\end{array}$ & $\begin{array}{l}0.380^{*} \\
(0.200)\end{array}$ & $\begin{array}{c}0.449 \\
(0.268)\end{array}$ & $\begin{array}{c}0.333 \\
(0.204)\end{array}$ & $\begin{array}{c}0.517 * * * \\
(0.119) \\
\end{array}$ & $\begin{array}{c}0.515^{* * *} \\
(0.121) \\
\end{array}$ & $\begin{array}{c}0.506^{* * *} \\
(0.112)\end{array}$ & $\begin{array}{l}0.357 * \\
(0.204)\end{array}$ & $\begin{array}{l}0.395^{*} \\
(0.210)\end{array}$ & $\begin{array}{r}0.340 \\
(0.213)\end{array}$ \\
\hline Observations & 983 & 1,032 & 991 & 1,008 & 871 & 871 & 871 & 1,032 & 1,032 & 1,032 \\
\hline $\mathrm{Nb}$ countries & 33 & 31 & 29 & 29 & 27 & 27 & 27 & 31 & 31 & 31 \\
\hline R-squared & 0.203 & 0.174 & 0.173 & 0.134 & 0.177 & 0.175 & 0.181 & 0.169 & 0.164 & 0.169 \\
\hline Country FE & YES & YES & YES & YES & YES & YES & YES & YES & YES & YES \\
\hline Period FE & YES & YES & YES & YES & YES & YES & YES & YES & YES & YES \\
\hline
\end{tabular}


Table 6.11: Reforms and structural change with distance to the technological frontier

\begin{tabular}{|c|c|c|c|c|c|c|c|c|c|c|}
\hline $\begin{array}{l}\text { Dependent variable } \\
\text { Structural change }\end{array}$ & (1) & $(2)$ & (3) & (4) & (5) & (6) & (7) & (8) & (9) & $(10)$ \\
\hline Dist_front & $\begin{array}{c}0.055 \\
(0.065)\end{array}$ & $\begin{array}{c}0.028 \\
(0.053)\end{array}$ & $\begin{array}{l}0.015 \\
(0.064)\end{array}$ & $\begin{array}{c}0.006 \\
(0.064)\end{array}$ & $\begin{array}{c}0.035 \\
(0.067)\end{array}$ & $\begin{array}{c}0.035 \\
(0.067)\end{array}$ & $\begin{array}{c}0.041 \\
(0.067)\end{array}$ & $\begin{array}{l}-0.001 \\
(0.049)\end{array}$ & $\begin{array}{c}0.006 \\
(0.053)\end{array}$ & $\begin{array}{l}-0.014 \\
(0.045)\end{array}$ \\
\hline \multicolumn{11}{|l|}{ Real sector reforms } \\
\hline Trade $(\mathrm{t}-1)$ & $\begin{array}{l}0.083^{*} \\
(0.045)\end{array}$ & & & & & & & & & \\
\hline Dist_front $(\mathrm{t}-1) * \operatorname{Trade}(\mathrm{t}-1)$ & $\begin{array}{l}-0.107 * \\
(0.054)\end{array}$ & & & & & & & & & \\
\hline Current_account(t-1) & & $\begin{array}{c}0.070 \\
(0.041)\end{array}$ & & & & & & & & \\
\hline Dist_front $(\mathrm{t}-1) *$ Current_account $(\mathrm{t}-1)$ & & $\begin{array}{r}-0.086^{*} \\
(0.048)\end{array}$ & & & & & & & & \\
\hline Agriculture(t-1) & & & $\begin{array}{l}0.089 * \\
(0.046)\end{array}$ & & & & & & & \\
\hline Dist_front $(\mathrm{t}-1)^{*}$ Agriculture(t-1) & & & $\begin{array}{r}-0.105^{*} \\
(0.053)\end{array}$ & & & & & & & \\
\hline Network(t-1) & & & & $\begin{array}{l}-0.010 \\
(0.125)\end{array}$ & & & & & & \\
\hline Dist_front $(\mathrm{t}-1) * \operatorname{Network}(\mathrm{t}-1)$ & & & & $\begin{array}{c}0.008 \\
(0.145)\end{array}$ & & & & & & \\
\hline Financial sector reforms & & & & & & & & & & \\
\hline Domestic_finance(t-1) & & & & & $\begin{array}{c}0.066 \\
(0.041)\end{array}$ & & & & & \\
\hline Dist_front $(\mathrm{t}-1) *$ Domestic_finance $(\mathrm{t}-1)$ & & & & & $\begin{array}{l}-0.084 \\
(0.050)\end{array}$ & & & & & \\
\hline Banking(t-1) & & & & & & $\begin{array}{c}0.063 \\
(0.037)\end{array}$ & & & & \\
\hline Dist_front $(\mathrm{t}-1) *$ Banking $(\mathrm{t}-1)$ & & & & & & $\begin{array}{l}-0.080^{*} \\
(0.045)\end{array}$ & & & & \\
\hline Securities $(\mathrm{t}-1)$ & & & & & & & $\begin{array}{c}0.066 \\
(0.050)\end{array}$ & & & \\
\hline Dist_front $(\mathrm{t}-1) *$ Securities $(\mathrm{t}-1)$ & & & & & & & $\begin{array}{l}-0.080 \\
(0.059)\end{array}$ & & & \\
\hline Capital(t-1) & & & & & & & & $\begin{array}{l}-0.002 \\
(0.065)\end{array}$ & & \\
\hline Dist_front(t-1)*Capital(t-1) & & & & & & & & $\begin{array}{l}-0.003 \\
(0.073)\end{array}$ & & \\
\hline Capital_resident(t-1) & & & & & & & & & $\begin{array}{c}0.017 \\
(0.058)\end{array}$ & \\
\hline Dist_front $(\mathrm{t}-1)^{*}$ Capital_resident $(\mathrm{t}-1)$ & & & & & & & & & $\begin{array}{l}-0.023 \\
(0.066)\end{array}$ & \\
\hline Capital_nonresident(t-1) & & & & & & & & & & $\begin{array}{l}-0.024 \\
(0.057)\end{array}$ \\
\hline Dist_front $(\mathrm{t}-1) *$ Capital_nonresident $(\mathrm{t}-1)$ & & & & & & & & & & $\begin{array}{r}0.022 \\
(0.065)\end{array}$ \\
\hline Constant & $\begin{array}{l}-0.045 \\
(0.059)\end{array}$ & $\begin{array}{l}-0.025 \\
(0.048)\end{array}$ & $\begin{array}{l}-0.014 \\
(0.058)\end{array}$ & $\begin{array}{l}-0.008 \\
(0.058)\end{array}$ & $\begin{array}{l}-0.032 \\
(0.061)\end{array}$ & $\begin{array}{l}-0.032 \\
(0.061)\end{array}$ & $\begin{array}{l}-0.039 \\
(0.061)\end{array}$ & $\begin{array}{l}-0.001 \\
(0.044)\end{array}$ & $\begin{array}{l}-0.008 \\
(0.048)\end{array}$ & $\begin{array}{c}0.011 \\
(0.041)\end{array}$ \\
\hline Observations & 983 & 1,032 & 991 & 1,008 & 871 & 871 & 871 & 1,032 & 1,032 & 1,032 \\
\hline $\mathrm{Nb}$ countries & 33 & 31 & 29 & 29 & 27 & 27 & 27 & 31 & 31 & 31 \\
\hline R-squared & 0.091 & 0.088 & 0.092 & 0.080 & 0.085 & 0.085 & 0.083 & 0.083 & 0.082 & 0.085 \\
\hline Country FE & YES & YES & YES & YES & YES & YES & YES & YES & YES & YES \\
\hline Period FE & YES & YES & YES & YES & YES & YES & YES & YES & YES & YES \\
\hline
\end{tabular}


Table 6.12: Reforms and 5-years growth of labor productivity

\begin{tabular}{|c|c|c|c|c|c|c|c|c|c|c|}
\hline $\begin{array}{l}\text { Dependent variable } \\
\operatorname{LnProd}(t)-\operatorname{LnProd}(t-5)\end{array}$ & (1) & (2) & (3) & (4) & (5) & (6) & (7) & (8) & (9) & $(10)$ \\
\hline \multicolumn{11}{|l|}{ Real sector reforms } \\
\hline Trade $(\mathrm{t}-5)$ & $\begin{array}{l}0.226 * * * \\
(0.0674)\end{array}$ & & & & & & & & & \\
\hline Current Account(t-5) & & $\begin{array}{l}0.236 * * * \\
(0.0587)\end{array}$ & & & & & & & & \\
\hline Agriculture(t-5) & & & $\begin{array}{c}0.0685 \\
(0.0551)\end{array}$ & & & & & & & \\
\hline Network(t-5) & & & & $\begin{array}{l}0.156^{* * *} \\
(0.0463)\end{array}$ & & & & & & \\
\hline \multicolumn{11}{|l|}{ Financial sector reforms } \\
\hline Domestic Finance(t-5) & & & & & $\begin{array}{l}0.191 * * * \\
(0.0517)\end{array}$ & & & & & \\
\hline Banking(t-5) & & & & & & $\begin{array}{l}0.179 * * * \\
(0.0514)\end{array}$ & & & & \\
\hline Securities $(t-5)$ & & & & & & & $\begin{array}{l}0.189 * * * \\
(0.0438)\end{array}$ & & & \\
\hline Capital(t-5) & & & & & & & & $\begin{array}{l}0.183^{* * *} \\
(0.0456)\end{array}$ & & \\
\hline Capital Resident(t-5) & & & & & & & & & $\begin{array}{l}0.169^{* * *} \\
(0.0501)\end{array}$ & \\
\hline Capital nonresident(t-5) & & & & & & & & & & $\begin{array}{l}0.117 * * \\
(0.0429) \\
\end{array}$ \\
\hline LNProd(t-5) & $\begin{array}{l}-0.254 * * * \\
(0.0759)\end{array}$ & $\begin{array}{l}-0.176^{*} \\
(0.101)\end{array}$ & $\begin{array}{l}-0.103 \\
(0.106)\end{array}$ & $\begin{array}{l}-0.0897 \\
(0.0955)\end{array}$ & $\begin{array}{r}-0.194 * * \\
(0.0873)\end{array}$ & $\begin{array}{l}-0.189 * * \\
(0.0871)\end{array}$ & $\begin{array}{l}-0.193 * * \\
(0.0916)\end{array}$ & $\begin{array}{c}-0.148 \\
(0.0910)\end{array}$ & $\begin{array}{c}-0.139 \\
(0.0935)\end{array}$ & $\begin{array}{l}-0.136 \\
(0.100)\end{array}$ \\
\hline Constant & $\begin{array}{c}2.466^{* * * *} \\
(0.776) \\
\end{array}$ & $\begin{array}{c}1.658 \\
(1.021) \\
\end{array}$ & $\begin{array}{c}1.027 \\
(1.088) \\
\end{array}$ & $\begin{array}{r}0.899 \\
(0.971) \\
\end{array}$ & $\begin{array}{l}1.918^{* *} \\
(0.889)\end{array}$ & $\begin{array}{l}1.876^{* *} \\
(0.887)\end{array}$ & $\begin{array}{l}1.903^{*} \\
(0.930) \\
\end{array}$ & $\begin{array}{r}1.437 \\
(0.934) \\
\end{array}$ & $\begin{array}{r}1.342 \\
(0.962) \\
\end{array}$ & $\begin{array}{r}1.362 \\
(1.017) \\
\end{array}$ \\
\hline Observations & 213 & 214 & 206 & 209 & 186 & 186 & 186 & 214 & 214 & 214 \\
\hline R-squared & 0.475 & 0.467 & 0.393 & 0.329 & 0.389 & 0.384 & 0.394 & 0.434 & 0.429 & 0.417 \\
\hline
\end{tabular}

Table 6.13: Decomposition for the 5-year growth of labor productivity

\begin{tabular}{|c|c|c|c|}
\hline & Within component & Structural change & Total \\
\hline \multicolumn{4}{|l|}{ Real sector reforms } \\
\hline Trade & $|+81|^{* * *}$ & 19 & 100 \\
\hline Agriculture & 98 & $|-2|$ & 100 \\
\hline Network & $|+86|^{* * *}$ & $|14|$ & 100 \\
\hline \multicolumn{4}{|c|}{ Financial sector reforms } \\
\hline Banking & $|+94|$ & $|6|$ & 100 \\
\hline Securities & $|99.5|^{* * *}$ & 0.5 & 100 \\
\hline Capital & $|+97| * * *$ & $|-3|$ & 100 \\
\hline Capital_resident & $|+90|^{* * *}$ & 10 & 100 \\
\hline Capital_nonresident & $|+84|^{* * *}$ & $|-16|$ & 100 \\
\hline
\end{tabular}


Figure 6.3: Agricultural reforms and productivity

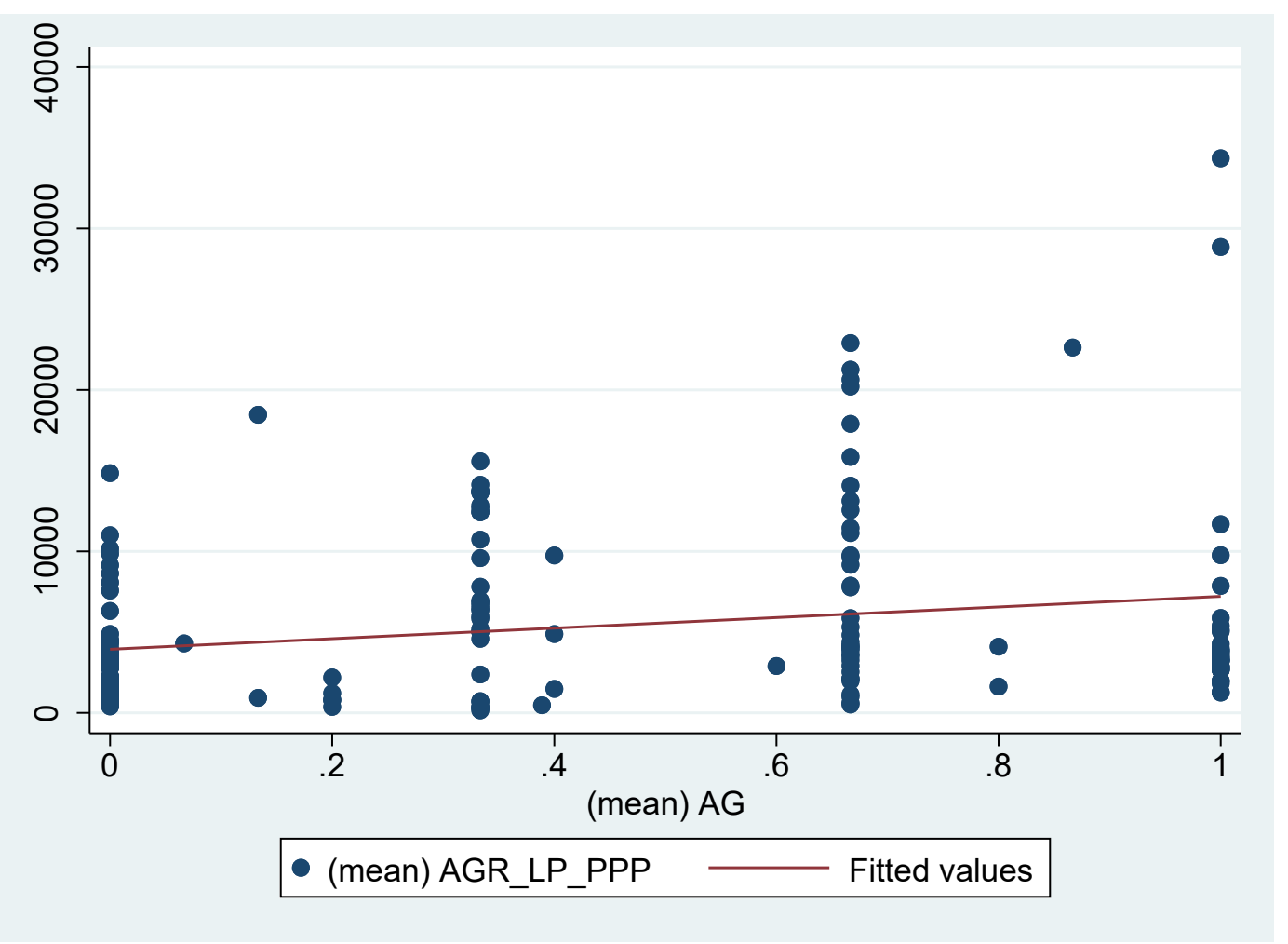

Table 6.14: Reforms and sectoral productivity growth

\begin{tabular}{lccc}
\hline & Agriculture & Industry & Services \\
\hline Real Sector Reforms & & & \\
Trade & 0.00451 & $0.00962^{*}$ & $0.0101^{*}$ \\
& $(0.00387)$ & $(0.00550)$ & $(0.00538)$ \\
Current Account & 0.00680 & 0.00857 & $0.0131^{* *}$ \\
& $(0.00467)$ & $(0.00515)$ & $(0.00555)$ \\
Agriculture & 0.000685 & 0.00140 & 0.00329 \\
& $(0.00286)$ & $(0.00458)$ & $(0.00354)$ \\
Network & -0.000378 & $0.00748^{* *}$ & $0.0118^{* * *}$ \\
& $(0.00258)$ & $(0.00328)$ & $(0.00397)$ \\
Financial Sector Reforms & & & \\
Domestic Finance & 0.00490 & $0.00673^{*}$ & $0.0104^{* * *}$ \\
& $(0.00311)$ & $(0.00369)$ & $(0.00371)$ \\
Banking & 0.00478 & 0.00566 & $0.00985^{* *}$ \\
& $(0.00315)$ & $(0.00382)$ & $(0.00367)$ \\
Securities & 0.00370 & $0.00939^{* * *}$ & $0.00932^{* * *}$ \\
& $(0.00274)$ & $(0.00322)$ & $(0.00335)$ \\
Capital & 0.00246 & 0.00442 & 0.00744 \\
& $(0.00390)$ & $(0.00419)$ & $(0.00461)$ \\
Capital Resident & 0.000737 & 0.00290 & 0.00375 \\
Capital Non-Residents & $(0.00306)$ & $(0.00401)$ & $(0.00441)$ \\
& 0.00268 & 0.00236 & $0.00766^{*}$ \\
& $(0.00349)$ & $(0.00438)$ & $(0.00425)$ \\
\hline
\end{tabular}




\section{Chapter 7: Conclusion}




\subsection{Empirical Findings}

\subsubsection{Data}

The main purpose of this thesis is to investigate the patterns, causes and (labor market) consequences of structural change in developing countries especially those in Africa. The thesis begins with the premise that the study of structural transformation in Africa is limited by a great statistical problem. These statistical problems produce a considerable amount of uncertainty in our continuous attempt to estimate the effect of structural change on productivity growth and other outcomes in Africa. Building on the existing work of McMillan and Rodrik (2011) and de Vries et al. (2015), we conduct a meticulous study of the statistical sources, methods, statistical reforms, and macroeconomic reforms, such as currency redenomination, to produce a new sectoral database that is used to analyze structural developments in Africa in the rest of the thesis. One clear lesson from the construction of the sectoral database is that while African statistical institutes are improving the production of information on sectoral output, production of data on inputs such as employment, hours worked and sectoral information on capital and Research and Development (R\&D) remains a challenge. The lack of key input data such as sectoral capital and R\&D impair empirical research on structural change (see limitations below).

In general, basic employment information such as the number of people engaged, hours worked, and occupation is severely limited in Africa. While this is the case for most African countries, there are also good practices on the continent. For example, South Africa conducts quarterly labor force surveys with detailed information on sectoral employment, occupation, and hours worked. In most parts of Africa, data on hours worked is mostly missing, an outcome largely due to the high level of informality on the continent. Although the informal sector is significant in Africa, reliable and consistent time series data on informal sector output and employment by sector is still missing from African statistics. Notwithstanding these data limitations, the thesis constructs sectoral indicators on value added and employment that covers both the formal and informal sector and accounts for 80\% of GDP in Africa.

\subsubsection{Patterns of structural change}

Using this database, the thesis further establishes many empirical regularities about the patterns of structural change in Africa. First and foremost, there is a process of de-agriculturalization in Africa, with the employment share of agriculture declining over time. Unlike, the experience of early industrializers in the $19^{\text {th }}$ century where technological progress in manufacturing was the main driver of the de-agriculturalization (i.e. a pull effect), the de-agriculturalization of Africa is linked to marginal improvements in agricultural productivity (i.e. a push effect). The experience of Africa contrasts with the well-established trajectory of economic growth where advances in industrial technology are essential for successful structural transformation at early stages of development.

The employment and value-added shares of agriculture have declined signaling the changing structure of production. However, the service sector is the main recipient of the workers exiting the agricultural sector. While some sub-sectors of services such as business and telecommunication are as dynamic as manufacturing, other sub-sectors such as trade, government and personal services are only marginally more productive than agriculture. Unfortunately, the majority of the reserve army exiting the agricultural sector are moving towards the less dynamic sectors such as domestic trade services, a 
phenomenon we describe as the informal tertiarization of African economies. The premature (informal) tertiarization in Africa means that structural transformation has been weaker than it would have been if resources had shifted to manufacturing or high-tech services.

In contrast to previous studies, our data suggest that the productivity of the service sector is higher than previously estimated (Table 3.2). This is due to the structural undercounting of some highproductivity services sub-sectors, such as telecommunications, business services, and important sectors such as entertainment and the informal sector.

Structural change is also more important than previously estimated (Table 3.3) due again to the undercounting of services in previous data. We have seen a massive exodus of agricultural workers to trade services and a moderate movement to ICT services particularly in tech start-ups. The systematic undercounting resulted in an underestimation of productivity levels, and hence an underestimation of productivity growth due to the reallocation of labor to these services. Aggregate productivity growth due to innovation within sectors comes mainly from manufacturing and agriculture. However, aggregate productivity due to the reallocation of workers arises mainly from trade and business services (see Table A3.5). This suggests that apart from manufacturing, dynamic services such as business services can play a key role in the transformation of African economies. This is beginning to show in the case of East African economies.

Being aware of the importance of regional technological interdependence (spatial externalities) in the process of structural transformation, the thesis makes a departure from the existing literature and studies technological change and technological catch-up within African by considering catch-up with respect to an African technology leader. We do this by using nonparametric methods (Data Envelopment Analysis) and structural methods (shift-share catch-up decomposition) to estimate an African production frontier. We further measure productivity change in Africa and disentangle the change due to general technological progress and catch-up. As shown in Chapter 4, catch-up within Africa is a sector-specific phenomenon. Our analysis shows that Botswana and Mauritius are the only two countries in Africa which have converged to the productivity level as well as the efficiency level of the frontier, with mining and manufacturing being the technological engines of catch-up in these two countries respectively. We explore the special role of technological catch-up by decomposing it into within-sector convergence, between-sector convergence, and initial specialization. The results highlight the special role of structural change in catch-up. The chapter contributes to recent evidence suggesting that countries can climb up the income ladder at a faster rate through a two-pronged transformation - i.e. structural change and technological catch-up.

The thesis further examines the question of premature deindustrialization in Africa. Chapter 5 show that deindustrialization is not the typical experience of most countries in the region. Rather, we observe a process of industrial stagnation where the manufacturing output share for a typical African country has not changed since 1970. We document, however, important regional differences with East Africa industrializing and Southern Africa deindustrializing. Based on this extensive evidence, we argue that the appropriate characterization of the evidence is industrial stagnation not premature deindustrialization.

\subsubsection{Potential causes of structural change}

In addition to the patterns of structural change, the thesis examines the potential drivers of 181 
deindustrialization, a specific phenomenon of structural change. We found that changes in income, technological change and international trade are essential for the industrial development and structural transformation of Africa. In particular, technical progress, through the price-taker mechanism, has had a negative effect on relative manufacturing employment, suggesting that African countries may have imported negative technology effects on employment from abroad. While international trade in general creates more manufacturing jobs than it displaces in Africa, intra-regional trade has played a limited role in the industrial development of the continent. Exchange rate competitiveness and domestic investment also play a significant role in the structural transformation of the Africa.

Several studies have shown that market and institutional frictions lead to a suboptimal allocation of scarce resources across sectors penalizing overall productivity growth (e.g., Bartelsman et al., 2013; Hsieh \& Klenow, 2009; Restuccia \& Rogerson, 2008). Structural reforms are often used to reduce rigidities that exist in markets in developing countries. Chapter 6 of this thesis examines how trade reforms, product market reforms, and financial reforms affect labor productivity growth and its two components - between effect and within effect - in developing countries. The results overwhelmingly show that reforms affect growth in developing countries mostly by inducing within-sector productivity growth but not structural change, further providing empirical support for the argument that many developing countries had structural adjustments programs without structural change (Page, 2012).

\subsubsection{Labor Market Consequences}

The process of informal tertiarization of African economies has not only slowed down productivity growth but has also affected job stability across sectors with attendant consequences on unemployment and income inequality in Africa. Jobs in the services sector are highly volatile compared to manufacturing, increasing uncertainties for a majority of workers. There is a strong shift towards services, with the highest annual job creation in the sector being in wholesale and retail trade services (largely informal) and personal and government services, and only a weak to moderate shift towards dynamic business services due to potentially restrictive opportunities that limit labor absorption into dynamic modern market services. The expansion of these non-tradable services has increased transitory employment since jobs in these sectors are often temporary or part-time in nature, less paid and protected, and have fewer fringe benefits and opportunities for career development. This has increased earnings inequality and stalled the expected poverty reduction associated with structural change because business services which is a high-wage services sector is creating fewer opportunities compared with lower-wage non-tradable services.

The labor market institutional arrangements in many countries in Africa have played a significant role in these outcomes. We find that rigid labor market institutional arrangements in the region discourage job reallocation, making it difficult to reallocate surplus labor into sectors where they could be more productive, penalizing productivity growth as a result.

\subsection{Policy Implications}

The patterns of de-agriculturalization, industrial stagnation, premature tertiarization, and technological trajectories observed are a result of persistent structural disequilibrium in African economies. Therefore, appropriate policies can alter these negative growth paths and mitigate associated costs. The first important policy implication from thesis is that deep and faster structural change is associated 
with a strong manufacturing sector (the case of Mauritius in the 1970s/80s). Countries that have enjoyed sustained growth and structural transformation did not leave industrial development to the whims and caprices of the market. They engaged in active industrial policies. In the past, it was argued that Africa's failed industrialization is due to government failure. Particularly, bad complementary macroeconomic management and inappropriate policy adoption. Therefore, structural adjustment programs were instituted to allow the private sector to drive growth with a resulting marginalization of industrial policy. The outcome of this approach to development is disastrous growth with no significant structural change. With the incoming youth bulge, it is now clear that industrialization is a possible pathway to the structural transformation of Africa. However, this thesis has shown that complementary policies may be key to avoiding the past industrial mistakes. Particularly, job reallocation towards dynamic sectors is restricted by rigid labor market institutions. Encouraging more flexible markets regulations with stricter enforcement and protection for workers could be a potential way of allocating resources efficiently across sectors.

The thesis has further shown that a multi-sector approach to development could also transform African economies. Business services such as ICT, banking, transportation, and healthcare are large scale, capital intensive and technologically dynamic and are an important source of productivity gains in Africa. Much of the productivity gains in East Africa, for example, comes from these services. While manufacturing should be the bedrock of development, evidence in this thesis suggests that modern services could offer significant opportunities for the transformation of African economies.

Results in the thesis imply that domestic income has not been sufficient to generate a manufacturing expansion. The majority of African economies are populated by poor consumers, with the expansion of the market through international trade potentially encouraging manufacturing growth and technological upgrading in African countries. With the low levels of intra-African trade, the Africa Continental Free Trade Agreements (AfCFTA) presents a unique opportunity for industrialization through the promotion of manufacturing exports and a reduction in trade frictions within Africa to expand intra-regional trade.

Another unique implication of the thesis has to do with the diffusion of productive knowledge within Africa to achieve productivity convergence. The spread of African-induced innovations such as Mpesa and Mpedigree has removed impediments to productivity growth within African countries. Since the diffusion of technological knowledge decreases with distance, encouraging the adoption of best practice within Africa can be an important means to encourage productivity convergence within Africa as shown in Chapter 4

Chapter 6 showed that market-oriented reforms work only through a short-term within productivity effect. Reforms have not been successful in inducing long term effects such as a structural change bonus. Therefore, there is a prima facie rationale for active industrial policy and complementary labor market and land reform policies that may help in the efficient allocation of resources across sectors.

\subsection{Limitations and Future research direction}

Though this thesis has contributed significantly to the literature on structural change in developing countries, we also take cognizance of the limitations of the analysis in the thesis. First, the reallocation 
effect may be sensitive to formal and informal transitions. The work of de Vries et al (2015) on the BRICs show that the total reallocation effect comprises a reallocation effect due to the transition between formal and informal sectors (i.e. $R_{i}$ ) and the reallocation between main sectors (i.e. $R$ ). Unlike the standard shift-share methodology used in Chapter 3 to study structural change in Africa this model shows that broad sectoral decompositions might hide considerable variation at a lower level of aggregation. A particular sector, say manufacturing, might encourage productivity growth by outsourcing labor-intensive activities to small informal firms. This detailed reallocation may not be picked up by aggregate shift-share analysis but a detailed decomposition that takes into account formal and informal sector transitions may pick this up as $-R_{i}$, indicating a negative reallocation effect between subsectors (de Vries et al, 2015). This requires that we move from a broad sector level to a detailed subsector level analysis based on a distinction between informal and formal activities especially in the context of Africa where the informal sector is sizeable. However, detailed sectoral data on the informal sector is not available. Recent studies have shed light on this detail transitions combining national representative surveys with national accounts data (e.g., Diao, Kweka, et al., 2018; Diao, Magalhaes, et al., 2018). Combining sectoral data by formality with nationally representative surveys to shed light on the details and nuances of structural change in Africa is an important future research agenda.

Second, mainstream growth theory has emphasized the role of capital deepening in the structural transitions of low-income countries. In Chapter 4 we emphasize the role of capital in improving productive efficiency of some African countries. However, tracing these patterns to the sectoral level proved difficult due to the non-existence of data on sectoral capital.

Third, the manufacturing share of GDP depends not only on manufacturing productivity and prices, but also on productivity and prices in other sectors, since these other sectors provide competing uses for the factors of production employed in manufacturing (Nickell et al, 2008: 1154). Therefore, understanding the causes of industrial development and the reasons why its pace varies among countries requires modelling all markets and the global economy in a consistent framework. In an empirical model, this requires modelling relative prices, technology, and trade. However, prices and technology are endogenous. A potential estimation strategy is to instrument for prices and technology using price-shifters and technology-shifters, respectively. In the literature, sectoral data on government consumption expenditure is used as an instrument for relative prices, but it is not available for the sample of African countries. One possible exogenous shock from the supply-side that we can use as a technology-shifter (instrument) is government $R \& D$ expenditure in basic science - which is less responsive to market incentives - but this is missing from African statistical databases. As a result, the conclusions derived from Chapter 5 and Chapter 6 are based on correlation analyses, and therefore we cannot make any causal claims. That is why Section 7.1.3 lists the findings as potential causes.

A possible way to overcoming this problem is theory. However, modelling demand, supply and trade is theoretically intractable and often entails considerable sacrifice of realism. A theoretical model that is able to abstract and still predict the patterns of structural change observed in Africa in a consistent manner may be a plausible solution to this challenge. As Friedman (1953) rightly said, "a theory is to be judged by its predictive power for the class of phenomena for which it is intended to explain", in that sense, a theoretical model that has a strong predictive power on structural change in Africa is the way forward, given the absence of data for IV. 


\section{Impact statement}

Structural change is the most prominent feature of modern economic growth (Kuznet, 1973), and remains the most important aspiration for developing countries in Africa and beyond. The importance of structural transformation has been emphasized in a number of Sustainable Developments Goals (SDGs), SDG 8 'Decent work and economic growth' and SDG 9 'Industry, innovation and infrastructure'. At the regional level, the African Union's (AU) Agenda 2063 emphasizes industrialization as a means and end to productivity growth in Africa. The Africa Development Bank has also stressed industrialization as one of its pillars (high fives) for transforming Africa. With the incoming youth bulge, the importance of structural change and the creation of decent jobs cannot be overemphasized. However, lack of reliable sectoral data and evidence have generated uncertainty surrounding the measurement of structural change in Africa, resulting in knowledge and policy deficits.

This thesis provides a new sectoral database on Africa that covers $80 \%$ of GDP in Africa. The thesis then uses the database to examine the sectoral trends and patterns, causes and consequences of structural change and its implications for sustainable development in Africa. The content of the thesis has so far received key media and academic coverage and stimulated passionate debate on structural transformation in Africa.

On the recent expansion of manufacturing in Africa and the different strategies that African countries can adopt to create a pathway of sustainable development, the June $11^{\text {th }} 2020$ edition of The Economist magazine cites Chapter 3 of the thesis. ${ }^{111}$ Chapter 2 of the thesis was cited in the 2019 African Economic Outlook (AEO) prepared by the African Development Bank (AfDB), which suggests that macroeconomic stabilization and employment outcomes in Africa are better when industry drives growth, showing that industrialization is a robust path to rapid job creation. This conclusion is based on analysis of sector-driven growth episodes and job dynamics using the Extended Africa Sector Database (EASD) discussed in Chapter 2. The AEO is the one of key policy briefs that provides scientific inputs and key recommendations to African governments. The 2019 AEO was translated into Amharic, Arabic, Hausa, Kiswahili, Pidgin English, Portuguese, Yoruba and Zulu that reached millions of Africans.

Chapter 2 and 3 are cited in the World Bank global productivity study/report and the World Bank global productivity database. ${ }^{112}$ The reports analyzes the evolution and patterns of productivity and assesses the effect of structural change, technological change and COVID-19 pandemic in 164 countries, and discusses many policy options to rekindle productivity growth. Again, Chapter 2 and 3 have been cited in the World Bank's report on the future of work in Africa. The report assesses how the adoption and diffusion of digital technologies may affect the nature of work in Africa by creating new opportunities and challenges. ${ }^{113}$ Chapter 3 is also cited in the World Bank's industrializing for jobs in Africa report. ${ }^{114}$ The study seeks to assess the prospects of countries in the region participating

\footnotetext{
111 See graphs (The Economist,2020 June 11th Edition). "How manufacturing might take off in Africa"

112 See (Editor: Alistair Dieppe, 2020). "Global Productivity: Trends, drivers and policy.” The World Bank Group.

113 See (Editors: Jieun Choi, Mark A. Dutz, Zainab Usman, 2020). "The Future of work in Africa: Harnessing digital technologies for all.” Office of the Chief Economist, African Region, The World Bank Group.

${ }^{114}$ Industrializing for jobs in Africa through global value chains. Forthcoming, Office of the Chief Economist, African Region, The World Bank Group.
} 
in specific manufacturing global value chains (GVCs) for significant and sustained gains in terms of jobs and productivity. Finally, Chapter 3 is cited in the Brookings Institution's assessment of employment intensities of industries without smokestacks. ${ }^{115}$

The thesis has also generated numerous academic interests. The chapters in the thesis have been cited in academic journals and working papers. ${ }^{116}$ It has also stimulated a passionate debate on the deindustrialization of Africa. Citing Chapter 2, which considers the recent statistical revision in Africa, a number of studies have begun to question the dominant view that Africa is deindustrializing prematurely. For example, a recent article in The Conversation ${ }^{117}$ questions the premature deindustrialization narrative and provides a more optimistic narrative about manufacturing patterns in Africa in recent years. The underlying academic paper for this article is based on the Extended Africa Sector Database presented in Chapter 2.

The findings and evidence in the thesis have been presented at conferences and workshops to stimulate further discussions on structural change in Africa. For example, chapter 5 was presented at UNIDO-UNU-MERIT Conference on the Future of Industrial Work (September 2019, UNIDO HQ, Vienna). Chapters 3 and 6 were presented at the CSAE Conference on Economic Development in Africa (2019, St. Catherine's College, Oxford University, UK). Chapter 4 was presented at GLOBELICS International Conference on Innovation, Economic Growth and Sustainable Development (2018, Accra Ghana) and the MIT Media Lab and YSI Workshop on Innovation, Economic Complexity and Economic Geography (2018, Cambridge, USA). Chapter 3 was presented at the PEGNet/African School Economics Conference on Improving the quality of education and learning outcomes in developing countries (2018, Cotonou, Benin); YSI Africa Convening (2018, Harare, Zimbabwe) and the Development Studies Association Conference on Global Inequalities: Parallel Session on Structural Change Tensions and Tradeoffs (2018, University of Manchester, UK). Chapter 2 of thesis was presented at the UNU-MERIT structural change research theme meetings and the internal conference in 2017.

The discussions, debates and the significant attention received from academia, media, and policy circles indicate the societal relevance of the thesis. Two analytical chapters are under review in academic journals. The other two chapters are currently being prepared for submission.

115 See (B. Coulibaly et al, 2020). "Job creation for the youth in Africa: assessing the potential of industries without smokestacks". AGI, Brookings Institution.

116 See Naudé, W. (2019). Brilliant technologies and brave entrepreneurs: A new narrative for african manufacturing. Journal of International Affairs, 17(No.1), 143-158.

Estmann et al. (2020). Merchandise export diversification strategy for Tanzania-promoting inclusive growth, economic complexity and structural change. DERG Working paper series 02-2020, University of Copenhagen

Baymul, C. \& Sen, K. (2020). Was Kuznets Right? New Evidence on the Relationship between Structural Transformation and Inequality. The Journal of Development Studies, 56:9, 1643-1662, DOI: $\underline{10.1080 / 00220388.2019 .1702161}$

117 See (W. Naude, 2020). “African countries can't industrialize? Yes, they can” The Conversation 


\section{References}

Abramovitz, M. (1986). Catching up, forging ahead, and falling behind. Journal of Economic History, 46(2), 385-406.

Acemoglu, D., \& Guerrieri, V. (2008). Capital deepening and nonbalanced economic growth. Journal of Political Economy, 116(3), 468-498.

ACET. (2014). Growth with depth. African Transformation Report.

Adamopoulos, T., Brandt, L., Leight, J., \& Restuccia, D. (2017). Misallocation, selection and productivity: a quantitative analysis with panel data from china. NBER Working Paper 23039.

Adamopoulos, T., \& Restuccia, D. (2019). Land reform and productivity: a quantitative analysis with micro data. NBER Working Paper 25780.

Aghion, P, Boustan, L., Hoxby, C., \& Vandenbussche, J. (2009). The Causal Impact of Education on Economic Growth: Evidence from U.S. 2009.

Aghion, Philippe, Blundell, R., Griffith, R., \& Howitt, P. (2005). Competition and innovation: An inverted-u relationship. The Quarterly Journal of Economics, 120(2), 701-728.

Aghion, Philippe, \& Howitt, P. (1994). Growth and unemployment. The Review of Economic Studies, 61(3), 477-494.

Alvarez-Cuadrado, F., \& Poschke, M. (2011). Structural change out of agriculture: Labor push versus labor pull. American Economic Journal: Macroeconomics, 3, 127-158.

Alvarez-Cuadrado, F., Van Long, N., \& Poschke, M. (2017). Capital-labor substitution, structural change, and growth. Theoretical Economics, 12(3), 1229-1266.

Amighini, A., \& Sanfilippo, M. (2014). Impact of south-south fdi and trade on the export upgrading of african economies. World Development, 64, 1-17.

Amiti, M., \& Konings, J. (2007). Trade Liberalization, Intermediate Inputs, and Productivity: Evidence from Indonesia. American Economic Review, 97(5), 1611-1638.

Antras, P. (2003). Firms, contracts, and trade structure. Quarterly Journal of Economics, 118(4), 13751418.

Arellano, M., \& Bond, S. (1991). Some tests of specification for panel data: Monte carlo evidence and an application to employment equations. The Review of Economic Studies, 58(2), 277-297.

Arnold, J. M., Javorcik, B., Lipscomb, M., \& Mattoo, A. (2016). Services reform and manufacturing performance: evidence from India. The Economic Journal, 126(590), 1-39.

Arther Lewis, W. (1954). Economic development with unlimited supplies of labour. Manchester School of Economic and Social Studies, 22, 139-191.

Bachmann, R., \& Burda, M. C. (2009). Sectoral transformation, turbulence, and labor market dynamics in Germany. German Economic Review, 11(1), 37-59.

Badunenko, O., \& Mozharovskyi, P. (2016). Nonparametric frontier analysis using stata. The Stata Journal, 16(3), 550-589. 
Bai, J. (Jianqiu), Carvalho, D., \& Phillips, G. M. (2018). The impact of bank credit on labor reallocation and aggregate industry productivity. Journal of Finance, 73(6), 2787-2836.

Baldwin, R., \& Harrigan, J. (2011). Zeros, quality, and space: Trade theory and trade evidence. American Economic Journal: Microeconomics, 3(2), 60-88.

Barrett, C. B., Christiaensen, L., Sheahan, M., \& Shimeles, A. (2017). On the structural transformation of rural Africa. Journal of African Economies, 26(suppl_1), i11-i35.

Barro, R. J., \& Sala-i-Martin, X. (1997). Technological diffusion, convergence and growth. Journal of Economic Growth, 2(1), 1-26.

Bartelsman, E., Haltiwanger, J., \& Scarpetta, S. (2013). Cross-country differences in productivity: The role of allocation and selection. The American Economic Review, 103(1), 305-334.

Basile, R., Capello, R., \& Caragliu, A. (2011). Interregional knowledge spillovers and economic growth: the role of relational proximity. In K. Kourtit, P. Nijkamp, \& R. R. Stough (Eds.), Drivers of Innovation, Entrepreneurship and Regional Dynamics (pp. 21-44). Berlin: Heidelberg: Springer.

Baumol, W. J. (1967). Macro-economics of unbalanced growth: The anatomy of urban crises. American Economic Review, 57(3), 415-426.

Beck, N., \& Katz, J. N. (1995). What to do (and not to do) with time-series cross-section data. The American Political Science Review, 89(3), 634-647.

Bell, D. (1976). The Coming of Post-Industrial Society. Harmondsworth: Penguin Books.

Bolt, J., Inklaar, R., de Jong, H., \& van Zanden, J. L. (2018). Rebasing “Maddison": New income comparisons and the shape of long-run economic development. GGDC Research Memorandum 174.

Boni, G. (2010). The flexibility of the labour market in Sub-Saharan Africa: Francophone countries , South Africa and Mozambique, comparative remarks. European Report on Development.

Borensztein, E., De Gregorio, J., \& Lee, J.-W. (1998). How does foreign direct investment affect economic growth. Journal of International Economics, 45(45), 115-135.

Bourlè, R., Cette, G., Lopez, J., Mairesse, J., \& Nicoletti, G. (2013). Do product market regulations in upstream sectors curb productivity growth? panel data evidence for oecd countries. Review of Economics and Statistics, 95(5), 1750-1768.

Cadot, O., Melo, J. De, \& Plane, P. (2015). Industrialization and structural change : can sub-saharan africa develop without factories? AFD Research Papers, No. 2015-1.

Caselli, F., \& Coleman II, W. J. (2001). The U.S. structural transformation and regional convergence: a reinterpretation. Journal of Political Economy, 109(3), 584-616.

Caselli, F., \& Coleman II, W. J. (2006). The world technology frontier. American Economic Review, 96(3), 499-522.

Casu, B., Clare, A., Sarkisyan, A., \& Thomas, S. (2013). Securitization and bank performance. Journal of Money, Credit and Banking, 45(8), 1617-1658.

Chang, H.-J. (2003). Kicking away the ladder: Infant industry promotion in historical perspective. 
Oxford Development Studies, 31(1), 21-32.

Charnes, A., Cooper, W. W., \& Rhodes, E. (1978). Measuring the efficiency of decision-making units. European Journal of Operational Research, 2, 229-444.

Chenery, H. (1982). Industrialization and growth: the experience of large countries. World Bank Staff Working Papers 539.

Chenery, H. B. (1955). The role of industrialization in development programs. The American Economic Review, 45(2), 40-57.

Chenery, H. B. (1960). Patterns of industrial growth. American Economic Review, 50(4), 624-654.

Chenery, H. B., \& Taylor, L. (1968). Development patterns: Among countries and over time. The Review of Economics and Statistics, 50(4), 391-416.

Cheremukhin, A., Golosov, M., Guriev, S., \& Tsyvinski, A. (2017). The industrialization and economic development of Russia through the lens of a neoclassical growth model. Review of Economic Studies, 84, 613-649.

Ciccone, A., \& Papaioannou, E. (2008). Entry regulation and intersectoral reallocation. Economics Working Papers 1353, Department of Economics and Business, Universitat Pompeu Fabra.

Coe, D. T., \& Helpman, E. (1995). International R\&D spillovers. European Economic Review, 39(5), 859_ 887.

Coelli, T. J., Prasada Rao, D. S., \& Battese, G. E. (1998). An introduction to efficiency and productivity analysis. Kluwer Academic Publishers, Boston, $M A$.

Cohen, W. M., \& Levinthal, D. A. (1989). Innovation and learning: The two faces of R\&D. The Economic Journal, 99(397), 569-596.

Comin, D. A., Lashkari, D., \& Mestieri, M. (2015). Structural change with long-run income and price effects . NBER Working Paper 21595.

Ghani, E., \& O'Connell, S. D. (2014). Can service be a growth escalator in low income countries? World Bank Policy Research Paper 6971.

Czegledi, P. (2006). Economic growth and institutional coherence. New Perspectives on Political Economy, 2(2), 1.25 .

D’Agostino, A., Serafini, R., \& Ward-Warmedinger, M. (2006). Sectoral explanations of employment in Europe-the role of services. IZA Discussion Paper 2257/ECB Working paper No.625.

Dabla-Norris, E., Ho, G., \& Kyobe, A. (2016). Structural Reforms and productivity growth in emerging market and developing economies. IMF Working Papers WP/16/15, 1-35.

Davis, S. J., Haltiwanger, J. C., \& Schuh, S. (1996). Job Creation and destruction. Cambridge, MA: MIT Press.

de Vries, G. J., Erumban, A. A., . Timmer, M. P., Voskoboynikov, I., \& Wu, H. X. (2015). Deconstructing the BRIC. In W. Naudé, A. Szirmai, \& N. Haraguchi (Eds.), Structural Change and Industrial Development in the BRICS.

de Vries, G. J., Timmer, M., \& de Vries, K. (2015). Structural transformation in Africa: Static gains , 
dynamic losses. The Journal of Development Studies, 51(6), 674-688.

de Vries, K., de vries, G., Gouma, R., \& Timmer, M. (2013). Africa Sector Database: Contents, Sources and Methods. GGDC.

Devarajan, S. (2013). Africa's statistical tragedy. Review of Income and Wealth, 59(SUPPL1), 9-15.

Diao, X., Harttgen, K., \& McMillan, M. (2017). The changing structure of Africa's economies. World Bank Economic Review, 31(2), 412-433.

Diao, X., Kweka, J., \& McMillan, M. (2018). Small firms, structural change and labor productivity growth in Africa: Evidence from Tanzania. World Development, 105(2018), 400-415.

Diao, X., Magalhaes, E., \& McMillan, M. (2018). Understanding the role of rural non-farm enterprises in Africa's economic transformation: Evidence from Tanzania. The Journal of Development Studies, 54(5), 833-855.

Diao, X., \& McMillan, M. (2018). Toward an understanding of economic growth in Africa: A reinterpretation of the Lewis model. World Development, 109, 511-522.

Diao, X., Mcmillan, M., \& Rodrik, D. (2017). The recent growth boom in developing economies: A structural change perspective. NBER Working Paper 23132, 1-60.

Diao, X., Mcmillan, M., \& Wangwe, S. (2018). Agricultural labour productivity and industrialisation: Lessons for Africa. Journal of African Economies, 27(1), 28-65.

Diprete, T. A., De Graaf, P. M., Luijkx, R., Tahlin, M., Blossfeld, H. P., Tå, M., \& Blossfeld, H.-P. (1997). Collectivist versus individualist mobility regimes? Structural change and job mobility in four countries. American Journal of Sociology, 103(2), 318-358.

Domar, E. D. (1957). Essays in the Theory of Economic Growth . Oxford University Press.

Douglas W . Caves, Laurits R . Christensen, W. E. D. (1982). The economic theory of index numbers and the measurement of input, output, and productivity. Economic Theory, 50(6), 1393-1414.

Duarte, M., \& Restuccia, D. (2010). The role of the structural transformation in aggregate productivity. The Quarterly Journal of Economics, 125(1), 129-173.

Easterly, W., \& Levine, R. (1997). Africa's growth tragedy: policies and ethnic divisions. The Quarterly Journal of Economics, 112(4), 1203-1250.

Economist. (2017). What technology can do for Africa - Special Report: Technology in Africa.

ElFayoumi, K., Ndoye, A., Nadeem, S., \& Auclair, G. (2018). Structural reforms and labor reallocation: A cross-country analysis. IMF Working Papers WP/18/64.

ENACT. (2018). The rise of counterfeit pharmaceuticals in Africa.

Ertur, C., \& Koch, W. (2007). Growth, technological interdependence and spatial externalities: Theory and evidence. Journal of Applied Econometrics, 22, 1033-1062.

Eslava, M., Haltiwanger, J., Kugler, A., \& Kugler, M. (2004). The effects of structural reforms on productivity and profitability enhancing reallocation: Evidence from Colombia. Journal of Development Economics, 75(2), 333-371. 
Fabricant, S. (1942). Employment in manufacturing 1899-1939. National Bureau of Economic Research. New York.

Faggio, G., \& Konings, J. (2003). Job creation, job destruction and employment growth in transition countries in the 90's. Economic Systems, 27(2), 129-154.

Fahnbulleh, M. (2005). The Elusive Quest for Industrialisation in Africa: A Comparative Study of Ghana and Kenya, c1950-2000. PhD Thesis LSE.

Färe, R., \& Grosskopf, S. (1985). A nonparametric cost approach to scale efficiency. The Scandinavian Journal of Economics, 87(4), 594-604.

Färe, R., Grosskopf, S., \& Lindgren, B. (1992). Productivity changes in swedish pharamacies 19801989: A non-parametric malmquist approach. Journal of Productivity Analysis, 3(1), 85-101.

Farrell, M. J. (1957). The measurement of productive efficiency. Journal of the Royal Statistical Society. Series A (General), 120(3), 253-281.

Feenstra, R. C., Lipsey, R. E., Deng, H., Ma, A. C., \& Mo, H. (2005). World trade flows: 1962-2000. NBER Working Paper 11040.

Felipe, J., \& Mehta, A. (2016). Deindustrialization? A global perspective. Economics Letters, 149 (2016) 148-151

Filippetti, A., \& Peyrache, A. (2017). Productivity growth and catching up: a technology gap explanation. International Review of Applied Economics, 31(3), 283-303.

Fisman, R., \& Love, I. (2004). Financial development and intersectoral allocation: A new approach. Journal of Finance, 59(6), 2785-2807.

Foellmi, R., \& Zweimüller, J. (2008). Structural change, Engel's consumption cycles and Kaldor's facts of economic growth. Journal of Monetary Economics, 55 (2008), 1317-1328.

Foster-McGregor, N., \& Verspagen, B. (2016). The role of structural change in the economic development of Asian economies. Asian Development Review, 33(2), 74-93.

Fox, L., Senbet, L. W., \& Simbanegavi, W. (2016). Youth employment in sub-saharan africa: challenges, constraints and opportunities. Journal of African Economies, 25(suppl_1), i3-i15.

Frobel, F., Heinrichs, J., \& Kreye, O. (1980). The New International Division of Labour: Structural Unemployment in Industrialised Countries and Industrialisation in Developing Countries. Cambridge University Press.

Galindo, A., Schiantarelli, F., \& Weiss, A. (2007). Does financial liberalization improve the allocation of investment?. Micro-evidence from developing countries. Journal of Development Economics, 83(2), $562-587$.

Garcia-verdu, R. (2014). A Review of Morten Jerven's' Poor Numbers : How We Are Misled by African Development Statistics and What to Do About It'. International Monetary Fund, (1-3).

Gollin, D. (2009). Agricultural productivity and economic growth. In R. Evenson \& P. Pingali (Eds.), Handbook of Agricultural Economics (1st ed., Vol. 4, pp. 3825-3866). New York: Elsevier B.V.

Gollin, D., Lagakos, D., \& Waugh, M. E. (2014). The agricultural productivity gap. Quarterly Journal of 
Economics, 129(2), 939-993.

Gopinath, G., Kalemli-“ Ozcan, E., Karabarbounis, L., \& Villegas-Sanchez, C. (2017). Capital allocation and productivity in southern europe. The Quarterly Journal of Economics, 132(4), 19151967.

Graham, M. (1996). Financial repression, interest rates, and credit allocation in sub-saharan africa. UNU-WIDER RIP 6.

Griliches, Z., \& Regev, H. (1995). Firm productivity in Israeli industry 1979-1988. Journal of Econometrics, 65(1), 175-203.

Grossman, G. M., \& Helpman, E. (1991a). Endogenous Product Cycles. The Economic Journal, 101(408), 1214-1229.

Grossman, G. M., \& Helpman, E. (1991b). Innovation and growth in the global economy. MIT Press.

Hall, R. E., \& Jones, C. I. (1999). Why do some countries produce so much more output per worker than others? The Quarterly Journal of Economics, 1140 .

Hallward-Driemeier, M., \& Nayyar, G. (2018). Trouble in the Making? The Future of Manufacturing-Led Development. World Bank Group.

Haltiwanger, J., Scarpetta, S., \& Schweiger, H. (2014). Cross country differences in job reallocation: The role of industry, firm size and regulations. Labour Economics, 26(116), 11-25.

Harchaoui, T. M., \& Üngör, M. (2018). The lion on the move towards the world frontier: catching up or remaining stuck? Journal of African Economies, 27, 251-273.

Harrod., R. F. (1948). The fall in consumption. Oxford Bulletin of Economics \& Statistics, 10(5), 162-167.

Harttgen, K., Klasen, S., \& Vollmer, S. (2013). An African growth miracle? Or: What do asset indices tell us about trends in economic performance? Review of Income and Wealth, 59(SUPPL1), S31-S61.

Hopenhayn, H., \& Rogerson, R. (1993). Job turnover and policy evaluation : A general equilibrium analysis. Journal of Political Economy, 101(5), 915-938.

Hsieh, C.-T., \& Klenow, P. J. (2009). Misallocation and manufacturing TFP in China and India. The Quarterly Journal of Economics, 124(4), 1403-1448.

ILO. (2018). World Employment and Social Outlook.

Javorcik, B. S. (2004). Does foreign direct investment increase the productivity of domestic firms? In search of spillovers through backward linkages. American Economic Review, 94(3), 605-627.

Jenkins, R. O. (2006). Globalization, FDI and employment in Viet Nam. Transnational Corporations, 15(1), 115-142.

Jerven, M. (n.d.). Poor numbers! What do we know about income and growth in sub- saharan africa? Retrieved from http://www.sfu.ca/ mjerven/

Jerven, M. (2009). The relativity of poverty and income: How reliable are African economic statistics? African Affairs, 109(434), 77-96.

Jerven, M. (2010). Random growth in Africa? Lessons from an evaluation of the growth evidence on 
Botswana, Kenya, Tanzania and Zambia, 1965-1995. Journal of Development Studies, 46(2), 274 294.

Jerven, M. (2011). Users and producers of African income: Measuring the progress of African economies. African Affairs, 110(439), 169-190.

Jerven, M. (2013a). Briefing for richer, for poorer: Gdp revisions and africa's statistical tragedy. African Affairs, 112(446), 138-147.

Jerven, M. (2013b). Comparability of GDP estimates in sub-saharan Africa: The effect of revisions in sources and methods since structural adjustment. Review of Income and Wealth, 59(SUPPL1), 1637.

Jerven, M. (2014). African growth miracle or statistical tragedy?: Interpreting trends in the data over the past two decades. WIDER Working Paper, 114.

Jerven, M., \& Duncan, M. E. (2012). Revising GDP estimates in Sub-Saharan Africa: Lessons from Ghana. The African Statistical Journal, 15.

Jerven, M., \& Johnston, D. (2015). Statistical tragedy in Africa? Evaluating the data base for African economic development. The Journal of Development Studies, 51(2), 111-115.

Jude, C., \& Silaghi, M. I. P. (2016). Employment effects of foreign direct investment: New evidence from Central and Eastern European countries. International Economics, 145, 32-49.

Kaplan, D. (2012). South African mining equipment and specialist services: Technological capacity, export performance and policy. Resources Policy, 37, 425-433.

Kaplan, D. (2015). Manufacturing in post-Apartheid South Africa: Performance and policy. In J. Weiss \& M. Tribe (Eds.), Routledge Handbook of Industry and Development (pp. 412-428). Routledge.

Keller, W. (2004). International technology diffusion. Journal of Economic Literature, 42(3), 752-782.

Keller, Wolfgang. (1998). Are international R\& D spillovers trade-related? Analyzing spillovers among randomly matched trade partners. European Economic Review, 42, 1469-1481.

Keller, Wolfgang. (2002). Geographic localization of international technology diffusion. American Economic Review, 92(1), 120-142.

Keller, Wolfgang. (2009). International trade, foreign direct investment, and technological spillovers. NBER Working Paper Series, 15442.

Keller, Wolfgang, \& Yeaple, S. R. (2013). The gravity of knowledge. American Economic Review, 103(4), $1414-1444$.

Kherallah, M., Delgado, C., Gabre-Madhin, E., Minot, N., \& Johnson, M. (2000). The road half traveled: Agricultural market reform in Sub-Saharan Africa. Food Policy Report IFPRI.

Killick, T. (2010). Development Economics in Action: A study of economic policies in Ghana (2nd Edition). Routledge.

Kollmeyer, C. (2009). Explaining deindustrialization: How affluence, productivity growth, and globalization diminish manufacturing employment. American Journal of Sociology, 114(6), 1644 1674. 
Kongsamut, P., Rebelo, S., \& Xie, D. (2001). Beyond balanced growth. The Review of Economic Studies, 68(4), 869-882.

Kouamé, W. A. K., \& Tapsoba, S. J. A. (2019). Structural reforms and firms' productivity: Evidence from developing countries. World Development, 113 (2019), 157-171

Krugman, P. R. (1994). The age of diminished expectations: U.S. economic policy in the 1990s. MIT Press.

Kumar, S., \& Russell, R. R. (2002). Technological change, tecnological catch-up, and capital deepening: Relative contributions to growth and convergence. The American Economic Review, 92(3), 527-548.

Kuznets, S. (1973). Modern economic growth: Findings and reflections. American Economic Review, 63(3), 247-258.

Kye, B. (2008). Internal labor markets and the effects of structural change: Job mobility in Korean labor markets between 1998 and 2000. Research in Social Stratification and Mobility, 26(1), 15-27.

Landesmann, M. \& Foster-McGregor, N. (2021). Trade Liberalization, structural change and economic growth. In N Foster-McGregor, A. Szirmai, L. Alcorta and B. Verspagen (eds), New Perspectives on Structural Change: Causes and Consequences of Structural Change in the Global Economy, Oxford University Press, Forthcoming.

Larrain, M., \& Stumpner, S. (2017). Capital account liberalization and aggregate productivity : The role of firm capital allocation. The Journal of Finance, LXXII(4), 1825-1858.

Lavopa, A. (2015). Structural transformation and economic development. Can development traps be avoided? PhD Thesis, Maastricht University.

Lavopa, A., \& Adam, S. (2014). Structural modernization and development traps: An empirical approach. UN-MERIT Working Paper Series No. 076.

Lavopa, A., \& Szirmai, A. (2018). Structural modernisation and development traps. An empirical approach. World Development, 112(2018), 59-73.

Leibenstein, H. (1957). Economic Backwardness and Economic Growth. New York: Wiley.

Levine, R. (1997). Financial development and economic growth: Views and agenda. Journal of Economic Literature, 35(2), 688-726.

Levine, R. (1999). Law, finance, and economic growth. Journal of Financial Intermediation, 8, 8-35.

Lewis, A. (1954). "Economic development with unlimited supplies of labour." Manchester School of Economic and Social Studies, 12(2), pp.139-191.

Lilien, D. M. (1982). Sectoral shifts and cyclical unemployment. Journal of Political Economy, 90(4), 777793.

Lind, J. T., \& Mehlum, H. (2010). With or without u? the appropriate test for a U-shaped relationship. Oxford Bulletin of Economics and Statistics, 72(1), 109-118.

Mankiw, N. G., Romer, D., \& Weil, N. . D. (1992). A Contribution to the empirics of economic growth. The Quarterly Journal of Economics, 107(2), 407-437.

Maroto-Sánchez, A., \& Cuadrado-Roura, J. R. (2009). Is growth of services an obstacle to productivity 
growth? A comparative analysis. Structural Change and Economic Dynamics, 20(4), 254-265.

Masso, J., Eamets, R., \& Philips, K. (2005). Job creation and job destruction in Estonia: labour reallocation and structural changes. IZA Discussion Paper No. 1707.

Matsuyama, K. (1992). Agricultural productivity, comparative advantage, and economic growth. Journal of Economic Theory, 58, 317-334.

McCaig, B., Mcmillan, M. S., \& Jefferis, K. (2015). Stuck in the middle? Structural change and productivity growth in Botswana. NBER Working Paper, No. 21029, 1-42.

Mckinnon, R. (1973). Money and Capital in Economic Development. Washington DC: Brookings Institution.

McKinnon, R. I., \& Pill, H. (1998). International overborrowing: a decomposition of credit and currency risks. World Development, 26(7), 1267-1282

McMillan, M., \& Headey, D. (2014). Introduction - Understanding structural transformation in Africa. World Development, 63(2014), 1-10.

McMillan, M., Rodrik, D., \& Verduzco-Gallo, I. (2014). Globalization, structural change, and productivity growth, with an update on Africa. World Development, 63(2014), 11-32.

McMillan, M. S., \& Harttgen, K. (2014). What is driving the African growth miracle? NBER Working Paper 20077, 1-51.

McMillan, M. S., \& Rodrik, D. (2011). Globalization, structural change and productivity growth. NBER Working Paper 17143.

Melitz, M. J. (2003). Impact of trade on intra-industry reallocations and industry aggregate productivity. Econometrica, 71(6), 1695-1725

Melitz, M. J., \& Ottaviano, G. I. P. (2008). Market size, trade, and productivity. The Review of Economic Studies, 75, 295-316.

Mencinger, J. (2003). Does foreign direct investment always enhance economic growth? Kyklos, 56(4), 491-508

Mensah, E. B., \& Szirmai, A. (2018). Africa sector database: Expansion and update. UNU-MERIT Working Paper Series, \#2018-020, 1-48.

Mijiyawa, A. G. (2017). Drivers of Structural Transformation: The case of the manufacturing sector in africa. World Development. https://doi.org/10.1016/j.worlddev.2017.07.007

Mummolo, J., \& Peterson, E. (2018). Improving the interpretation of fixed effects regression results. Political Science Research and Methods, 6(4), 829-835.

Naudé, W. (2019). Brilliant technologies and brave entrepreneurs: A new narrative for african manufacturing. Journal of International Affairs, 17(No.1), 143-158.

NBS. (2016). Nigerian GDP Post Rebasing Revision 1981 to 2010.

Newfarmer, R., Page, J., \& Tarp, F. (2018). Industries without Smokestacks. Industrialization in Africa Reconsidered. (R. Newfarmer, J. Page, \& F. Tarp, Eds.). Oxford University Press.

Newman, C., \& Page, J. (2017). Industrial clusters: The case for special economic zones in Africa. 
WIDER Working Paper 2017/15.

Newman, C., Page, J., Rand, J., Shimeles, A., Söderbom, M., \& Tarp, F. (Eds.). (2016). Manufacturing Transformation: Comparative Studies of Industrial Development in Africa and Emerging Asia (First Edition). Oxford University Press.

Ngai, L. R., \& Pissarides, C. (2007). Structural change in a multisector model of growth. American Economic Review, 97(1), 429-443.

Nguimkeu, P., \& Zuefact, A. (2019). Manufacturing in structural change in Africa. World Bank Policy Research Working Paper 8992.

Nickell, S., Redding, S., \& Swaffield, J. (2008). The uneven pace of deindustrialisation in the OECD. World Economy, 31(9), 1154-1184.

Nicodeme, G., \& Sauner-Leroy, J.-B. (2007). Product market reforms and productivity: A review of the theoretical and empirical literature on the transmission channels. Journal Industry, Competition and Trade, 7, 53-72.

Nissanke, M. (2019). Exploring macroeconomic frameworks conducive to structural transformation of sub-Saharan African economies. Structural Change and Economic Dynamics, 48(2019), 103-116.

Nordhaus, W. (2005). The Sources of the productivity rebound and the manufacturing employment puzzle. NBER Working Paper 11354.

Nurkse, R. (1953). Problems of capital formation in underdeveloped countries. Basil Blackwell.

Obstfeld, M. (1994). Risk-taking, global diversification, and growth. American Economic Review, 84(5), 1310-1329.

Page, J. (2011). Should Africa Industrialize? WIDER Working Paper No. 2011/47.

Page, J. (2012). Can Africa industrialise? Journal of African Economies, 21(SUPPL.2).

Pahl, S., Timmer, M. P., Gouma, R., \& Woltjer, P. J. (2019). Job in global value chains: New evidence for four African countries in international perspective. World Bank Policy Research Working Paper, 8953.

Papke, L. E., \& Wooldridge, J. M. (2008). Panel data methods for fractional response variables with an application to test pass rates. Journal of Econometrics, 145 (2008) 121-133.

Pariboni, R., \& Tridico, P. (2019). Structural change, institutions and the dynamics of labor productivity in Europe. Journal of Evolutionary Economics. https://doi.org/10.1007/s00191-019$00641-y$

Pavcnik, N. (2002). Trade liberalization, exit , and productivity improvements: Evidence from Chilean plants. Review of Economic Studies, 69(1), 245-276.

Pelletier, A., Khavul, S., \& Estrin, S. (2019). Innovations in emerging markets: the case of mobile money. Industrial and Corporate Change, 2019, 1-27.

Prati, A., Onorato, G., \& Papageorgiou, C. (2013). Which reforms work and under what institutional environment? Evidence from a new dataset on structural reforms. Review of Economics and Statistics, 95(3), 946-968. 
Pritchett, L. (1996). Measuring outward orientation in LDCs: Can it be done? Journal of Development Economics, 49(2), 307-335.

Restuccia, D., \& Rogerson, R. (2008). Policy distortions and aggregate productivity with heterogeneous establishments. Review of Economic Dynamics, 11(4), 707-720.

Revenga, A. (1997). Employment and wage effects of trade liberalization: The case of Mexican manufacturing. Journal of Labor Economics, 15(S3), 20-43.

Rodrik, D. (1998). Who needs capital account convertibility? Princeton Essays in International Finance, 207, 55-65.

Rodrik, D. (2008). The real exchange rate and economic growth. Brookings Papers on Economic Activity.

Rodrik, D. (2014). An African growth miracle? Finance Development, (Richard H Sabot Lecture), 1-40.

Rodrik, D. (2015). Premature Deindustrialization. NBER Working Paper No. 20935.

Rodrik, D. (2016). Premature deindustrialization. Journal of Economic Growth, 21, 1-33.

Rodrik, D. (2018a). An African growth miracle? Journal of African Economies, 27(1), 10-27.

Rodrik, D. (2018b). New technologies, global value chains and developing economies. NBER Working Paper 25164.

Romer, P. M. (1990). Endogenous technological change. Journal of Political Economy, 98(5), 71-102.

Romer, P. M. (1994). The origins of endogenous growth. The Journal of Economic Perspectives, 8 (1), 3-22.

Rosenstein-Rodan, P. N. (1943). Problems of industrialisation of Eastern and South-eastern Europe. The Economic Journal, 53 (210/211), 202-211.

Rostow, W. W. (1960). The Stages of Economic Growth: A Non-Communist Manifesto. Cambridge: Cambridge University Press.

Saeger, S. S. (1997). Globalization and deindustrialization: Myth and reality in the OECD. Weltwirtschaftliches Archiv, 133(4), 579-607.

Sandefur, J. ; Glassman, A. (2015). The political economy of bad data: Evidence from African survey and administrative statistics. The Journal of Development Studies, 51(2), 116-132.

Sauré, P. (2007). Revisiting the infant industry argument. Journal of Development Economics, 84 (2007), $104-117$.

Schumpeter, J. (1912). The Theory of Economic Development trans. 1934. Joseph Alois Schumpeter. Cambridge, MA: Harvard University Press.

Shaw, E. S. (1973). Financial deepening in economic development. New York: Oxford University Press.

Signé, L. (2018). The potential of manufacturing and industrialization in Africa Trends, opportunities, and strategies. Brookings Institution

Simar, Leopold, \& Wilson, P. W. (2011). Performance of the bootstrap for DEA estimators and iterating the principle. In W. W. Cooper, L. M. Seiford, \& J. Zhu (Eds.), Handbook on Data Envelopment Analysis (Second, Vol. 164, Inter, pp. 241-270). Springer US. 
Simar, Léopold, \& Wilson, P. W. (2000). A general methodology for bootstrapping in non parametric frontier models. Journal of Applied Statistics, 27(6), 779-802.

Simar, Léopold, \& Wilson, P. W. (2002). Non-parametric tests of returns to scale. European Journal of Operational Research, 139(1), 115-132.

Songwe, V. (2019). Intra-African trade: A path to economic diversification and inclusion. Brookings Institution.

Subramanian, A. (2009). The Mauritian success story and its lessons. UNU WIDER Research Paper, No.2009/36, 1-25.

Sy, A. (2015). Are African countries rebasing GDP in 2014 finding evidence of structural transformation? Retrieved April 5, 2020, from https://www.brookings.edu/blog/africa-infocus/2015/03/03/are-african-countries-rebasing-gdp-in-2014-finding-evidence-of-structuraltransformation/

Syrquin, M., \& Chenery, H. (1989). Three decades of industrialization. World Bank Economic Review, 3(2), 145-181.

Szirmai, A. (2012). Industrialisation as an engine of growth in developing countries, 1950-2005. Structural Change and Economic Dynamics, 23(4), 406-420.

Thurlow, J., Zhu, T., \& Diao, X. (2012). Current Climate Variability and Future Climate Change: Estimated Growth and Poverty Impacts for Zambia. Review of Development Economics, 16(3), 394 411.

Timmer, M., de Vries, G. J., \& de Vries, K. (2015). Patterns of structural change in developing countries. In J. Weiss \& M. Tribe (Eds.), Routledge bandbook of industry and development (pp. 79-97).

Timmer, M. P., \& de Vries, G. J. (2009). Structural change and growth accelerations in Asia and Latin America: A new sectoral data set. Cliometrica, 3(2), 165-190.

Topalova, P., \& Khandelwal, A. (2011). Trade liberalization and firm productivity: The case of India. Review of Economics and Statistics, 93(3), 995-1009.

Tregenna, F. (2015). Deindustrialisation, structural change and sustainable economic growth. UNIDO/UNU-MERIT Background Papers for the UNIDO, Industrial Development Report 2016: IDR 2016 WP 4 UNU-MERIT Working Paper 032, 1-60.

UNDP. (2004). Unleashing entrepreneurship: Making business work for the poor. The UNDP Commission on the Private Sector and Development. New York.

UNECA. (2016). Greening Africa's industrialization. Economic Report of Africa. Retrieved from www.uneca.org

Üngör, M. (2013). De-agriculturalization as a result of productivity growth in agriculture. Economics Letters, 119, 141-145.

Üngör, M. (2017). Productivity growth and labor reallocation: Latin America versus East Asia. Review of Economic Dynamics, 24, 25-42.

Van Dijk, M., \& Szirmai, A. (2011). The micro-dynamics of catch-up in Indonesian paper manufacturing. Review of Income and Wealth, 57(1), 61-72. 
van Neuss, L. (2018). Globalization and deindustrialization in advanced countries. Structural Change and Economic Dynamics, 45, 49-63.

van Neuss, L. (2019). The drivers of structural change. Journal of Economic Surveys, 33(1), 309-349.

Verspagen, B. (1991). A new empirical approach to catching up or falling behind. Structural Change and Economic Dynamics, 2(2), 359-380.

Visagie, J. C., Uys, M., Linde, H. M., \& Havenga, W. (2012). A comparative analysis of current trade union trends in the European Union and South Africa. African Journal of Business Management, 6(44), 11095-11109.

Wacziarg, R., \& Wallack, J. S. (2004). Trade liberalization and intersectoral labor movements. Journal of International Economics, 64(2), 411-439.

Wang, Y. M., \& Lan, Y. X. (2011). Measuring Malmquist productivity index: A new approach based on double frontiers data envelopment analysis. Mathematical and Computer Modelling, 54(11-12), 2760-2771.

WHO. (2017). Global Surveillance and Monitoring System for Substandard and Falsified Medical Products. Geneva.

World Bank. (1981). Accelerated Development in Sub-Saharan Africa:An Agenda for Action. Washington DC.

Wurgler, J. (2000). Financial markets and the allocation of capital. Journal of Financial Economics, 58(12), 187-214.

Yaremye, A. H. (2008). Economic proximity and technology flows: South Africa's influence and the role of technological interaction in Botswana's diversification effort. UNU WIDER Resarch Paper, 92(2008).

Zhou, H. (2009). Population growth and industrialization. Economic Inquiry, 47(2), 249-265. https://doi.org/10.1111/j.1465-7295.2008.00151.x 


\section{About the author}

Emmanuel Buadi Mensah is currently a postdoctoral researcher at the University of Groningen, Faculty of Economics and Business, and Fellow at Groningen Growth and Development Center. He holds a Master of Science in Development Economics from SOAS, University of London and Bachelor of Arts degree in Economics from the Kwame Nkrumah University of Science and Technology, Ghana. Before joining UNU-MERIT/Maastricht University as a $\mathrm{PhD}$ student, Emmanuel worked at IMANI Center for Policy and Education as an Economist/Monitoring and Evaluation Specialist. At IMANI, Emmanuel worked on development projects for the World Bank, OSIWA, AfDB, and Agricultural Development Bank. Emmanuel was among the first cohort of fellows at IMANI who pioneered the assessment of the feasibility of political party manifestos in Ghana. Owing to this work, keen interest in critical evaluation of party manifestos has taken root and become an integral part of Ghana's political cycle.

His research focuses on development economics, in particular, the economics and measurement of structural change. He also has a strong interest in global value chains, innovation, firm performance and trade. Emmanuel has consulted for the African Chief Economist Office of the World Bank on industrialization in Africa and the East African Region of the World Bank on the construction of a sectoral database. Emmanuel's research has also been cited by notable media outlets and policy institutions like the Economist, the Conversation, the African Development Bank, the Brookings Institution, and the World Bank. 